\title{
Copyright
}

by

Mark David Dietz

2008 
The Dissertation Committee for Mark David Dietz

certifies that this is the approved version of the following dissertation:

\section{An Awkward Echo:}

\section{Matthew Arnold and John Dewey}

Committee:

Ozro L. Davis, Jr., Supervisor

Sherry L. Field

Mary L. Webeck

Norvell W. Northcutt

Jo Ann Carson 


\title{
An Awkward Echo:
}

\section{Matthew Arnold and John Dewey}

by

Mark David Dietz, B.A.; M.S.

\author{
Dissertation \\ Presented to the Faculty of the Graduate School of \\ The University of Texas at Austin \\ In Partial Fulfillment \\ Of the Requirements \\ For the Degree of \\ Doctor of Philosophy
}

The University of Texas at Austin

May 2008 
SONNET 87

Farewell! thou art too dear for my possessing, And like enough thou know'st thy estimate: The charter of thy worth gives thee releasing; My bonds in thee are all determinate. For how do I hold thee but by thy granting? And for that riches where is my deserving? The cause of this fair gift in me is wanting, And so my patent back again is swerving. Thyself thou gavest, thy own worth then not knowing, Or me, to whom thou gavest it, else mistaking; So thy great gift, upon misprision growing, Comes home again, on better judgment making. Thus have I had thee, as a dream doth flatter, In sleep a king, but waking no such matter.

—William Shakespeare

\section{Preface}

I am thankful for the assistance I have received from many quarters. First and foremost I must express my thanks to Dr. O. L. Davis. I managed, through some lucky scheduling to have a class with Dr. Davis every semester during my progress on the doctorate of which this dissertation is the summa.

The very first day of my classes at UT introduced the thought that would evolve into the present dissertation. Dr. Davis had recalled the debate between C. P. Snow and F. R. Leavis on the "Two Cultures.” And then, turning to me, for he knew I had some background in history and literature, he asked, “Wasn’t there another debate that preceded that one?” I had only just that summer before read Matthew Arnold's Culture 
and Anarchy at the urging of my friend Hadrian Wise, and recalled having read about the debate between Arnold and his good friend T. H. Huxley,- a much friendlier debate than that between Leavis and Snow. In one of those serendipitous moments I rather astounded Dr. Davis, myself, and, I have no doubt, my fellow classmates by bringing forth a ready and easy answer.

Although I actually came into the program through Dr. Oscar Mink, I had already decided that I wanted to work with Dr. Davis (and Dr. Mink in that wonderfully gracious, very student-oriented way he had pushed me in that direction). Knowing that Dr. Davis had some interest in Dewey, I had already begun searching through the Dewey literature for something of relevance that might make for a reasonable dissertation topic. I had even begun reading a few bits and pieces of Dewey before I started my classes. Certainly, I could not have realized at the time that a more than casual link existed between Arnold and Huxley's debate on the respective educational merits of literature and science and my quest for a dissertation topic. When (within that very first semester) I came across Dewey's response to the Huxley-Arnold debate, I was well on my way to the present dissertation, although, of course, it would be several more semesters before I came to a full revelation of the fact.

The two names, Arnold and Dewey, came together for me, again, in the course of side conversations with Dr. Davis in his classes on the history of the curriculum. I began wondering how their two seminal ideas, education as culture and education as experience, were related. 
A class with Dr. Sherry Field allowed me an opportunity to dig very deep into Dewey by way of that wonderful book, Art as Experience. Dr. Field allowed both David Hefner and I to work on the same book, knowing that we both had an interest in art and in Dewey. The result has been that throughout this process I have enjoyed the collegiality of working in parallel with David as he has sought to work out his own Deweyan concerns.

The hermeneutic and rhetorical elements in the paper represent a third strain and these go back much further than my interest in either Arnold or Dewey. The same friend who had recommended that I read Arnold, Hadrian Wise, was a member with me of an online community engaged in discussion of the classics (this was on the Penguin Classics Discussion site). In the course of a discussion on the relevance of intentionality to an understanding of literature I began exploring, with admirable and challenging prods from Hadrian, Himadri Chatterjee, and a number of others, the relationships among writer, text, and reader, and formulated the $\mathrm{X}^{1}, \mathrm{X}^{2}$, and $\mathrm{X}^{3}$, or congruence argument that appears in the chapter of this paper devoted to the intentional mind. Dr. Norvell Northcutt prodded me further to develop this model as a model for research. Dr. Mary Lee Webeck suggested I look at the writing of Mikhail Bakhtin and from Bakhtin I moved on the Hans Georg Gadamer. Neither make an appearance in this paper, but I must admit that Gadamer, in particular, has proven very refreshing and I look forward to the opportunity to explore his thought further. I was also fortunate to encounter Dr. Jo Ann Carson at Texas State University. She has provided me with very insightful critiques of the more philosophical aspects of my dissertation. 
I must mention the work of one Arnold scholar, in particular, in this head note. Donald Stone not only has written the best assessment so far of the influence that Arnold had on Dewey, but he also had the kindness to write me confirming my supposition that he saw Dewey as Arnold's successor and encouraging me in my academic venture.

One of the rich joys I found in studying in the Curriculum and Instruction department here at UT, was how wonderfully refreshing were those class hours and how much my fellow students added to my experience. I cannot thank them all here personally, but my thanks to them is very personal and very deep. I would be quite remiss, however, if I were not to mention Christopher Ketcham with whom I had many fascinating and enjoyable conversations in the course of writing this dissertation.

Finally, I must thank my older brother, Dr. Albert Steven Dietz, who preceded me through this program and provided me with all the advantages of the wisdom he had gained from the experience. My love to him and my family (my parents, my brothers, Michael and Steven, my sister-in-laws, my nieces and nephew) who have been so supportive.

I dedicate this paper to the two Alberts: my father, Albert Emil, and my brother, Albert Steven.

$$
\cos 20
$$

\section{Notes to the Dissertation}

Notes to the body of the dissertation follow a somewhat unusual pattern. I have made use of two sets of notes: footnotes identified with small alpha characters and 
endnotes identified with numerals. The footnotes contain comments and clarifications to the content of the dissertation itself. I found that these were rather likely to get lost among the citations that make up the bulk of the endnotes, moreover, by placing them as footnotes they are more easily accessed in the course of reading. The endnotes, as a result, consist almost entirely of citations.

I have used, as much as possible, original publication dates in the endnote citations. This is particularly significant for the citations to Arnold and Dewey's work. For both Arnold and Dewey I have relied on the standard editions of their prose work,R. H. Super's Complete Prose Work (abbreviated CPW) for Arnold, and the electronic edition of Jo Ann Boydston's The Collected Works of John Dewey, 1882-1953 for Dewey. Not wanting to lose sight of the historical progression of each man's thought, best made apparent through the publication dates for the original works, I have included that date in my citation along with the relevant page number to the standard edition. The bibliography provides the publication dates for the standard editions. In the page numbering for Dewey: $e w$ stands for early works, $m w$ for middle works, and $l w$ for late works. I have kept to the formatting of the page numbers as they appear in the electronic edition as much as possible,- - my sense is that this is fast becoming the convention in Dewey research. The use of the CPW page numbering, I have noted, is also increasingly conventional in Arnold research. In the case of Arnold's poetry, I have provided no dating since publication date does not seem to reflect with any accuracy date of composition. All of Arnold's poetry is taken from Allott's standard edition of the poems. 


\title{
An Awkward Echo:
}

\section{Matthew Arnold and John Dewey}

\author{
Publication No. \\ Mark David Dietz., Ph.D. \\ The University of Texas at Austin, 2008 \\ Supervisor: Ozro L. Davis, Jr.
}

\begin{abstract}
My study looks at the influence that Matthew Arnold, $19^{\text {th }}$ century English poet and literary critic, had on John Dewey, American pragmatist and educational philosopher. While the influence of Arnold on Dewey was more pervasive than I had expected, my real purpose in writing this dissertation was to discover a middle ground between the educational philosophies the two men espoused and to construe a fuller approach to a pluralistic educational philosophy. I have looked at four aspects of mind that draw Arnold and Dewey into close correspondence. The first aspect I have called the tentacled mind from Dewey's favored metaphor of the mind as having tentacles that reach out and encounter directly the physical world. This aspect of mind allows me to look at the common use that both Arnold and Dewey made of the term “experience.” The second aspect of mind I call the critical mind. I have explored this aspect of mind by looking at a
\end{abstract}


brief history of English literary criticism from Dryden to Stanley Fish. The third aspect of mind is the intentional mind which deals with the rhetorical-hermeneutic relationship of mind to the intentionality of other voices and to its own intentionality. This aspect crosses into reader response theory, but I have found within it results that differ significantly from traditional reader-response theory. The final aspect of mind I have called reflective-response. In both Arnold and Dewey the reflective aspects of the mind differ widely from more contemplative conceptions of the mind in a reflective state; most notably for both Arnold and Dewey the reflective mind is never passive. I believe that when these four aspects of mind are brought together they amount to a truly pluralistic educational philosophy. In the course of my argument I have, as well, identified a need to rehabilitate both the concept of intentionality and that of authority. 


\section{Table of Contents}

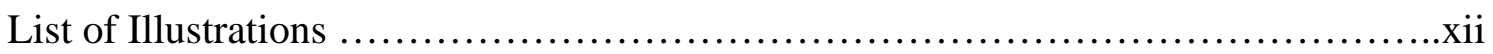

Sketches of Matthew Arnold and John Dewey ................................... 1

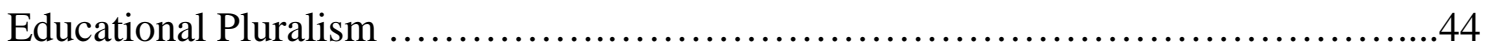

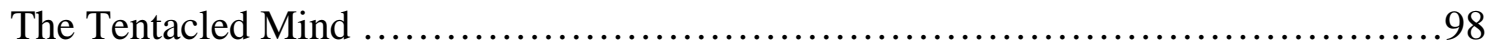

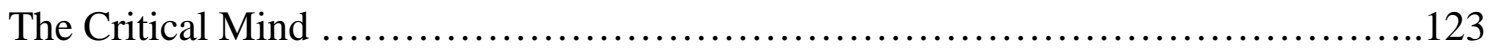

The Intentional Mind ...................................................190

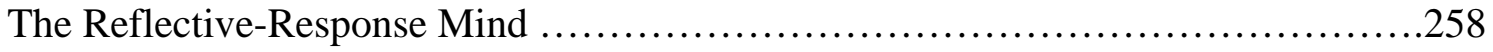

An Adequate Echo .......................................................283

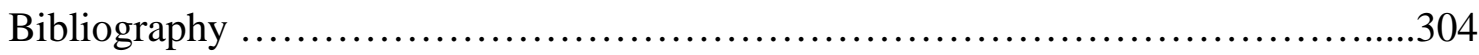

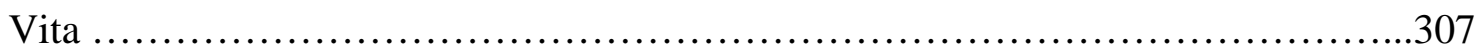




\section{List of Illustrations}

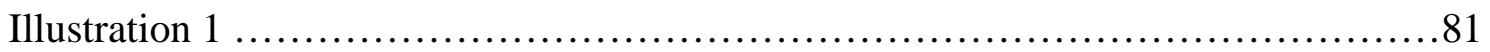

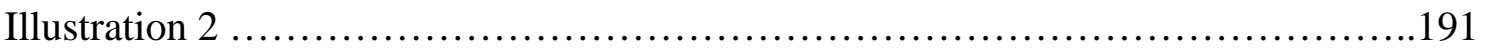

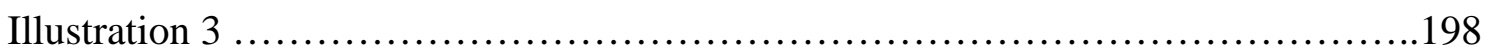

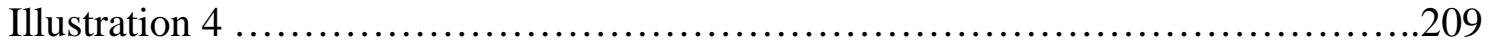

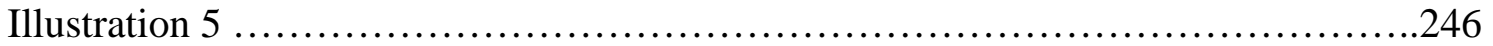

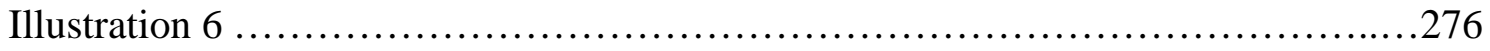


Written in Emerson's Essays

'O monstrous, dead, unprofitable world, That thou canst hear, and hearing, hold thy way! A voice oracular hath peal'd to-day, To-day a hero's banner is unfurl'd;

Hast thou no lip for welcome?'-So I said. Man after man, the world smiled and pass'd by;

A smile of wistful incredulity As though one spake of life unto the dead-

Scornful, and strange, and sorrowful, and full Of bitter knowledge. Yet the will is free; Strong is the soul, and wise, and beautiful;

The seeds of godlike power are in us still; Gods are we, bards, saints, heroes, if we will!-

Dumb judges, answer, truth or mockery?

- Matthew Arnold ${ }^{\mathrm{a}}$

\section{Sketches of Matthew Arnold and John Dewey}

That which remains of Empedocles is fragmentary, - hexameter lines from two poems entitled On Nature and Purifications, - or perhaps they may come from a single poem entitled On Nature and Purifications. Empedocles, a pre-Socratic philosopher, was either a mystic who thought himself a living god, or a pragmatic materialist whom his followers mistook for a god.

a Arnold and Allott (editor), “Written in Emerson's ‘Essays',” pg. 53. The original of the final line was “O
barren boast, o joyless mockery,” but, as Miriam Allot has noted in The Oxford Authors: Matthew
Arnold, pg. 506, Arnold shifted from this extreme pessimism to the more ambiguous line as printed here. 
A twofold tale I shall tell: at one time it grew to be one only from many, and at another again it divided to be many from one. There is a double birth of what is mortal, and a double passing away; for the uniting of all things brings one generation into being and destroys it, and the other is reared and scattered as they are again being divided. And these things never cease their continuous exchange of position, at one time all coming together into one through Love, at another again being borne away from each other by Strife's repulsion. ${ }^{1}$

Anecdotal myth grew up around Empedocles. In one such myth, when he was sure he was about to die, he threw himself into the volcano of Mount Etna; thus his body would be immolated, leaving no embarrassing earthly remains to challenge his claim to godhood. Mount Etna, however, in an act of wicked spite, spit forth one of his bronze sandals, revealing the ruse. ${ }^{2}$

Matthew Arnold wrote a dramatic poem, arguably one of his best, and called it “Empedocles on Etna.” His friend, J. C. Shairp, said that the poem "seemed not so much about the man who leapt into the crater - but his name and outward circumstances are used for the drapery of his [Arnold’s] own thoughts.” He adds, “I wish Matt would give up that old greek form..."3

Written sometime between 1849 and 1852, Arnold’s Empedocles wends his way to the crater's edge and there he unburdens his mind.

\section{Slave of sense}

I have in no wise been; but slave of thought? ...

And who can say: I have been always free, Lived ever in the light of my own soul? -

I cannot; I have lived in wrath and gloom, Fierce, disputatious, ever at war with man, Far from my own soul, far from warmth and light.

But I have not grown easy in these bonds -

But I have not denied what bonds these were.

Yea, I take myself to witness,

That I have loved no darkness, 
Sophisticated no truth, Nursed no delusion, Allowed no fear! ${ }^{4}$

And so saying, Empedocles threw himself into the waiting crater. Had John Dewey, thirty-seven years Arnold’s junior, written “Empedocles on Etna,” I am inclined to believe that his Empedocles would have come to throw not himself into the yawning volcano, but the lumber of old philosophy, which even in pre-Socratic days had already grown thick and hazardous; all the while chanting,

If slave of these I may have been, No slave of thought I shall be more; If awkward, stumbling I must seem, Experience now shall lead me fore-

$\cos 80$

Matthew Arnold died on April 15, 1888. He and his wife, Fanny Lucy, were in Liverpool to meet their daughter who had just returned from America. Fanny Lucy had run ahead of Matthew to stop a horse-drawn tram that would take them to the Liverpool Landing Stage where they would meet their daughter. As Arnold approached the tram, he fell forward into the street. Fanny Lucy called for brandy to revive him. Four minutes later, in the study of a doctor who lived nearby, Arnold was dead of the heart disease he had inherited from his father. ${ }^{5}$

John Dewey was twenty-nine years old at the time Arnold died. Dewey had read Arnold while an undergraduate at the University of Vermont where library records show him checking out a collection of Arnold's literary essays, two of Arnold's works on

\footnotetext{
b The present author alone must be held responsible for these "awkward, stumbling” verses.
} 
religion, Literature and Dogma and God and the Bible, and one of Arnold's volumes on education, The Popular Education of France. ${ }^{6}$

Two years after Arnold died, Dewey published a critical essay on the poet (essentially Dewey’s only excursion into poetry criticism). In this essay, entitled "Poetry and Philosophy,” Dewey wondered if something in the agnostic sentiment of the age had led Arnold, as a poet, to respond to the modern condition with such a deep pessimism and profound sense of isolation.

Arnold's distinguishing sign among modern poets is the melancholy beauty with which he has voiced the sense of loss; his sad backward glance at the departure of old faiths and ideals; the brooding memories of joys whose spring has fallen away; the shapeless, hopeless hope for the dawn of a new joy, new faith. I should say that the source of regret which expires from Arnold's lines is his consciousness of a twofold isolation of man - his isolation from nature, his isolation from fellow-man. No longer, he seems to say, may man believe in his oneness with the dear nature about him: the sense of a common spirit binding them together has vanished; the sense of a common purpose outworking in both has fled. Nature, in ceasing to be divine, has ceased to be human. The faith that one idea, one fulfillment, unites in cherished bonds man to nature, is no more; in its stead, the consciousness of isolation. ${ }^{\mathrm{C}}$

\section{(3) 80}

We live in a world of awkward messiness.

Matthew Arnold, the poet, responded with a shrill note of pessimism to the "monstrous, dead, unprofitable world” ${ }^{\text {, }}$ he found himself in as the nineteenth century reached its middle course; upon the other side of the century's mid-point, Matthew

\footnotetext{
c Dewey, "Poetry and Philosophy,” 1890, pg. ew.3.114-115. This is not the Dewey of awkward and messy sentences. "Poetry and Philosophy" is one of Dewey's most finely crafted essays with passages like this that could well be collected into a thin (very thin!) volume entitled The Beauties of John Dewey.

d Hamlet I. ii. 133-4: 'How weary, stale, flat and unprofitable / seem to me all the uses of this world.' (Miriam Allott’s note, The Oxford Authors: Matthew Arnold, pg. 506.)
} 
Arnold, the essayist and literary critic, sought an optimistic touch of "sweetness and light” with which to reproach and mend this world gone awry.

John Dewey, a generation or two later, manufactured his own awkwardness, his own messiness. He said that he would not "give way to the dialectic development of a scheme," but would stumble forward, in awkward words, in awkward sentences, toward whatever awkward conclusions his "heavy" and "intellectually honest” course would allow him; "the pressure of concrete experiences," he insisted, was paramount, and, thus, he could not, in good conscience, write more fluidly, more fluently. ${ }^{7}$

Into this messiness both Arnold and Dewey entered,- - into the awkward messiness of modernity against which each in his own way hoped to make some measured progress: Arnold with his critical essays exploring the edges of literature, politics, society, education, and religion; Dewey with his pragmatic reconstruction of philosophy.

Arnold would sit at his desk in his study, a stack of student-teacher papers sitting to one side, either just read and commented upon, or needing to be read and commented upon, across the desk, neatly arranged, loose stacks of papers with notes jotted on them, a bit of an unfinished poem, the manuscript of an older poem, a common-place notebook in which he had captured resonant thoughts from his reading, and, most formidable of all, an essay or lecture in some state of half-finish, taunting him to make something of it, to round it out, to put it in a finished state. 
Dewey had the machine, an Underwood typewriter. He would sit in front of it, his shoulders slightly rounded from hours spent hovering over its keys, and type long strings of awkward verbiage, chastened by "the pressure of concrete experience.”»

If there is any truth in myth, children played noisily about Dewey's feet as he typed away at his polemical essays. And Arnold was happily drawn from his study to walk through England's fast changing fields of nature with his laughing children and his overweight dachshunds.

$$
\cos 80
$$

Matthew Arnold was a poet, a literary critic and, by vocation, an inspector of schools. Today he is probably best known as the author of a handful of poems that make perennial appearances in poetry anthologies: "Dover Beach," "Thyrsis," and "The Scholar Gypsy” chief amongst them. Sometimes his love lyrics to the mysterious "Marguerite” will make an appearance. And his emblematic words, pessimistically suggesting the loss of a world of faith and the advance of an awkward modernity, have taken on a life of their own:

Wandering between two worlds, one dead, The other powerless to be born... ${ }^{\mathrm{e}}$

Words from his essays have also taken on their own life. Arnold, himself, was a great promoter of his own slogans. If his ideas have suffered a reduction and

\footnotetext{
e Arnold and Allott (editor) "Stanzas from the Grande Chartreuse," pg. 288. The Norton Anthology of Poetry (4 ${ }^{\text {th }}$ edition, 1996) includes Arnold's poems: "Shakespeare," "To Marguerite," "The ScholarGypsy,” "Thyrsis," and "Dover Beach.” It also includes four selections from Arthur Hugh Clough that might well have surprised Arnold who regarded his friend as a failed poet.
} 
simplification, both in his own time and ours, he is himself as much to blame as any of his critics. Dewey quite nearly never quotes himself; Arnold often does.

Some of you may possibly remember a phrase of mine which has been the object of a good deal of comment, an observation to the effect that in our culture, the aim being to know ourselves and the world, we have, as the means to this end, to know the best which has been thought and said in the world. ${ }^{9}$

"To know the best which has been thought or said," to this day this phrase is the Arnoldian rubric that draws the most extensive celebration. In drawing such celebration, it is often used to reduce Arnold's thought to an obsession with Latin and Greek culture, or a mere aggrandizement of the western canon,- - the great books that, as Arnold Bennett tells us, "the person of average culture is supposed to have read" for not to have done so would be a terrible "social sin." ${ }^{, 0}$ Many have seen in this and other Arnoldian phrases a kind of dogmatism. Perhaps on a certain level that is precisely what it is. But like Dewey, Arnold wanted to move beyond dogmatism. If both men occasionally fall into their own kind of awkward dogmatism, I wonder if that is, simply, to be expected, perhaps even tolerated,- try for yourself to make a statement against dogmatism, and see if the nature of polemical speech does not kennel you back amongst the dogmatists.

This is not to say that Arnold's "to know the best which has been thought or said" does not suffer a bit from his unsystematic approach,_- for Arnold this phrase had a tendency to become both the means for achieving and the ends toward which culture was directed. In other words, for Arnold, culture could be both "the best which has been thought or said,” which we might describe as a "thing,” or rather a collection of things,- 
a collection of books, belle letres, literature,- and the means, not a thing, but an action, by which we come to know "the best which has been thought or said.”

One of Arnold's most striking criticisms of Christianity was that Christ delivered to his followers both a secret, "self-renouncement," and a method, "inwardness and sincerity."11 Arnold, the apostle of culture, had a secret, "the best which had been thought or said," and a method "the free play of mind.”

If a man without books or reading, or reading nothing but his letters and the newspapers, gets nevertheless a fresh and free play of the best thoughts upon his stock notions and habits, he has got culture. ${ }^{12}$

But Arnold the prophet sometimes talked over the head of Arnold the apostle, ${ }^{\mathrm{f}}$ and so,

from time to time, awkwardly, the secret and the method could get a bit confused.

Many objections have been made to a proposition which, in some remarks of mine on translating Homer, I ventured to put forth; a proposition about criticism, and its importance at the present day. I said: 'Of the literature of France and Germany, as of the intellect of Europe in general, the main effort, for many years, has been a critical effort; the endeavour, in all branches of knowledge, theology, philosophy, history, art, science, to see the object as in itself it really is. ${ }^{, 13}$

This phrase, "to see the object as in itself it really is,” particularly when coupled

with Arnold's desire for a "free play of mind," possessed something of an emergent

pragmatism. This pragmatism, first noted by Lionel Trilling, will be of great importance

f This, I must admit, is an unrepentant parody of Arnold himself. In his religious criticism spoke of Christ as being “manifestly above the heads of his reporters," i.e. the apostles (Arnold, Literature and Dogma, 1883, CPW pg. 6:145). He used this argument to move past the immediate words of the new testament and gain access to Christ's intentional thought. We will have more to say about Arnold's hermeneutics later, but no where is it more delightfully, playfully, and profoundly on display than in his religious criticism, - and this is so even if his theology is rather, well, awkward. Somehow, however, even as a failed critic, Arnold is always interesting; one might say that his method, rather all too commonly, was more important than the secret it betrayed. (Oddly enough, many would say that the opposite was true of his poetry, but this must be taken as a critique, and in his best poetry, such as "Dover Beach," method and secret are well paired, indeed.) 
to us as we continue our comparison of Arnold and Dewey. ${ }^{\mathrm{g}}$ The phrase here, "to see the object as in itself it really is," is not an echo of Kant; ${ }^{\text {h }}$ or if it is, then it is a most awkward echo, indeed. Arnold, again much like Dewey, does not feel alienated from the noumenal world; the word "endeavour” in the statement above may suggest only a movement toward "seeing," as opposed to an absolute state of "seeing," but the movement toward the object is real, optimistic of success, and active (not passive),- which is as much as to say it is pragmatic.

Another of Arnold's many turns at phrase-making is illustrated in the following passage.

The pursuit of perfection, then, is the pursuit of sweetness and light. He who works for sweetness and light, works to make reason and the will of God prevail. He who works for machinery, he who works for hatred, works only for confusion. Culture looks beyond machinery, culture hates hatred; culture has one great passion, the passion for sweetness and light. It has one even yet greater! — the passion for making them prevail. It is not satisfied till we all come to a perfect man; it knows that the sweetness and light of the few must be imperfect until the raw and unkindled masses of humanity are touched with sweetness and light. ${ }^{14}$

“Sweetness and light” like so many of Arnold’s phrases holds a complex meaning. Here it is "reason and the will of God;" elsewhere it is beauty and reason. "Sweetness and

\footnotetext{
${ }^{g}$ Note, for example, this passage from Literature and Dogma in which Arnold describes the middle ground between Hebraic miracles and Hellenic metaphysics into which he is attempting to direct Christian thought: the "we" here is the royal we,-_ Arnold is in high polemic mode. "...we preach a doctrine not thaumaturgical and not speculative, but practical and experimental; a doctrine which has no meaning except in positive application to conduct, but in this application is inexhaustible." Arnold, Literature and Dogma, 1873, CPW pg. 6:357-8.

$\mathrm{h}$ "A [kind of] knowledge must be possible, in which there is no sensibility, and which alone has reality that is absolutely objective. Through it objects can be seen as they really are, whereas in the empirical employment of our understanding things will be known only as they appear.” Immanuel Kant, 1787, Critique of Pure Reason, pg. 267. Arnold affects no distinction between phenomena and noumena,even had he the philosophical background to have posited such a distinction, one cannot see him having any desire or need to make use of it. Nor was this distinction of much use to Dewey. For Arnold "seeing the thing as in itself it really is" involved not a mind "in which there is no sensibility," but rather a mind in which sensibility was foremost,-_ playfully, disinterestedly, and actively so.
} 
light” was part of Arnold's campaign for culture. He felt that the society he lived in needed "sweetness and light" which he associated with what he called Hellenism, more than it needed the "fire and strength", of what he called Hebraism. Hebraism was Arnold's general term both for the cultural inheritance deriving from Christianity and Judaism, and for that active element in contemporary English culture which reasoned from faith and obedience to authority. Hellenism, by contrast, was both the cultural inheritance from classical Greek writers and that active element in thought and judgment that pursued reason and beauty, "sweetness and light.” He opposed Hebraism, not because he opposed faith (or authority), but because he saw no good to be gained in "rehearsing the praises of fire and strength to ourselves, who dwell too exclusively on them already."j In other words, he thought faith had become too fanatical,- - reason, not sufficiently so. At another time under other conditions, he tells us, he could as easily oppose Hellenism and champion Hebraism, and to some extent in his religious criticism he brings himself much closer to expressing the .

\footnotetext{
${ }^{\mathrm{i}}$ Arnold borrowed this phrase from one of his critics but did not give it the extended use he did "sweetness and light." (See Arnold, Culture and Anarchy, 1880, CPW pg. 178-179.) Arnold borrowed the phrase, "sweetness and light," from Jonathan Swift's "The Battle of the Books." "Sweetness and light" has gone on to become a popular English idiom (see Ammer, Christine. The American Heritage Dictionary of Idioms. Houghton Mifflin. Boston. 1997,_ - I have depended here upon a reference in Wikipedia,http://en.wikipedia.org/wiki/Sweetness_and_light accessed 21 November, 2007.)

${ }^{j}$ Occasionally his strictures against Hebraism have been misread as anti-Semitic. That Arnold's chief offenders in fanatical Hebraism were evangelical Christians suggests that this is a serious misreading. Arnold's insistence upon referring to the whole of Victorian religious culture as Hebraic seems to reflect a growing fascination with the Jewish church and Jewish history among intellectuals of this period. Although in Arnold's particular use of this term, one senses something of a polymath's declaration of depth of knowledge,- - a knowingness about the origins of the Christian church and the source of its beliefs,- - this is a tendency very much on display in Arnold's religious criticism. To what extent, if any, Arnold's use of this term served as a rapprochement to the Jewish members of Victorian society, is difficult, if not impossible to tell.
} 
If the twin effects of these two modes of thought, Hebraism and Hellenism, had their impact upon Victorian culture, so, too, according to Arnold, did the natural tendencies of England's three great social classes.

Thus we have got three distinct terms, Barbarians, Philistines, Populace, to denote roughly the three great classes into which our society is divided; and thought this humble attempt at a scientific nomenclature falls, no doubt, very short in precision of what might be required from a writer equipped with a complete and coherent philosophy, yet, from a notoriously unsystematic and unpretending writer, it will, I trust, be accepted as sufficient. ${ }^{15}$

Here, too, Arnold's penchant for phrase-making had a ready success, and his use of the term Philistine for the middle-class, the primary target of his critique, created a popular idiom that echoes yet today (and echoed in Dewey's writing where usage would suggest it comes directly from Arnold). One might suspect that the aristocracy would have been most put out at being called Barbarians, while the relatively new word, Philistine, would have been altogether ignored. But the opposite happened. In truth, Arnold's critique of the aristocracy was good-natured fun, and the aristocracy seems to have taken it as such. Arnold's critique of the middle-class, on the other hand, cut deep and was met with more than a little resentment. As for his feelings toward the lower classes, the Populace, one might argue that here he expressed something of that paternalism that seemed to come so natural to Victorian intellectuals; nonetheless, something in his approach to the lower classes suggests a hard-nosed practicality. He often referred to them as our future masters, and was quite certain that they would eventually inherit the political power which in Arnold's time was fast moving from the hands of the aristocracy to that of the middle-class. What he is not forgiven for, today, is his suggestion that for the lower 
classes, or the middle classes for that matter, to take over political power effectively, they needed a heavy dose of culture,- - that which the aristocracy, bruising barbarians that they were, had gained by virtue of their landed leisure. Indeed, culture, he thought, was the path to equality. He was not above a little redistribution of material well-being, but without culture, he doubted that true equality could be attained.

This is the social idea; and the men of culture are the true apostles of equality. The great men of culture are those who have had a passion for diffusing, for making prevail, for carrying from one end of society to the other, the best knowledge, the best ideas of their time; who have laboured to divest knowledge of all that was harsh, uncouth, difficult, abstract, professional, exclusive; to humanise it, to make it efficient outside the clique of the cultivated and learned, yet still remaining the best knowledge and thought of the time, and a true source, therefore, of sweetness and light. ${ }^{16}$

One of his critics jokingly called Arnold the "apostle of culture," and he, in high, good humor, stole the epithet and used it on himself. As Dewey came to own the word experience, so Arnold owned culture. Arnold's culture was not the culture of anthropology. It was high culture, Greek and Latin literature, "the best that has been thought and said," and it was caricatured, in his time and ours, as a kind of retrograde elitism. Arnold, himself, in that ironic voice in which he clearly took too much delight, could sound the elitist note, with a schoolboy's wicked wink, in a way that was surely too high and facile to allow the serious-minded of any democratic age to feel at all comfortable. Today's masters of irony, oddly, have little more capacity to appreciate Arnold's ironic voice than did Arnold's peers. But then irony is surely not today what it was then.

1038 
Matthew Arnold was born in Laleham, in the county of Surrey in southeast England, on December 24, 1822. He was the son of Thomas Arnold, then a local schoolmaster, soon to be the headmaster of Rugby School, and Mary Penrose, daughter of a Nottinghamshire clergyman. In December 1827, his father was elected headmaster of Rugby School and received his doctor of divinity as a precursor to taking the position. He carried his young family with him to Rugby which became their new home until in the summer of 1834, the family occupied a holiday home, Fox How. The Arnold family invested Fox How, in the Lake District near Ambleside and not far from Wordsworth's home at Rydal Mount, with all the deepest sentiments that one would expect of a Victorian home and hearth. Matthew and his siblings hiked across the mountains, sailed the lakes, and played freely and delightedly in the bosom of that nature which Wordsworth had so deeply imbedded in the English romantic imagination.

But Matthew's romanticism of nature would never be so fierce and free as Wordsworth’s had been. Matthew's love of nature would forever be an unrequited love,- - the modern condition imposed itself upon him. Unlike Wordsworth, he could neither simply turn his back upon the age in which he lived, nor forfeit the need to find a way to live in that age without giving in to compromises too dreary for a gay and fanciful young man to contemplate.

We are perhaps best served in moving quickly past Matthew's educational experience,— tied as it was to Rugby, Oxford and that curious dandyism that seems so out of tune with Arnold the poet, the essayist and the school inspector, we might sum up his education as two prize poems, a bent toward hunting and fishing and gambling when 
he ought to be studying, no distinct outward signs of seriousness, expensive tastes in perfumes and waistcoats, a curious tendency toward a kind of distancing-intimacy with his friends, a fascination with all things French, and, as a final touch, an embarrassing second at Oxford. After graduation, he spent a few months as a tutor at Rugby before returning to Oxford as a Fellow at Christ's Church. In 1847, he attained a position as secretary to Lord Landsdowne which brought him to London and allowed plenty of free time to compose poetry.

Then in 1848, Arnold met and fell in love with Lucy Wightman, a beautiful stranger with "eyes of gray"k and the daughter of a Tory judge who was none too keen on the thought of having this impecunious, young man from a notable Liberal family paying court to his daughter. Moreover, Arnold's current position would not allow for marriage: he could not support a family on his pay as secretary to Lord Lansdowne, and marriage would mean having to give up his fellowship at Oxford. Making use of the family connections, however, he secured a position as an inspector of schools, a position he would hold for thirty-five years. The judge grudgingly accepted him into the family, and thus, in the year 1851, Arnold found himself with a career and a wife. Arthur Stanley, his father's biographer and Matthew's close friend, said that in marriage Arnold had retained "all the genius and nobleness of mind ... with all the lesser faults pruned and softened down."17

$$
\cos 80
$$

\footnotetext{
${ }^{\mathrm{k}}$ Honan interprets these words from Arnold's poem "Absence” (Allott: pg. 138-139) as referring to Miss Wightman by way of comparison to Arnold’s earlier flame, “Marguerite.” Honan, pg. 188.
} 
In 1851, when Arnold became a school inspector, education in England, certainly

by comparison with America and much of the continent, was in a fairly primitive state.

The Massachusetts System, stimulated by a visit from Horace Mann in 1844, ${ }^{1}$ was much

debated and was the preference of those who wished to secularize schools. What passed

in England for a school system was spotty at best. The great "public schools," such as

the Rugby of Dr. Arnold, were not state-run schools, but private ventures which by and

large served only the sons of the wealthy and elite. Beyond this were the many charity

("ragged") schools for the poor which were run by Dissenter ${ }^{\mathrm{m}}$ churches who attempted,

through these schools, to reach out to a lower class that was, otherwise, notoriously

${ }^{1}$ The Educational Thought and Influence of Matthew Arnold, W. F. Connell, with an introduction by Fred Clarke, M.A., 1950, pg. 3. Most of the information in this section derives from Connell's detailed analysis of Arnold's educational thoughts. I happened upon this book by way of recommendation in the introduction to R. H. Super's notes on The Popular Education of France (Arnold, CPW 2:327). By sheer luck the volume I purchased was, in fact, from Super’s personal library. I scoured it for marginal comments that might provide additional insights, but alas it contained only a handful of proofing notes. Super clearly had an editorial mind; I have purchased other volumes on Arnold and Clough from his personal library and, in general, the margins contain a few odd proofing marks and nothing more,- - he even proofed texts he had no intention of editing professionally, such as the Connell text. One of the volumes I purchased, however, Essays, Letters, and Reviews by Matthew Arnold, collected and edited by Fraser Neiman (1960), contains clear indications that Super used it as a foundation for developing his own multi-volume collection of Arnold's prose work. The contents pages have penciled roman numerals beside each item indicating the volume into which each would be consigned, except for two pieces, "University Reform" and "The Autobiography of Mrs. Fletcher," beside which Super has written "Not A.” The margins throughout Neiman's book are filled with those wonderful hieroglyphic proofing marks which would, no doubt, have brought a curious, ironic smile to Arnold's face. On page 191, correcting a bit of inaccurate French in a quotation from Renan, Super comments waspishly, "correct in my text." (See my Bibliography for Super's The Complete Prose Works of Matthew Arnold.)

${ }^{\mathrm{m}}$ Dissenter here means those churches that dissented from the Established or Anglican church,— either because of significant theological or dogmatic differences, or because the Anglican church was the state church,- - having pulled away from the authority of the pope, many protestants were not willing to replace the authority of the pope with the authority of the state. While early usage of the term Dissenter (or Non-conformist) included the Catholic church, in Arnold's time the term Dissenters was almost exclusively used for the great variety of Protestant sects: Methodist, Presbyterian, Baptist, Congregationalist, Unitarian, etc. Francois Bédarida, in his A Social History of England: 1851-1990, provides an overview of the variety of religious sects in England including a helpful graphic (pages 8889). As Bédarida shows, the Anglican church itself was not an homogenous whole,- it had its High, Broad and Low church and its Evangelical and Oxford movements of the 1830s all pulling in contrary directions. 
indifferent to religion. ${ }^{\mathrm{n}}$ These were the schools that Arnold inspected. The masters of these schools were jealous of their independence and sometimes would refuse inspection even though this meant losing the state subsidies that came with the inspection. Religion was the great stumbling block of national education in Arnold's time. A small movement of intellectuals felt that religious education could be set aside to be handled within the family itself or by the church in Sunday schools. But this was not the overwhelming sentiment of the times. The moral character of education (which as we shall see, not even Dewey could desert) demanded something more consequential, and to the mind of the Victorian, the Bible was a necessary component of a child's moral education. ${ }^{\circ}$ Arnold came down solidly in favor of a common, mandatory school system run by the state with the inclusion of a rather compartmentalized section of biblical education

\footnotetext{
${ }^{\mathrm{n}}$ My own mother, who comes out of the London lower classes of the 1930s and 1940s, is something of an example of this indifference and the degree to which it continued for many years after the Victorian period. She seems not to have been entirely aware of the differences between the Anglican church and the Dissenter churches. Her descriptions of the few times she went to church with her family, when she was a child, suggest that the services they went to were Dissenter. Her parents showed no interest in religion, and neither did she. When my mother came to America, she assumed that she was Church of England (Anglican), because it was essentially the only church she knew by name, and she assumed that, in general, all English were members of the Church of England by default (Arnold would have much approved).

${ }^{\circ}$ We will approach this issue of moral education in more depth later, but even at this point we ought to be careful not to assume that the Victorian moral sensibility conforms to that unnuanced, late-twentiethcentury, reductive conception of morality which assumes that the adjective absolute invariably adheres to the word morality. The Victorian conception of morality goes beyond a mere learning of absolute rules (although something of a rule-bound sensibility was almost invariably present); the Victorians had sense that rules alone were insufficient and that morality demands the growth of "character." This focus upon character creates something much different, and intriguingly more malleable, than a mere ranting Decalogue of thou-shalts to which we tend to reduce morality today. One might also note that a not inconsequential link in many educational writers, including Arnold, and to some extent Dewey, links character and democratic citizenship. In Dewey and Arnold, we must read the concept of character rather broadly to fully understand how they saw it functioning in democracy,- Dewey opposed the teaching of character as a series of rather wooden traits (bravery, honesty, etc.); Arnold would, no doubt, have been more sanguine (as am I, since as an educational element the teaching of character traits is really only harmful if seen as altogether sufficient). Like Dewey, Arnold made an active sense of conduct central to his notions of culture and thus of education,- - and it is to Arnold and Dewey's conceptions of conduct that we will need to turn when we begin to explore morality more fully later in this paper.
} 
which could be farmed out to the local protestant ministers and Anglican priests to meet the wishes of parents and the local community. His General Report of 1852, when his inspectorial district covered one-third of England and Wales (it would later be reduced until it amounted to a small area in and around London), introduced much of the experiential and philosophic matter that would characterize his educational, and social for the rest of his life. He worried that school fees were excluding "the children of the very poor;" he complained that the children of lower middle class were not "sufficiently enlightened;" he insisted that Welsh schools should focus upon "the Acquirement of the English language" since "it must always be the desire of a Government to render its dominions, as far as possible, homogenous, and to break down barriers to the freest intercourse between the different parts of them;" he worried over teacher-student ratios and suggested that the communal relations of the class were more important for educational organization than separation based upon intellectual attainment (a concept not often associated with Arnold, but one which is not inconsistent with his overall educational aims); he complained that the pupil-teachers (an essential part of the school faculties was the use of young men and women, up to about the age of eighteen, as teaching assistants to the school-master) exhibited, "towards the close of their apprenticeship," an "utter disproportion between the great amount of positive information [they had attained] and the low degree of mental culture and intelligence.”18

The necessities that placed Matthew Arnold as a school inspector and caused him to travel incessantly across England, wearied him such that writing and family were at odds for his minimal spare time throughout much of the rest of his life, and made him 
doubt the virtues of politics, Liberal and Tory,—- these necessities surely must be thanked for the reality they impressed upon his thought, for the complexity and many-sidedness of his educational philosophy. The educational issues he faced were many and difficult to answer: what should be the role of the state in education? Should education be voluntary? Gratuitous (free)? Can religion and education be separated? Can a nation with a state religion support the religious efforts of other churches? Was the role of education intellectual or character-forming? Or was it, rather, the making of a productive member of society? How much control of the school system should be central, how much local? How should teachers be selected and trained? Where are texts and curricula to come from? How should one inspect schools? How evaluate and comprehend effectiveness? How did one handle pupils whose parents needed them to be breadwinners? So complex were the issues that most observers threw up their hands and opted for a series of compromises.

Arnold addressed all of these issues and more. He recognized that until real wages matched the rise in prices, no efforts at compulsory education could be effective; he urged his countrymen to put aside their fear of the state for the sake of the more important issue of the necessity and inevitability of class equality; he understood education as intellectual, character-forming and, in a democracy, the means by which one created productive members of society; he understood that without good textbooks, good teachers and good administration, no school system could be effective; he could not see a separation of education and religion, if only in that, other than religion, he saw no alternative source for character education; even with his vaunted love for Greek 
literature, he could not deem Homer and Plato adequate to the purpose. ${ }^{\mathrm{P}}$ Not until the

Education Act of 1944 would most of these issues find resolution.

There can be no greater tribute to Arnold's work and influence than the fact that so many more would re-echo his sentiment in our own day [1950] than would have been prepared to do so in his. One can imagine him contemplating the Education Act of 1944 with its generous presuppositions and saying, "Yes, something like that." But would he be quite at ease? Would he feel that the battle had been won? It is to be doubted. We may hazard the guess that he would measure the extent of the moral commitment and decide that the fight had still to go on. ${ }^{19}$

\section{$\operatorname{Cos} 8$}

Arnold's personality makes a mess of any attempt at biography. He could be a bully to his brother, Tom, and his friend, Arthur Hugh Clough, but seemed always to expect that they would forgive his roughness and insensitivity. He laughed too much and spoke too loud, but could not bring himself to smile for a photographer. He cultivated a superficial dandyism. He pretended not to take the world seriously, and then wrote poetry that demanded serious attention. He revered Marcus Aurelius and stoicism, but surely he is the least stoical of literary critics. He was very much the sentimental Victorian pater familias, whose love for his children, his family, and even the family dogs, was unbounded. ${ }^{\mathrm{q}}$ His poetry betrays a worldly pessimism, while his essays reveal a man who optimistically sought political and social solutions to the world's maladies. Park Honan, in his admirable biography, calls him "one of the least dogmatic of

\footnotetext{
${ }^{\mathrm{p}}$ Admittedly this abbreviates Arnold's position considerably, but surely it suggests more than the "take two doses of Greek literature and call me in the morning" parody of his thought that has become the common formula credited to him by both his detractors and his proponents. Connell provides an infinitely fuller and richer discussion of all of these issues.

${ }^{\mathrm{q}}$ We have two poems upon the deaths of his dogs and one upon a budgerigar, and yet none upon the untimely deaths of his children.
} 
writers, ${ }^{20}$ but Arnold himself knew better; he knew that he could be quite overbearing at times, knew that his passion could carry him too far, that his irony often cloaked a desire to sort out all this awkward messiness once and for all.

When he finally published his first book of poetry he wrote to one of his sisters,

Fret not yourself to make my poems square in all their parts, but like what you can my darling. The true reason why parts suit you while others do not is that my poems are fragments, i.e. that I am fragments, while you are a whole; the whole effect of my poems is quite vague and indeterminate: this is their weakness: a person therefore who endeavoured to make them accord would only lose his labour: and a person who has any inward completeness can at best only like parts of them: in fact such a person stands firmly and knows what he is about while the poems stagger weakly $\&$ are at their wits end. I shall do better some day I hope. Meanwhile change nothing, resign nothing, that you have in deference to me and my oracles: \& do not plague yourself to find a consistent meaning for these last, which in fact they do not possess through my weakness. There- I would not be so frank as that with everyone. ${ }^{21}$

By mid-life, as the Arnold myth would have it, his poetic voice had dried up. It was replaced by a more prosaic voice,_- the voice of the literary critic. In 1857, he took the poetry chair at Oxford. His lectures drew mixed responses,- - he clearly needed to grow into his new role. He began to write journal articles and eventually to make a name for himself beyond that of the son of a famous headmaster.

Arnold was never so prolific as Dewey. His work and family often kept him away from his study, and he could fret long hours over a single essay before ever putting anything down on paper, then he would turn to it at the last moment and hurry it through, making it all the more necessary to fuss with again should it find a place in one of his books. Here are a handful of the titles that stretch across Super's eleven-volume Complete Prose Works: "Preface to First Edition of Poems” (1853), The Popular 
Education of France (1861), “Marcus Aurelius” (1863), "Heinrich Heine” (1863), "Spinoza and the Bible” (1863), "The Function of Criticism at the Present Time” (1864), Culture and Anarchy (1869), Literature and Dogma (1873), God and the Bible (1875), “Equality” (1878), “Literature and Science” (1882), “Emerson” (1884), and “Numbers, or The Majority and the Remnant” (1884), — the last three Arnold read to his audiences during his speaking tour of America in 1883, five years before his death.

$$
\text { Co3 } 80
$$

John Dewey was born on October 20, 1859, in Burlington, Vermont, to Archibald and Lucina Dewey. (Arnold had been an inspector of schools for eight years, had been married those same eight years, had written his first volumes of poetry, and for two years had held the Chair of Poetry at Oxford when Dewey was born.) Dewey attended the University of Vermont from 1875 to 1879. He taught high school in Pennsylvania and Vermont, without much success, before entering John Hopkins University to study philosophy at a graduate level.

At John Hopkins he studied with George Sylvester Morris and G. Stanley Hall, but avoided C. S. Peirce, who would share with Dewey the mantle of the father of pragmatism. At the time Dewey followed Morris into the world of the German idealists. He would later shake off Hegel and the idealists in favor of that "pressure of concrete experience" we have already spoken of.

He taught at the University of Michigan in 1884, University of Chicago in 1894, and Columbia University in 1904. At the University of Chicago he founded his famous Laboratory School. And he wrote books, lots of books: The School and Society (1900), 
The Child and the Curriculum (1902), How We Think (1910), Democracy and Education (1916), Reconstruction in Philosophy (1920), Human Nature and Conduct (1922), The Public and its Problems (1927), A Common Faith (1934), Liberalism and Social Action (1935), Experience and Education (1938), Experience and Nature (1938), Freedom and Culture (1939), etc.

His life, at least what we know of it, is a grand list of events and publications. It is as skeletal as a curriculum vitae, almost entirely devoid of that human sympathy that marks the seasoned melodrama of a good biography. He, himself, knew all to well how the work of a philosopher must reduce itself to the works of a philosopher. We search his life for that humanizing experience that speaks solidly in our imaginations to a pragmatic experience of the world. What we find is implicit of a man who lived his life in the most homely and ordinary way. Like Arnold he carried on his own sort of unrepentant Philistinism, setting the comfort and conformity of the lived life before the nobility and radicalism of the life of writing.

We shall have no epic paeans to these men. None is wanted, none is needed.

$$
\text { Cog数 } 80
$$

If I have short-changed Dewey’s biography, surely that biography itself is in no small measure to be blamed. And yet his life was not without incident and interest. His conduct of the Laboratory School shall, no doubt, provide perpetual meat for dialog in educational circles; his participation in such organizations as the New York City Teachers Union, the nascent NAACP, and numerous other such causes speaks to his willingness to engage in broad paths of social activism; his trips abroad to Japan, China, 
Mexico, Turkey and the Soviet Union, and the contributions he made to the educational programs of each are indicative of Dewey's desire to carry his educational message across national borders; his stewardship of the Trotsky Commission had the suspense of a courtroom drama and clarified his relationship to communism and liberalism in ways that his writings alone could not. ${ }^{22}$

The Chicago School which formed around him during his years at the University

of Chicago is surely one of the great occurrences in the annals of intellectual history.

The rest of the world [says William James] has made merry over the Chicago man's legendary saying that 'Chicago hasn't had time to get round to culture yet, but when she does strike her, she'll make her hum.' Already the prophecy is fulfilling itself in a dazzling manner. Chicago has a school of thought! ... Professor John Dewey, and at least ten of his disciples, have collectively put into the world a statement, homogenous in spite of so many coöperating minds, of a view of the world, both theoretical and practical, which is so simple, massive, and positive that, in spite of the fact that many parts of it yet need to be worked out, it deserves the title of a new system of philosophy. ${ }^{23}$

$$
\text { Cos旅 } 80
$$

And John Dewey had an affair, or at least it is now commonly supposed that he did. In 1918, he met a young polish woman named Anzia Yezierska. In two short stories and two novels, Anzia fictionalized the affair,— at least that is the conjecture of Jo Ann Boydston who arrays the evidence rather convincingly in her introduction to The Poems of John Dewey. The more significant news here, stepping away from the melodrama, is that Dewey wrote poetry, some of which he appears to have used to work out his personal feelings about the affair, but much of which seems to have involved a playful experimentation with poetic forms. 
Ninety-eight poems by Dewey have survived and are published in The Poems of John Dewey, edited by Jo Ann Boydston. Kenneth Allott includes 143 poems and twenty-one fragments in his authoritative The Poems of Matthew Arnold. By comparison Dewey's ninety-eight poems (although they are exclusively short lyrics with nothing to compare to Arnold's longer dramatic pieces) suggest a solid and sustained output, particularly if Boydston’s rough dating of them as occurring between 1910 and 1918 is accurate. ${ }^{24}$ Boydston breaks down the poems as follows:

Forty-five poems expressing personal emotions are lyric poems, even though most lack the musical quality usually associated with lyrics. Seventeen poems are nature poems; twenty-eight are philosophical poems and the last five are children's poems. ${ }^{25}$

Boydston associates several of the lyric poems with Yezierksa. And in one of the poems, “To us you came from out of dark," Dewey writes about the deaths of his sons Morris and Gordon. ${ }^{26}$ In many ways, Dewey's poems are more personal than Arnold's (for example, Arnold wrote no poems on the deaths of his own children). Arnold, indeed, insisted that poetry required the poet to look to the horizon, a task that cannot be performed if one's views are too personal,_- “where man his deepest personal feelings being in play, finds poetical expression as man only, not as artist." ${ }^{27}$ Dewey, in an article for Seven Arts Magazine, confided that he lacked "the passion as well as the art" to be a poet. $^{28}$

For Dewey, no doubt, these poems were a kind of palliative for personal anxieties, and one suspects he was conscious that they did not quite rise to the level of public poetry,- or poetry written for consumption by a larger audience. Although Boydston 
suggests that at least one poem, “Creation,” Dewey may have crafted and refined with such a view in mind, only two of his poems appeared in his lifetime, and these two were published within Yezierska's novels and would, no doubt, have been taken as productions of the novelist and not the philosopher.

However, something more than merely personal seems to be going on in Dewey’s poetry, - a kind of experimentation and an attempt to create a linkage between poetic, emotive expression and his own philosophic prose, which Yezierska, after the affair, somewhat spitefully described as "devoid of the intimate, self-revealing touches that make writing human.”29 When Dewey’s daughter Jane first heard about the poems she "suggested that these might be poems that her father corrected for any one of a large number of young people he was interested in, but she added that naturally anyone might experiment with writing poetry in the course of a long lifetime."30 In his poetry, Dewey tries on the clothes of the poet, experiments with poetic diction and poetic emotions, recasts segments of his own prose in poetic form, and even attempts to shift his eyes away from himself and toward the larger, deeper horizon that Arnold pointed to.

We would be remiss to have spoken at such length about Dewey’s poetry without at least sampling some of it. Here is an excerpt from “To Death.”

Art thou there, my love Within the pale gold silence In loneliness enshrined? Where thou waitest is my doom; Move gently then within the embroidered dark, Till I can send thee Dispatches of my love, Doves decked with cool bells, Dipping their soft wings, Shining, soundless, 
In sign of my subjection. ${ }^{31}$

The meter is open, almost approaching free verse, but qualified by the measured cadence of the occasional iambic line. The subject, a sort of Liebestod (love-death), is a curious one for Dewey, - is it possible that his romance with Yezierska led him to consider suicide? Nothing in Boydston's analysis of the affair suggests this. Based largely on a reading of the Yezierska's fiction and the few poems she assigns to the relationship, Boydston suggests that the affair ended more prosaically, with Dewey’s recognition of "the temporary and peripheral nature” of his involvement with Yezierska. The relationship that Boydston paints is more richly human and complex for not moving toward grand melodramatic effects. For example, Boydston notes that Yezierska used the phrase "cold in the heart, clear in the head" to describe Anglo-Saxons and may have teased Dewey with the phrase. ${ }^{\mathrm{r}}$ Dewey's poetry contains more than a little of his response to this critique,- - arguably much of his poetry might be ascribed to his efforts to resolve this problem, to find a way to express the warmth in his heart, without losing the clearness in his head. Nonetheless, this would seem to suggest that this poem, "to Death,” is more a product of the head than the heart,- - more an intellectual, than emotional excursion. "Swinburnian," another poem that is thematically extreme, certainly from our image of Dewey the mild-mannered, absent-minded professor,

\footnotetext{
${ }^{\mathrm{r}}$ Dewey and Boydston (editor), The Poems of John Dewey, 1977, pg. xxxii. Boydston cites the following passage from Dewey, Human Nature and Conduct, 1922, pg. mw.14.177-178.

The separation of warm emotion and cool intelligence is the great moral tragedy. This division is perpetuated by those who deprecate science and foresight in behalf of affection as it is by those who in the name of an idol labeled reason would quench passion. The intellect is always inspired by some impulse.

This theme as it develops in Dewey's philosophy seems to contain more than a faint echo of Arnold's Hebraism and Hellenism, particularly when he moves toward a need to balance the two elements.
} 
pointedly plays with Swinburne’s wild, violent, sadistic themes,- - Dewey seems to be just trying them on,- - in privacy of course; Swinburne was not the sort of poet one consorted with publicly.

In “To Death” and many of the other lyrical and nature poems, Dewey has taken his themes and motifs from romantic (and post-romantic) poetry. Like Arnold, he finds himself searching the edges of those themes and becoming, at times, rather hopelessly pessimistic,- a new tone for Dewey. But in “To Death” the couplet, “Till I can send thee / Dispatches of my love” is not only rather too playful for the poem’s overall theme, but decidedly optimistic, suggesting the "universal and freest form of communication”32 which Dewey assigns (in Art as Experience) to the plastic arts, having discovered (through personal experiment, we might note) that literature does not have the same communicative efficacy,_ not even when it contains “Dispatches of my love.”

$$
\cos 80
$$

Arnold, also, had an affair, if affair it may be called. It occurred before he was married, so affair in this case has that less colorful sense we find in a phrase like "the affairs of life.” He sought, rather effectively as it turns out, to keep the woman's identity a secret. He called her "Marguerite” and wrote several poems about her. Park Honan believes her to have been a young woman named Mary Claude, who summered near the Arnolds in Westmoreland. 33 “To Marguerite_Continued” is one of Arnold’s most successful poems; Alan Roper says bluntly, “it is Arnold’s most perfect poem.”34

Yes! in the sea of life enisled With echoing straits between us thrown, Dotting the shoreless watery wild, We mortal millions live_-alone-. 
The islands feel the enclasping flow

And then their endless bounds they know.

But when the moon their hollows lights, And they are swept by balms of spring, And in their glens, on starry nights, The nightingales divinely sing; And lovely notes, from shore to shore, Across the sounds and channels pour-

Oh! then a longing like despair

Is to their farthest caverns sent; For surely once, they feel, we were Parts of a single continent!

Now round us spreads the watery plainOh might our marges meet again!

Who order'd, that their longing's fire Should be, as soon as kindled, cool'd? Who renders vain their deep desire?A God, a God their severance ruled! And bade betwixt their shores to be The unplumb'd, salt, estranging sea. ${ }^{35}$

Arnold and Dewey, as poets, seem both to have been intent upon using their poetry as a way of directly experimenting with life. This experimentation took many forms for each of them: from an experimentation with the language of poetry, to the use of poetry as a kind of personal consolation for life's pangs and miseries (more so for Dewey than for Arnold), to attempts to stretch the mind out to the horizons of life, and as a way of regarding the whole of life and not just its constituent parts. Arnold famously called poetry “a criticism of life.”

In poetry, as in criticism of life under the conditions fixed for such a criticism by the laws of poetic truth and poetic beauty, the spirit of our race will find, we have said, as time goes on and as other helps fail, its consolation and stay. But the consolation and stay will be of power in proportion to the power of the criticism 
of life. And the criticism of life will be of power in proportion as the poetry conveying it is excellent rather than inferior, sound rather than unsound or halfsound, true rather than untrue on half-true. ${ }^{36}$

The "consolation and stay" that Arnold refers to here was not that of the palliative of personal poetry that Dewey, like so many other amateur poets, seems to have sought. For Arnold, "the best poetry is what we want. ${ }^{, 37}$ Let us set aside for now the more general discourse that this equation between poetry and criticism suggests (we will turn to it again when we discuss the critical mind later in this paper, at which time we will even note Dewey's relative agreement). For now our concern is to discover what Arnold made of this dictum in his own poetry. In truth, Arnold never entirely gave up on certain forms of personal expression in his poetry (nor in his prose). He set his poems into personal landscapes remembered from his youth; his elegiac poetry was central to his oeuvre and inevitably had something of a personal tone to it; he tended in both poetry and prose to delight in exploring his own personal response to the events going on around him.

Shortly after his first book of poetry was published, one of Arnold's sisters noted: ${ }^{\mathrm{s}}$

I do not think those poems could be read—quite independently of their poetical power - without leading one to expect a great deal from Matt; without raising I mean the kind of expectation one has from and for those who have in some way or other, come face to face with life and asked it, in real earnest, what it means. I felt there was so much more of this practical questioning in Matt's book than I was at all prepared for; in fact that it showed a knowledge of life and conflict which was strangely like experience if it was not the thing itself; and this with all Matt's great power I should not have looked for. ${ }^{38}$

\footnotetext{
${ }^{\text {s }}$ The poem we are focused on here, “To Marguerite—Continued,” first appeared in 1852. Arnold's first volume of poetry, The Strayed Reveller, and Other Poems, by A, appeared in 1849. That is to say, Arnold's sister, Mary, is clearly not referring directly to this poem, nonetheless, her comment, so often repeated by Arnold's biographers and critics is a powerful one that captures something rather distinctive in Arnold's poetic vision.
} 
Arnold may have expressed himself in what Dewey would call an Either-Or,- either the poet is expressing himself as an individual concerned with particularly personal matters, or as an artist concerned with more universal matters,- - but the truth as it found itself, practically in Arnold's poetry, lay somewhere in between, in something "strangely like experience.” The true criticism of life that Arnold sought was a more pluralistic thing than his momentary, jingoistic prose could express effectively. It included personal expression, along with the trying on of poetic clothes inherited through tradition, and attempts, increasingly difficult, to raise the poetic voice toward high seriousness.

In the opening line of "To Marguerite—Continued," the repetition of that old war horse "the sea of life" is, itself, not so important as what Arnold makes of it. The word “enisled” may recall John Donne’s “every man is an island,” but, again, this historical echo is only a part of the whole that Arnold is shaping. Dewey saw this poem as one of Arnold's most pessimistic. "As the islands of the sea are separated by that sea which is common to them all, so men are separated by that very life in which all share."39 But the poem's inquiry seems to strain against its pessimism. "But when...," "For surely once...," "Oh might...," "Who order'd...," "Who rendered...” The "Yes!” with which the poem opens is a curious entre for a paean to pessimism. The "But when" of the second stanza seems to say rather,- - we may be isolated, but something in us, some desire, keeps pulling us back toward each other, as if we were once "Parts of a single continent!” (The second of four exclamation points!) In each of us is a desire to reconnect,_— “Oh might our marges meet again!” (The third exclamation point!) And our desire might be achieved, but that “a God their severance ruled!” (Final exclamation 
point!) And with that we return to the point where we started, on the shores of "The unplumb'd, salt, estranging sea.” (Clearly Arnold forgot the exclamation point!)

Even so the matter seems hardly settled. The "salt" inserted in that final line acts as a bit of grit holding this criticism of life in an unsettled state. ${ }^{t}$ As Alan Roper puts it,

We can say that, while no one gloss is especially pertinent, the whole complex of glosses - analogues, sources, allusions, reminiscences-greatly contributes to the almost majestic inevitability of a poem which ends exactly as it begins. In between, we move from the rhetorician's figure of metaphor to a fully achieved image, whose descriptive coherence is such that, while suggesting “meanings," it forbids articulation. It is tempting indeed to rest in a symbol, the $O$, altitudo of an imagistic critic. $^{40}$

However, unsettled as it may be, as forbidding of articulation as its “meanings” may be, one senses that Arnold does find meaning here. The awkward echo of a true criticism of life is such that in straddling these middle grounds, - when we are "in the sea of life enisled," - we must struggle, nonetheless, to find voice,_ - not because the objects or thoughts lack solidity, nor because language is so devilish that it steals from us all possibility of meaning, but because the middle ground of this “unplumb'd, salt, estranging sea” contains those tiny bits of new thought, which in a world rich in old, pervasive, and jealous thoughts, what new thoughts we may find will be terribly difficult aborning.

\footnotetext{
'Dewey echoes Arnold's salt motif in a short quatrain entitled “A Journey” Virgin waters and veilèd snows closely and which seems likely to have been at least somewhere in Dewey's consciousness when he penned his quatrain. The reference to a journey and the following of the river's path not only echoes "To Marguerite-Continued,” but also “The Terrace at Berne” another of the Marguerite poems. Clearly something of the pessimism that Dewey disdained in Arnold shows here as the "virgin waters" move toward "foul,” "brackish,” and Arnold’s pin-point of division, "salt.”
} 
Nonetheless, the "salt" in the midst of that "unplumb'd ... estranging sea" is every bit as real as our desire for oneness.

$$
\text { Co3 } 80
$$

Now let us return to this awkward messiness, this modernity, toward which both Arnold and Dewey directed such intense concern.

Arnold was born in 1822, fifteen years before Queen Victoria came to the throne; he died in 1888, fourteen years before death would remove this long-lived queen from her throne. Dewey was born in 1859, two years before Abraham Lincoln would become the sixteenth president of the United States of America; he died in 1952, while Harry S. Truman, the thirty-third president, was leading America through the bloom of the postwar years. Whatever one might call the "modern age," surely these one hundred and thirty years, from the early nineteenth to the mid-twentieth century, may be said to encompass much of what we have come to regard as modernity.

Arnold and his peers still felt the reverberations of the French Revolution, "The Terror," - so much so that the Revolution of 1848, which saw the emergence in France of the Second Republic, left Arnold, and many of the English middle-class, with concerns that the poor of their own country might rise up in violent revolution. ${ }^{41}$ The days of the aristocracy were over; the time of the middle-class had arrived; and soon enough, thought Arnold, the populous, the lower classes, would have their turn.

Dewey was four years old, the Christmas of 1864, when his mother carried him and his brothers to West Virginia to visit with his father who was stationed there as a quartermaster in the First Vermont Cavalry. The Civil War was nearing its end; the next 
year Lincoln would be assassinated: Dewey remembered "seeing the buildings of Rousses Point draped in black for Lincoln’s death.”42 If the horrors associated with popular uprising animated Arnold's thoughts on equality and freedom, the dangers of a too authoritarian government, the pogroms of Hitler, the purges of Stalin, clearly affected Dewey's conceptions of democracy ("the future holds the menace of confusion moving into chaos, a chaos that will be externally masked for a time by an organization of force, coercive and violent, in which the liberties of men will all but disappear"433).

Modernity surely must have seemed to both men a time in which uncertainty and violence, held at bay by only the thinnest fabrics of social decorum and human conduct, were in danger of becoming the common currency of a world going through a fit of change beyond anything that their predecessors could have imagined; in which what had been held as truth would now be open to question, to be reconstructed along new lines, in ways more adequate to the age; in which the bonds that united humanity to nature and man to man were coming undone, necessitating new bonds and new ways of uniting.

Both men lived solidly middle-class, respectable lives. Arnold could return from his inspecting tours of English poor schools to his comfortable house in Chester Square with his happy children, his lovely wife, their maids and their nannies. He was not a wealthy man and was often on the edge of impecuniousness. Nevertheless, he had no fear of dropping into that poverty which through his inspectorship he knew better than did most of the social critics then writing for the Victorian journals: The Cornhill Magazine, Fraser's Magazine, The Pall Mall Gazette, The Nineteenth Century, The National Review, amongst many others. ${ }^{44}$ Dewey could resign from the University of Chicago in 
1904 over disagreements with its President, William Harper, only to fall comfortably into the safety net of Columbia University before his relationship with Chicago had been fully terminated,- - which is not to say that Dewey did not have some anxious moments of "money concerns" in the few weeks between his resignation and his acceptance of Columbia’s offer. ${ }^{45}$ He was a middle-class college professor who wrote books and gained a nominal fame writing for popular journals like the New Republic; while Arnold was a middle-class inspector of schools who moonlighted as a literary and social critic. Neither ever really left the middle-class, although both had their brief forays into the upper and lower reaches of society,_- and, arguably, the philosophies of both never entirely left the middle behind.

Dewey was more a social activist, in the sense we might give the term today, than was Arnold. ${ }^{46}$ But Arnold never entirely turned his back on politics and was certainly active in school reform issues and, as an inspector, battled the injudicious realities of schooling in his own way. In Arnold's time, liberalism was still largely a middle-class concern. Although Arnold, as a school inspector was not without his worries for the situation of the poor, his energy would be directed toward the needs of the middle-class. He seems to have been curiously certain that the concerns of the working-class would be resolved in good time; the present demanded that the middle class be put right, if only that it might serve as a model for the rising working class. ${ }^{u}$

\footnotetext{
" In a letter to his wife shortly after they were married, Arnold writes, I think I shall get interested in schools after a little time; their effects on the children are so immense, and their future effects in civilising the next generation of the lower classes, who, as things are going, will have most of the political power of the country in their hands, may be so important.

Lang, Letters, October 15, 1851, To Frances Lucy Wightman Arnold, Vol. I, pg. 227.
} 
Dewey could harbor no such certainties. For him, as for so many of his intellectual peers in those grey years at the end of the nineteenth century and the pale yellow springtime of the twentieth, the focus had to turn toward the needs of the poor and the working-class upon whose backs the mighty machine of modernity had been hoisted. If Dewey was never wholly enamored of Marxism,- - he would, in fact, come to distrust its monotonic focus upon economics, - throughout his career, he voiced his concern for the disproportionate social patterns of life. As he put it on the cusp of the Great War, "the economic situation, the problem of poverty by the side of great wealth, of ignorance and absence of a fair chance in life by the side of culture and unlimited opportunity, have, indeed, always served to remind us that after all we were dealing with an opportunity for progress rather than with an accomplished fact., ${ }^{47}$

Cog犊 80

Was John Dewey an extravert? Surely the anecdotal portrait we have of him suggests quite the opposite,- - and yet his philosophy was in many ways an extraverted philosophy. Like the extravert, Dewey "thought out loud,"48 — that is to say that in his writings we have the sense that his thoughts are coming together on the page before us, as though he had only just thought them at the moment that his fingers touched the keys,- one continuous behavior of mind and body. No introverted reflection, nothing of the careful composition in the quiet cloister, no shaping, no self-referential meandering. He is focused on the object; his mind and body wrap themselves around it,— the typewritten words falling on the page, the similes and metaphors crudely cut, blank and naked. 
Like Arnold, we associate with Dewey certain words and phrases,- - words perhaps more than phrases, as Dewey was not nearly so given to sloganeering and phrase-making as was Arnold. “Experience” is surely one of Dewey’s words,- - a word that he owned as had no one before him, or since.

We have an experience when the material experienced runs its course to fulfillment. Then and then only is it integrated within and demarcated in the general stream of experience from other experiences. A piece of work is finished in a way that is satisfactory; a problem receives its solution; a game is played through; a situation, whether that of eating a meal, playing a game of chess, carrying on a conversation, writing a book, or taking part in a political campaign, is so rounded out that its close is a consummation and not a cessation. Such an experience is a whole and carries with it its own individualizing quality and selfsufficiency. It is an experience. ${ }^{49}$

The language a writer uses, the vocabulary of repetition, in which words come into place not so much because they are the best for a particular service, but because they are patterned into the background of an author's thoughts, so that they quickly, often too easily, recommend themselves,- - these oft-repeated words, even when they are not given primacy, tell us much about an author. Dewey’s “habit,” for example, with its subtle echo of David Hume, is such a word,- - as is the word, "thing," which in Dewey’s writing became a veritable instrumentality unto itself. The phrase "ready-made," a word of disapprobation for a cultural inheritance that requires of its user no thought, nor criticism, may be an echo of Arnold who used the phrase in much the same way.

For Arnold, such an unconscious use of words finds a less direct expression. As a word came to repeatedly recommend itself, Arnold tended to foreground it and, indeed, the very phrase in which he thought it was most memorable, most at home, - the word- 
habit, perhaps, of a poet, but more particularly of a poet rather too conscious of the weight of the historical age in which he lived.

“Thing,” as I have already indicated, was surely one of the most fascinating of Dewey's words; it becomes part of the inevitable texture of pragmatism, of the need for an honest, native (i.e. Anglo-Saxon rather than Latin) term for the external, the object and the object-like,- a word that in itself contains the very object-like immediacy that both forms in our minds and forms our minds, the real qua real, unprejudiced by forethought or reflection, the first tenuous tentacles of experience, its substance, its object. "I use 'things,'” Dewey says parenthetically in a discourse on logic, "in the broadest sense, as equaling res, and covering affairs, concerns, acts, as well as 'things' in the narrower sense" ${ }^{, 50}$; - "thingness" is the world as common currency. ${ }^{\mathrm{v}}$

For Arnold, "thing” is but shorthand for "the thing as in itself it really is,"w — a phrase that combines both a Dewey-like pragmatism of thinking with and through the things of the world, with Arnold's ironic, perhaps, even comic delight, in using a purposely homely phrase (can one doubt he smiled to himself when he wrote those words, "the thing as in itself it really is,” and again when he re-read them and again when he repeated them, and again and again, repeated them).

$$
\cos 80
$$

\footnotetext{
' I am tempted to associate the etymology of the word thing with Dewey's understanding of it, but, frankly, I am certain that that would amount to a gross over reading. I am reminded of a passage in which Arnold turned up his nose at Ruskin for doing the same thing with names in Shakespeare. Nonetheless, certainly we can appreciate the unconscious poetry of thing as Old English (ding) for meeting in "My image of the mind is a sort of biological thing with arms or tentacles reaching out everywhere..." Thing, thus, has the connotation of a meeting between mind and object. Dewey, "Memory and Judgement," 1902, pg. lw.17.334. Dictionary.com Unabridged (v 1.1) Based on the Random House Unabridged Dictionary, (c) Random House, Inc. 2006.

${ }^{\mathrm{w}}$ See the more detailed discussions of this phrase in later chapters of this dissertation.
} 
In a 1902 lecture at Brigham Young Academy, Dewey related a parable of a man “carrying around a great lumber house.”

We occasionally meet a man who prides himself on his good memory, and thank the Lord that we are not cumbered down like him with all the rags and tags we have ever studied. We feel instinctively that he is lost in this mass of material which he has accumulated. The last thing we should do would be to go to him for advice. We might go to him for information as we go to a dictionary; but as for the rest we look upon him as a kind of handy repository, a mere encyclopaedia of useful information. ${ }^{51}$

This trope equating useless memorization with "lumber” recurred five more times in Dewey's writings: in a 1907 syllabus on the history of education (which describes the predecessors of the Greeks as so "bound up with fixed and traditional beliefs and methods of doing things that progress was very slow, consisting mainly in accumulation; moreover, errors and useless lumber were also accumulated" ${ }^{\text {"2 }}$ ); in How We Think ("it remains in the mind as so much lumber and debris, it is a barrier, an obstruction in the way of effective thinking when a problem arises"53); in Democracy and Education ("the reaction against useless lumber seems to have gone to the extent of supposing that no subject or topic should be taught unless some quite definite future utility can be pointed out by those making the course of study or by the pupil himself, unmindful of the fact

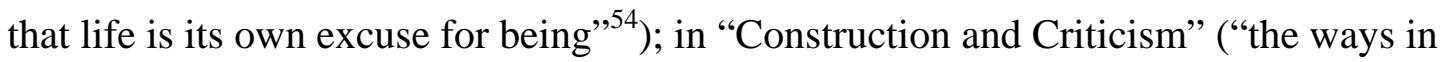
which creative energy would be freed to operate if we got rid of the lumber and the burden”,55); and in Dewey's sole autobiographical excursion, "From Absolutism to Experimentalism.” In this last, the concerns for the uselessness of mental "lumber" are a central feature of the concluding paragraph. 
In any case, I think it shows a deplorable deadness of imagination to suppose that philosophy will indefinitely revolve within the scope of the problems and systems that two thousand years of European history have bequeathed to us. Seen in the long perspective of the future, the whole of western European history is a provincial episode. I do not expect to see in my day a genuine, as distinct from a forced and artificial, integration of thought. But a mind that is not too egotistically impatient can have faith that this unification will issue in its season. Meantime a chief task of those who call themselves philosophers is to help get rid of the useless lumber that blocks our highways of thought, and strive to make straight and open the paths that lead to the future. Forty years spent in wandering in a wilderness like that of the present is not a sad fate-unless one attempts to make himself believe that the wilderness is after all itself the promised land. ${ }^{56}$

Arnold had his own concern for wandering in the wilderness. Here is the final paragraph to Arnold’s “The Function of Criticism at the Present Time.”

Still, in full measure, the sense of creative activity belongs only to genuine creation; in literature we must never forget that. But what true man of letters ever can forget it? It is no such common matter for a gifted nature to come into possession of a current of true and living ideas, and to produce amidst the inspiration of them, that we are likely to underrate it. The epochs of Æschylus and Shakespeare make us feel their preëminence. In an epoch like those is, no doubt, the true life of literature; there is the promised land, towards which criticism can only beckon. That promised land it will not be ours to enter, and we shall die in the wilderness: but to have desired to enter it, to have saluted it from afar, is already, perhaps, the best distinction among contemporaries; it will certainly be the best title to esteem with posterity. ${ }^{57}$

One might almost say that if for Dewey the lumber was to be cleared away, for

Arnold it was to be gathered up so that one might build anew. ${ }^{\mathrm{x}}$ For Dewey the past, certainly that of Europe, contained a "provincial” note. But ever as he warred upon the past a note of moderation found its way in. Note the quotation above from Democracy and Education, in which the "reaction against useless lumber" resulted in an unnecessary

\footnotetext{
${ }^{\mathrm{x}}$ In Culture and Anarchy, he says (ironically) “...my head is still full of a lumber of phrases we learnt at Oxford from Aristotle, about virtue being in a man, and about excess and defect, and so on...” Arnold, Culture and Anarchy, 1868, pg. CPW 5:126-127.
} 
clearing away, "unmindful of the fact that life is its own excuse for being,"58 — from which we can only draw the conclusion that even the dead past had some claim upon life, some claim to our sympathies.

As so often in Dewey's writing, this lumbering metaphor outreached his needs; the immediacy of his argument, the desire to speak in objects of the moment, hyperextends the concept so that even those aspects of the past in which Dewey saw value would come crashing down were we to take this as a systematic mandate which, of course, it certainly was not. In the quotation from "Construction and Criticism" above Dewey goes on to say,

But I am more concerned to suggest that there is here indicated a service for criticism that is universal. There is no one among us who is not called upon to face honestly and courageously the equipment of beliefs, religious, political, artistic, economic, that has come to him in all sorts of indirect and uncriticized ways, and to inquire how much of it is validated and verified in present need, opportunity, and application. Each one finds when he makes this search that much is idle lumber and much is an oppressive burden. Yet we give storeroom to the lumber and we assume the restriction of carrying the burden. ${ }^{59}$

Thus Dewey turned Arnold's ideal of criticism to the service of clearing the lumber house, which was, frankly, not an altogether un-Arnoldian use of the critical faculty. Arnold, himself, treated a disbelief in superstition within religious thought in much the same way,- - as a criticism that could clear out the lumber house of religious beliefs leaving behind only the necessary,- - that which pointed most effectively toward fellowship and provided the best guide for human conduct.

Whoever has to impugn the soundness of popular theology will most certainly find parts in his task which are unwelcome and painful. Other parts in it, however, are full of reward. And none more so than those, in which the work to be done is positive, not negative, and uniting, not dividing; in which what 
survives in Christianity is dwelt upon, not what perishes; and what offers us points of contact with the religion of the community, rather than motives for breaking with it. ${ }^{60}$

One almost feels that Dewey and Arnold were approaching the same thought from different directions. Dewey, distrustful of tradition, intent upon letting the active world live again, and wishing to remove from philosophy, and thought in general, the irksome burden of the multiplicitous past, used the critical faculty to build, to reconstruct the world in the present, drawing upon the past only so much as was necessary, and always standing upon the active nature of the present and its promise for the future. While Arnold, fearing the same multiplicity of past, the burden not merely of past ages, but of the bookish present as well, the monstrous and overgrown clutter of uncritical superstition, and the careless, awkward philistinism of the practical managements of modern life, used the critical faculty to draw from the well-founded thought of the past a new age, and with it the promise of a new epoch of creativity. But for both, the words of Virgil rang true, Ab integro saeclorum nascitur ordo. ${ }^{\mathrm{y}}$

\footnotetext{
y "The order of the age is born anew." Virgil, Eclogues iv 5. Arnold quotes this famous phrase from Virgil’s "Messianic Eclogue” in "The Function of Criticism at the Present Time,"1864, pg. CPW 3:258.
} 


\section{Notes}

${ }^{1}$ In Gordon Campbell, "Empedocles (of Arcagas)" in The Internet Encyclopedia of Philosophy, 2006, accessed on 19 November, 2006 (http://www.iep.utm.edu/e/empedocl.htm), quoting from the translation by Wright, M. R. (2nd edn.), Empedocles the Extant Fragments (London, 1995).

${ }^{2}$ Gordon Campbell, "Empedocles (of Arcagas)" in The Internet Encyclopedia of Philosophy, 2006, accessed on 19 November, 2006 (http://www.iep.utm.edu/e/empedocl.htm).

${ }^{3}$ Allott, in preface to "Empedocles on Etna," pg. 147.

${ }^{4}$ Arnold, "Empedocles on Etna," Allott, pg. 191, the ellipses are in the original.

${ }^{5}$ Park Honan, Matthew Arnold: A Life, 1981.

${ }^{6}$ Lewis S. Feuer, “John Dewey’s Reading at College,” 1958.

${ }^{7}$ Dewey, "From Absolutism to Instrumentalism,"1930, pg. lw.5.151.

${ }^{8}$ Dewey, "From Absolutism to Instrumentalism," 1930, pg. lw.5.151.

${ }^{9}$ Arnold, "Science and Literature," 1882, pg. CPW 10:56.

${ }^{10}$ Arnold Bennett (1867-1931), British novelist. The Journals of Arnold Bennett, entry for Oct. 15, 1896, ed. Frank Swinnerton (1932). Quoted in The Columbia World of Quotations, Copyright (c) 1996 Columbia University Press, where the good fortune of a first name and last name held in common returned a witty search result.

${ }^{11}$ Arnold, Literature and Dogma, 1883, CPW pg. 6:255 passim for "method" and “secret," but pg. 6:352 for the specific quotations here.

${ }^{12}$ Arnold, Culture and Anarchy, 1868, pg.

${ }^{13}$ Arnold, "The Function of Criticism at the Present Time," 1864, pg. CPW 3:258.

${ }^{14}$ Arnold, Culture and Anarchy, 1868, pg. CPW 5:112.

${ }^{15}$ Arnold, Culture and Anarchy, 1868, pg. CPW 5:143.

${ }^{16}$ Arnold, Culture and Anarchy, 1868, pg. CPW 5:113.

${ }^{17}$ A Writer's Recollections, Mrs. Humphrey Ward, New York, Harper \& Brothers, 1918, pg. 70.

${ }^{18}$ Arnold, Reports on Elementary Schools, 1889, pg. 1-20.

${ }^{19}$ Fred Clarke in the introduction to Connell, 1950.

${ }^{20}$ Honan, Matthew Arnold: A Life, 1981, pg. 270.

${ }^{21}$ Lang, Letters,[March 17, 1849], To Jane Martha Arnold, Vol. I, pg. 143.

${ }^{22}$ Dietz and Davis, "John Dewey and Social Action," 2007.

${ }^{23}$ William James and Bruce Kuklick (editor), Writings1902-1910, “The Chicago School,” 1904, pg. 1136.

${ }^{24}$ Dewey and Boydston (editor), The Poems of John Dewey, 1977, pg. xvii. Even though Arnold's primary output comes from a comparatively compact period of time, roughly 1843-1864, it is, nonetheless, more than twice as long as what Boydston calls Dewey's "poetry period."

${ }^{25}$ Dewey and Boydston (editor), The Poems of John Dewey, 1977, pg. xx-xxi. Three of the poems are not included in this breakdown and are printed in an appendix.

${ }^{26}$ Dewey and Boydston (editor), The Poems of John Dewey, 1977, pg. xviii.

${ }^{27}$ Lang, Letters, early February 1849, To Arthur Hugh Clough, Vol. I, pg. 131.

${ }^{28}$ Dewey, "In a Time of National Hesitation,” 1917, pg. mw.10.256.

${ }^{29}$ Dewey and Boydston (editor), The Poems of John Dewey, 1977, pg. xlvii.

${ }^{30}$ Dewey and Boydston (editor), The Poems of John Dewey, 1977, pg. xii. Boydston provides ample evidence to suggest that the poems are, indeed, Dewey's.

${ }^{31}$ Dewey and Boydston (editor), The Poems of John Dewey, 1977, pg. 29.

${ }^{32}$ Dewey, Art as Experience, 1934, pg. lw.10.275.

${ }^{33}$ Honan, Matthew Arnold: A Life, 1981, pg. 150 passim.

${ }^{34}$ Alan Roper, Arnold's Poetic Landscapes, 1969, pg. 155.

${ }^{35}$ Arnold, "To Marguerite-Continued," Allott, pg. 125.

${ }^{36}$ Arnold, "The Study of Poetry," 1880, CPW 9:163. 
${ }^{37}$ Arnold, "The Study of Poetry,” 1880, CPW 9:163.

${ }^{38}$ Lang, Letters, March, 1849, Mary Arnold Twining to [?] Thomas Arnold, Vol. I, pg. 146, emphasis in original.

${ }^{39}$ Dewey, "Poetry and Philosophy," 1890, pg. ew.3.116.

${ }^{40}$ Alan Roper, Arnold's Poetic Landscapes, 1969, pg. 157.

${ }^{41}$ Honan, Matthew Arnold: A Life, 1981, pg. 134-137.

${ }^{42}$ Martin, The Education of John Dewey, 2002, pg. 12-13.

${ }^{43}$ Dewey, Liberalism and Social Action, 1935, pg. lw.11.65.

${ }^{44}$ Honan, Matthew Arnold: A Life, 1981, pg. 295 passim.

${ }^{45}$ Martin, The Education of John Dewey, 2002, pg. 210 passim.

${ }^{46}$ Dietz and Davis, "John Dewey and Social Action," 2007.

${ }^{47}$ Dewey, "Progress,” 1916, pg. mw.10.235.

${ }^{48}$ Dewey, Democracy and Education, 1916, pg. mw.9.357.

${ }^{49}$ Dewey, Art as Experience, pg. lw.10.42.

${ }^{50}$ Dewey, "The Logical Character of Ideas," 1908, pg. mw.4.92.

${ }^{51}$ Dewey, Educational Lectures before Brigham Young Academy, 1902, pg. lw.17.333-4.

${ }^{52}$ Dewey, "Syllabi: History of Education,” 1907-08, pg. lw.17.172.

${ }^{53}$ Dewey, How We think, 1910, pg. mw.6.336.

${ }^{54}$ Dewey, Democracy and Education, 1916, pg. mw.9.252.

${ }^{55}$ Dewey, "Construction and Criticism," 1930, pg. lw.5.142.

${ }^{56}$ Dewey, "From Absolutism to Experimentalism,” 1930, pg. lw.5.160-1.

${ }^{57}$ Arnold, "The Function of Criticism at the Present Time," 1864, pg. CPW 3:285.

${ }^{58}$ Dewey, Democracy and Education, 1916, pg. mw.9.252.

${ }^{59}$ Dewey, "Construction and Criticism," 1930, pg. lw.5.142.

${ }^{60}$ Arnold, “A Psychological Parallel,” 1876, pg. CPW 8:111. 


\section{From Stanzas from the Grande Chartreuse}

Wandering between two worlds, one dead,

The other powerless to be born, With nowhere yet to rest my head, Like these, on earth I wait forlorn. Their faith, my tears, the world deride I come to shed them at their side.

- Matthew Arnold ${ }^{1}$

\section{Educational Pluralism}

Let me begin with a question,- - one that is fairly simple to conceive, but potentially quite difficult to answer: How does thought move from one mind to another?

A simple question, but one fraught with rather astonishing difficulties. For a thought to move from, let us say, my mind to your mind, - that is from the mind of the author of this dissertation to the minds of any of its possible readers, - - the thought must first be transformed into something else, something different from what it is as it stands in my mind. Within our minds, our thought is a curious sort of bio-chemical-electric thing which even the most sophisticated of our modern technologies cannot read as anything more than a peculiar pattern of energy,_- form without content.

Outside our minds, our thought, if we wish to communicate it, must be newclothed,- - converted to some form of readable action, such as a gesture, a grimace, a motion,- - or translated into words, into a text, spoken or written. Without recourse to 
extra-sensory perception, or something like a "Vulcan mind-meld,"” thought cannot move directly between two minds; we have no choice but to utilize some form of expression; expression is not thought itself, but rather a kind of stand-in for real thought,- a stand-in that has increasingly caused us to feel a sort of intellectual dubiety concerning the possibilities, or rather impossibilities, of ever achieving anything like a true movement of thought from one mind to another.

My words fly up, my thoughts remain below: Words without thoughts never to heaven go. ${ }^{2}$

While this question ("how does thought move from one mind to another?”) looks rather like the question at the center of epistemology ("how do I know what I know?"), it is not the same question. Indeed, it is closer to the central question of hermeneutics (“how do I interpret this text?"), but even that question is quite distinct from our present question. The hermeneutic question ("how do I interpret this text?") does not, of necessity, assume that the text has an author, or rather it leaves whatever author may have produced the given text as an elliptic presence which may or may not be worth our attention. With the coinage of the intentional fallacy, which I shall discuss in a later chapter, the author is all but banished from the interpretive process. On the other hand, "How does a thought move from one mind to another?" assumes that the relevant text has an author (another mind), - as a result this question is fundamentally social, while the epistemological and hermeneutic questions have all too often isolated themselves in the

\footnotetext{
a I suppose I need hardly point out that my focus here will not be on the speculation of ESP, nor the fiction of Star Trek. (And I must give credit to Dr. Northcutt for suggesting the Vulcan mind-meld as an apt exemplar of this obvious, but so often overlooked aspect of hermeneutics, which elsewhere I have linked to the notion that no communication between two minds can ever be immediate, i.e. un-mediated.)
} 
individual, — this broader question (let us call it the full-hermeneutic question) has implications that are as much ethical as they are epistemological or hermeneutic; it cannot be reduced to the isolated, individual experience, since it makes explicit the existence of multiple minds and multiple thoughts. Such is the nature of the question that we must equally concern ourselves with the mind that creates the thought and the mind that receives the thought. I describe this question in the next chapter as representing what I call the "whole journey" as opposed to the "half journey" of the "what is this object?" or "how do I know what I know?” questions. The full journey of "how does thought move from one mind to another" is not even limited to the mental, the intellectualized field of Cartesian dubiety, since thoughts can never move directly from one mind to another, but must follow the path of some medium, an intermediary object, such as a text, or the sounds of spoken words, both of which have a distinctly measurable physicality. In other words the stand-in and the thought (or intention) behind it are both participants in this question, - - thought is not isolated from gesture; gesture is not an empty and careless consequence of the communicative act. Thus "how does thought move from one mind to another" is that question which captures simultaneously the demands of science and philosophy and insists that the two conform, cooperate, and seek common ground,- - it is the pragmatic question, par excellence.

A rather extreme tendency today, although one that despite its extremism is widely held, draws upon the assumption that because these stand-ins (words or other forms of expression) are inadequate, — and they are always to some degree inadequate,the movement of thought between two minds is so entirely suspect that we might as well 
not bother; words are empty, cantankerous things, without meaning,-— they exist upon the edge of being, mere metaphysical traces, forged in the smithy of ancient and suspect philosophies.

I am not of that school. Communication of thought from one mind to another is not, has never been, will never be perfect,_- although I am willing to suspect it may be perfectible. ${ }^{\mathrm{b}}$ Practically speaking we all know that some form of movement of thought occurs between minds, - perfect or not, we form a kind of dependence on it. We suffer the frustrations of miscommunication with a smile or a grimace and carry on; we never give up entirely upon our attempts to communicate with each other; we cannot give up,for to give up would be to cease to be human,- - to become, instead, a voiceless rock. Even the most skeptical amongst us, the most despairing, the most nihilistic, the most anti-logocentric, still will trial and taste and test and experience the world. We have no way to opt out, — even suicide is an attempt to move a thought from one mind to another: it is a message writ in large, flaming, red letters saying, "I have a thought,_- please hear it.”

$$
\cos 80
$$

Here is my second question: Can we have education without a movement of thought from one mind to another?

\footnotetext{
${ }^{\mathrm{b}} \mathrm{I}$ am in my use of the term "perfectible" reflecting one of Arnold's arguments. He speaks of culture as perfection, but seems largely to mean it is a desire to move toward perfection (perfectibility) as opposed to an attainment of perfection or a study of what is somehow already perfect (although, he does tend to suggest the latter view from time to time). Cf. Arnold: Culture and Anarchy, 1869, CPW: 5: 187.
} 
Seems an almost impertinent question, does it not? But suppose we were to isolate a mind, any mind, from the thoughts of all other minds, could that mind achieve what we call education?

Most of us would be rather quick to say that such a conception of education is not only impractical, but clearly impossible. I suspect we would say this even if we were willing to assume that such a complete isolation of one mind from all others ${ }^{\mathrm{c}}$ were possible, - which it most likely is not. Some of us, myself included, would be quick to add that an education composed entirely of thoughts from other minds, an education that was dominated by the will of another, that was composed of the uncritical, rote, absorption of ready-made thoughts, that allowed nothing for the thoughts that grow unbidden in the individual learner's mind, or that allowed no possibility for the growth of individual intellect and cognitive abilities; such an education, if education we may call it, would be a monstrous thing,- - something more akin to mind-washing and propaganda than what today we would be likely to class as education.

\footnotetext{
${ }^{\mathrm{c}}$ By all accounts it was not even possible for Alexander Selkirk (the original of Robinson Crusoe) to achieve such an absolute state of isolation on his desert island,- - society, in absentia, insisted upon imposing itself upon his every thought and action as it does in these lines from William Cowper ("Verses, Supposed to be written by Alexander Selkirk, during his solitary abode in the island of Juan Fernandez,” William Cowper and Robert Willmott (editor), The Poetical Works of William Cowper, [185?], pg. 159.)

When I think of my own native land, In a moment I seem to be there;

But alas! recollection at hand Soon hurries me back to despair.

Dewey tells us rather directly, "Persons do not become a society by living in physical proximity, any more than a man ceases to be socially influenced by being so many feet or miles removed from others. A book or a letter may institute a more intimate association between human beings separated thousands of miles from each other than exists between dwellers under the same roof.” Dewey, Democracy and Education, 1916, pg. mw.9.7
} 
This monstrous thing, this conception of education as an imposition,- consisting of thoughts transferred into the mind of the learner with no respect for what grows there naturally, - we often rather flatly call "traditional education.” Many of us today harbor a sort of caricature of traditional education, not far from what I have described above, nor from this description that John Dewey wrote in Experience and Education:

The limitation that was put upon outward action by the fixed arrangements of the typical traditional schoolroom, with its fixed rows of desks and its military regimen of pupils who were permitted to move only at certain fixed signals, put a great restriction upon intellectual and moral freedom. Strait-jacket and chain gang procedures had to be done away with if there was to be a chance for growth of individuals in the intellectual springs of freedom without which there is no assurance of genuine and normal growth. ${ }^{3}$

In Experience and Education, Dewey tried to pull progressive education back from its excesses; it is the same book in which he tells us that he does not "wish to refer to the traditional school in ways which set up a caricature in lieu of a picture."4 But he does so anyway. And we need hardly blame him. The caricature is a beguiling one,the linkage to militarism, to prisons (the latter would make Foucault proud), even to the insanity of the Bedlamite’s straight-jacket,- - these are strong metaphors, and Dewey was enough of a polemicist to recognize and make use of their strength.

We have another set of metaphors for a different kind of education, one free of the authoritarian voice of the other, and they are themselves, as metaphors, quite beguiling,finding one’s own wings, realizing one’s own sense of identity, nurturing one's individuality. Clearly the tenor of these metaphors is not the same as those of the prison, the insane asylum, and the military billet. Surely we ought not to wonder that our 
educational philosophy has found the path toward individual freedom, nurturing and selfrealization far more appealing.

But as Dewey would tell us,- - as Dewey did tell us,- - this is not an Either-Or. We need not fear that when we introduce the voice of the other we will drive out the voice of the self. To the contrary, without the voice of the other, I have grave doubts that we can ever attain to the voice of the self.

\section{Pluralism}

My contention in what follows will be that education requires a thoroughly pluralistic approach. By pluralistic, I mean more than the traditional equation of pluralism with multiple voices, multiple points of view,- although, I do indeed, certainly mean to include in my conception of pluralism the vitality of multiple voices, multiple cultures, and multiple points of view. We tend to use the phrase pluralistic in the sense of a "pluralistic society" by which we mean that our society is not homogeneous; it draws from across the spectrum of peoples and cultures,- - what Horace Kallen and Alain Locke called cultural pluralism, ${ }^{5}$ and what today we call multiculturalism.

In A Pluralistic Universe, William James presented ${ }^{6}$ a broader, more philosophical conception of pluralism. William James had a strong influence on Dewey. Arnold had been a close friend of William's brother Henry, the novelist; indeed, Henry's earliest critical writing was much influenced by Arnold. ${ }^{\mathrm{d}}$ Arnold knew William and even

\footnotetext{
d See Donald Stone's Communications with the Future, 1997, particularly the chapters on Henry James and on the American pragmatists. Stone notes a number of influences that flowed from Arnold to William James, including a rather intriguing connection between Arnold's "aberglaube" and James' "overbelief."
} 
corresponded with him, ${ }^{7}$ but he died before most of William’s major writings saw publication.

William James presented pluralism as an oppositional philosophical position to the idealism and unity of monism. Monism, as a word, first appeared in English in the 1860s, but dates back to the eighteenth century in German. ${ }^{8}$ It is the belief that all things merge toward an ideal, toward a single indissoluble state, and eventually, certainly in neo-platonic thought, toward a single evanescent godhead that is the unity of all things. Pluralism suggests, to the contrary, that things have distinct existences, one from another. If we say this is a table and this a chair, we do not mean to suggest a unity between the two, even if we may immediately see an association between them. The table and chair are discontinuous, but contiguous. They are not joined in a unity, but they are side-byside (contiguous). Plurality sees a world in which many things exist, often side-by-side (contiguous), but without dissolving into unity (continuous). At the extreme, this plurality can become a state of unresolved fragmentation, an isolation in which man is separate from nature, separate from divinity, and, most uncomfortably, separate from other men,- - the very sort of isolation that Arnold worried over in his poetry,- poetry which, as we have already noted, Dewey shuddered at and thought too pessimistic.

Thou hast been, shalt be, art alone:

Or, if not quite alone, yet they Who touch thee are unmating things,Ocean and clouds, and night and day, Lorn autumns and triumphant springs. ${ }^{9}$

Dewey, reading Arnold, tells us that, in the modern condition Arnold was describing, "companionship no longer is rooted in the heart of things; it is no longer the 
outcome of a single life. Man, repulsed from the intimacy of communion with Nature, may turn to man for fellowship; but here, too, is found isolation:_„”10

Like drift-wood spars which meet and pass

Upon the boundless ocean plain, So on the sea of life, alas!

Man meets man, meets and parts again. ${ }^{\mathrm{e}}$

Although James only spoke of two states, pluralism and monism, Dewey and

Arnold give us the suggestion of a third state,- - an extreme of fragmentation that is not consistent with pluralism. The three states, then are: the ideal or continuous (unity monism), the side-by-side or contiguous (pluralism), and a complete state of fragmentation in which no relationship amongst objects is possible (anarchy or chaos). Today we are most likely to call this latter state entropy, ${ }^{\mathrm{f}}$ but this is not Arnold's or Dewey’s word. Arnold's preference was clearly for the term "anarchy," — as seen in the title of his most famous book, Culture and Anarchy. For Dewey, the preferred term for

\footnotetext{
e Arnold and Allott (editor), “The Terrace at Berne,” pg. 481. But I have taken this passage directly from Dewey's essay (Dewey: "Poetry and Philosophy,"1890, pg. ew.3.115). Dewey may have been recalling the passage from memory as he makes two small orthographic errors, leaves out a dash, and misquotes the final line, however, I think it more likely that he was simply careless in his transcription. (Arnold does not hyphenate "driftwood," but does "ocean-plain." The final line should read "Man meets man, meets - and quits again,” although, an earlier version of the poem had "..and leaves again," but not Dewey's “....and parts again.”)

f The word entropy was coined in 1865 by Rudolph Caussius from en - "in" and trope "a turning." The source from which I have drawn this etymology makes reference to the literary term trope, "from Gk. tropos 'turn, direction, turn or figure of speech'." "Turning” in entropy suggests an extreme of discontinuity, but "turn" in trope suggests the very opposite,_ - "a turning toward or into," so that what had been a distant and discontinuous thought, turns and moves toward something with which it had previously not been associated. The movement is clearly beyond mere contiguity and can become so continuous as to utterly blur any distinction at all,_- this is particularly true as the trope becomes increasingly a cliché. Personally, I was introduced to this word, entropy, through Thomas Pynchon's novels which I read when I was an undergraduate. I cannot help but feel that the era in which I grew up connected an odd sort of romanticization with this word,- it was a part of the zeitgeist, a talisman against encroaching chaos that worked by way of embracing that chaos. If I am not mistaken it is as sentimentally charged today as it was then.

Entries for trope and entropy. Dictionary.com. Online Etymology Dictionary. Douglas Harper, Historian. http://dictionary.reference.com/browse/entropy (accessed: October 27, 2007).
} 
this extreme state of disaffection seems to have been "chaos.” No matter what we call it, clearly, Arnold sensed that it was both the modern condition and the modern problem. Dewey, on the other hand, ever seems to have sought an optimistic alternative; he battles chaos and fragmentation at the fringes of his philosophy, but never seems willing to entirely concede to fragmentation,- - to grant it the power and determinacy that so many other modern philosophers were willing to give it. Nonetheless, we ought not to read into Dewey's opposition to tradition and authority a failure to distance himself from the chaos that over-zealous freedom and antiauthoritarianism could imply. Likewise, we should take care not to read Arnold as so fearful of mobocracy and fragmentation that we ignore that native liberalism he inherited from his father. ${ }^{\mathrm{g}}$

In his contributions to the Dictionary of Philosophy and Psychology, Dewey describes the problems that pluralism faces; most particularly, he states that pluralism must resolve the inherent problems "in the ideas and facts of relationship, order, law, or harmony: if this harmony exists, we seem to have not a sheer plurality, but already an organized system; if it does not we have only chaos, no universe.” ${ }^{11}$ In this phrase we can see the clear outlines of the three categories I have already outlined above: "an organized system” at one end, and "only chaos" at the other, while in between we find the

\footnotetext{
${ }^{g}$ A search of the John Dewey online database returned no results for either "entropy” or "entropic." "Chaos," on the other hand, appeared 136 times, and "chaotic" appeared 70 times (this subtracts the 16 uses of these two words that appear in editorial matter). "Anarchy" appears 83 times and "anarchic" 21 times (and 13 times in the editorial matter). Arnold's complete writings are, unfortunately, not available in electronic form, but a search of the Project Gutenberg text of Culture and Anarchy (excepting appearances in the title) turned up 18 uses of the word "anarchy," and one use of the word "chaos" ("chaotic" does not appear at all; "anarchical" appears once; and the vituperative "anarchy-mongering" is used as a descriptor for one of the leaders of the Hyde Park mob.)
} 
promised middle ground of pluralism. He suggests three qualities that he feels must be present to assure such a pluralistic state.

It need hardly be mentioned that we have here to do with one of the most serious problems of philosophy; one which was among the earliest to attract attention, and about which the conflict is most stubborn. The needs which pluralism endeavors chiefly to serve are (1) the possibility of real change, or an objectively valid dynamic view, since monism seems to make change a mere incident in the totality of being, or even a partly illusory phenomenon (Heraclitus and Hegel, however, seem to be dynamic monists in asserting the one reality to be essentially process); (2) the possibility of real variety, particularly in the differences of persons, as monism appears to lend itself to a pantheistic view, regarding all distinctions as simply limitations of the one being; (3) the possibility of freedom, as a self-initiating and moving power inherent in every real qua real. ${ }^{12}$

All three of these qualities have a distinct relevance to the educational pluralism we are concerned with here. We might, indeed, replace the word pluralism with education and say that education must present all three qualities, — dynamism, variety and freedom. With this in mind let us explore how these three qualities relate to education.

Firstly, we need to think of dynamism as central to our conception of education,_- not that the concept of education itself is constantly going through changes (although, clearly it has and will do so), but that education is inherently a process of change. Or more precisely, we must come to think of education in its most active sense,- - as a verb, not a noun. It is what education does, not what it is, that makes it pluralistic. Much of Dewey's waffling on coming to a definitive conclusion around the goals and aims of education seems to me centered on this notion,- - that education has its great relevance as an act, not as a goal,-— that it becomes a part of how we live, no matter what aim or goal we set for ourselves. For Arnold the sense of the goal (in his case the cultivation of a democratic society) was more apparent than it is for Dewey,- although, 
Dewey never really sets aside educational goals. In the long run, something like Arnold's goal of democracy, conduct, and the demands of a future humanity remain implicit in his writings.

Following our application of Dewey's definition of pluralism, education should also be various. Two dangers exist here: one is that this variety will be subsumed into a kind of pantheism in which all the varied qualities of education are seen as aspects of a single over-riding belief; the other is that education becomes a system that subsumes the differences amongst the individuals engaged in it. The second of these has been the overwhelming concern of education during the progressive era. But the two must go hand in hand. An educational approach that does not allow for variety in education itself will soon become dogmatic in its approach, and the leap from dogma to pantheism is quite short. In other words, we should be wary of allowing any single conception of education to dominate our thinking and become the sole method of our educational endeavor. This is not to say we should not be critical and make use of the best that educational thought has to offer us, but the monistic approach, be it that of "great books" culture (which, as we shall see, almost never fully reflects Arnold's own position), or citizenship-development for a democratic society (a common misreading, because too reductive, of Dewey). The point of variety in pluralistic education is that multiple conceptions of education must come together to inform our approach to education,- - and that these approaches must be seen as contiguous, not made bland and unresponsive through amalgamation into a single coherent world view (be that view progressive or 
traditional), nor held at arms length one from another as a mere laundry list of possibilities.

The last of the three is the most intriguing and can easily belie the tension that Dewey hints at. In essence, freedom acts here as something of a glue, holding the pluralism within the middle space between unity and chaos. Monism requires no freedom of action,- - since all acts move toward a unity, any act becomes inconsequential to the overall system. In chaos, freedom is equally irrelevant,- - all actions move toward fragmentation, i.e. they move away from each other. In the middle, contiguous state, freedom becomes the act of moving either toward or away, - it is an act that, because it begins in a middle state, must be self-initiated, must be active, not passive. Without this sense of freedom as the ability to move both toward and away, to engage or disengage, the pluralistic state does not exist. Thus in education the possibility for movement, free and self-initiated, on the part of each actor becomes inherent if the educational process is to maintain its pluralism.

However, as Dewey pointed out, a kind of false sense of freedom often finds expression here.

The ideal aim of education is creation of power of self-control. ${ }^{\mathrm{h}}$ But the mere removal of external control is no guarantee for the production of self-control. It is easy, in other words, to escape one form of external control only to find oneself in

\footnotetext{
${ }^{\mathrm{h}}$ Dewey moves back and forth on the issue of the aim of education. He is, I suspect, using this phrase for rhetorical effect here. Nonetheless, his statement here has at least some consistency with his summary statement to the chapter “Aims in Education” from Democracy and Education (1916). “An aim denotes the result of any natural process brought to consciousness and made a factor in determining present observation and choice of ways of acting. It signifies that an activity has become intelligent. Specifically it means foresight of the alternative consequences attendant upon acting in a given situation in different ways, and the use of what is anticipated to direct observation and experiment.” [pg. mw.9.117] Surely, as a quick shorthand "self-control" would seem to suit this definition of educational aims,_ - interestingly, we might note how closely it echoes Arnold’s frequent shorthand for culture,_- “conduct.”
} 
another and more dangerous form of external control. Impulses and desires that are not ordered by intelligence are under the control of accidental circumstances. It may be a loss rather than a gain to escape from the control of another person only to find one's conduct dictated by immediate whim and caprice; that is, at the mercy of impulses into whose formation intelligent judgment has not entered. A person whose conduct is controlled in this way has at most only the illusion of freedom. Actually he is directed by forces over which he has no command. ${ }^{13}$

In my own description of the role of freedom in a pluralistic education, I used the phrase "toward and away,” and the reader would have every right to ask,_- "toward and away from what?” Dewey's answer throughout Experience and Education was to reassert, as he has done in the passage above, that control and authority must continue to play a role in the educational process. Without some element of authority present, self-initiating freedom cannot create the movement necessary to produce pluralism. In chaos movement is irrelevant,- lost in the cacophony of disjointed movement. In a unity, movement becomes a mere continuation of the all,-- it has no separability, no distinct identity. In pluralism an awkward tension exists amongst competing authorities,without this awkward tension true freedom is not possible, nor is true pluralism.

Before leaving Dewey's comments on pluralism let us take a look at one final point. Dewey states that "while opposed to monism as a theory of the essential and ultimate unity of all being, it [pluralism] may agree with it in opposition to a dualistic theory of the opposition of subject and object.” Dewey had no intention, when adopting his own form of pluralism, of giving up on his desire to dissolve the distinction between mind and body. But in dissolving this dualism, he had no intention of formulating a new kind of monism in which subjectivity (the mind) and objectivity (the body) melt into a single cohesive whole. Subject and object retain something of a distinction, but that 
distinction is not between the internal (mind) and the external (body). An easy way to understand this is to think of an object you are very familiar with, let us say a favorite chair, the one you sit in every night to watch your programs on TV: set this familiar object against one that you have only a passing association with, say the chair you sat in the last time you were in the waiting room of your doctor or dentist. For which of the two chairs have you the most objective data? For which of the two have you the strongest subjective feelings? Most likely in both cases it is the familiar chair. Subjectivity does not preclude objectivity,- - indeed, the two often seem to increase in tandem, - the old saying "familiarity breeds contempt" suggests this, even if the subjectivity is expressed as a negative affect. Alternatively, using another familiar saying, "love blinds us to our lover's faults," we can sense that the two, subjectivity and objectivity, have a complex relationship that at times may allow one to preclude, or occlude, the other. Subjective-relativism sought to take this occlusion and, ironically, develop it into a kind of universal: all observation is subjective, therefore, as subjectivity is the opposite of objectivity, no observation can ever be objective. Deweyan pragmatism, of necessity, needed access to both the subjective and the objective, thus subjective-relativism, and its concomitant lack of nuance, had to be rejected.

\section{The Idea of God}

Dewey makes another rather interesting point in this article on pluralism we have been exploring, - a point that might be lost on us if we are a little too factional, either one way or the other, on the notion, concept, or reality of God. Both Arnold and Dewey 
have often been accused of being agnostics, if not quite atheists, but neither of them ever completely rejects God. Arnold thought of God as "the Eternal not ourselves that makes for righteousness,” but if asked to prove the existence of such a God he merely defers to practical experience.

But if ... they [the masses] ask: "How are we to verify that there rules an enduring Power, not ourselves, which makes for righteousness?”- we may answer at once: "How? why as you verify that fire burns,- - by experience! It is so; try it! you can try it; every case of conduct, of that which is more than threefourths of your own life and of the life of all mankind, will prove it to you! Disbelieve it, and you will find out your mistake as surely as, if you disbelieve that fire burns and put your hand into the fire you will find out your mistake! Believe it, and you will find the benefit of it!” This is the first experience. ${ }^{14}$

A rather homely response and not particularly convincing. Dewey responded in $A$

Common Faith.

A humanistic religion, if it excludes our relation to nature, is pale and thin, as it is presumptuous, when it takes humanity as an object of worship. Matthew Arnold's conception of a "power not ourselves" is too narrow in its reference to operative and sustaining conditions. While it is selective, it is too narrow in its basis of selection-righteousness. The conception thus needs to be widened in two ways. The powers that generate and support the good as experienced and as ideal, work within as well as without. There seems to be a reminiscence of an external Jehovah in Arnold's statement. And the powers work to enforce other values and ideals than righteousness. Arnold's sense of an opposition between Hellenism and Hebraism resulted in exclusion of beauty, truth, and friendship from the list of the consequences toward which powers work within and without. ${ }^{15}$

Dewey is quite right in noting that something of Jehovah continues to reside in Arnold's conception of God (one should be quite surprised, frankly, if it did not). More telling, however, is Dewey's comment on the duality in Hellenism and Hebraism which separated beauty, truth and friendship from the qualities of God. But most appealing to Dewey surely must have been that portion of the phrase that he carries forward 
verbatim,- - "power not ourselves," - for as he notes it removes the presumptiveness of replacing God with humanity and realizes the much needed resolution of the problem of pluralism, - the need for an idea of God that involved simultaneously a sense of God as the highest of monads, who encompassed the greatest breadth of the good without attempting to subsume into the idea of God the whole of the system of monads.

But why would a pluralistic system need "the idea of God" at all? When Dewey set aside metaphysics, I believe, he felt that, equally, he had set aside the varied pressing questions of theology,- and most particularly proofs of the existence of God. Such proofs may have meant much to Aquinas and Spinoza; in our age they still seem awkwardly relevant to a few, although the arguments have become flaccid, crude and unnuanced. For Dewey, however, such questions could be set aside along with metaphysics, teleology and epistemology. The idea of God, however, could not be so easily set aside,_- pragmatically such an idea does exist (and, I would argue, will continue to exist) apart from any proof of the existence of God. The idea of God, as Arnold tried to show, could be understood in an active sense,- - when we act, when we engage in that world of conduct,_- we step outside the inner walled world of our mind, and we realize that the world in which we act contains not only ourselves, but that "something not ourselves" which we could only see in dull shadow when locked within our own minds. Pluralism demands an accounting of that "something not ourselves" because without such an accounting we have dissolved into a unity or fragmented into a chaos. Education, then, if it is to be pluralistic, must deal with this "something not ourselves." Now whether we call that "something not ourselves" God, or humanity 
(which, as Dewey pointed out, is grossly presumptive), or nature (which is pantheistic and leads us back to monism), or, generically, "the idea of God," — still we will have to deal with it. As for proofs, pragmatically speaking, I think both Arnold and Dewey were right,- - something rather trivial and small-minded adheres to both the proofs and counter-proofs of God's existence today. I have often said, jokingly,- well, halfjokingly, - that I have little problem believing in God, I just wish someone could prove to me that atheists exist.

But God also has a role in pluralism that is quite difficult and which we shall have to tend to later in this paper. God is, in many ways, conceptually, the foundation of our sense of authority. Often that sense we have of "something not ourselves” resides in our belief that beyond us resides an authority, telling us what to do, how to behave, who to be, what is proper conduct, what is not,- - and today we are inclined to ask, "by what right does this authority exist?” and perhaps, all too quickly, to respond, “such authority has no right of existence at all.” As we have already seen, however, Dewey saw the need for some sort of authority residing within the province of education, allowing that only when something of such an authority is present can a true possibility of freedom find expression. The common question we hear today when we attempt to resolve this question of authority is, “Who says so?” as if we expect some particular individuals, or some shrouded conclave of hegemonic devils, to raise their hands and say, "Oh, that was us. We've decided we are the reigning authorities on this matter and, of course, we're sure you will cooperate,- - and thank you very much. Have a nice day.” But the question (“Who says so?”) has the unfortunate effect of diverting us from more fruitful questions 
such as, "Is this a reasonable expectation?" "What will result from my compliance or my failure to comply?” "What are my alternatives?” "How might I suggest alternative actions?" "What will I lose, what gain, by acting in accordance with this authority?" and most important, "What action should I take?” "What should I do?” is such a more meaningful question than, "Who should I blame for having dared to presume authority?" Interestingly, the concept of "something not ourselves" continues to reside in the question "Who says so?” Almost as if, in lieu of a benignant God, it would seek to create a human devil. The question, "Who says so?” is a highly moralistic question, dependent (perhaps co-dependent is the right term) upon that system of morality that adheres to an absolutist authority. Dewey offers us a much more practical, pragmatic, course when he suggests that we respond critically and actively to that authority which resides within any system.

\section{Voices}

Returning to our general discussion of pluralism, at one end of the scale, we have an extreme of unity in which all things blend,-— no individuality is relevant,-— some maker, a God or an hegemony of some sort, presses its authority across the universe and says that all is homogenic, common, unified, soluble into a single, great monad. At the other end of the scale, we find that everything is individualized, no commonality exists, no absolutes, no universals, no capacity for any true movement of thought from one mind to another, - all thought is subjective, unique and incapable of being truly shared,"Man meets man, meets and parts again." In truth, both of these states tend to exalt a 
kind of extreme of subjectivity. As Dewey, and even the philosophically unsophisticated Arnold, had come to realize, objectivity has an intriguing impact on subjectivity, — not acting so much in opposition, but rather becoming a sort of gravitational pull that disrupts the absolute conditions to which, in either unity or chaos, subjective thought tends. Although certainly many modern thinkers have sought to make of objectivity a pure, absolute state, neither Arnold nor Dewey attempt this. Their objectivity is a middle ground that teases out the possibilities of a richer, more human, more malleable, more changeful, more playful thought that can only exist when objects and subjects share common accord, and in which harmony is less important than balance.

Thus, both Arnold and Dewey promoted a pluralistic view that was a middle state between the ideal unities of monism and the utter fragmentation that appeared to be overwhelming the modern condition. ${ }^{\mathrm{i}}$ Pluralism must inevitably be seen as a balancing act between fragmentation and unity, between the Either-Ors of dogma and the relativism of the intellect. But, most particularly, it must be seen as a mind at play, ever seeking the multiple views of a thing, ever challenging and appreciating, ever active, ever doing.

That is the pluralism that I believe I have found in bringing these two disparate voices together in this disquisition. Educational pluralism surely must encompass that wealth of voices we hear today,- - voices of the present and of the past, voices of reason

\footnotetext{
${ }^{\mathrm{i}}$ Jane Garnett in her introduction to a new (2006) edition of Arnold's Culture and Arnarchy, makes a rather subtle distinction on this count: "Rather than moving to a pluralistic or relativistic position, his [Arnold's] goal was always to maintain a principle of unity. At the same time he wanted to distinguish his position from latitudinarianism.... He wanted to acknowledge cultural diversity and harness its critical power, but always within a cultural whole” (pg. xxiv). My own inclination is, as I have shown, to read pluralism as the middle ground and dissociate it from relativism which by emphasizing an extreme of discontinuity and discontiguity places itself beyond a Jamesian conception of pluralism. Nonetheless, she is correct in noting that Arnold never fully freed himself from some of the larger cultural bounds of his European heritage, although it seems more than a little anachronistic to expect that of him.
} 
and of compassion, voices of individualism and of communalism, voices that had been marginalized as well as those that have had ample platform to say their say, voices of authority from without and voices of authority from within, - voices not merged into a unified, homogenized über-kultur, but equally not voices of isolation and fragmentation, anarchy and chaos.

Matthew Arnold was the foremost English literary critic of his generation. His critical approach owed something to Charles Augustin Sainte-Beuve; however, Arnold's criticism was, in many ways, uniquely his own. His voice, the Arnoldian voice, was neither overly formal, nor brazenly informal; polite, but not always well-mannered; he was astonishingly prone to irony for one who professed to prefer the high-minded and serious, the Grand Style of Homer and the ancients. He loved irony, and was more adept at it than many of those today who have come to believe that irony is a necessary critical stance, an inevitable outcome of a post-structural, post-modern reality. ${ }^{\mathrm{j}}$ His brother,

\footnotetext{
${ }^{\mathrm{j}}$ I cannot help but recall an item I stumbled on not too long ago,- - an introduction to a collection of the writings of a notable post-modernist, D—. D— was known for upsetting the simple conventions of writing; for example, he once shifted the thesis in one particularly infamous paper from the main text to the footnotes,- - as if to say that reality lay in the margins and not the center,- as if, in his own eccentric way, he wished to show how right Yeats was when he warned us that "the center will not hold." D- in his antiauthoritarian way, often would upset the apple-carts of tradition, for no other reason than that the apple-carts of tradition are so easily upset. How does one write an introduction, then, to such a writer and do so in a way that the reader can clearly understand that the editor has conformed to D-'s "strictures" (even if it is odd to think of one who upsets apple-carts for a living as having strictures) to unsettle and "problematize" this rigidly logocentric world we live in? A conventional introduction would not do, and so the editor of this collection of D-'s writings proceeded to write a "non-introduction," announcing his intention from the start in a plain, ham-handed way; as he proceeded in his non-task, his non-ability with words became rather too apparent, and his attempts at irony contorted themselves into a ghastly non-irony, too plain, too simplistic, too shallow,_- the sort of thing where one wants to look away,- - where one feels such embarrassment for the poor editor, whose incompetence in irony clearly ought not to have so ruined him for his role as an editor,- - but, at times, one cannot look away,- - the grotesque can have such an indomitable hold upon one when one has come across it so unexpectedly. Nonetheless, I can promise, his example has been a good lesson to me,-— and I will avoid, mercilessly, and mercifully, any attempt at irony in these pages.
} 
Tom, referred to Matthew’s gift for “banter, rallying, persiflage, whatever one may call it."16

Arnold would have expected, no doubt, that over time a more serious, more highminded approach than his own irony-tinged satires could be fostered, and, indeed, he wished that he himself could attain to such a state, both as a poet and a critic; but he lived, as he told his friend Arthur Hugh Clough, in a non-poetic age ${ }^{\mathrm{k}}$,- the time was out of joint, the zeit-geist incommodious. Faced with the expanded literacy, shifting class dynamics, and incomplete educational system of mid-nineteenth century England, Arnold chose irony over the grand style as the rhetorical weapon best suited to unseating both old and new biases. With irony, Arnold could raise those notions that he regarded as either antiquated or foolishly new (he often struck in both directions) to a high state of nonsense, and then direct his reader toward what he regarded as a more critical response,- - a response informed by and the product of culture. His irony-tinged rhetoric, however, worked intermittently,- sometimes he was taken at his word (which for an ironist inevitably leads to a disastrous misreading), - at other times he was regarded as too much a contrarian to be taken seriously,_ - and, rather frequently, he was dismissed as much too rude, or much too clamorous, or much too heretical, or, simply too lightweight.

Stefan Collini introduces his short, graceful little book on Arnold with a chapter entitled "The Arnoldian Voice."

One cannot read very far into Arnold's prose ... without realizing that much the most important, if also the potentially most troublesome, feature of his style is his

\footnotetext{
$\mathrm{k}$ "Reflect too, as I cannot but do here more \& more, in spite of all the nonsense some people talk, how deeply unpoetical the age \& all one's surroundings are. Not unprofound, not ungrand, not unmoving,but unpoetical.” Arnold: Letters, To Arthur Hugh Clough, [early February, 1849], 1:131.
} 
irony... Irony is a particularly vital resource for a writer who wishes to embody as well as recommend an alternative to stridency, exaggeration, and oversimplification. Skillfully used, irony can conjure up the suggestion of much wisdom and judgement held in reserve, accumulated stocks of experience which are not drawn on directly, but which enable too-simple or too-loud to be seen for what they are. ... The danger that Arnold runs, of course, is of seeming lofty and sneering, and once that happens, his 'high-hat persiflage,' as it has been nicely termed only compounds the offence. ${ }^{17}$

This approach, unpleasant as it may have been to certain members of his audience (then and now) gave rise to some of his most intriguing writing,-—Culture and Anarchy not least among them. All the same, I am quite sure that Arnold would not have thought, as many critics do today, that irony was an absolute necessity for criticism. Although, he wrote in 1867, that he could "see more and more what an effective weapon, in a confused, loud-talking, clap-trappy country like this, where every writer and speaker to the public tends to say rather more than he means, is irony, or according to the strict meaning of the original Greek word, the saying rather less than one means.”18

Arnold almost seemed at times to delight in being misunderstood; his ripostes could be quite disarming and contained some of his most telling arguments,- - and these rejoinders depended much upon an initial misunderstanding. The periodic installments of a journal article allowed the opportunity of a response, sometimes a near dialog with his critics. The response allowed Arnold not only an opportunity to extend his irony, but also an opportunity to revitalize and reframe an argument, to make subtle shifts that evoked the virtues of what Arnold would call "a free play of mind.” As Collini points out, Arnold created a sense of intimacy with his readers. "To read Arnold at his best is to find oneself in the company of a mind of such balance and sympathy that we come, without really noticing, to see experience in his terms, and, unusually, to think the better 
of ourselves for it."19 A part of this intimacy comes from a quality we find in Dewey as well,- - one has a sense in reading both writers that the thought is coming out as a natural flow, as if the author were thinking out loud with all the natural little twists and turns and quirks of thought as it stumbles awkwardly toward a conclusion.

Something in Arnold's voice still lingers with us, even if his particular critical judgments no longer hold much sway. We hear his voice echoed, awkwardly enough, in the voices of our critics today, - the practical, world-weary tone, the self-certainty (even oddly enough amongst those who profess a disdain for certainty ${ }^{\mathrm{l}}$ ), the quick dismissal of the non-informed, not-sufficiently-critical philistine, the search for a mid-point between scholarly knowledge and enlightened amateurism, the weight of history set against the needs of the present, and the burden of a literature that seems intent upon growing out of all proportion with the capacity of any single general critic to absorb it in totality. One great difference does seem to stand between Arnold and the Arnoldian voice today,whether it claims to be Arnoldian, or is that most awkward of echoes, the anti-Arnoldian post-modernist who unwittingly, but with extreme verisimilitude, mimics the Arnoldian voice, - and that difference is that Arnold did not allow the fear of the philistine to become the overpowering pessimism it has become today, even amongst those who

\footnotetext{
${ }^{1}$ The concern for uncertainty has found a rather curious expression today. Most of us tend to see uncertainty as the opposite of certainty, - an absolute Either-Or. Thus any expression of certainty is easily met by a disdainful, but no less certain, appeal to uncertainty. Uncertainty, however, is better understood as a mixture of certainty and not knowing (ignorance). Thus ignorance is the real opposite of certainty. Uncertainty, a mixed and temporal state, lies between the two. Or as Dewey would suggest, uncertainty is really certainty perceived as an action, as a process of knowing. Thus when we see a dichotomy created between those who believe in certainty (generally referred to erroneously as positivists) and those who believe in uncertainty, we are really seeing a continued reduction of certainty to the passive state of the known and unknown. (Cf. Dewey: The Quest for Certainty: A Study of the Relation of Knowledge and Action, 1929, pg. lw.4.1 passim.)
} 
equate Arnold's distaste for pessimism with elitism (which, to a certain degree, it was).

Arnold's poetry might express his pessimism about the age in which he lived, but his prose ever falls back upon an optimistic note. Dewey clearly heard that note of optimism, - it resurfaces in his voice and becomes the indomitable tone of Deweyan pragmatism.

The Deweyan voice contained no Arnoldian irony,_- indeed, considering the vast extent of his writing, its near encyclopedic range, and the degree of intellectual curiosity and insight it so often betrayed, Dewey’s writings showed no perceptible irony of any kind. Dewey's is a difficult voice,- he tends not to use that specialized language of the philosopher which allows a shorthand for complex ideas, - he preferred to turn out his complex thoughts in fairly conventional dress; moreover, his syntax was often quite choppy and his arguments confusingly serpentine. But he was not, as Alan Ryan makes clear in the following passage from John Dewey and the High Tide of American Liberalism, the terrible writer many of his readers have claimed he was.

Generations of readers have complained that Dewey was a terrible writer. This is not entirely fair. Justice Holmes's quip that Dewey wrote as God would have done if he had been terribly anxious to tell us something of great importance but had found himself temporarily at a loss for words catches the combination of seriousness and stylistic awkwardness that makes Dewey an engrossing read but a strenuous one. Dewey was not a dull writer; the problem was that he wrote all too exactly as his subject matter dictated. His short polemics were brisk and clear; the more complicated the subject, the more his prose wound around and about to follow it. It is not surprising that Justice Holmes's quip was sparked by reading Experience and Nature or that Holmes observed after reading the book that he felt as though he had for the first time seen the universe "from the inside."20

Dewey wanted to reconstruct the world anew, to turn to every aspect of this world in which we live and reconceive it in new thought based upon the evidence of personal 
experience. As a result he pulled away not only from the findings of the past, but from

the very terminology in which those findings had been proclaimed, dismissing them as

"ready-mades." As Dewey put it in his short autobiographical sketch, "From Absolutism

to Experimentalism,”

I imagine that my development has been controlled largely by a struggle between a native inclination toward the schematic and formally logical, and those incidents of personal experience that compelled me to take account of actual material. Probably there is in the consciously articulated ideas of every thinker an overweighting of just those things that are contrary to his natural tendencies, an emphasis upon those things that are contrary to his intrinsic bent, and which, therefore, he has to struggle to bring to expression, while the native bent, on the other hand, can take care of itself. Anyway, a case might be made out for the proposition that the emphasis upon the concrete, empirical, and "practical" in my later writings is partly due to considerations of this nature. It was a reaction against what was more natural, and it served as a protest and protection against something in myself which, in the pressure of the weight of actual experiences, I knew to be a weakness. It is, I suppose, becoming a commonplace that when anyone is unduly concerned with controversy, the remarks that seem to be directed against others are really concerned with a struggle that is going on inside himself. The marks, the stigmata, of the struggle to weld together the characteristics of a formal, theoretic interest and the material of a maturing experience of contacts with realities also showed themselves, naturally, in style of writing and manner of presentation. During the time when the schematic interest predominated, writing was comparatively easy; there were even compliments upon the clearness of my style. Since then thinking and writing have been hard work. It is easy to give way to the dialectic development of a theme; the pressure of concrete experiences was, however, sufficiently heavy, so that a sense of intellectual honesty prevented a surrender to that course. But, on the other hand, the formal interest persisted, so that there was an inner demand for an intellectual technique that would be consistent and yet capable of flexible adaptation to the concrete diversity of experienced things. It is hardly necessary to say that I have not been among those to whom the union of abilities to satisfy these two opposed requirements, the formal and the material, came easily. For that very reason I have been acutely aware, too much so, doubtless, of a tendency of other thinkers and writers to achieve a specious lucidity and simplicity by the mere process of ignoring considerations which a greater respect for concrete materials of experience would have forced upon them. ${ }^{21}$ 
I find this passage rather intriguing. It speaks of that Dewey with whom we, as readers, have the most familiarity,_- the Dewey of the awkward, rambling, serpentine sentences; it tells us that these sentences were not without intent,- - that the awkwardness, itself, was intentional. "Struggle,” "the pressure of the concrete,” "hard work," - these are more than just the characteristics of the Deweyan style,— they are the substance of Deweyan pragmatism. Something of what we have already commented on, the sense of Dewey thinking aloud, is here made even more intentional. The sense that Dewey is, himself, personally present in the text, not abstracted and distant, not "specious" in "lucidity and simplicity," is in itself instrumental to creating a linkage between the concrete and the theoretical. What we do not get here, however, is that sense, so common today, of a struggle with language itself, with the logocentric, - the sense that words themselves are inherently specious. Dewey struggles with language not because he has ceased to believe in its capacity to convey meaning, but because the struggle to move language toward "the concrete, empirical, and 'practical'” is alien to the metaphysical tradition of philosophy against which he was reacting. His struggle with thoughts and words meant that he would, forever, be thinking out loud in his writing, hunched over his typewriter,- - an awkward, rambling reconstruction machine. But if the struggle was decidedly awkward, it was, as well, curiously provocative and, now and then, almost tragically clear and resounding,-— tragically, because, while Dewey was not a systematic thinker, he was by no means aphoristic. The awkward struggle is a necessary part of understanding Dewey; the brief moments of clarity, often heightened by hyperbole, are simply not sufficient to get at what he intended. I shall throughout this 
paper use an occasional passage from Dewey, often opting for longer segments when I can, but I must admit that I never feel quite comfortable with any single passage,_— I know all too well how much I have left behind. But to discuss Dewey without Dewey’s voice, that half-murmured, tonally flat, awkwardly cadenced yawp, ${ }^{22}$ would be to deny something that in itself is essential to an understanding of Dewey.

How two such disparate voices as Arnold's and Dewey's could possibly have anything in common, surely, must make us wonder. And yet, they had more than a little in common. In rather significant ways Dewey, awkwardly, echoes Arnold, in much the same way that Arnold, awkwardly, echoes the grand and noble style of ancient literature. Dewey, as we shall see, was quite as much concerned with the changing face of morality as was Arnold; Dewey inherited the connection between democracy and education from Arnold; and, quite significantly, Dewey saw in the critical voice the same centrality that Arnold had seen. Arnold's critical voice carried him from literature to education to society to religion,_- in Dewey, the critical voice becomes the exemplar of philosophy, the motive force that allows us to take hold of the world around us and solve our most pressing problems. As they came from two such different worlds (Arnold is known best in literary circles, Dewey amongst philosophers and educators), the comparison between the two has been largely under-explored.

In a recent book, ${ }^{23}$ Donald D. Stone has gone a long way to establish the influence of Arnold upon Dewey. Stone's book deals with Arnold's relationship to many other thinkers, but it ends with Dewey. In an email to the present author, Stone acknowledged that he had "treated Dewey as Arnold's closest heir." 
But this was a conclusion I came to after I had begun work on the book. The book developed out of an essay I contributed to Nineteenth-Century Studies in 1988, linking Arnold with Nietzsche. As I continued reading and rereading Arnold, I began to see other links — with Arnold and James, for example (fellow cosmopolites), Arnold and Gadamer (heirs to the Germanic humanist tradition), Arnold and the French (the notion of criticism as a prod to social change). But my sense of Arnold's multitudinousness (a trait he deplored in Clough and others) led me inevitably into Arnold's affinity with the pluralists (I define pragmatists, somewhat jokingly, as pluralists with standards). And Dewey (like Arnold, a liberal and educator) seemed the modern figure most committed to the common cause (or common faith). ${ }^{24}$

Stone's argument will be dealt with more fully in the section below entitled “Communications with the Future” (the title of Stone's book and a phrase from one of Arnold's essays), but we may say, at this point, that his argument for Arnold's influence on Dewey is strong and persuasive. My own study of Arnold and Dewey suggested many of the same findings that Stone relates in his book. Frankly, I had inclined, at first, to be more tentative in my conclusions relative to Arnold's influence on Dewey.

However, the deeper I get into the study of these two thinkers, the more I have found myself agreeing with Stone on all his major findings relative to the two. The influence is, no doubt, present, and its depth is greater than I had expected to find. Reading Dewey in light of Arnold provides something of the same significance as reading Dewey in light of William James or George Herbert Mead,- - apparently elliptic thoughts take on a greater richness and vitality in light of these influences.

\section{Educational Pluralism}

However, my concern, in this dissertation, will not be to establish a pattern of influence, but rather to make use of that influence and the tension it creates between two 
strong thinkers in order to explore a path that neither fully took,- - a path that, nonetheless, seems to me to be very much suggested by each in his own way, and most assuredly by the pull or tension between them. Stone gives us a good clue to this path when he says that he sees in Arnold an "affinity with the pluralists.” My primary concern will be with educational philosophy, and my intention will be to suggest a pluralistic philosophy that builds off of Arnold and Dewey and attempts to resolve something of the awkward strain that currently exists between the culture-driven educational philosophy of the Arnoldians and the progressivism of modern Deweyans.

Dewey’s own pluralism is often so awkwardly stated that it tends, in my opinion, to be misread. Dewey's style of writing, his constant thinking out loud, his tendency to rather bluntly set aside the Either-Or aims of other educational philosophies, have resulted in a tendency for his message to read a bit too much as a series of negations, leaving the richer pluralization that should result from undoing Either-Ors sounding ultimately rather monotonic. I recently sat through a discussion among several Dewey scholars who rather seriously debated whether or not Dewey’s real intention for education was the production of good citizens; in the back of my mind I thought I heard that crackling, monotonous yawp, "But this is just another Either-Or.”

For example, if culture (in the Arnoldian sense that we now tend to qualify as "high culture”) is not, as Dewey tells us in Democracy and Education, with a light swat 
at Arnold, ${ }^{\mathrm{m}}$ a sufficient aim for education, it is, likewise, not something we should want to exclude from education.

General or comprehensive aims are points of view for surveying the specific problems of education. Consequently it is a test of the value of the manner in which any large end is stated to see if it will translate readily and consistently into the procedures which are suggested by another. We have applied this test to three general aims: Development according to nature, social efficiency, and culture or personal mental enrichment. In each case we have seen that the aims when partially stated come into conflict with each other. The partial statement of natural development takes the primitive powers in an alleged spontaneous development as the end-all. From this point of view training which renders them useful to others is an abnormal constraint; one which profoundly modifies them through deliberate nurture is corrupting. But when we recognize that natural activities mean native activities which develop only through the uses in which they are nurtured, the conflict disappears. Similarly a social efficiency which is defined in terms of rendering external service to others is of necessity opposed to the aim of enriching the meaning of experience, while a culture which is taken to consist in an internal refinement of a mind is opposed to a socialized disposition. But social efficiency as an educational purpose should mean cultivation of power to join freely and fully in shared or common activities. This is impossible without culture, while it brings a reward in culture, because one cannot share in intercourse with others without learning - without getting a broader point of view and perceiving things of which one would otherwise be ignorant. And there is perhaps no better definition of culture than that it is the capacity for constantly expanding the range and accuracy of one's perception of meanings. ${ }^{25}$

Culture, then, as an educational aim is only a "partially stated" aim. By itself, it is insufficient. But this does not mean that it is irrelevant.

We will not find in Dewey an absolute correspondence with Arnold's conception of culture as the epitome of education, but we should be careful not to reduce Arnold to a mere huckster of great books and classics. We associate with him the notion that education consists of reading "the best that has been thought and said." As a result, acolytes of the great books often take Arnold as their patron saint. But Arnold meant

\footnotetext{
${ }^{\mathrm{m}}$ He takes a much bolder swat at Arnold in Dewey: Contributions to Dictionary of Philosophy and Psychology, 1902, Page mw.2.233.
} 
much more, as we shall see, by this oft-repeated phrase. Left out of such a simplification is Arnold's desire to encourage a full play of mind and an openness to other ideas and other cultures. When Dewey states that "there is perhaps no better definition of culture than that it is the capacity for constantly expanding the range and accuracy of one's perception of meanings," consciously or not, he is echoing Arnold's conception of culture as "perfection" and of critical thought as "a free play of mind."

These two men could be subtle and evocative thinkers. Although, admittedly, they were given to the hyperbole of the polemicist and at times dreadfully overstated themselves upon a topic. For all Arnold's joy in phrase-making, neither he nor Dewey fits comfortably into the aphorisitic mode to which our cut-and-paste literature reviews and the urge for citation-as-a-proof-of-sound-research-practices so often reduce them. They did not jump assuredly from one high mountain of consequential thought to another, nor can we expect that we may easily follow in their van by citing this or that passage out of context. ${ }^{\mathrm{n}}$ They were awkward thinkers and writers, - - which is as much as to say they were modern thinkers and writers. Arnold knew all too well that he could never achieve for himself the clarity, the simplicity, the nobility of the grand style he associated with Homer. Dewey purposely eschewed anything even remotely like a grandness of style. Arnold echoes the time in which he lived in awkward passages full of rich irony and occasional bursts of telling insight; Dewey awkwardly professionalizes the modern philosopher in stumbling prose.

\footnotetext{
${ }^{\mathrm{n}}$ I believe this statement to be generally true, but in Arnold's case it requires something of a caveat. He, frankly, tended to behave at times as something of an aphorist, and his constant self-quotations are certainly indicative that he had some desire to be taken as an aphorist. Nonetheless, his discursive style kept him from ever realizing this tendency. Aphorists do not tend to argue with their interpreters.
} 
I have, no doubt, overemphasized for both Arnold and Dewey this quality of awkwardness, this struggle to communicate. Nonetheless, I want to suggest that this very awkwardness may ultimately be at the heart of what we now call pragmatism. Arnold famously suggested that in the modern age we find ourselves "wandering between two worlds, one dead, / The other powerless to be born.” ${ }^{26}$ Dewey thought this pessimism, but it may actually be as fine a definition of pragmatism as we have available to us. Arnold on the one hand kept asking us to find ways not to attain perfection, but to move toward perfection; Dewey continued, optimistically, to deny that a fall into chaos held any virtue at all. Pluralistic pragmatism is that awkward middle ground in between perfection and chaos in which "a specious lucidity and simplicity" are not necessarily advantages.

To recover Arnold's and Dewey's pluralism, and perhaps by combining them, or even asserting something of myself, go a bit beyond them, is my true purpose here. I shall own, as well, an additional purpose: to rehabilitate, if possible, our notions of intentionality and authority. I will suggest a pluralistic model somewhat more systematic than either Arnold or Dewey were wont to suggest (but not greatly so). In this model I will propose four different characters of mind, and suggest that our education succeeds best when it has the pluralistic capacity to address all four. Each quality of mind has its roots in the thoughts of Arnold and Dewey.

The first, the tentacled mind, comes directly from one of Dewey's most colorful metaphors; the tentacled mind occurs when the mind is at its most experiential, engaged with and apprehending the world in its full flower and richness. Arnold often used the 
word experience, that word we most strongly associate with Dewey; his usage of the term differs from Dewey's, but not as greatly as one might expect. For all his complaints against philistines and men of action, Arnold never really turns his back upon practical experience. However, much of our discussion of this particular quality of mind will require us to understand how Dewey's conception of experience relates to Arnold's conception of "a free play of mind," - both of which share a kind of dynamism that is not only an essential element of pragmatism, but a necessary means by which the mind is tempted from that hermetic path down which so much of the history of philosophy has led us.

The second quality is the critical mind; in Arnold, this quality grows out of his role as a literary critic; in Dewey it comes out of the experimentalism of the scientist. In both it takes on a richness and vivacity that is essential to understanding their educational ideals. Dewey often added to his discussion of criticism the word appreciation; in Arnold, I believe, this was an understood quality. Critical thinking, for Arnold, was in many ways more of a synonym for culture than was humane letters. I plan to take a look at the practice and history of descriptive criticism in English to see if from that practice and history we may learn something essential about the critical mind.

The third quality of mind, somewhat more mercurial, is a double-sided concern: it focuses on the intentions of those voices we overhear and also upon the intentions we frame in our own voice. This is the intentional mind,- it is the mind that both expresses itself and seeks to understand the intention of others; it is the linkage that carries us past the philistinism of a world of empty objects and allows us to find the means of 
connecting with the minds of others. That this thought is present, although somewhat tentative, in Dewey we have already seen,- - "one cannot share in intercourse with others without learning — without getting a broader point of view and perceiving things of which one would otherwise be ignorant."27 The concern for intentionality is ultimately a concern for meaning, - again turning to the same passage from Dewey, "there is perhaps no better definition of culture than that it is the capacity for constantly expanding the range and accuracy of one's perception of meanings."28 A concern for intentionality ultimately is a concern for our own capacity to communicate to others and our willingness to hear other voices. If we have no faith that thoughts may move between minds with the possibility of achieving some comparability of conception in so doing, then the essence of intentionality has deserted us,- - self-expression and willingness to listen to others, as a result, become mere platitudes. But a willingness to listen to others, to allow that the voice of the other may have an equal if not greater role in our thoughts as do our own, brings in the pressing concerns of authority, - of Arnold's "something not

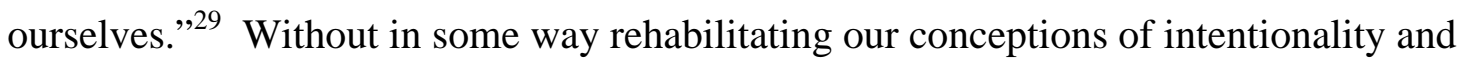
authority, we can in no way address this essential quality of mind which, if not sufficient as an aim for education, is, nonetheless, necessary.

The fourth quality of mind I have called reflective-response. If the third was more mercurial than the first two, this quality is by far the most mercurial of all. Frankly, I began by calling it simply the reflective mind, but the more I read Dewey’s conception of reflective thought, the more it became obvious to me that this term by itself was insufficient. Reflection holds for us a strong synonymy with contemplation and 
meditation, - we tend to see in it the mind in a withdrawn state, outside of the hurlyburly of everyday life. Dewey seldom seems to use the word reflection in quite this way. For him, reflection is often portrayed as an intermediate state within a stream of thought; he often shows it informing action and subsequent thought; occasionally, but not very persuasively, he shows it forming a terminus to thought. If we are to erase the distinction between mind and body that Dewey wished to achieve, then reflection must remain connected to externalities and not become isolated. As a result it seems to be necessary to allow within reflection that external release which is best characterized as response. The result is "reflective-response," - the unfortunate and awkward title I have chosen for this quality of mind. But more significantly, I believe the reflective-response quality of the mind carries the weight of what we have traditionally called morality, conduct, or character. The most difficult aspect of our discussion on this particular quality shall involve an effort to understand what this thing called morality might mean for us today.

Let me see if I can draw a picture of these four qualities in a more contiguous fashion so that they may suggest something of a whole. To begin with the tentacled mind apprehends the world in which it finds itself,- - it discovers reality in much the way that the "discovery learning" of current educational practitioners would suggest. This is the mind in full engagement with the world. But this engagement alone is not sufficient. To make sense of this engagement with the world, the mind must discern, judge, appreciate, evaluate, - in other words, the critical mind must be brought into play. But how does the mind communicate its findings about the world, how does it clarify all these judgments, how does it make sense of them? Something more is needed and that something more is 
the voice, — the voice of the self, and the voice of the other, — the translating of the self's intentions into voice, and the translating of the other's intentions out of voice. This is the

intentional mind. Finally, we have the reflective-response mind which in both Arnold and Dewey is an active state; it goes beyond our traditional notions of passive contemplation. Moreover, despite my use of the word "finally" in the preceding sentence, the reflective-response is not a true terminus; rather it is a link, through memory, discourse, or action, to future learning.

I should add that what I have identified here as four separable qualities of mind were regarded by Arnold and Dewey as a singular quality of mind. Arnold called them culture; Dewey called them experience. I have separated them primarily with the hope of achieving a greater understanding of their constituencies and their relevance today. But, ultimately, I do not disagree that they really must be seen as an educative whole.

\section{Hermeneutics and the Reader-Writer}

My own concern for hermeneutics, well reflected in Arnold's writings, also forms a part of the analysis here and has led me to one conclusion which I have personally found rather startling and surprising, although, it is clearly necessitated by the final two characters of mind: intentional and reflective-response. I tend to handle hermeneutics in what I believe is a fairly simple and straightforward way. Much of what makes most sense to me in hermeneutics comes from the simple and obvious model of the writer, text and reader shown in Illustration 1. 


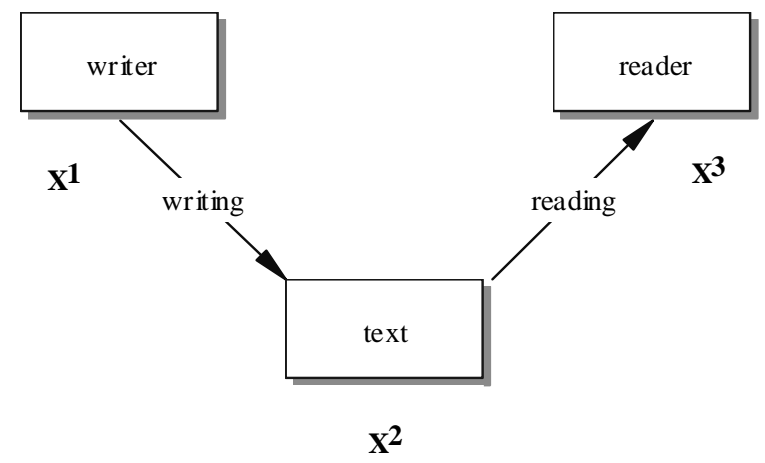

Illustration 1 A simple model for understanding the systemic relationships implicit in any hermeneutic analysis.

Hermeneutics is the study of interpretation. Its primary focus is on how we read a text. Or, how the intention of the author (which I show here as $\mathrm{X}^{1}$ ) moves through the meaning of the text $\left(\mathrm{X}^{2}\right)$ to the inference of the reader $\left(\mathrm{X}^{3}\right)$. In the next chapter, I shall talk about the relationship amongst these three (intention, meaning, and inference) and will follow Arnold in suggesting that while a great danger does exist in our confusing our inference with the author's intention, we may, nonetheless, with some effort, bring our inference close to the author's intention. More to the point right now is the relationship implicit in this model between the writer and the reader. For the reader to have a text to read, the writer must first have written the text. Thus the model imposes a logical sequence upon our understanding: the writer must precede the reader.

Two sciences (or practices, since both have rather significant traditions of application that go well beyond the passive sense of "study" inherent in the word science) have arisen from this phenomenon: one is rhetoric, the other is hermeneutics. Rhetoric focuses on how a writer persuades a reader. Hermeneutics, with its concern for interpretation, focuses on how a reader reads and, through reading, understands what the writer has written. For much of our history, rhetoric has held a central position as a 
practical tool for those who were politically-minded and wished to walk boldly through the public forums of life, engaged and active. Hermeneutics was the tool of scholars, priests and bookish hermits, who lived away from life in their quiet, ill-furnished cells forever trying to reach back through their texts to the evanescent word of God. Today the two have changed places in the scale of value: rhetoric has dropped considerably in general appreciation and is now often little more than an epithet for hollow deceit,while hermeneutics has risen, at least amongst intellectuals, and at times can seem the most practical of all possible scholarly tools. Rhetoric seems more and more to be studied not as a means of improving one's ability to persuade, but as a kind of hermeneutics focused on learning how not to fall victim to the influence and authority of others.

As I pointed out above, the hermeneutic model suggests a distinct directionality,- from writer, through text, to reader. However, the nature of hermeneutics causes us to invariably begin, where interpretation begins, with the reader, then work backward, through the text, to the writer. The apparent incompatibility of these two flows had bothered me for some time. When I came to realize the necessity, in the conception of educational pluralism I was constructing, for an intentional quality of mind, I was immediately struck by the presence of two types of intentionality: the first is the intentionality of the writer which comes through the text and which is the subject of study in one direction (from the point of view of the writer) in rhetoric, and in the opposite direction (from the point of view of the reader) in hermeneutics. This is what is traditionally meant by intentionality. From this point of view, certainly when perceived 
through hermeneutics (or its practical stepchild, literary criticism), intentionality possesses a distinct other-ness, — intentions are what someone else has, - a writer, an author, an authority.

The second type of intentionality is what we might call self-expression, but which I prefer to call response (as I believe all of our expressions have some element of response in them). This second intentionality can be described as inference-expressed, but, as we shall see, it is far more complex than that. Most significantly, this seemed to me to mean that the reader was not simply a reader, but rather a more complex creature, a reader-writer, - the model, simple and clear as it is, can, unfortunately, keep us from seeing the dynamic qualities of the relationships amongst the three elements, - a dynamic that Dewey, we note, had insisted on.

This concept of the reader-writer, is not, to my mind, wholly present in current reader-response theories, - although, I am conscious that what I have called the readerwriter partakes of something of the insights that have come from those theories. The reader-writer, as I have defined it, differs from reader-response theory in three respects:

1) In the reader-writer conception the response of the reader is not an isolatable whole,- - as I have stated above, Dewey saw reflection more as an intermediate, than a terminal activity. The response that results from a reader's reflection, then, is an extension of the intermediate activity from which more will hopefully follow. As a result the response is not, in itself, a whole. Another way to look at this, is to recognize that our response is just one part of the activity of our minds and bodies as we engage the world. Placing too much emphasis on the reader's response to a text without balancing it against 
the other elements of the hermeneutic model (the writer and the text), or the larger field in which the hermeneutic model is situated (context), or those qualities of mind I have outlined above (the tentacled mind, the critical mind, the intentional mind, the reflectiveresponse mind) is something of a regression,- - it pushes us back toward hermetical skepticism and dubiety, - toward the mind-body duality that Dewey hoped to eliminate.

2) The second way in which the reader-writer differs from reader-response is that the shift from reader to writer is only one of two types of intentionality. Our own intentionality does not exist in isolation; it does not trump all other intentionalities; to imagine it as supreme and intractable is, frankly, a kind of psychosis. This is not merely a question of subjectivity versus objectivity. The question, more difficult, more awkward, less sure of a certain answer, is what to do with these twin intentionalities: how to manage our own voice when it projects our own intentionality into the world,- - for when we write or speak a text we become an author, and so an authority? And, secondly, how to deal with the voices of others, the other-intentionalities, which come from the writers (authors, and thus, by definition, authorities) that surround us every day and have things they wish to tell us? These questions are ethical questions and cannot be answered by either the tentacled mind or the critical mind in isolation. We must engage all of the qualities of our minds: the apprehension of the tentacled mind; the judgment and appreciation of the critical mind; the discernment of multiple voices, including our own, of the intentional mind; and the reflection and ongoing engagement of the reflectiveresponse mind. In other words we must approach such problems through the full plurality of our minds and the world we live in. 
3) I see the reader-writer in a pluralistic sense. We read. We write. The two activities are distinct even if in practice they often tend to blur. That a reader is also, invariably, a writer does not mean that reading and writing disappear as distinct activities, no more than it means that meaning occurs only in the mind of the reader or even of a community of readers, and does not occur in the mind of the original author and is not present in the text. It only means that the human being in which the two acts (reading and writing) are located is a complex organism capable of complex tasks. In a pluralistic world we must distinguish contiguity from continuity,_- no matter how awkward the results.

\section{Communications with the Future}

Before moving on to a discussion of the four qualities of mind described above, let me here rehearse the evidence as it exists today for Arnold's influence on Dewey. Frankly, little has been written about this influence, but what has been written frames many of the issues of greatest significance. Lionel Trilling saw Arnold as a sort of protopragmatist. S. Morris Eames drew the conclusion that Arnold's conception of poetry as “a criticism of life” significantly influenced Dewey’s overall conception of philosophy as a "criticism of criticism." Alexander Meiklejohn connected Arnold with Dewey in a tradition of anti-dogmatism. Masao Miyoshi noted that Arnold had the same focus on experience that characterized pragmatism. Alan Ryan, Steven Rockefeller and others have demonstrated the dependence that Dewey's A Common Faith had upon Arnold's writing. Ryan also argued that Arnold and Dewey were alike in their faith in liberal 
education as a means of achieving a democratic society. However, Donald Stone’s Communications with the Future provides the most thorough comparison of the two men's thoughts, - and to my mind essentially establishes the foundations for the breadth of Arnold's influence on Dewey. ${ }^{\circ}$

S. Morris Eames, in his introduction to the third volume of Dewey's Early Works, comments broadly on Arnold's influence on Dewey.

Dewey is appreciative of many of the insights of Matthew Arnold, and in later years he turns again and again to ideas he attributed to this poet and critic. Arnold once wrote that "poetry is a criticism of life," and while Dewey thinks that poetry is more than this, he was influenced by Arnold's view in transferring it into philosophy, for he later writes that philosophy "is inherently criticism," and in his own method makes philosophy "a criticism of criticisms." ${ }^{30}$

This particular insight has been, for me, particularly important. The whole of my chapter on the critical mind is founded upon Eames' brief, but extremely potent recognition of the debt that Dewey owes to Arnold in his elaboration of criticism as a central tenant of not only the core of pragmatic thought, but of how our minds think. Arnold seems to me somewhat tentative in his first attempts to link criticism to poetry; he seems to be speaking more metaphorically (as I have little doubt he was when he saw poetry as a kind of factotum for religion in the modern world). Dewey, for one, was not entirely convinced of the full link between poetry and a criticism of life, but he, nonetheless, saw the opportunity that Arnold presented and took up criticism in a much expanded way. In the chapter on the critical mind I will explore this connection further.

\footnotetext{
o Stone's conjectures find assent in Linda Ray Pratt's Matthew Arnold Revisited (2000). "In the early part of the twentieth century, the sanity of Arnold's defense of democracy and his pragmatic hope for public education unquestionably informed the thinking of early modern intellectuals such as John Dewey.” (pg. 3)
} 
Some mention must be made of Alexander Meiklejohn's Education Between Two Worlds (New York and London: Harper \& Brothers, 1942). With a chapter on Arnold, five chapters on Dewey, and a title that clearly alludes to Arnold's famous line about “wandering between two worlds,” one would expect more of a comparison between Arnold and Dewey than is provided. What we get is, however, a solid confirmation of our general theme: "The animus of pragmatic education has been directed against Victorianism. With greater force and sharper weapons it has fought essentially the same fight in which Matthew Arnold was engaged.”31 Meiklejohn goes on to say that Arnold would have seen the pragmatist agenda as little more than a "mopping up" action. Arnold was quite as strong in his anti-dogmatist views as was Dewey; Meiklejohn recognizes this and astutely places Dewey in the Arnoldian educational tradition.

In The Divided Self: A Perspective on the Literature of the Victorians, Masao Miyoshi notes the increasing use Arnold makes of the term “experience.”

He always tried to see life whole, all its aspects related. Further his observations and evaluations on everything in life, from literature to religion, are all tied to his personal experience. As his critical horizon expanded over the years, experience became more and more the source of his thought, rapidly approaching the status it enjoys in the pragmatic philosophy of Dewey and James. ${ }^{32}$

Arnold's emphasis on experience provides an interesting counterpoint to the idealism of his cultural philosophy. He uses experience in a way that is suggestive of action and engagement. The critique, common in his time and still in use today, that he was wholly opposed to the active life does not quite survive a careful reading of his essays. His attack upon an action-orientation reads more like that common aphoristic joke of the manager who approaches work in the "ready, fire, aim” mode,- Arnold understood, as 
we do, that one should aim before one fires. Culture was the tool he proposed for improving one’s aim, and experience was an essential part of culture.

In John Dewey and the High Tide of American Liberalism, Alan Ryan provides an intellectual history of Dewey that rivals Lionel Trilling's intellectual history of Arnold. He clearly sees Arnold's influence on Dewey's A Common Faith as significant and pervasive.

With the assimilation of religion and poetry we are in the territory of Matthew Arnold and Coleridge; neither is discussed at any length, but their presence broods over Dewey's discussion. Dewey does quotes Arnold's famous definition of religion as "morality tinged by emotion" (just as he later mentions Arnold's definition of God as that "power not ourselves that makes for righteousness") and whatever may be said against this as a definition, it catches the point that what is common to religious experiences in Dewey's account of them is their confirmation that nature is 'on our side,' implicated in our projects, friendly rather than hostile to our ideals. ${ }^{33}$

He does not point out what we should note here, and that is that Dewey most likely first absorbed Baruch Spinoza through Arnold.

Donald Stone’s Communications with the Future: Matthew Arnold in Dialogue $e^{34}$ contains the only prolonged and in depth discussion of Arnold's influence on Dewey to date. Stone's book looks at Arnold's thought through the dynamics of influence, seeking both those whom Arnold influenced and those who have been influenced by Arnold. He characterizes each as a part of an ongoing dialogue that centers on Arnold. Amongst those he discusses are Henry James, Charles-Augustin Saint-Beuve, Ernest Renan, Friedrich Nietzsche, Michel Foucault, Hans-George Gadamer, Richard Rorty, Sidney Hook, and John Dewey. Stone draws some significant insights on Arnold's thought throughout his thesis, but his discussion of Arnold's influence on Dewey and pragmatism 
is not only most relevant for us, it suggests something of the continuity of thought from the Victorian period into the early twentieth century.

...Dewey['s] ... faith in education as the instrument best capable of nourishing cultivated and creative democracy resembles Arnold's own abiding faith.

Arnold's description of himself, in the introduction to Culture and Anarchy, as "a Liberal tempered by experience [and] reflection," as, "above all, a believer in culture" is not a bad description of Dewey, too. For if Arnold's keyword culture gives way to Dewey's keyword democracy, the two terms were intertwined from the beginning in Arnold's mind. Arnold's culture was never meant to be a defense against democracy but was meant to be a preparation for, and safeguard, of democracy. ${ }^{35}$

Stone sees Arnold and not John Mill as Dewey’s "true forebear.” Arnold, "like Dewey, ... suggests that the worship of individual freedom is often done at the expense of the other two principles of the French Revolution, equality and fraternity. ${ }^{, 36}$ He points out that charges of elitism against Arnold, the prophet of high culture, ignore Arnold's desire to achieve education for "all our fellow-men., ${ }^{37}$ Mill was far more laissez-faire in his approach to education, allowing parents the freedom of full choice in education, even should that include the null choice of no education, a choice that Arnold felt modern changes in society would ultimately mitigate. Arnold saw democracy as a process "trying to affirm its own essence; to live, to enjoy, to possess the world, as aristocracy had tried, and successfully tried, before it." ${ }^{, 38}$ He saw a role for the state in education that Mill would have regarded as state interference. According to Stone,

Arnold is not setting up the state as an authoritarian ideal. Rather, he is positing an ideal of the solidarity of men, "a true bond of union," in which the "best self" of each citizen finds a "rallying-point for the intelligence and for the worthiest instincts of the community." To those who demand, "Leave us to ourselves!" Arnold suggests that they look at the present state of England, to the widespread indifference to beauty, the paucity of intelligence, the scarcity of essential services that such an attitude has prompted."39 


\section{Comparing Arnold's essay "Democracy” (the preface to Popular Education in}

France and thus one of the writings that we have reasonable evidence Dewey read, and read early) with Dewey’s 1888 essay “The Ethics of Democracy,” Stone sees Dewey as building on "Arnold's position that each individual in a democracy is not to be seen as a 'disorganized fragment' ... but rather as a member of an 'organism.”’

There is no such thing as a "non-social individual," Dewey maintains, and the Platonic (and liberal) notion that "democratic freedom" means "doing what one likes," without respect for ideals is wrongheaded. ("For men are solidary, or copartners; and not isolated," Arnold says in a late religious essay.... Dewey's democracy is thus "a social, that is to say, an ethical conception"; "it is a form of government only because it is a form of moral and spiritual association." Dewey's vision of democracy is more idealized than Arnold's; but for both educators, the goal of their vocations is the guidance of the masses toward ideals of self-fulfillment (affirming "one's own essence") and solidarity. ...only with "equality," Dewey and Arnold agree, do we have an "ideal of humanity."

Stone recognizes that to have a common conception of democracy, to recognize in democracy the demands not only of the freedom, but of equality and fraternity, would not account for the pragmatic movement in the thoughts of either Arnold or Dewey.

The pragmatist thrust of Arnold's and Dewey's essays rests upon their belief in the efficacy of the ideal to move us forward. ("Perfection will never be reached," Arnold says in the conclusion to "Democracy"; "but to recognize a period of transformation when it comes, and to adapt ourselves honestly and rationally to its laws, is perhaps the nearest approach to perfection of which men and nations are capable.") And they share an awareness that "civilization" or "culture" is connected to "character," to conduct. ${ }^{41}$

Stone sees Dewey's philosophy of education as expanding “three basic Arnoldian

premises: that in a democracy all students should have access to the best, that critical thinking should be encouraged, and that education should instill a sense of social solidarity." "42 "Education,” says Dewey, "must have a tendency, if it is education, to form attitudes. ${ }^{43}$ Conduct and the forming of attitudes were for both Arnold and Dewey 
more important aspects of education than the attaining of any explicit knowledge. In this, Arnold is not entirely at odds with the general conception of education in England during the Victorian age, while Dewey, in an aspect of his thought seldom commented upon, seems to be reaching back to older notions more easily associated with the morality of religious sentiment than with progressive concepts of socialization.

Both Dewey and Arnold were concerned with progress, movement forward, the need to be responsible to the future; as Arnold put it in his essay on Falkland, "he and his friends, by their heroic and hopeless stand against the inadequate ideas dominant in their time, kept open their communications with the future.”44 But Arnold tempered his concerns for the future with a passion for the past. As Stone points out,

Such Deweyan disregard for the past might seem to mark a considerable gap between Dewey and Arnold, the former fixated (as Santayana complained) on the "foreground," the latter supposedly enmeshed (in the eyes of detractors) in a flimsy web called “culture.” But many of Dewey’s views are extensions or restatements of Arnoldian ideas, especially Arnold's views on education, culture, and democracy. The two men shared a common faith in the efficacy of a democratic culture that included (or came to include, in Dewey's case) the fruits of science, religion and art. ${ }^{45}$

Pragmatism is more than a way of seeing the world; it is more than Arnold's desire to "see the thing as in itself it really is." Rather it is to see and act and in acting to know that one's actions have become a part of what it is one sees, and, as well, a part of the future of what one sees and how one acts,- - or, to use Dewey's term, it is experience in both its character as act and thing, that which we do and that which we may anticipate and reflect upon. In other words, knowing that democracy is not only freedom, it is as well equality and fraternity, becomes relevant only once we have incorporated this concept into our sense of how we conduct ourselves, how we will act. Education 
becomes the means by which our understanding and our experience of how we will act, how we will conduct ourselves, are formed.

One might think, at this point, that Dewey and Arnold were of a mind on many of their most fundamental thoughts. Stone, however, points to several divergences between the two. Their disagreement over the relative value of a scientific or literary education can be seen by comparing Arnold's "Literature and Science” and Dewey’s "Science as Subject-Matter and as Method." As Stone puts it, Dewey takes "issue with what he interprets to be Arnold's underestimation of a scientific education," siding instead "with Arnold's friendly opponent, T. H. Huxley." ${ }^{\text {46 }}$ However, I would point out that Dewey’s primary argument in "Science as Subject-Matter and as Method" is with Huxley and not with Arnold. Dewey's concern is explicit in his title; he wishes to focus upon how science should be approached in education. Thus the question of a preference in subjectmatter for science over literature is important, but secondary to the question of method; Arnold's appeal to critical thinking, which Dewey overlooks (or “under-reads), places him closer to Arnold than to Huxley.

Stone points to another misreading. "In a brief account of "The Aims and Ideals of Education, Dewey in 1921 condensed the Arnoldian program into two goals: to transmit 'the "best of what has been thought and said,"' and to work for the reformation of society. ${ }^{\text {47 }}$ More than merely condensing Arnold's position, Dewey goes on to say that "the ideal of transmission," which he associates with Arnold, "regards education as essentially a process of instruction by which the mind is molded into conformity with the models presented in the subjects studied. ${ }^{48}$ While this may apply to some of those who 
have followed Arnold, it does not properly characterize Arnold's approach at all. For Arnold the reality of conformance to models of thought and conduct is the very thing he disparaged in philistinism and for which he saw culture as the cure. Thus, we are confronted with Dewey having misread Arnold's most fundamental conception of education.

Stone admits that he has underplayed the "differences in taste and sensibility" between Dewey and Arnold. "Arnold," he points out, "makes more of the internal dimensions of culture and education than does Dewey, although both ultimately agree on the social ends of these two forces." ${ }^{\text {49 }}$ This final point that Stone makes has become for me, a particularly telling one. I have struggled with Dewey's tendency to push so strongly away from the internal qualities of mind. When this tendency is placed against Arnold's tendency to extol the virtues of internality the result is surely the most awkward echo that crosses between the two. In the chapter on the reflective-response mind I shall have more to say about this. For now let me say simply that the middle ground is the space that both most comfortably occupy,- - a middle ground that neither wholly deserts the external nor the internal qualities of mind, but attempts to meld the two.

\section{Conclusion}

When I initially wrote and presented my proposal for this dissertation, I focused more on the issue of Arnold's influence on Dewey than I intend to do in the present paper. I have come to accept that Stone and the others I have discussed above have amply established that Arnold had a significant influence on Dewey. My interest in the 
meanwhile has shifted increasingly toward gaining a fuller understanding of the implications of seeing the thoughts of these two educators brought into some form of combination that may allow for a more adequate and mature philosophy of education relevant to today's educational needs.

I suppose I need not point out that today Arnold and Dewey are embraced by opposing political positions. Arnold, as the apostle of culture, is often embraced by conservative educators who see in him a support for an education founded on great books and Victorian values, ${ }^{\mathrm{p}}$ while Dewey still has a notably liberal coloring and is not too infrequently tarred for the excesses of progressive education, even those for which he bears no responsibility at all. Both, I think, are misread by those who rather carelessly use them as idol-images for their own politics of education. Nonetheless, I must admit that the idea of linking two such apparently opposing icons appeals to my own sense of moderation and centrism, - and that bit of Arnoldian irony in me that delights at tweaking the noses of the philistines,- conservative and liberal alike. What a rare treat it is to contemplate the post-modern philistine,- - and what irony to think that such a curiosity truly does exist, and how delightful to note that it is really not such a rara avis as one might expect.

\footnotetext{
p Stefan Collini in Public Moralists, 1991, rather acerbically points out that "reviving Victorian values" is "ignorant and tendentious nonsense" largely, he suggests, because Victorian morality depended as much upon certain structural elements, such as a sense of character formation as the end or purpose of society, as it did upon explicit statements of values. As I will suggest, a more coherent sense of the relevance and meaning of morality today, not only in education but within our larger cultural realities, may be needed if we are to enable that aspect of education which both Arnold and Dewey saw as essential,_- i.e. conduct. Clearly, morality cannot be a mere authoritarian rule-book of thou-shalts, but I shall have more to say on this in the chapters on the intentional mind and the reflective-response mind.
} 
Well, something of that sensibility, I have no doubt, animates my efforts here. I truly hope that the pluralistic model I am proposing may have some capacity to heal wounds and suggest a path forward, but I am equally certain that that is asking much too much of a simple model and an awkward argument. I am, quite honestly, less concerned with the politics or history of education, than I am with the possibility of discerning an adequate and reasonable philosophy of education that presents a possibility for both understanding and formulating coherent solutions for the demands of education today. 


\section{Notes}

${ }^{1}$ Arnold and Allott (editor), "Stanzas from the Grande Chartreuse,” pg. 288-89.

${ }^{2}$ William Shakespeare, Act 3, sc. 3.

${ }^{3}$ Dewey, Experience and Education, 1938, pg. lw.13.39.

${ }^{4}$ Dewey, Experience and Education, 1938, pg. lw.13.34.

${ }^{5}$ Menand, Pragmatism: A Reader, 1997, pg. xxvii.

${ }^{6}$ William James, A Pluralistic Universe; Hibbert Lectures at Manchester College on the Present Situation in Philosophy (1908-1909), from William James: Writings 1902-1910, edited by Bruce Kuklick, (New York : The Library of America, 1987).

${ }^{7}$ Cf. Lang, Letters, December 3 [1883], To William James, vol. V, pg. 345.

${ }^{8}$ monism. Dictionary.com. Online Etymology Dictionary. Douglas Harper, Historian. http://dictionary.reference.com/browse/monism (accessed: November 01, 2007).

${ }^{9}$ Arnold: “Isolation: To Marguerite," Allott, pg. 122.

${ }^{10}$ Dewey, "Poetry and Philosophy," speech delivered in 1890, pg. ew.3.115.

${ }^{11}$ Dewey, Contributions to Dictionary of Philosophy and Psychology, 1902, pg. mw.2.204.

${ }^{12}$ Dewey, Contributions to Dictionary of Philosophy and Psychology, 1902, pg. mw.2.204.

${ }^{13}$ Dewey, Experience and Education, 1938, pg. lw.13.42.

${ }^{14}$ Arnold, Literature and Dogma, 1873, pg. CPW 6:370.

${ }^{15}$ Dewey, A Common Faith, 1934, pg. lw.9.36-37.

${ }^{16}$ From a letter to his sister, Frances, cited in Bernard Bergonzi, A Victorian Writer: The Life of Thomas Arnold the Younger, 2003, pg. 223.

${ }^{17}$ Collini, Arnold, 1988, pg. 15-16.

${ }^{18}$ Arnold: Letters, December 5, 1867, To Mary Penrose Arnold, vol. III, pg. 195-196. (Cited in Collini, Arnold, 1988, pg. 15, who took it from Super's introductory note (1965) to Culture and Anarchy, 1869, CPW, 5: 414.)

${ }^{19}$ Collini, Arnold, 1988, pg. 1.

${ }^{20}$ Ryan, John Dewey and the High Tide of American Liberalism, 1995, pg. 20.

${ }^{21}$ Dewey, "From Absolutism to Experimentalism,” 1930, pg. lw.5.150-1.

${ }^{22}$ A short clip of Dewey reading from Art as Our Heritage is available from The Center for Dewey Studies: http://www.siu.edu/ deweyctr/resources.htm\#media, accessed 14 November, 2007.

${ }^{23}$ Stone, Communications with the Future: Matthew Arnold in Dialogue, 1997.

${ }^{24}$ Stone, Extract from private correspondence, August 24, 2006.

${ }^{25}$ Dewey, Democracy and Education, 1916, pg. mw.9.130.

${ }^{26}$ Arnold and Allott (editor), "Stanzas from the Grande Chartreuse," pg. 288-89.

${ }^{27}$ Dewey, Democracy and Education, 1916, pg. mw.9.130.

${ }^{28}$ Dewey, Democracy and Education, 1916, pg. mw.9.130.

${ }^{29}$ Dewey, Experience and Education, 1938, pg. lw.13.42.

${ }^{30}$ Eames, Introduction to the third volume of The Collected Works of John Dewey, 1969. Dewey: pg. ew.3.xxxvii.

${ }^{31}$ Alexander Meiklejohn, Education Between Two Worlds, New York and London: Harper \& Brothers, 1942, pg. 138.

${ }^{32}$ Miyoshi, The Divided Self: A Perspective on the Literature of the Victorians, 1969, pg. 244.

${ }^{33}$ Ryan, John Dewey and the High Tide of American Liberalism, 1995.

${ }^{34}$ Stone, Communications with the Future: Matthew Arnold in Dialogue, 1997.

${ }^{35}$ Stone, Communications with the Future, 1997, pg. 143.

${ }^{36}$ Stone, Communications with the Future, 1997, pg. 145.

${ }^{37}$ Arnold, Culture and Anarchy, 1869, CPW 5:216.

${ }^{38}$ Arnold, Introduction to The Popular Education of France (“Democracy”), 1860, CPW, 2:7. 
${ }^{39}$ Stone, Communications with the Future, 1997, pg. 145; Arnold, “Democracy,” 1860, CPW, 2:19.

${ }^{40}$ Stone, Communications with the Future, 1997, pg. 146; Arnold, "Bishop Butler and the Zeit-Geist,"1876, CPW, 8:43, Dewey: “The Ethics of Democracy,” 1888, pg. ew.1.240.

${ }^{41}$ Stone, Communications with the Future, 1997, pg. 146; Arnold, "Democracy,” 1860, CPW, 2:29.

${ }^{42}$ Stone, Communications with the Future, 1997, pg. 166.

${ }^{43}$ Dewey, "The Challenge of Democracy to Education," 1937, pg. lw.11.189.

${ }^{44}$ Stone, Communications with the Future, 1997, pg. 148; Arnold: "Falkland," 1877, CPW, 8:204.

${ }^{45}$ Stone, Communications with the Future, 1997, pg. 162; George Santayana, "Dewey's Naturalistic Metaphysics" in The Philosophy of John Dewey, ed. Paul Arthur Schilpp (Evanston, Ill.: Northwestern University, 1939) pg. 251.

${ }^{46}$ Stone, Communications with the Future, 1997, pg. 164.

${ }^{47}$ Stone, Communications with the Future, 1997, pg. 166-167; Dewey, Contribution to Encyclopaedia and Dictionary of Education, 1921, pg. mw.13.400.

${ }^{48}$ Dewey, Contribution to Encyclopaedia and Dictionary of Education, 1921, pg. mw.13.400.

${ }^{49}$ Stone, Communications with the Future, 1997, pg. 173. 


\section{From Empedocles on Etna}

We shut our eyes, and muse How our own minds are made. What springs of thought they use, How rightened, how betrayed And spend our wit to name what most employ unnamed.

-Matthew Arnold ${ }^{1}$

\section{The Tentacled Mind}

“My image of the mind,” Dewey once said, creating what is surely one of his most colorful metaphors, "is a sort of biological thing with arms or tentacles reaching out everywhere, and when they get appropriate food, just fastening down upon it.”2

The tentacled mind that Dewey here describes is the first of the four minds we will focus upon as we look to find a pluralistic model of education, desiring, as I have said in the previous chapter, not to educate one aspect of the mind, but all aspects of the mind. The tentacled mind, as Dewey presents it to us in his colorful metaphor (assuming we can set aside the science fiction images it conjures up ${ }^{\mathrm{a}}$ ), appeals to a certain basic sense we all have of how the mind works,- - a sense that the mind is not entirely locked

\footnotetext{
a I have to admit, for me, it calls to mind Basil Wolverton's wonderfully odd comic book story, “The Brain Bats of Venus,” Mister Mystery \#7, 1952. Wolverton’s "brain bats” looked less like bats and more like flying cephalopods, - in the midst of stretched out tentacles, connected by leathery membranes, were heads that looked like odd brainy protrusions with kohl-lined, sinister eyes inserted deep inside tuberous, brainy folds. In Wolverton's story the "brain bats" would land upon the heads of hapless spacemen, take over their brains and turn them into, of course, zombies. Wolverton was of the "spaghetti and meatball" school of cartooning (actually, "spaghetti and meatball" is a term invented by Wolverton himself to describe his style which really did not look like anyone else's work). His drawing style and his wild graphic inventiveness were truly fascinating, but we may assume, I think, that Dewey's intention was the very opposite of Wolverton's, - that Dewey's tentacled mind was not meant to turn us into zombies, but rather to free us from a kind of zombie-like isolation within our walled off minds.
} 
away behind our boney brows, - that the world of hard, physical objects is not entirely alien, that our minds do, indeed, "grasp" what our hands take hold of, that images within our minds have something to do with the objects our eyes see, that the voices we hear are not mere echoes of our own voice, that the food we place in our mouths has some causal relationship to the savor we sense on our tongue and the aroma we breathe through our nose, - that our senses are not so intermediate that something of our mind is not physically present in the material world through which we move. We cannot doubt that the mind will, in a near animalistic fashion, perform much in the way that Dewey describes. It will reach out and "fasten down upon" its surroundings, engage and be a part of the world,- for, if it did not, where would humanity have been in those many years before the subtleties of philosophy asked us to reconstruct our world having, in Cartesian fashion, cast doubt upon our senses and the primitive constructs of our mere tentacled minds.

Dewey placed great importance upon the necessities of learning that derive from this essential quality of the mind,- - its tendency to reach out and encounter the world, a tendency which Dewey knew continued apace despite the philosophical dubieties that he associated with metaphysics, ontology and epistemology. I will follow Dewey’s lead here in setting aside these dubieties, even if I am somewhat inclined to think that they have, perhaps, more to say to us, and carried more weight with Dewey than he let on. Indeed, I would argue that Dewey, far from eliminating metaphysics, ontology and epistemology from philosophical concern, simply repositioned them (or one might argue that he put them right back where philosophy originally found them, — as corollaries to a 
science of wisdom, not as ends in themselves). What then did Dewey position in the foreground to replace the primacy of metaphysics, ontology and epistemology? I would argue that Dewey ultimately moved ethics to the foreground; education is, after all, an aspect of ethics more than of epistemology, for how we know answers but partially our educational concerns. To act, to experience, to understand how to conduct ourselves in this complex world,- - these are ethical concerns, never entirely isolatable to an individual, even if Dewey's scientific naturalism often obscures the larger social picture in which education, experience and action occur.

But for now we must reach out our tentacled mind and grasp hold of the world around us, alighting upon the first object we see, say a billiard ball rolling across a neat green felt, striking another billiard ball, and making it run the remainder of the table to land gently in a corner pocket.

\section{Hume's Billiard Ball}

That which early on drew me to John Dewey was his answer to David Hume’s skepticism. Hume's skepticism, arguably, has dominated philosophy from the German idealists to today's poststructuralists. Hume thought that our perceptions are incompetent to tell us truthfully what is going on in the world around us. We are forever at the mercy of what seems to be real, but can never know, with any certainty, what $i$ s real. To demonstrate this he used the now famous example of the billiard ball.

We are determined by CUSTOM alone to suppose the future conformable to the past. When I see a billiard-ball moving towards another, my mind is immediately carry'd by habit to the usual effect, and anticipates my sight by conceiving the second ball in motion. There is nothing in these objects, abstractly considered, 
and independent of experience, which leads me to form any such conclusion: and even after I have had experience of many repeated effects of this kind, there is no argument, which determines me to suppose, that the effect will be conformable to past experience. The powers, by which bodies operate, are entirely unknown. We perceive only their sensible qualities: and what reason have we to think, that the same powers will always be conjoined with the same sensible qualities? ${ }^{3}$

Hume surely did not have any real doubts that when the first billiard ball strikes the second, the second billiard ball will proceed to roll across the green felt in such a way that a billiard shark could manage the expectations so as to achieve considerable personal profit. $^{\text {b }}$ He was far too worldly a man to have ever finitely denied those small observations that together account for our ability to function in the world, to form habits of mind, and to engage each other in social intercourse. Rather, Hume was saying that nothing in our experience really tells us that we can expect such results, that this bold combination of perception and expectation are not quite as sure as we should like them to be. Thus relationships, such as causality, are unobservable. We may infer them, but we do not actually see them. When the second billiard ball begins to roll after the first billiard ball has apparently struck it, what we actually see are the separate movements of the two billiard balls, - what we infer is that one was the cause of the other. The relationship of causality is not a thing we see, but rather a concept that we formulate in our minds. How we perceive, how we form our habits, how we come to develop those various associations that support our mental character, - these, and not the actualities of the real world, were Hume's primary concerns. The world beyond the mind, such as it was, was very nearly irrelevant to Hume.

\footnotetext{
b The "wager" with its probabilities and possibilities would, in the late nineteenth century, point a way out of Hume's dilemma, but Dewey was not much interested in a statistical solution to the problem Hume presented. See Louis Menand, The Metaphysical Club, 2005.
} 
Dewey’s answer to Hume was astonishingly direct and simple. Dewey simply did not allow for thought that was “independent of experience.”4 Experience was a central concept for Dewey. With alarming disregard for the pathetic fallacy, Dewey defined experience using by way of example the proverbial rolling stone.

A generalized illustration may be had if we imagine a stone, which is rolling down hill, to have an experience. The activity is surely sufficiently "practical." The stone starts from somewhere, and moves, as consistently as conditions permit, toward a place and state where it will be at rest-toward an end. Let us add, by imagination, to these external facts, the ideas that it looks forward with desire to the final outcome; that it is interested in the things it meets on its way, conditions that accelerate and retard its movement with respect to their bearing on the end; that it acts and feels toward them according to the hindering or helping function it attributes to them; and that the final coming to rest is related to all that went before as the culmination of a continuous movement. Then the stone would have an experience, and one with esthetic quality. ${ }^{5}$

Despite Dewey’s final sentence, the description here is peculiarly anesthetic; it seems more than a little flat and unemotive,- very peculiar in that Dewey was trying to suggest an antidote to the anesthetic qualities in traditional morality,-

One great defect in what passes as morality is its anesthetic quality. Instead of exemplifying wholehearted action, it takes the form of grudging piecemeal concessions to the demands of duty. But illustrations may only obscure the fact that any practical activity will, provided that it is integrated and moves by its own urge to fulfillment, have esthetic quality. ${ }^{6}$

Dewey continues his discussion of the rolling stone with the following,-

If we turn from this imaginary case to our own experience, we shall find much of it is nearer to what happens to the actual stone than it is to anything that fulfills the conditions fancy just laid down. For in much of our experience we are not concerned with the connection of one incident with what went before and what comes after. There is no interest that controls attentive rejection or selection of what shall be organized into the developing experience. Things happen, but they are neither definitely included nor decisively excluded; we drift. We yield according to external pressure, or evade and compromise. There are beginnings and cessations, but no genuine initiations and concludings. One thing replaces 
another, but does not absorb it and carry it on. There is experience, but so slack and discursive that it is not an experience. Needless to say, such experiences are anesthetic. $^{7}$

Oddly enough, this passage is considerably less anesthetic than that in which Dewey had described the progress of the rolling stone. The inattention, the things happening, the beginnings, cessations and driftings, - these all echo in our emotional response, even as they speak to those aspects of the modern condition that most beguile and frustrate our aesthetic sensibility; perhaps we ought not wonder that from Arnold's time on poets have found more to tantalize in the capricious stumbling and awkward foibles of humanity than in the particularized and more complex aesthetics of the life lived in active, continuous and thoughtful engagement. The true human as she drifts, evades and compromises, is surely more likely to appeal to us emotively than the rolling stone that did or did not stop to smell the roses.

The problem, of course, is that Dewey, and Arnold before him, had, of necessity, to intellectualize that aspect of their thought which called for a direct engagement, for an experience that involves both the head and the heart. But we are a little ahead of ourselves here; these distinctions will become relevant as we move toward the reflectiveresponse mind and the ping-pong effect of the mind moving back and forth in the role of reader and writer. Dewey’s primary end here is not the notion that an experience has start and end points, but that it occurs over a period of time and cannot be isolated to any single point in time. Experience is dynamic, - it consumes time. The peculiar philosophical interests that would seek to define an isolated moment in time are irrelevant to Deweyan experience. Experience must consume time, - where does an experience 
begins and where does it end? What amounts to a consummation? These are minor contingencies that shape themselves unconsciously and uncertainly in the critical mind, and are relevant only in so much as they further or hinder the critical act as we shall see in the next chapter.

Dewey used this conception of experience to deny the separation of mind and body, since in the course of having an experience, the mind alone is not employed; the senses reach out to the world of objects; the body is not an empty shell, but a sensing feeling thing,- - the experience extends from the mind to the hand to the tactile surface, and through the questing fingers to the object itself; the stone rolls forward, not resting a moment, acting and feeling as it follows its downward course.

In Hume, the senses by which we perceive are distanced from the thought by which we reason,- - a mere defect in our perceptions, defects which we must all possess to some degree or another, ${ }^{\mathrm{c}}$ will forever leave us incapable of apprehending the real world, so that we may never have it whole in our mind, nor ever really act upon it with conscious impunity. For Dewey, however, the separation of mind and body were symptomatic of that erroneous temptation toward the small and irrelevant matters of metaphysics that had so undone European philosophy.

It would be impossible to state adequately the evil results which have flowed from this dualism of mind and body, much less to exaggerate them. Some of the more striking effects may, however, be enumerated. (a) In part bodily activity becomes

\footnotetext{
c Hume: "Of the Standards of Taste,” London, 1741, ESY Pt. 1 E. 23 Para. 13/36 mp. 234 pg. 272, "Many and frequent are the defects in the internal organs, which prevent or weaken the influence of those general principles, on which depends our sentiment of beauty or deformity. Though some objects, by the structure of the mind, be naturally calculated to give pleasure, it is not to be expected, that in every individual the pleasure will be equally felt. Particular incidents and situations occur, which either throw a false light on the objects, or hinder the true from conveying to the imagination the proper sentiment and perception.”
} 
an intruder. Having nothing, so it is thought, to do with mental activity, it becomes a distraction, an evil to be contended with. For the pupil has a body, and brings it to school along with his mind. And the body is, of necessity, a wellspring of energy; it has to do something. But its activities, not being utilized in occupation with things which yield significant results, have to be frowned upon. They lead the pupil away from the lesson with which his "mind" ought to be occupied; they are sources of mischief. ...

(b) Even, however, with respect to the lessons which have to be learned by the application of "mind," some bodily activities have to be used. The sensesespecially the eye and ear-have to be employed to take in what the book, the map, the blackboard, and the teacher say. The lips and vocal organs, and the hands, have to be used to reproduce in speech and writing what has been stowed away. The senses are then regarded as a kind of mysterious conduit through which information is conducted from the external world into the mind; they are spoken of as gateways and avenues of knowledge. ${ }^{8}$

The “mysterious conduit” of the senses: this splendid bit of irony was how Dewey dismissed the empiricist's emphasis on the mechanics of perception and the bothersome clichés into which these empiricist notions had devolved: "gateways and avenues of knowledge.” Merely dismissing the distinction between mind and body, however, was not sufficient to meet Dewey’s needs. He had to go a step further: he needed to show that this dualism had a significant unwanted effect that could and often did result in a serious misreading of reality.

The traditional conception of the separation of mind and body can be seen as having two aspects. In the first, the mind and its mental activities are separated from the body and its physical activities. In the second, the material world itself is separated into things and relationships among things. Things were out there, in the material world, but relationships existed only within the mind. As a result, things and the relationships among them were part of the mind-body duality that Dewey sought to overcome. 
(c) On the intellectual side, the separation of "mind" from direct occupation with things throws emphasis on things at the expense of relations or connections. It is altogether too common to separate perceptions and even ideas from judgments. The latter are thought to come after the former in order to compare them. It is alleged that the mind perceives things apart from relations; that it forms ideas of them in isolation from their connections - with what goes before and comes after. Then judgment or thought is called upon to combine the separated items of "knowledge" so that their resemblance or causal connection shall be brought out. As matter of fact, every perception and every idea is a sense of the bearings, use, and cause, of a thing. We do not really know a chair or have an idea of it by inventorying and enumerating its various isolated qualities, but only by bringing these qualities into connection with something else-the purpose which makes it a chair and not a table; or its difference from the kind of chair we are accustomed to, or the "period" which it represents, and so on. ${ }^{9}$

Within European philosophy, ${ }^{\mathrm{d}}$ the word "materialism” was largely used as an epithet to be flung at those who had not the mental ability to rise above the debased world in which we live and achieve higher modes of thought; the world of things was hierarchically below the world of ideas. The world of things was inevitably imperfect; on the other hand, the world of ideas was, in the influential conceptions of the neoPlatonists, the very stereotype of perfection. Thus perceptions were a part of the world of materiality, hence imperfect, while the mind was part of the world of ideas, and hence capable of perfection. Hume tore that perfection away when he insisted that the mind was in thrall to the imperfection of the senses. Few of his contemporaries were willing to forgive him that slight.

\footnotetext{
${ }^{\mathrm{d}}$ Although, we would be wrong to associate this concept with European philosophy alone. For example, Hindu philosophy places significant concerns upon the effects of the material world, as do many other traditions. This would suggest that some natural tendency toward such a duality may be an inevitability of human thought. Arnold, who never made the leap that Dewey did in attempting to subvert the mind and body duality, and who had shown an early interest in the Hindu Bhagavad Gita, holds on to the desire to rise above materiality. Indeed, it animates much of his thought.
} 
In the nineteenth century, however, materiality began to gain ground upon idealism, at least amongst a certain sect of intellectuals. Science had come along and suggested that, no matter how imperfect the instruments of our perceptions, what we needed to understand was what was out there in the material world, not what was inside our heads, which they came to perceive as a world of speculation and metaphysical mumbo-jumbo. Moreover, the material world is not passive. Modern physics, indeed, presents a physical world which is constantly in motion, a world in which relations, connections, and processes are, arguably, more important than "things" themselves. So, even within materiality, a certain hierarchy of value survives.

Dewey sided with the scientists, but not to such a degree that he could allow himself to completely give way to a positivistic materiality. Something of the value of ideas, of the virtues of the mind, of the emotions of the heart, and even, perhaps, of the spiritual qualities we tend to refer to as God, continued to hold sway with Dewey. He sought, as did so many other late nineteenth and early twentieth century philosophers, to mend the break between the material and the ideal. By denying the duality of mind and body, he took the most direct route possible.

Dewey's portrait of the mind, with its tentacles reaching out, is of a mind that is more than simply at one with its own body. The mind, in Dewey's conception, seems to have a habit of stepping out into the rough and ready world and manhandling things in a very direct way. Alternatively, Hume’s revelations about perception depend upon framing a single, isolated moment in time, "independent of experience,"10 so that the sole mechanism of mind available becomes our limited and limiting perception. Dewey 
attempted to bypass this limitation; he allowed perception to become an active part of mind itself and not a separate function,_- as if mind were not simply the "thing" behind the brow, but sat upon the very outer-most edge of the eye, or nestled itself in the shell of the ear, or rolled itself in the pit of the tongue, or rode upon the ridges of our tactile fingertips.

Having dismissed the age old separation of mind and body, Dewey was able to set the "mind-body" free upon the world around it. He did this by recourse to "experience," that word with which he will forever be associated. In doing so, he did not deny the uncertainty of the real world, nor even the uncertainty of perception. He did not merely swerve toward the simple declarations of a Scotsman's common sense; ${ }^{11}$ nor did he reject Hume's reasoning on the effects and relevance of "habit" in the formation of our thought. He set himself free of Hume’s conception of "association," but only in so much as it had been aggrandized into the ideation of German philosophy. He gave to mind a social character that went beyond the simplicities of individualized freedom. In one step, he overleapt Cartesian dubiety, and did so without reverting to a shallow positivism. Dewey, quite simply, reached out and took hold of the real and gave it back to us with all its matter-of-fact nature intact.

His tool for accomplishing this amazing feat was simple experience. Experience comes from the Latin $e x$-, meaning "out of," or "from,” pīrī, "to try," or "test;" the word experiment has a common derivation. The trial or test, the piri $\bar{p}$ portion of the word, implies our interaction with the world around us. The $e x$-, implies that this is not merely a trial, but rather what comes out of that trial, what comes "from" our efforts to test the 
world around us. Experience is the organism reaching out into the world, testing the world, and taking something out of that act, something that in general we may call learning. Or as Dewey put it, "learning is active. It involves reaching out of the mind. It involves organic assimilation starting from within.”12

Experience, as a result, was a ready-made word for explaining what Dewey thought was the basis of all learning. It implied activity; it took something from that activity; it captured, reflected on, and memorized the effect of that taking; and it led the organism to a potential solution for a problem or trial. Moreover, it provided a substance for thought without which thought simply was not possible.

An experience, a very humble experience, is capable of generating and carrying any amount of theory (or intellectual content), but a theory apart from an experience cannot be definitely grasped even as theory. It tends to become a mere verbal formula, a set of catchwords used to render thinking, or genuine theorizing, unnecessary and impossible. Because of our education we use words, thinking they are ideas, to dispose of questions, the disposal being in reality simply such an obscuring of perception as prevents us from seeing any longer the difficulty. ${ }^{13}$

The ancient Gnostic creation myth provides a wonderful corollary to Dewey’s insight. God, the unknown and unknowable, existed. And God thought. But having nothing to think about,_ - for God was a unity, God was all there was,- — God thought about himself. That thought was the first emanation. Emanations piled up as each emanation thought of that alone which was available to think about, itself, until we come to a self-deluded emanation which mistakenly thought itself to be the one true God; it was this emanation that set about creating the heavens and earth, plants and animals, Adam and Eve, and so on, and set in motion all the other wondrous events portrayed in the first book of Genesis. 
But let us go back to that very first thought: God thinks of himself. The Gnostics imply what we all know to be true, thought in pure abstraction, thought, with nothing to think about, is not thought. The Gnostics saw God in the abstract, thinking upon the purely abstract,_- that which results when all things are a unity, an ideal; to them this was the universe in a state of absolute perfection; and they wished to return the universe to that perfect state, before it had been corrupted by materiality. However, faced with the possibility of thought in pure abstraction, they found no recourse, but to turn thought upon that one possibility for materiality, God,_- and in so doing set in motion the course of materiality, for even they, these pure idealists, these precursors of Neo-Platonism, could not imagine what objectless thought really entailed,- - it was, indeed, unimagined and imaginable, unknown and unknowable.

Notice as well in this myth that thought, at least the thought of God, can attain to a state of materiality, can move from ideal to real, from perfection to imperfection. This would seem to imply that thought itself has something of the material world in it. Much as Dewey had done in trying to mend the duality of mind and body, this myth asserts a substantial materiality to thought. The difference, and it is a significant difference, was that Dewey did not see the movement of mind toward materiality as inherently evil. This was Dewey's great heterodoxy. ${ }^{\mathrm{e}}$

\footnotetext{
${ }^{\mathrm{e}}$ This is a heterodoxy that post-structuralism has found difficult, if not altogether too paradoxical, to fully embrace. Dewey found in it no paradox; this, it seems to me, is where his instrumentalism most often succeeds. Materialism and idealism are only at odds if one accepts the basic distinctions between mind and body. Even if one were to invert the hierarchy and place materialism on high, idealism on low, the problem remains in the dichotomy, and the effect of Dewey's great leap is subverted. But this does not mean that no distinction exists between materialism and idealism, nor that the two are not often at odds.
} 
For the Gnostics, the materiality that had corrupted that world was thought itself. It was thought that produced each emanation. In this myth thought is materiality. Perfection, the ideal, thus lies somewhere beyond thought, outside of thought, in some unknown and unknowable state,- - unknown and unknowable because to know is to think. Dewey faced with such idealism blanched and pulled away,- - and taking thought with him, he tied it to the active, material world so that he might get on with the practical matters that have no real existence in an ideality beyond thought.

Nonetheless, Dewey did see notable ways in which this materiality could corrupt thought. 1) We have a bad habit of confusing our words with our ideas,- - we reify our words and let them become a kind of extreme reality; they ossify, or materialize, and the extreme of such practice we call dogma. Dewey saw this as a movement away from meaning. Or, to put it in more positive terms, a certain type of knowledge, that which comes from a more fully-engaged experience, can produce a "mental reward" such that "even if we fail" to solve the problem at hand, "we have the satisfaction of experiencing a meaning instead of merely reacting physically."14 Meaning occurs when ideas are in full contact with the material world, while not estranged from the dynamic demands of thought and problem solving. As Dewey put it, "we use words, thinking they are ideas, to dispose of questions, the disposal being in reality simply such an obscuring of perception as prevents us from seeing any longer the difficulty.” 15

2) We let things dominate our thought, when the real business of experience is not with things in isolation, but with things in relationship either one to another, or in their relationship to us. This was, of course, Hume's problem. Hume wondered, how can we 
see these relationships when all we see are objects? Dewey answered him by releasing the mind into materiality, but he did not do so in order to leave the objects in place and the relationships locked within the mind. We see the relationships because our minds are active participants in those relationships; we look with critical eyes, and we share our experiences with others, i.e. we think as much socially as we do individually.

3) And that leads us to the third danger of materiality. Stated briefly the danger is that experience can so powerfully affect thought that we are in danger of thinking (as did the deluded creator God) that our thoughts occur in isolation, but thought, particularly that thought that finds expression in words, can never exist in isolation. Our thought is social, and we materialize it, or vulgarize it, when we mistakenly regard it as the sole product of our own overgrown (overly materialized) ego.

\section{"The Thing as in Itself It Really Is"}

In an early lecture-essay, On Translating Homer, Arnold described "critical effort" as "the endeavour in all branches of knowledge,— theology, philosophy, history, art, science,—- to see the object as in itself it really is." "Object" in this oft-repeated phrase was soon transformed into "thing."

Nay, and the very desire to see things as they are implies a balance and regulation of mind which is not often attained without fruitful effort, and which is the very opposite of the blind and diseased impulse of mind which is what we mean to blame when we blame curiosity. ${ }^{17}$

“To see the thing as in itself it really is," - surely, having just crossed paths with Hume and Dewey, such a bald and frank declaration of untutored epistemology must strike us as emphatically unsophisticated. Hume made it clear, we could not "see things 
as they really are;” some mote in the eye, our errant biases, our wayward perceptions, and the great associative leaps we make to capture the unobservable connectivity of things,all work against any such possibility. Dewey, even in his awkward, listless way, could only bypass Hume through a tremendous leap across the chasm that philosophy had erected between mind and body, thought and thing. But Arnold rather boldly declares that all we need do is "to see the thing as in itself it really is." Carefree, unsystematic, non-philosophizing Arnold seems almost to mean that we ought to trust our empirical senses. But such a reading leaves out something essential and highly intuitive in Arnold's thought. He had absorbed enough of German idealism and of Emerson's transcendentalism to suggest that “seeing things as they really are” might well mean seeing beyond the thing itself toward its ideal or "perfect" state. In other words, the thing as we might empirically know it was caught up as well in how it might be known were it achieved in a more perfect way.

For Arnold, the act of "seeing things as they really are" was experiential; and his conception of experience was not altogether different from Dewey’s. For Arnold experience consumed time, engaged itself with the things of the world in which we live, had an aesthetic component, and needed criticism and reflection to resolve or consummate itself. For Dewey, as we have seen, we can say exactly the same. In other words, Arnold reasons from the same sort of experiential, tentacled mind that Dewey did. Arnold emphasizes experience in much the same way as does Dewey. Arnold's usage, however, is more general in tone and suggests something of the quality of character or character-building which Stefan Collini saw as an essential element of Victorian 
morality. ${ }^{18}$ As in the passage that follows, Arnold often uses experience as a noun, but the emphasis is not upon its static qualities as a thing attained, but as an active agency. ...perfection, - - as culture, from a thorough disinterested study of human nature and human experience, learns to conceive it,- - is an harmonious expansion of all the powers which make the beauty and worth of human nature, and is not consistent with the over-development of any one power at the expense of the rest. ${ }^{19}$

Where Arnold differs from Dewey is in his conception of "perfection." For

Arnold this desire for perfection was to be found in culture.

...culture, then, is a study of perfection, and of harmonious perfection, general perfection, and perfection which consists in becoming something rather than in having something, in an inward condition of the mind and spirit, not in an outward set of circumstances... ${ }^{20}$

What, to my mind, is most important in this concept is not its press toward a transcendent and vague ideal,_- or the sense that Arnold rather too often gives us, that such an ideal is inherently Eurocentric ${ }^{\mathrm{f}}$,- but that it contains within it a kind of arrow pointing toward something; - that is to say that his concept of culture is far more dynamic than we tend to think it is. We chop it off within Arnold's Eurocentrism and fail to note that within that Eurocentrism, Arnold's intention was progressive,-— his desire was to move forward, not backward. Most particularly he was aware that we could not perfect our own vision if we left it in isolation,- - we needed recourse to other voices, and particularly voices that previously have engaged in critical thought,_- without these voices we could not hope to "see the thing as in itself it really is." His is not a dubiety of

\footnotetext{
${ }^{\mathrm{f}}$ I cannot help but feel that this word, Eurocentric, has already become a peculiar late-twentieth, earlytwenty-first century nonce term whose occurrence will only make our children twenty years from now smile and think themselves our intellectual betters.
} 
the senses, but a dubiety of the mind in isolation. He pushed his contemporaries to throw off their parochial world view and begin, with a "free play of mind,"g to see the world through other eyes, through other cultures, both current and past. His is a kind of multiculturalism, but multiculturalism that seeks broader authorities, broader conceptions of perfection, and not new limiting parochialisms.

As I have already suggested, Arnold added to "seeing things as they really are” a second phrase, "the free play of mind.” For Arnold such a free play of mind meant both searching across and through the "thing" under consideration and looking at the "thing" from multiple view points. Most particularly it meant seeing past the machinery of easy thoughts and easy conclusions, conclusions that too readily became fetishes and inscribed themselves upon human experience as incontrovertible and unchanging dogma. ${ }^{\mathrm{h}}$

It is noticeable that the word curiosity, which in other languages is used in a good sense, to mean, as a high and fine quality of man's nature, just this disinterested love of a free play of the mind on all subjects, for its own sake,- - it is noticeable, I say, that this word has in our language no sense of the kind, no sense but a rather bad and disparaging one. But criticism, real criticism, is essentially the exercise of this very quality. It obeys an instinct prompting it to try to know the best that is known and thought in the world, irrespectively of practice, politics, and everything of the kind; and to value knowledge and thought as they approach this best, without the intrusion of any other considerations whatever. ${ }^{21}$

${ }^{g}$ Arnold , Culture and Anarchy, 1869, pg. CPW 5:529. "If a man without books or reading, or reading nothing but his letters and the newspapers, gets nevertheless a fresh and free play of the best thoughts upon his stock notions and habits, he has got culture.”

h Arnold: Culture and Anarchy, 1896, "But although culture makes us fond stickers to no machinery, not even our own, and there fore we are willing to grant that perfection can be reached without it, — with free churches as with established churches, and with instrumental statesmen as with creative statesmen,- - yet perfection can never be reached without seeing things as they really are; and it is to this, therefore, and to no machinery in the world, that we stick" (pg. CPW 5:253). I find it hard to read this passage and not see in it the echoes out of which Dewey would grow his own instrumentalism. 
Arnold's conception of a free play of mind did not go unnoticed by Dewey. He anchors his thought in its playfulness, and recognizes in this notion a quality of enormous value to his own conceptions of educational experience.

It is also desirable to distinguish an attitude of mind as playful. Matthew Arnold, for example, called ability to occupy the imagination fruitfully with a subject, the ability to allow the mind to play freely about the subject, a sign of culture. This attitude of mind is distinguished from inability to enjoy intellectual activity upon a subject except in the interest of some preconceived theory or some practical utility. This capacity to draw satisfaction from the immediate intellectual development of a topic, irrespective of any ulterior motive, represents a genuine outgrowth of the play attitude-a special form which it may take. Unless play takes this intellectual form, the full spirit of scientific inquiry is never realized; much, if not all, of what is termed the love of truth for truth's sake in scientific inquiry represents the attitude of play carried over into enjoyment of the activities of inquiry for its own sake. The putting forth of observation, reflection, testing, is enjoyed on its own account, irrespective of ulterior by-products, just as in early childhood certain strenuous and even hazardous forms of physical effort may be intrinsically satisfactory. ${ }^{22}$

Today, this concept of "free play of mind," at least amongst a certain class of intellectuals and within a certain mode of common aphoristic thought (a descendant of Arnold's "machinery"), is looked upon favorably, although, it is usually seen as the very opposite of "disinterestedness." Surely one cannot be disinterested when allowing a free play of mind, as, indeed, one has only one's own mind with which to play freely, and, axiomatically, the mind (as Hume had taught us) is never capable of a pure disinterest,its biases, its leaps of connectivity and association, its inevitable subjectivity, the incapacities of its perceptions, all serve to limit the possibilities of that soulless scientific "disinterest” that has so deadened modern scientific thought, so deafened it to the appeals of the essentially subjective nature of human thought. 
What, then, did Arnold mean by “disinterest”? Certainly he did not mean the sort of disinterest that we have come to associate with scientific enquiry in the intervening century and a half. He seems, in fact, to have been reacting against utilitarianism; his disinterest is a counter to the utilitarian assertion that we act only out of self-interest. Arnold used "disinterest” to signify that self-interest need not be present for one to act,mere curiosity was sufficient. Humans he thought were capable of, indeed inclined toward, the acquisition of knowledge as an end in itself. Disinterest meant that we were inclined to want to know things whether or not we saw any personal utility in them. To some extent, this particular term, “disinterested," functions almost as an early corollary to Dewey's tentacled-mind, reaching out and glomming on to whatever comes its way. If we read in place of “disinterested” an "acquisitive, curious mind," we have no need to force upon Arnold any extreme conception of unbiased objectivity,- just as we have no need to seek in "the thing as in itself it really is," the noumenal world of Kant. Although, forebear playing out his little satire on curiosity,- - a truly "cultured” free play of mind, one that is truly “disinterested," has to it "a balance and regulation” in opposition to that "blind and diseased impulse of mind" that is the worse sort of curiosity, the old gossip’s curiosity. $^{23}$

In an intriguing passage from Dewey we find something approaching a critique of Arnold's conception of “seeing things as they really are.” Dewey is here describing a carpenter working with his materials.

Fitness to effect certain special changes that he wishes to see accomplished is what concerns him in the wood and stones and iron which he observes. His attention is directed to the changes they undergo and the changes they make other things undergo so that he may select that combination of changes which will yield 
him his desired result. It is only by these processes of active manipulation of things in order to realize his purpose that he discovers what the properties of things are. If he foregoes his own purpose and in the name of a meek and humble subscription to things as they 'really are' refuses to bend things as they 'are' to his own purpose, he not only never achieves his purpose but he never learns what the things themselves are. They are what they can do and what can be done with them,- - things that can be found by deliberate trying. ${ }^{24}$

If this is, indeed, a reference to Arnold rather than Kant (although I suppose he could be referring to both), then Dewey here shows his indebtedness to Arnold's conception of "things as they really are." Arnold's is hardly a "meek and humble subscription to things as they 'really are'." When Arnold speaks of a "free play of mind" he is clearly moving toward Dewey's "active manipulation of things.” Nonetheless, something in Arnold does fall short of Dewey. For Dewey the "thing" was dynamic; it changed over time, and, most importantly, it changed through manipulation. Human action could remake, reconstruct the world. He was conscious that his view of the world, this "seeing the thing as it would become," was new; that in the past (the Greek past of Plato and Aristotle, in particular) men had come to understand changefulness as a negative. "Wherever there is change, there is instability, and instability is proof of something the matter, of absence, deficiency, incompleteness. ${ }^{25}$

Arnold was becoming aware of this changefulness. He recognized that a thing may only be properly understood if one allowed a free play of mind, of seeing from different vantage points, of setting aside the narrowing effects of self and an inadequate sense of society that for Arnold fell below the fullness of culture. Arnold attempted to transform the idea of "perfection" to serve as a mechanism for understanding "things as they really are," - to see perfection as not an attainment, but a continuous reaching , an 
approach toward,- - a nearness. Dewey understood perfection, as did so many of Arnold's peers, as knowledge in stasis. He rejected it, but did not fully reject its optimism, - its sense of possibility, - he held on to that arrow that points forward. He might no longer seek a means to uncover "reality point by point,"26 but through his transformation of Arnoldian disinterest into the tentacled mind, through his grasp of Arnoldian critical thought and free play of mind, he turned Arnold's “the thing as in itself it really is, into the thing as in itself it might become.

\section{Conclusion}

We could not really get close to a pure version of the tentacled mind in Arnold,other than our indirect reading of the concept in his use of the word "disinterested," the concept we have come here to understand as the tentacled mind seemed almost a foregone conclusion to Arnold,- - as it was and is to most people. I stumble rather awkwardly whenever I try to explain this concept to my friends, because it seems to them rather an absurd nothing. Tell them that we all see the world differently and they assent with no problem; - tell them that our minds reach out and grab hold of the world around us and that we tend to want to know all we can know and, again, they come to a ready assent; - tell them that these two concepts are mutually exclusive and their eyes glaze over, and something in the back of their heads reminds them how many of those "damned intellectuals” are really much too busy counting the angels dancing on the head of a pin. In truth, the two thoughts are not mutually exclusive provided one does not treat either in too absolutistic a sense. If we believe that each of us sees the world in an absolutely, 
inviolably unique way, we have no choice but to declare each mind an isolate, walled off in dubiety from the world around us. If we take no account of the vagaries of bias and the Humean "motes" that condemn our eyes to imperfection, we have left ourselves open to the sportive whims of our fancies and prejudices.

Dewey’s great leap is really, as I am sure he realized, no great leap at all. He pretends to have reasoned anew, from his own experience. But I suspect that, at least to some extent, he was motivated by a desire to make this thing called philosophy speak more readily (if not directly) to the worldly conception of the average human. Experience is really that,- - it is how we, all of us, no matter our culture, no matter our interests, no matter our philosophical bent, engage the world,- - we, all of us, in one way or another, are "chewing the scenery," — and what might make for bad acting in a dramatic sense, makes for good acting in a human sense.

Now the reader may have noticed that in trying to get to this sense of the tentacled mind in Arnold I had no choice but to move through rather a number of ancillary concepts: "free play of mind" and "perfection," in particular. And that even with Dewey, we had recourse to thoughts (notably for Dewey the need to add critical thought as a caveat for the immediacy of the tentacled mind) that went beyond our immediate concern and drew us toward ideas that would, no doubt, be more at home in some of the chapters that follow. I had said in the last chapter that these qualities of mind cannot be completely separated one from another. We are building a mind as a whole, even as we look at in parts. Multum in parvo. The many in the little. We cannot stop here. We cannot build our educational philosophy upon this tentacled mind alone. 
That education is not an affair of "telling" and being told, but an active and constructive process, is a principle almost as generally violated in practice as conceded in theory. ${ }^{27}$

If we read this passage from Dewey as a mere aphorism, if we subject it to no critical thought, if we think in it we have all we need know about education, then we have failed Dewey, even as we have failed ourselves. Let us not make too little of the tentacled mind, but let us, equally, not imagine that it is in anyway sufficient to our purpose. 


\section{Notes}

${ }^{1}$ Arnold and Allott (editor), “Empedocles on Etna," pg. 169.

${ }^{2}$ Dewey, "Memory and Judgement,"1902, pg. lw.17.334.

${ }^{3}$ Hume, An Abstract of A Treatise of Human Nature, London, 1740, ABST Text pg. 16. Excerpts from Hume come from the on-line Past Masters Hume Database.

${ }^{4}$ Hume, An Abstract of A Treatise of Human Nature, London, 1740, ABST Text pg. 16.

${ }^{5}$ Dewey, Art as Experience, 1934, Page lw.10.46.

${ }^{6}$ Dewey, Art as Experience, 1934, Page lw.10.46.

${ }^{7}$ Dewey, Art as Experience, 1934, Page lw.10.46-7.

${ }^{8}$ Dewey, Democracy and Education, 1916, pg. mw.9.147-9.

${ }^{9}$ Dewey, Democracy and Education, 1916, pg. mw.9.150.

${ }^{10}$ Hume, An Abstract of A Treatise of Human Nature, London, 1740, ABST Text pg. 16.

${ }^{11}$ Cf. Reid, Inquiry into the Human Mind on the Principle of Common Sense, 1764.

${ }^{12}$ Dewey, The Child and the Curriculum, 1902, pg. mw.2.276.

${ }^{13}$ Dewey, Democracy and Education, 1916, pg. mw.9.151.

${ }^{14}$ Dewey, Democracy and Education, 1916, pg. mw.9.351.

${ }^{15}$ Dewey, Democracy and Education, 1916, pg. mw.9.151.

${ }^{16}$ Arnold, “On Translating Homer,” 1862, pg. CPW 1:140.

${ }^{17}$ Arnold, Culture and Anarchy, 1869, pg. CPW 5:90.

${ }^{18}$ Stefan Collini, Public Moralists, 1991, Chapter 3. "The Idea of Character: Private Habits and Public Virtues,” pg. 91-118.

${ }^{19}$ Arnold, Culture and Anarchy, 1869, pg. CPW 5:94.

${ }^{20}$ Arnold, Culture and Anarchy, 1869, pg. CPW 5:95.

${ }^{21}$ Arnold, "The Function of Criticism at the Present Time," 1864, pg. CPW 3:268.

${ }^{22}$ Dewey, Contributions to A Cyclopedia of Education, 1912-13, pg. mw.7.322.

${ }^{23}$ Arnold, Culture and Anarchy, 1869, pg. CPW 5:91.

${ }^{24}$ Dewey, Reconstruction in Philosophy, 1920, pg. mw.12.146.

${ }^{25}$ Dewey, Reconstruction in Philosophy, 1920, pg. mw.12.141.

${ }^{26}$ Dewey, Reconstruction in Philosophy, 1920, pg. mw.12.142.

${ }^{27}$ Dewey, Democracy and Education, 1916, pg. mw.9.43. 
From Resignation: To Fausta

The poet, to whose mighty heart Heaven doth a quicker pulse impart, Subdues that energy to scan Not his own course, but that of man. Though he move mountains, though his day Be passed on the proud heights of sway, Though he hath loosed a thousand chains, Though he hath borne immortal pains, Action and suffering though he knowHe hath not lived, if he lives so.

-Matthew Arnold ${ }^{1}$

\section{The Critical Mind}

With the help of the tentacled mind we have now bypassed the isolation of our senses, - we have reached outside of our selves and begun the necessary and important process of constructing a tangible world. But for all the willingness of our minds to engage the world, we remain conscious of the mote of which Hume complained,- - the limits of our senses. Some process must be present to allow us to, at least, reduce the impact of that mote, - to ascertain if not a perfect conception of that world in which we live, at least a conception that moves toward perfection. For both Arnold and Dewey that process was criticism.

\section{A Criticism of Life}

In the chapter that follows I have chosen a somewhat unusual, perhaps even a bit digressive, approach to understanding the nature of criticism. Eames ${ }^{2}$ has told us that 
Dewey's approach to criticism derives from Arnold. Arnold's own approach grew out of the critical practices of his time and those that preceded him. In what follows I will provide a general outline of practical or descriptive criticism, coming up to and even going past Arnold, ending with reader response theory which is, to some degree, the most current of practical criticisms, - - which, indeed, as we shall see has been linked back to Dewey.

What I hope to establish is something of the nature of practical criticism, - to learn what lessons we may take from literary criticism to apply to our understanding of criticism as a general tool with value for education.

Arnold famously characterized poetry as a criticism of life, — a didacticism for which many of his critics never quite forgave him.

It is important, therefore, to hold fast to this: that poetry is at bottom a criticism of life; that the greatness of a poet lies in his powerful and beautiful application of ideas to life, - to the question: How to live. ${ }^{\text {a }}$

As we have noted S. Morris Eames's recognized that Dewey took Arnold's "poetry is a criticism of life" and transformed it into a vision of philosophy as "inherently criticism," or "a criticism of criticisms." ${ }^{3}$ We are certainly not concerned here with definitions of poetry, nor of philosophy for that matter. Indeed, we may wonder, more fruitfully, if this definition, “a criticism of life,” may have renewed power when applied to education. Is education, then, a criticism of life? Or a criticism of criticisms? Or is it a sort of prelude to the critical life? A means by which the critical faculty, unnatural though

\footnotetext{
a Arnold: “Wordsworth,” 1879, CPW 9:46. In his essay on Byron, Arnold clarified that it was to "literature in general" that he applied this phrase, indeed, he goes much beyond any limiting conceptions of literature: "the main end and aim of all our utterance, whether in prose or in verse, is surely a criticism of life.” Arnold: “Byron,” 1881, CPW 9:228.
} 
it may be, is formed and shaped? With this thought in mind, let us delve deeper into the nature of criticism if only to understand what it is that Arnold and Dewey meant by this word and how through it they were able, sometimes rather effectually, if often rather awkwardly, to define this aspect of education I have called the critical mind.

As an economical way of pressing forward with my intention of providing a short survey of criticism in English, I should like to resurrect a 1962 Pelican paperback by George Watson entitled The Literary Critics. ${ }^{4}$ Written in the interstices between the New criticism of the 1930s and the Postmodernism of the 1980s, Watson's book seems to me to express the pragmatism of literary criticism when it is practiced as discriminating appraisal and judgment rather than as a means to a theoretical end, or as a way of establishing explicit rules of poetry. Indeed, he begins by distinguishing among three kinds of criticism: legislative, theoretical and descriptive. Criticism in English begins with the how-to-books of the legislative category,- - books of rhetoric being the most notable contributions to this category; Judson Jerome's Poet's Handbook ${ }^{b}$ from 1980 is a recent (and quite good) example of this particular category. Legislative critics, Watson tells us, were "for the most part depressingly uninspired." ${ }^{5}$ Theoretical criticism "first arose in England in the Sidney circle, in the 1570s, under the influence of Spanish and Italian critics.” ${ }^{\prime 6}$ But, with the exception of Coleridge, it made little headway; it certainly did not have that expansive life that the Germans and the French would impart to it, nor

\footnotetext{
b Judson Jerome, Poet's Handbook, 1980, Cincinnati: Writer's Digest Books. Jerome's book is not without its theoretical moments, - and his handling of such poems as Frost's "Home Burial" not only draws upon the tradition of practical criticism, but (as portions were originally published as journal articles) brings forth (Arnold-like) rebuttal to reader response. Nonetheless, his clear intention here is to educate potential poets, - to teach prosody in practical terms for the maturing poet, to clarify that free verse is not the easiest but the most difficult of verse forms, and, in a decidedly rhetorical spirit, to make clear his expectation that poetry retain some vestiges of meaning.
} 
should we be surprised that Coleridge had to turn to the Germans, often plagiarizing his sources, to undergird his own sallies into literary theory.

Descriptive criticism, the final of our three kinds, is the criticism that most concerned Watson. This is criticism as judgment and appraisal. We shall call it here practical criticism which is, frankly, its more common term, and has the additional advantage for us of providing a partial verbal link back to the pragmatism with which we are so obviously concerned. Let us glance back at the passage in which Dewey asserted that philosophy is a "criticism of criticism." He goes on to say,

Criticism is discriminating judgment, careful appraisal, and judgment is appropriately termed criticism wherever the subject-matter of discrimination concerns goods or values. Possession and enjoyment of goods passes insensibly and inevitably into appraisal. First and immature experience is content simply to enjoy. But a brief course in experience enforces reflection; it requires but brief time to teach that some things sweet in the having are bitter in after-taste and in what they lead to. Primitive innocence does not last. Enjoyment ceases to be a datum and becomes a problem. As a problem, it implies intelligent inquiry into the conditions and consequences of a value-object; that is, criticism. If values were as plentiful as huckleberries, and if the huckleberry-patch were always at hand, the passage of appreciation into criticism would be a senseless procedure. If one thing tired or bored us, we should have only to turn to another. But values are as unstable as the forms of clouds. The things that possess them are exposed to all the contingencies of existence, and they are indifferent to our likings and tastes. ${ }^{7}$

We shall have more to say of Dewey's conception of criticism below, but, even to the inclusion of the fanciful metaphor of huckleberries in an huckleberry-patch, this is a wonderful introduction to practical criticism with its concerns for "the contingencies of existence" and the objects possessing these values. Notice here that the values are in the objects not in the inference of the critic, — they are indifferent to our likings and taste. This is a criticism that is not so wholly subjective that it willfully changes the world to 
adhere to its own peculiarities of taste, even as it is adamant to make bold declaration of those peculiarities.

\section{John Dryden (1631 - 1700)}

Watson begins his survey with John Dryden, not the first practical critic in English, but surely the first notable critic. Legislative and theoretical criticisms were directed toward poets, not readers. Dryden wrote a single legislative essay, $O f$ Dramatique Poesie, of which Watson tells us he was "evidently embarrassed by his legislative intention, and took some trouble to disguise it.” ${ }^{8}$ His prefaces were directed to general readers and sounded a defensive note. In the first of them, he defended his choice of rhyme in a heroic play. In a later essay, he defended his use of unrhymed blank verse. No appeal to theory could quite satisfy both endeavors, but Dryden drew sufficiently upon neo-classical theory to satisfy himself (and, perhaps, his reader) that he was not too outré for the time; nonetheless, he would go his own way, not straying too far from theory, but far enough to meet the practical exigencies of his craft.

\section{Alexander Pope (1688 - 1744)}

Watson mashes the Augustan critics,- - Alexander Pope, Joseph Addison and Henry Fielding,-— into a single chapter. Pope’s Essay on Criticism is notoriously better poetry than it is criticism. Pope displays something of Dryden's “contempt for French neo-classical theory. ... In so far as the rules are French, Pope argues, they are bad; in so far as they ancient, and judiciously interpreted by Englishmen, they are good." ${ }^{\prime 9}$ Pope even continues Dryden's early attempts at historicism, 
Know well each Ancient's proper character;

His fable, subject, scope in every page;

Religion, country, genius of his age:

Without all these at once before your eyes,

Cavil you may, but never criticize. ${ }^{10}$

Watson calls this "an impossibly high level of scholarship,"11 and we should hardly

wonder that practical criticism, even with the maturation of historical literary practices

today, fails to achieve this sort of historical reading in its full measure; practical criticism

at its best is too pragmatic to be either overly tantalized by this ideal, or to dismiss it

because it is unattainable in its perfect state. Something of this lay behind Arnold's

dismissal of historicism some one hundred years later.

\section{Joseph Addison (1672 - 1719) and Henry Fielding (1707 - 1754)}

Addison and Fielding we may deal with more cursorily. Watson repeats what so many have said before him, that Addison is hardly the greatest of writers in English, "but with Addison it is clear that something important has happened to English criticism. ...

With him the revolution is complete: a revolution from law to actuality, from interference with the poet in his act of creation to help and advice for the thousands who read.”c

Fielding repeats Dryden in his own way, by writing prefaces to his novel Joseph Andrews

\footnotetext{
' Watson: The Literary Critics, 1962, pg. 68; to be honest, I rather enjoy Addison; as light as his writing is, it still has a wonderful cadence to it, and, perhaps because it is so light, it makes a pleasant read. Not withstanding this, I do much prefer his friend and fellow-writer, Richard Steele $(1672$ - 1729) and have long delighted in their wonderful co-creation, Sir Roger de Coverly. Samuel Johnson on Addison: "His prose is the model of the middle style; on grave subjects he is not formal, on light occasions, not groveling; pure without scrupulosity, and exact without apparent elaboration; always equable, and always easy, without glowing words or pointed sentences. Addison never deviates from his track to snatch a grace; he seeks no ambitious ornaments, and tries no hazardous innovations. His page is always luminous, but never blazes in unexpected splendour.” From John Gross (editor), The New Oxford Book of English Prose, edited by, 1998, pg. 223.
} 
(1742), but criticism of the novel really must wait for Henry James who turned prefatory self-criticism into something more than a mere act of self-defense.

\section{Samuel Johnson (1709 - 1784)}

Now we come to Samuel Johnson in whom, "English criticism achieves greatness on a scale that any reader can instantly recognize." ${ }^{12}$ The phrase "any reader” is rather significant; it will have its reflection in Johnson's use of the phrase "common reader" as we shall see. Johnson was such a monumental figure in criticism that we do him much disservice in focusing narrowly upon but a few of his critical efforts. However, we are presenting here what is but a survey of a survey, and so the dictionary, a critical work in itself, the prefaces to the dictionary and his edition of Shakespeare (in which, with his many notes, it has been argued, somewhat hyperbolically, that he invented Shakespeare criticism), and the delightful essays of the Rambler, and the Idler, shall all have to sit this one out, as shall the table-talk and myth of Johnson that James Boswell and Mrs. Piozzi have bequeathed us (Johnson had not been long dead when the first of the many reminiscences of his conversational prowess began to appear, becoming — under the rubric Johnsoniana — an expansive part of the Johnson canon).

Johnson's greatest achievement in criticism, however, came in his late years when he took on the opportunity to write prefaces for a collection of the major English poets from Chaucer up to the mid-eighteenth century. Johnson balked at writing the earlier prefaces and only Milton and Cowley are left from the period prior to the Restoration. Now known as the Lives of the Poets, Johnson's prefaces followed a common framework 
beginning with a biography, followed by a characterization of the poet and ending with a critical appraisal.

This is not quite the historicism that Pope had spoken of in his Essay on Criticism. Biography and criticism were for Johnson, each, an end in itself. "One striking aspect of the Lives," Watson points out, "is the total absence of bridge-passages (which might have been easy enough to invent) connecting the two major sections, the biographical and the critical. The character-section, for instance, might have been used as a link...”13 Johnson is the last great neo-classical English writer; Romanticism looms on the horizon with its foretastes in the poetry of Gray, Young and Cowper. Historicism with its desire for placing each poet and each poem within its historical context, with its suggestion of a changefulness in historical continuity, and with its perhaps inevitable undermining of the absolutism of classical rules was on the rise and would, by Arnold's time, be the dominant mode of criticism. In the Lives of the Poets, Johnson had his formula: biography, character and criticism. "He is," says Watson, "writing to a recipe, and he does not stir the ingredients." ${ }^{\prime 14}$

Johnson gave us a criticism that is Johnsonian in its fullness; excepting Shakespeare, he dealt primarily with his contemporaries and near contemporaries; despite his interest in biography, he could, in writing criticism, set aside historicism and speak wholly and completely from himself. "It should be obvious, then, that Johnson is not a biographical critic in a manner that foreshadows Sainte-Beuve. He is rather a critic who has discovered that criticism may usefully be practiced as an appendage to biography. 
Johnson’s explicit interest in biography, like Dryden’s before him, is moral and cautionary.”15

In fact, he could be jadedly prejudiced in his biographies as he shows in the Life of Milton. As Watson tells us, "the two principal sections of biography and criticism are in full collision: the biography goes far beyond an attack upon Milton’s political views to the point of personal vindictiveness." ${ }^{\text {"16 }}$ Whereas, "Johnson’s critique of Paradise Lost, sixty years later than Addison's, is so far its superior that it is worth posing the contrast in reply to any question of Johnson's powers as an analyst. It is obvious that he is vastly nearer to Milton's text than Addison is, and worth noticing, at the same time, that he contrives to be so almost without quotation."17

Johnson was no more aggressively a neo-classical theoretician than the average English critic of his time. In general, theory was for him an auxiliary to be used as needed and no more than as needed. However, as Watson points out "Johnson is clearly embarrassed by his own 'laws.' The ambiguity of his judgments, and the force that 'prescriptive veneration' of established masterpieces always held for him, emerges almost as clearly in his life of Milton as in the preface to Shakespeare. Johnson writes of Paradise Lost as if the poem were a visit to the dentist..."18 With Johnson we have a monument and, to some degree, a type. His was a vast declaration of self,- - a willingness, perhaps even a near-neurotic need, to declare an opinion,- - to argue, as it were, for victory,- but his was not a self entirely ungrounded. Analysis, the text itself, admonished and corrected the over-ripe opinion, and when it did not, the pen itself faltered ever so much that the disagreement, the cognitive dissonance as we should say 
today, made itself known. And Johnson allowed himself to be tempered by what he called the “common reader.” Writing of Thomas Gray’s “Elegy in a Country Churchyard," he says,

In the character of his Elegy I rejoice to concur with the common reader; for by the common sense of readers, uncorrupted with literary prejudices, after all the refinement and subtilty and the dogmatism of learning, must be finally decided all claim to poetical honors. The Church-yard abounds with images which find a mirror in every mind, and with sentiments to which every bosom returns an echo. ${ }^{\mathrm{d}}$

\section{William Wordsworth (1770 - 1850) and Samuel Taylor Coleridge (1772 - 1834)}

As we turn from Johnson to Wordsworth and Coleridge, Watson's summary of the first hundred years of English literary criticism (from Dryden to Johnson) is noteworthy.

...no European critic [of the neo-classical period] can be produced who believed in the whole of neoclassical doctrine as scholars now expound it. And, ultimately, it does not matter whether Dryden, or Johnson, believes in it or not: the critic's strategy in the field, like any good general's is likely to vary with the needs of the moment, and the study of theory is more likely to reveal his characteristic manner of excuse and justification than to produce any other result of intrinsic interest. Criticism is incurably pragmatic: Dryden will write blank verse if it suits him to do so, and Addison's love of Paradise Lost, or Johnson's admiration for the Rape of the Lock, is instinctive rather than principled. ${ }^{19}$

“Criticism is incurably pragmatic.” We should keep this thought in mind as we progress toward the criticism of Arnold and Dewey. For that matter, we should keep it in mind as we review Watson's commentary, since, arguably, this inclination does come between him and some of the later critics he deals with.

\footnotetext{
' John Gross (editor), The New Oxford Book of English Prose, 1998, pg. 224. This passage and that upon Addison in the note above are both derived from the respective Lives of the Poets. Thomas Gray's dates are 1716 - 1771; his poem “Elegy Written in a Country Churchyard” was published in 1751.
} 
Watson finds Wordsworth "badly out of his depth as a critic." 20 He completed the outline that Coleridge had prepared for the preface to the Lyric Ballads, only to have Coleridge turn upon him in the Biographia Literaria. Although Wordsworth's Preface contains much that is relevant to literary criticism, as with Coleridge's work, it is less concerned with practical criticism. His most telling phrases are prescriptive, addressed to other poets, or to the poet in himself, and thus belong more to Watson's first category of legislative criticism, than to that category that most concerns us here, descriptive or practical criticism. His famous injunction, "Poetry is the spontaneous overflow of powerful feelings; it takes its origin from emotion recollected in tranquility," has had a lasting effect on how we perceive poetry and the poetic task, despite its rather obvious self-contradiction. As much as we should like to dwell on Wordsworth, whose influence on Arnold was profound and openly acknowledged, even as Arnold thoroughly reinvented the old man, we must, for the sake of brevity, move on.

With Coleridge we take a turn back toward theory.

The achievement of Coleridge is rightfully held to be supreme amongst the English critics, but no one seeking to expound it faces his task with much confidence. ... There is no hypothesis of the real or ideal reader, in his criticism, corresponding to Johnson's consensus of informed opinion down the ages. There is just Coleridge. ${ }^{21}$

Coleridge's great achievement in criticism was the massive, half-plagiarized Biographia Literaria, which still baffles today and has been an editor's nightmare since its first hasty appearance. In it Coleridge attempted "to provide criticism with a systematic basis of its own."22 Watson sees Coleridge as "essentially a critic who practices criticism only as illustration."23 
For Coleridge, ultimately, only a theory of poetic creation matters: he analyses, not so much poems as they exist, but the creative act that makes them what they are. Now this is an interest of revolutionary significance. No English critic since Dryden had much concerned himself with the question of poetic process, and Dryden's interest had been no better than a passing one, based on his acquaintance with Hobbesian psychology. For eighteenth century critics, a poem is simply there, and it is the variety or uniformity of human reactions to it that is worth discussing. With Coleridge creation is central. ${ }^{24}$

Throughout this paper we shall find ourselves always just a step ahead of the issue at hand. When we spoke of Dewey's great leap across the perceptual boundaries, we saw out of the corner of our eye the press of society, the potential of a problem solving that made a fuller journey, past the object to its author. Now that we find ourselves faced with the authored-object, the poem, we seem to be looking even further ahead, not only to the intentionality we shall have to confront in the next chapter, but to the creative act of inference that will be our concern in the fourth chapter of our argument. Coleridge carries us toward these issues before we are quite ready for them, and so we must set him aside now and return to the less heady world of the more textually grounded critic.

Arnold made relatively little use of Coleridge's writings. Dewey, in Art as Experience, referred to Coleridge half a dozen times. He struggled with esemplastic, and admitted that he could not "profess to an exact understanding of what Coleridge meant by his distinction between imagination and fancy." ${ }^{25}$ But, perhaps most interestingly, he concurs with Coleridge on the active role of readership.

The man who poked the sticks of burning wood would say he did it to make the fire burn better; but he is none the less fascinated by the colorful drama of change enacted before his eyes and imaginatively partakes in it. He does not remain a cold spectator. What Coleridge said of the reader of poetry is true in its way of all who are happily absorbed in their activities of mind and body: "The reader should be carried forward, not merely or chiefly by the mechanical impulse of curiosity, 
not by a restless desire to arrive at the final solution, but by the pleasurable activity of the journey itself." ${ }^{26}$

Throughout Art as Experience, Dewey is often unclear as to whether he is speaking of the writer (artist), or of the reader (viewer). His confounding of these two positions is intriguing and surely a preamble to a number of positions strongly held today. The reader provides that one advantage to Dewey that when the artist has done the work of the "work" of art, the reader is able to continue the activity of experience. We can little doubt that he read Coleridge's quotation with an emphasis upon "pleasurable activity" as a "doing” of the most concrete sort.

\section{Charles Lamb (1775 - 1834)}

Watson's chapter on Arnold approaches, but a glance at Thomas De Quincey, Charles Lamb and William Hazlitt in an intermediate chapter provides an insight on criticism we ought not pass too readily. Watson makes the point that these critics, romantic though they are, did not follow precisely in Coleridge's footsteps, - they are not the school of Coleridge, who had no school and whose influence had to wait for the twentieth century to come into bloom, and then not as a direct origin, but as a reinforcement for movements begun on their own terms, or out of their own necessity. Lamb and Hazlitt have their respective interests; Watson says of Lamb that he is "one of those rare authors who can make a virtue of timidity and amateurism.”27 A quick glance at Lamb, the timid and amateurish, gives a startling sense of what timidity and amateurism can produce in criticism.

By what subtile art of tracing the mental processes it is effected, we are not philosophers enough to explain, but in that wonderful episode in the cave of 
Mammon [in Spencer's The Faerie Queen], in which the Money God appears first as a miser, is then a worker of metals, and becomes the god of all treasures of the world: and has a daughter, Ambition, before whom all the world kneels for favours - with the Hesperian fruit, the waters of Tantalus, with Pilate washing his hands vainly, but not impertinently, in the same stream - that we should see at one moment in the cave of an old hoarder of treasures, at the next at the forge of the Cyclops, in a palace and yet in hell, all at once, with the shifting mutations of the most rambling dream, and our judgment yet all the time awake, and neither able nor willing to detect a fallacy,- is proof of that hidden sanity which still guides the poet in the widest seeming-aberrations. ${ }^{28}$

See how here he starts with the somewhat timid, if a bit disingenuous, "we are not philosopher enough to explain” which Arnold will repeat, - then how fast the details follow, piled upon each other in a sentence that gathers tropes like treasure hoards without ever becoming a mere ramble, - then ends with a seeming rule, a bit of theory that is the dénouement the practical critic can allow once he has amassed his descriptive hoard. Lamb insists here upon the sanity of the writer, - the passage comes from an essay entitled "Sanity of True Genius," — and upon something more than merely sanity. He compares the vision of the writer to our own visions (he clearly includes himself),"the most romantic of us, that has been entertained all night with the spectacle of some wild, magnificent vision," — he challenges us to use our "waking judgment” upon these visions, - to see if the vision, "when it comes under cool examination, shall appear so reasonless and so unlinked, that we are ashamed to have been so deluded.” But returning to the visions of the poet, we find that "the transitions in the episode are every whit as violent as in the most extravagant dream, and yet the waking judgment ratifies them."29 Lamb, then, is the critic of the "waking judgment," — an epitome we should have thought 
better suited to Johnson. “There are moments,” Watson tells us, “when we feel that Lamb’s real mentor is not Coleridge but Samuel Johnson.”

\section{William Hazlitt (1778 - 1830)}

Hazlitt, unlike Lamb, was not at all timid; born late into the romantic scene, he wrote to make a show of himself; he tells us bluntly he does not read as much as he read in his youth, that what he is commenting on he read quite a long time ago and cannot really remember; he continues the well-established practice in English criticism (up to that time and continuing much longer after than one would expect) of misquoting his sources; he holds on to old ideas and thoughts and refuses stubbornly to change in any way. He is the romantic reactionary par excellence and is far more at home in the personal essay than in the critical review. We have seen already how critics have shifted their audience from the poet to the reader. What we see in Hazlitt is a submergence in the reader's position, the critic becomes the reader,- proud of his own idiosyncrasies,as awkwardly ignorant of other readers as he is of his text and his author.

Dewey, in fact, made use of Hazlitt’s essay on “Jeremy Bentham” in his 1908

Ethics. ${ }^{30}$ In the 1934 Art as Experience, he returned to Hazlitt, added Charles Lamb, and even threw in a dash of Pater, whom we will come to shortly.

Sir Walter Scott is classed as a romanticist in literature. Yet even in his own day, William Hazlitt, who savagely denounced Scott's reactionary political opinions, said of his novels that "by going a century or so back and laying the scene in a remote and uncultivated district, all becomes new and startling in the present advanced period." The italicized words with another phrase, "all is fresh as from the hand of nature," indicate the possibility of incorporation of the romantically strange into the meaning of the present environment. Indeed, since all esthetic experience is imaginative, the pitch of intensity to which the imaginative may be raised without becoming outré and fantastic is determined only by the doing, not 
by the a priori rules of pseudo-classicism. Charles Lamb had, as Hazlitt said, "distaste to new faces, to new books, to new buildings, to new customs" and was "tenacious of the obscure and remote." Lamb himself said: "I cannot make these present times real to me." Yet Pater in quoting these words said that Lamb felt the poetry of things old indeed but, "surviving as an actual part of the life of the present and as something quite different from the poetry of things gone from us and antique. ${ }^{31}$

How odd to see Dewey respond in this way to the decidedly romantic language of Hazlitt. But this should suggest to us how, "by the doing," Dewey's pragmatism had an ability to absorb the romantic even as it dismissed "the a priori rules of pseudo-classicism.” He understood that Romanticism was "politically allied as a rule with the Tory party" and that it opposed "the consequences of the industrialization of England."32

The romantic movement profoundly affected some who had grown up in the straitest sect of laissez faire liberalism. The intellectual career of John Stuart Mill was a valiant if unsuccessful struggle to reconcile the doctrines he derived, almost in infancy, from his father with a feeling of their hollowness when compared with the values of poetry, of enduring historic institutions, and of the inner life, as portrayed by the romanticists. He was keenly sensitive to the brutality of life about him and its low intellectual level, and saw the relation between these two traits. $^{33}$

Mill is not alone subject to such an influence. Dewey, like Arnold before him, rehearsed his own struggle between the gross experience of life and the sensitivity of aesthetic values. His own brand of empirical naturalism, as we shall see, reflected something of romanticism even as it attempted to reject the imaginative forces in romanticism that would withdraw from the empirical and move toward the ideal.

\section{Thomas De Quincey (1785 - 1859)}

In De Quincey, the role of the critic as reader takes a truly astonishing new step.

Watson focuses his discussion on De Quincey's “most famous critical essay, 'On the 
Knocking at the Gate in Macbeth,' which appeared in London Magazine as early as October 1823, not long after the successful series Confessions of an Opium Eater (September-October 1821) that made his reputation. ${ }^{34}$ Quincey begins this essay on a very personal note,

From my boyish days I had always felt a great perplexity on one point in Macbeth: it was this: the knocking at the gate, which succeeds to the murder of Duncan, produced to my feelings an effect for which I could never account ... ${ }^{35}$

His answer to this apparently eccentric question is, according to Watson, "as neatly organized as the logician could wish.”36 Needing to insulate his murderers and their act, the playwright must make the world at large disappear, so that "a new world may step in.”

...we must be made sensible that the world of ordinary life is suddenly arrested laid asleep - tranced - racked into a dread armistice; time must be annihilated; relations to things without abolished; and all must pass self-withdrawn into a deep syncope and suspension of early passion. Hence it is that when the deed is done when the work of darkness is perfect, then the world of darkness passes away like a pageantry in the clouds: the knocking at the gate is heard; and it makes known audibly that the reaction has commenced; the human has made its reflux upon the fiendish; the pulses of life are beginning to beat again ... ${ }^{37}$

What follows in Watson's text is very telling. I have said before that, writing in the early 1960s, he seems caught between New Criticism and the wisps of thought that would eventually become Post Modernism. Here he reacts to one of the shibboleths of New Criticism. New Criticism placed a high value on the text. In order to clarify the singular position of the text any effort to move either toward the intention of the author or the inference of the reader was seen as a fallacy. The first of these they called the intentional fallacy, the second the affective fallacy. Watson spoke decisively to the latter 
in discussing De Quincey: “modern critics who worry about something they call 'the Affective Fallacy,' or the 'confusion between the poem and its results' are certain to be embarrassed by De Quincey's excellence as a critic - no critic could be more frankly 'affective'- and certain to be puzzled why it is that Macbeth does not 'tend to disappear' under such analysis. ${ }^{38}$ In today's criticism, be it called post modernism, or post structuralism, or the reader response theory we shall look at shortly, the intentional fallacy still holds a dominant, even imperious position (dare to say "I think I know what the author meant" in an English class today and see if you do not receive, in consequence, a snooty dismissal, or an intemperate harangue), but the affective fallacy has been so far put aside that its opposite holds sway, and, at times, more value is placed upon the affective reading of literature than upon the analytical reading implicit in the text-first approach of new criticism (nonetheless, nothing could be less true of Stanley Fish’s criticism, and it will be to Fish that we turn as an exemplar of reader response). Watson could not have known of the dominance the reader's response would gain in later literary criticism; as a pragmatist, he simply steered a middle course.

Certainly the affective reactions of some critics to some poems may be too eccentric and too extravagant to be worth analyzing (Arnold's personal fallacy ${ }^{\mathrm{e}}$ ); and again, an irresponsible critic may tiresomely insist upon his own emotional response to a given poem to the extent of neglecting or denying its intelligible content. Both offenses arise from a failure in the critic's historical sense, and both can be rebutted, if at all, only by appeal to history. ${ }^{\mathrm{f}} \ldots$.. But to admit all this is not

\footnotetext{
e Watson refers here to Arnold's “The Study of Poetry,” 1880, (CPW 9:161-188). “...a poet or poem may come to us on grounds personal to ourselves. Our personal affinities, likings, and circumstances, have great power to sway our estimates of this or that poet's work, and to make us attach more importance to it as poetry than in itself it really possesses, because to us it is, or has been of high importance" (CPW 9:164). We should avoid reading this to mean that Watson thought Arnold's poetry "too eccentric or too extravagant to be worth analyzing."

${ }^{\mathrm{f}}$ Arnold precedes his account of personal fallacy with an account of historical fallacy. "The course of development of a nation's language, thought, and poetry, is profoundly interesting; and by regarding a
} 
to admit that it is never proper for a critic to analyze his own emotional reactions. In a sense, there is nothing else he can ever do. It is simply to insist that such reactions should be historically informed as well as deeply experienced. Much of De Quincey's criticism shows how good 'affective' criticism can be: he feels Wordsworth to be the greatest of contemporary poets, and then seeks reasons for his unique quality. He feels the knocking on the gate in Macbeth to be magnificently theatrical, and twenty years late he discovers why. To pose such questions at all, and so frankly, is to make descriptive criticism one degree more honest and more sane. ${ }^{39}$

\section{Matthew Arnold (1822 - 1888)}

We now come to Matthew Arnold. Arnold is, for Watson, as for so many other literary critics from Arnold's day to the present, something of a lightning rod attracting attention both pro and con, with an influence that may well be out of all proportion to his actual critical accomplishment, but an influence that, nonetheless, cannot be ignored.

A historic estimate of Arnold must always show him to have been the most influential force among the Victorian critics. But there seems no good reason now for accepting his claims to greatness as a critic. ${ }^{40}$

We need not dwell on Arnold's successes or failings as a literary critic. He insisted that criticism should be the study of the best, but devoted a rather large portion of his effort to minor works and minor poets; he insisted that the subject-matter of poetry was of the utmost importance, but remained vague upon what that subject-matter was to be; he seemed to have cared little for scholarly study of poetry, and was "too amateur a scholar to find any use for the new German tradition of historical research." ${ }^{, 1}$ Nonetheless, his voice, as Stefan Collini tells us, "soars above the circumstances that prompted it, and moves, instructs, and amuses us still., ${ }^{42}$

poet's work as a stage in this course of development we may easily bring ourselves to make it of more importance as poetry than it really is, we may come to use a language of quite exaggerated praise in criticizing it; in short, to overate it” (CPW 9:164). Surely Watson is tweaking Arnold by suggesting that the only cure for the personal fallacy is an historical perspective. 
Watson begins his discussion of Matthew Arnold with this excerpt from Arnold's

“A French Critic on Milton,”

...the method of historical criticism, that great and famous power in the present day ... The advice to study the character of an author and the circumstances in which he has lived, in order to account to oneself for his work, is excellent. But it is a perilous doctrine that from such a study the right understanding of this work will "spontaneously issue."g

Watson sees this as an indication of "how untypical a Victorian critic he was, and how proudly he knew it.”43 The nineteenth century was the age of historical criticism,- - the age of historicity, that moment in time when looking backward we were able to see, not in intellectual ones or twos, but as a society, our advancing differences with the past, our growing technologies and industrial mechanisms, our changing thoughts and customs, our widening vistas matched to our narrowing personal circumstances. To be historically-minded in the nineteenth century was to be modern. Arnold, says Watson, wrote in "a spirit of denial;" he is "the most insistent and professional of nonconformists” who delighted in waving "a red rag to a bull,” John Bull; “Arnold, like his contemporary Marx, challenged his own world to suicide and rebirth.”44

He began by reacting against his own writing, famously censuring his poem Empedocles on Etna. We have seen how Dryden turned to prose criticism to justify his own poetic decisions; - how different was this move on the part of Arnold, it "begins in a more hostile spirit, in self-disgust, and his attack upon the rejected Empedocles in the

g Arnold: “A French Critic on Milton,” 1877, 8:175. Quoted in Watson: The Literary Critics, 1962, pg. 144. The French Critic in question is Edmond Schérer. One might argue that in this Arnold is suggesting that even history must be viewed as a whole and not in its parts. Watson does not say this, but he does demonstrate, as we shall see, how Arnold took what he wished from the historical view even as he openly dismissed it. 
1853 preface, upon its subjectivity and its lack of action, is not much less than an attack upon the whole of his brief career as a poet.”45 In his Oxford lectures, his journal articles and his letters to his friend, the poet Arthur Hugh Clough, Arnold struggles to reinvent poetry as something that he knew it could not be and that he, in his own work, could never make it, although he would, at least briefly try in works (Sohrab and Rustum, Merope) that seem predestined to fail. As Watson puts it, "the literary values he recommends are those that the poetry of his day was least able to achieve; his cultural values are everything that cultivated opinion was not." ${ }^{\text {"6 }}$ Most interesting is his attempt to use poetry as a means of meeting the religious needs of an increasingly complex and secular society.

Modern poetry can only subsist by its contents: by becoming a complete magister vitae as the poetry of the Ancients did: by including, as theirs did, religion with poetry, instead of existing as poetry only, and leaving religious wants to be supplied by the Christian religion. ${ }^{47}$

Along with his definition of poetry (again, he insisted that he meant not poetry as metered verse, but poetry as a synonym for literature in its entirety) as a criticism of life, this equation between poetry and religion has drawn much debate. Did he mean that poetry was to take the place of religion? To augment it? To perform a task that religion had performed without actually becoming, in the dogmatic and church-institutional sense, a religion? Arnold, himself, seemed hardly to know.

Arnold had a fondness for the French critic, Charles Augustin Sainte-Beuve (1804 - 1869), whom he was in the habit of dining with on his occasional trips to France. As Watson tells us, Sainte-Beuve's “biographical-critical essays, which began to appear in 
French journals in 1824 to continue till his death in 1869, are the source of critical inspiration that Arnold always appealed to and he twice acknowledged his debt to this 'perfect one' among European critics.” ${ }^{48}$

It is obvious indeed that Sainte-Beuve's portrait littéraire is the structural model for an Arnoldian essay in criticism. Here, as in Johnson's Lives, most studies begin in biography and end in criticism; but now the two principal components are utterly merged, so that we should seek in vain the moment of separation, and both subserve a mysterious end superior to biography and critical analysis alike. For a Sainte-Beuve portrait has a symbolic function, and his heroes, like Arnold's, are like saints in a secular canon of excellence. ${ }^{49}$

"Saints in a secular canon," - we are reminded here of Arnold's attempt to link

poetry to religion. In Arnold's “The Study of Poetry,” we read,

We should conceive of poetry worthily, and more highly than it has been the custom to conceive of it. We should conceive of it as capable of higher uses, and called to higher destinies, than those which in general men have assigned to it hitherto. More and more mankind will discover that we have to turn to poetry to interpret life for us, to console us, to sustain us. Without poetry, our science will appear incomplete; and most of what now passes with us for religion and philosophy will be replaced by poetry. ${ }^{50}$

Watson comments on this passage, creating the sort of apologetic that Arnold himself often resorted to, that "it is the sham religion of dogmatic assertion which will be replaced by poetry, not the true religion of Christian humanism. Arnold's real purpose is to defend what he considered the essentials of Christianity by means of a tactical retreat involving the abandonment of dogma." ${ }^{, 51}$ Nonetheless, the link between poetry and religion is an undeniable aspect of Arnold's criticism. Certainly, Johnson was not without his moralizing and religious zeal, but in Arnold's case the role of both poet and critic become more stringently defined by their capacity to meet the spiritual and moral needs of society; - we might argue that, more so than Johnson, Arnold felt that 
increasing secularization and the growth of sectarian divisions within Christianity were having a negative impact on society; however to have turned to poetry as a means of curing these ills seemed odd both to Arnold's peers and to later literary critics like Watson,- - and may, indeed, have felt the same way to Arnold himself, for eventually he would shift this role from poetry to critical prose. No doubt, Johnson had his frustration with the "low church," but he could not have thought that poetry offered any singular remedy: religion held the cure for religion; and public morality needed but the aid of cautionary preaching and the keen application of a stout rod to the back side to amend the situation.

If Arnold had sought a different purpose for poetry, he equally hoped to find a new purpose for criticism.

What distinguishes the Arnoldian essay-in-criticism is the novel disproportion of fact and re-creation. There is a great deal of icing and not much cake. The essays are usually constructed on a similar plan to Sainte-Beuve - an interpretation of a biography and criticism, often with a brief, generalizing opening - but Arnold's pocket-biographies do not, like Sainte-Beuve's, suggest toil in libraries or a passionate concern for facts. They plagiarize heavily - sometimes upon an essay by Sainte-Beuve. And their manifest purpose lies elsewhere, in directing us, by a series of examples and cautionary tales, how (and how not) to behave. ${ }^{52}$

How to behave,- how to conduct oneself: "conduct," Arnold famously opined, "is threefourths of human life." ${ }^{\text {h }}$ For Arnold, poetry has a moral quality that as often as not trumped any more inwardly-focused poetic demands; the critic's role, in turn, was to prepare the way for the poet, to create an epoch in which it was possible to be poetic, to

\footnotetext{
${ }^{\mathrm{h}}$ Arnold: Literature and Dogma, 1871, CPW 6:407. Dewey repeats Arnold's phrase turning it a bit on its ear: “ 'Conduct is three-fourths of life,' but in some sense it is more: it is four-fourths. All conscious human life is concerned with ends, and with selecting, arranging, and employing the means, intellectual, emotional, and practical, involved in these ends. This makes conduct. But it does not follow that all conduct has moral import.” Dewey: Ethics, 1908, pg. mw.5.190.
} 
teach the age what it meant to live life. Arnold's conception of the Grand Style, for example, seemed to point more toward his fascination with stoic philosophy and Marcus Aurelius than to the explicit style of Homer. Arnold defined the grand style as he found it in Homer as: "that he is eminently rapid; that he is eminently plain and direct, both in the evolution of his thought and in the expression of it, that is both in his syntax and his words; that he is eminently plain and direct in the substance of his thought, that is in his matter and ideas; and, finally that he is eminently noble. ${ }^{, 53}$ As his argument progressed it became obvious that Arnold was speaking of much more here than a way of deploying text in a poem,- - that qualities of rapidity, plainness, directness, substantial thought, nobility, somehow inform not merely the text, but the character of both Homer and his translators, and, more importantly, the shape of conduct to be absorbed in turn by the reader. Style, character, biography, and moral conduct are moving toward one another in his earliest critical work, as they had done in that early self-censuring act,- - the excluding of Empedocles on Etna.

Arnold is not the first critic to ask,- what is the function of criticism? ${ }^{\mathrm{i}}$ but the question has for him a more necessary centrality than it did for Dryden, who turned to criticism with an almost embarrassed humility, or for Johnson, who wrote with a bold and unapologetic hubris as if he assumed that what he wrote was important in and of itself and needed no function beyond its role as criticism to warrant that importance. When Arnold asks, — what is the function of criticism? he finds he cannot stop at the role of criticism in literature. Criticism projects beyond the narrowing path of the text; for

${ }^{i}$ Cf. Arnold, "The Function of Criticism at the Present Time,” 1864, CPW 3:258-285. T. S. Eliot's The Use of Poetry and the Use of Criticism (1933) famously echoes Arnold's title. 
Arnold, much to the dismay of many of his literary followers, it led not only to religious and social criticism, but away from the creative act,— away from poetry,— to which Arnold responds: "I conclude what I have said at the beginning: to have the sense of creative activity is the great happiness and the great proof of being alive, and it is not denied to criticism to have it." ${ }^{, 54}$

For us this broadening of the conception of criticism is of the utmost importance, for students of literary criticism, it was more a disturbance in the course of an otherwise notable literary career. George Saintsbury mused on the possibilities of an Arnold without the social and religious essays.

It is probably idle to wish that a man had done anything different from that which he has done. Without being a rigid Determinist, one may be pretty well convinced that the actual conduct is the joint result of abilities, and of desires, and of opportunity to exercise them.... But I am sure that had I been arbiter of Mr. Arnold's fate at this moment [1867, when Arnold largely turned away from literature to write social and religious criticism] I should have arranged it differently. He should have given us more poems.... And in his prose he should have given us infinite essays, as many as De Quincey's or Sainte-Beuve's.... ${ }^{55}$

Watson is more sanguine, finding in Arnold's writings on religion hints to Arnold's aesthetic theory. As Watson puts it, "Johnson and Hazlitt, even Coleridge, would have thought it improper for a critic to venture so far; but for Arnold it was obvious that poetry and religion are aspects of a wider entity called 'culture,' or the total current ideas in which a given society lives." ${ }^{, 56}$ As we have seen, Dewey, if we may include him among literary critics, was quite willing to carry criticism even farther afield.

For Watson, the tension with historical criticism is a significant aspect of Arnold's criticism. Sainte-Beuve wrote in 1825, as Watson tells us, “when Arnold was 
three years old,” that "after long considering literature as something invariable and absolute, capable of submitting itself to prearranged forms, criticism now regards it as the variable changing product of its own society." Arnold's response to this was subtle: partly it was that biography and history were not sufficient to an understanding of a writer's intentions, partly it was that literary purpose had a larger social role than could be apparent in an historical understanding,- - that it could be susceptible to an understanding that was adequate to the age in which the reader lived. We have already explored Arnold's concepts of "free play of mind" and "disinterestedness." The term disinterest, as Watson points out, Arnold had lifted "from an essay of Sainte-Beuve, who had spoken of the critic's task of introducing a 'un certain souffle de désintéressement. ${ }^{, 57}$ As we noted, however, Arnold used this term rather uniquely; for him it meant that we simply do not always act in our own self-interest, either because our own self-interest may not be involved, or because we are able to recognize our selfinterest and see it anew as we allow our mind that "free play" which brings the object, "the thing as in itself it really is," whole into our thoughts. As Watson puts it, "to recreate the past, not as it was but as it is for us: 'to see the object as it really is,' as Arnold defines the critical function, suggests a certain unconcern for the poem as a document in time, 'as it really was.'”58

We find something of the same sensibility in Dewey.

\footnotetext{
${ }^{j}$ Watson: The Literary Critics, 1962, pg. 145. Sainte-Beuve's declaration that literary criticism should begin with biography resulted in Contre Sainte Beuve, Marcel Proust's (1871 - 1922) response to the older critic; the response would eventually evolve into À la recherche du temps perdu (translated in English as Remembrance of Things Past, or In Search of Lost Time) a novel that has, by now, become intractably caught up in the biography of its author.
} 
Systematic exposure of how, where and why philosophies appropriate to ancient and medieval conditions and to those of the few centuries which have elapsed since the appearance of natural science on the human scene is so irrelevant as to be obstructive in intellectual dealings with the present scene, is itself an intellectually challenging task. ${ }^{59}$

This awkward sentence, with its two predicates moving in different directions, displays Dewey’s tendency to express a more than mild ambivalence toward history. "Ambivalence" with its sense of multiple valences is the true note here. Dewey never completely dismissed history; he could grudgingly recognize its necessity as a carrier of thought and language and culture; but thought and language and culture were the very things that Dewey thought were the most likely prospects for reconstruction.

As unlikely as it is that anyone might come away from a study of Dewey with the notion that Dewey delighted in reading history, equally Dewey does not come across as thoroughly anti-historical, nor for that matter did Arnold. Something else seems to be going on here; pragmatism, it would seem, attempts to use history in the same free way it uses theory. As Watson put it, “the critic's strategy in the field, like any good general's is likely to vary with the needs of the moment, and the study of theory is more likely to reveal his characteristic manner of excuse and justification than to produce any other result of intrinsic interest." ${ }^{\prime 0}$ If we replace "theory" with "history” we have a sense of how Arnold and Dewey wished to use history. This does not mean that either Arnold or Dewey are intentionally careless of history, or have any desire to rewrite history to suit their purposes, but rather that they are willing to reason against historic trends. Arnold is less concerned with the historic Homer than he is with what Homer had to say that is relevant to us today. The modernity of the ancient Greeks is what fascinated Arnold, not 
their antiquity. Watson never seems to quite understand this; perhaps, this is because he approaches criticism from more of a truly academic viewpoint, one in which knowledge is valued no matter its utility, than does Arnold. Arnold now and then pretends to such a position, but never entirely inhabits it. For Watson, literary criticism and literary history can have their isolated existences. For Arnold, as for Dewey, life as lived in the present is the ultimate object of all criticism.

Arnold's aesthetic theory, such as it was, Watson identifies within Arnold's thoughts on religion. In "The Study of Poetry” Arnold says,

Our religion has materialized itself in the fact, in the supposed fact; it has attached its emotion to the fact, and now the fact is failing it. But for poetry the idea is everything; the rest is a world of illusion, of divine illusion. Poetry attaches its emotion to the idea; the idea is the fact. The strongest part of our religion to-day is its unconscious poetry. ${ }^{61}$

Watson responds,

The most astonishing aspect of this display of Poor man's Platonism is that Arnold should think it called for so little defence. He offers none. The utterly staggering assertion that poetry assumes the real world not to exist is made as casually as if two and two were being added to make four. But the doctrine that poetry is unworldly and evanescent is not just Arnold's - it is Victorian, and could certainly be paralleled in the writings of Newman and Mill, and traced back to the poems and letters of Keats. It is too incoherent to be dignified by the title of an "aesthetic.",62

Watson's desire to find an aesthetic theory in Arnold is consistent with his conception of the relationship between the practical critic and aesthetic theory. The practical critic, generally speaking, is not intent upon formulating an aesthetic theory, and is quite content to forego theory for practical results, but, absent the tension between aesthetic theory and practice, the practical critic's work lacks definition. Arnold's vagueness 
hampers his critical endeavors, although it does not undercut them entirely. Conscious that he was living in a time that he regarded as unpoetic, one wonders if Arnold might not have achieved more had he recognized that this vagueness in his and his age's aesthetic theories represented its own kind of Philistinism, received ideas that lacked sufficient refinement,_- a Philistinism against which the cultural criticism he promoted could gain little or no purchase.

Before we leave Arnold, one final aspect of Watson's assessment deserves our attention. In a word, it is Arnold's 'snobbery.'

With Arnold, indeed, snobbery enters English criticism with a vengeance, and it has never been quite eradicated since. The Arnoldian critic invites the reader to enter a charmed circle of connoisseurship, as Johnson and Coleridge had never done, to separate himself from a brute mass of Barbarians, Philistines, and Populace. In "The Function of Criticism at the Present Time," a programme of connoisseurship is offered, and in a manner of high bred disdain which is almost as significant as the programme itself. ...this combination of academic hauteur and lazy-man-about-town insolence enlivens, and disfigures, much of his criticism and all of his controversial writings forever after. Both the romantic young poet and the austere young critic of the 1853 preface are dead: the new pose is adult, scintillating, intriguingly decadent, one is, he complains languidly, "but the last sparkle of flame before we are all in the dark, the last glimpse of colour before we all go drab - the drab of the earnest, prosaic, practical, austerely literal future."63

Arnold was, no doubt, something of an elitist and a snob, although, perhaps, not as robustly so as the "Arnoldian critic" that Watson speaks of, and there were, as we shall see, critics who followed very much in Arnold's footsteps. No apologetics on my part will liberate Arnold from this charge, nor for that matter will it undo the ill-effects that a kind of literature-as-salvation philosophy, even if it is a bit of a misreading of Arnold, can produce. Watson notes that "those who see civilization as a cause rather than a 
condition of mind will always be attracted to this most insistent and eloquent of its advocates. "64 The charmed circle is still a part of the criticism of literature; complex words like semiotics, hermeneutics, hegemony and a robust pantheon, as Greek as Arnold's classic literature, which act to ward off the uninitiated; and even the desire to open up literature to the marginalized and oppressed has succeeded largely in creating new charmed circles of connoisseurship. Arnold's desire was, as Watson points out, to "invite" readers into the circle, as, no doubt, is true of those today who are busy creating their own circles, but the effect upon the common reader, whom Johnson so prized, can at times be more than a little off-putting. Perhaps, when Dryden first found it necessary to speak ex cathedra to his readers, the possibility of a common reader, a non-initiate, was doomed.

More to the point, no doubt, is Arnold's short essay entitled "Numbers; or the Majority and the Remnant.” In it he clearly states his belief in a small remnant, "a holy seed" of intellectually superior individuals whose task it must be to save civilization from itself, from the overwhelming effect of the vast numbers who, left to their own devices, will surely, with philistine zeal, wreck the world around them and bring about anarchy. Surely no advantage can be gained in working some vast and subtle apologetics on this score. I wonder that most intellectuals do not to some degree, in some fashion, partake of this thought. Not long ago I had a conversation with a woman at an education conference; I disagreed with her on a certain point,_ - a matter of what I thought an inappropriate use of ad hominem argument on her part; she puffed her chest up and said, “But—but, I am a senior scholar!” The point being that as I did not yet possess a Ph.D. I 
was somehow an inferior scholar and intellect. Can anyone who has ever practiced any form of Ph.D. snobbery, ever thought themselves superior to another by bent of argument, or specialized knowledge, or seniority in a discipline, or who has filled an essay with arcane, cryptic verbiage just to demonstrate command over that catalog of received-ideas now dominant in the discipline, really turn upon Arnold and say, "Shame upon thee, thou art an elitist”? If I said I was somewhat ambivalent to Arnold’s argument, I suppose some would say I, too, am an elitist. Well, yes, I suppose to some degree I am. It will help little, I am sure, if I say that, like Arnold, I know myself to be a philistine,- - unlike Arnold I feel uncomfortable with a good portion of his argument against philistines, for at times it seems to me a little too cruel, a little too intolerant. I suppose my ambivalence on this issue is really a measure of my own awkwardness,- - the world is rich in character and conduct,_- and shall always bear something of elitism in its complex mix; moreover, elitism seems to me to be something more complex than a simple Either-or,- - to treat it as an absolute is almost a bit of regressive morality,- by regressive I mean an absolutistic morality. Those who would write off Arnold by virtue of his elitism intrigue me,- - for to discard him on this issue alone is to engage in a very demanding and high form of moralistic judgment. I know it has often been said that morality is dead, but I think this is a terrible calumny,_- post-modernism, poststructuralism, call it what you will, has kept morality alive and used it to engage, with unstated authority, against the unrepentant past in ways that would make the strongest Victorian moralist seem weak and hollow by comparison. 
George Saintsbury (1845 - 1933)

I have raised George Saintsbury up to the level of a headline critic; he is given no such position by Watson. He shares space with Arthur Quiller-Couch and Edmund Gosse at the beginning of Watson's chapter on Henry James. But Saintsbury gives us a face to put upon the Edwardian critic; and he is very much an Arnoldian. The Edwardian period (1901 - 1910) was "confused and eclectic, heartily indifferent to dogmatic consistency, and delightedly aware of the variety of uses to which literature can be put.” Watson says of Saintsbury, that "the immense mass of critical essays and literary histories" he wrote are "built upon the assumption that no critical law is ultimately worth observing through thick and thin." ${ }^{\circ 5}$ It was an awkward age and thus, by necessity, a pragmatic one.

Let us have a little of Saintsbury on Arnold the social critic (the Arnold

Saintsbury so strongly dislikes). Here his meat is Arnold's book Irish Essays (1882).

Minor contradictions do not matter, though in a copy of the book I have read there is a damaging comparison by some annotator between Mr. Arnold's description of English Government at p. 4 and his rosy picture of education under the Government at p. 107. This might happen to anybody, and is not fatal. What is fatal is that this censor of the "unideaed" has evidently himself no "ideas," no first principals, in politics at all. ${ }^{66}$

Now let us pick Saintsbury up for a taste of a good Arnoldian critic on a fine pair of Arnold's literary essays, — in this case, Arnold's introductions to his selections of poems by Wordsworth and Byron.

Mr. Arnold had..., in the Essays in Criticism, expressed a wish that the practice of introducing books by a critical and biographical Essay, which had long been naturalized in France, and had in former times not been unknown in England, should be revived among us. ... 
"Why,” says one haughty critic,_- “why mar a beautiful edition of So-and-so’s works by incorporating with them this or that man's estimate of their value?" "The publishers," says an inspired communiqué, "are beginning to recognise that the public has no need of such things in the case of works of established repute, of which there is nothing new to be said.”...

But Mr. Arnold did not agree with these severe folk. He thought - and not a few good wits have thought with him - not only that these Introductions are an opportunity for men like himself, with original gifts of thought and style, to display these gifts, but that the mighty public, for all its knowledge of everything that has been thought and said about everybody, might find something new to it even in the observations of lesser folk. As a matter of fact, of course, and neither to talk nor to quote nonsense, the utility of such Introductions, even if moderately well done, is unmistakable. Not one in a thousand of the probable readers of any book has all the information which even a fairly competent introducer will put before him; not one in a hundred knows the previous opinions of the author; not many possess the acquaintance with his whole work which it is part of the business of the introducer to acquire...

As for the "Wordsworth" and the "Byron," they gain enormously by "this man's estimate of them," and do not lose by "this man's" selection. ...

And the Introduction (for after all we can all make our selections for ourselves, with a very little trouble)... I know few critical essays which give me more pleasure in reading and re-reading than this [Wordsworth]. Not that I agree with it by any means as a whole; but he is the mere "Pettys" of criticism (it is true not many seem to get beyond) who judges a critical essay by his own agreement with it. Mr. Arnold puts Wordsworth, as a poet and an English poet, far higher than I can put him. ${ }^{67}$

I have sampled at length from several paragraphs of Saintsbury's critical biography of Arnold to suggest the wonderfully discursive quality not only of an Arnoldian critic such as Saintsbury, but of that kind of practical criticism we find not only here but in Lamb or Hazlitt or Arnold, for that matter, in which one gets the sense of a fine raconteur telling stories, - were the critic speaking aloud, we would expect to hear the characters done in different voices, - and fully engaging one-side of a conversation that does not appear to 
entirely leave the reader out. If Arnold did bring in a snobbish voice, if the critic now stands between the reader and the work, still, as Saintsbury demonstrates, when done well, the business of the critic ought to be welcome and is surely not an entirely unpleasant affair; it ought, indeed, to have the ability to invite the reader into the charmed circle, - and if a charmed circle is a thing inevitably manipulative, incorrigibly marginalizing and oppressive, a thing of which we ought to be inherently suspicious, then let us, at least, exercise that suspicion first and then exorcise the charm out of the circle only as our suspicions prove to be well founded.

\section{Walter Pater (1839 - 1894) and Oscar Wilde (1854 - 1900)}

We must, at this point, include two notable critics who find ill-favor with Watson, and who, with no chapter to themselves, could easily fall outside of our purview. They are Walter Pater and Oscar Wilde; Watson's brief mention of them is rather telling.

In this complicated story, the criticism of Walter Pater (1839 - 1894) occupies an ambiguous position: it is almost as moralistic as Arnold's and James's, and we are never allowed to forget that Pater was an Oxford don of serious Christian inclinations. But the doctrines which, in all seriousness, he offers are fatally trivializing, and no good critic could afford to swallow them. For Pater, the content of literature is an embarrassing necessity, "mere matter" and "nothing without the form," which is, ideally, "an end in itself." "All art constantly aspires toward the condition of music" is a slogan bound to reduce descriptive criticism to the level of unfalsifiable statements, ${ }^{\mathrm{k}}$ for analysis only flourishes where content is seriously regarded and where the text is respected by the critic and reader as a common point of reference. Pater's uncertain attack was quickly reinforced. Oscar Wilde (1854 - 1900), in a few flimsy essays on critical issues, popularized anti-historicism in epigrams that turned historicism on its head and had no difficulty in making it look old-fashioned. "All bad poetry springs from genuine feeling" - the fallacy is not worth exposing, but its vogue in the nineties and after suggests how close the critical tradition was to total collapse. ${ }^{68}$

\footnotetext{
${ }^{\mathrm{k}} \mathrm{I}$ am inclined to note here that Watson makes much of the falsifiable nature of practical criticism; one suspects he has read or been influenced by Karl Popper.
} 
The key to Watson's concern here lies in his statements about practical criticism. As we have seen practical criticism is robustly pragmatic, in the sense of pragmatic that Dewey and Peirce have bequeathed to us. Pater and Wilde were many things, but pragmatic they were not. Watson simply cannot follow them where they would go. Wilde's witticism on bad poetry undercuts the common sense standards that are necessary for the practical critic to function at the level of the particular. In fact, the witticism is hardly a fallacy since it only implies, but does not state, that good poetry is founded upon false or nongenuine emotions; alternatively, it can be taken to mean that genuine emotions are insufficient to create good poetry. ${ }^{1}$

Dewey (should we be surprised at this juncture?) provides his own commentary

upon Pater's oft-quoted "All art constantly aspires toward the condition of music."

I should say, then, there are two fallacies of interpretation in connection with the matter under discussion. One is to keep the arts wholly separate. The other is to run them altogether into one. The latter fallacy is found in the interpretation often given by critics who content themselves with the tag in quotation of Pater's saying that all "arts constantly aspire to the condition of music." I say interpretations rather than Pater himself, because the complete passage shows that he did not mean that every art is developing to the point where it will give the same effect that music gives. He thought that music "most perfectly realises the artistic ideal of complete union of form and matter." This union is the "condition" to which

\footnotetext{
${ }^{1}$ Moreover, bad poetry does have a nasty habit of wallowing in genuine emotions. More often than not these emotions are supported by an appeal to clichés. A cliché is not a false emotion,- it becomes a cliché because it does, indeed, represent a common, if superficial feeling. Bad poetry tends, as well, to be sentimental, which according to a rather curious common definition is false emotion; sentimental emotions, however, tend not to be false emotions (whatever it can mean to have a false emotion), but rather emotions that rise quickly and easily to the surface, that are shallow and not profound or deep. The emotions of good poetry are no more nor less genuine than those of bad poetry, but the poet brings to them something more, some greater sense of depth, some new setting, something of a rounder and more resonant music than the common cliché can provide. The romantics can often seem to us today, horribly mired in cliché because they found such resonance and advertised it in their poems, to the extent that now we may find their most easy and lyrical lines rather a little too sentimental. Wilde, I have always suspected, was really the most sentimental of writers, if only for his tendency to deal so openly with our clichéd and easy thoughts; he loves tantalizing the surface of things and letting the depths come into play only by silent or ironic echo.
} 
other arts aspire. Whether he is correct or not in holding that music does most perfectly realize this interfusion of substance and form, there should not be imputed to him the other idea. ${ }^{69}$

Again we should note that Watson was writing at the juncture between new criticism and post-modernism. Wilde, in particular, if not Pater, increasingly gained stature in the decades that followed Watson's work. Wilde's irony, his undercutting of traditional critical values, were incompatible with Watson's more pragmatic, more historicist approach to criticism; we might add that something of Arnold's irony seems to have been lost on Watson, as well. We will notice something similar in Watson's approach to T. S. Eliot, and when we reach I. A. Richards, we will have little choice but to turn away from Watson entirely, hoping in the meanwhile that we have, at least, captured something from him of the spirit of pragmatic, practical criticism.

\section{Henry James (1843 - 1916)}

What is most significant in Henry James’s case, aside from the rich subtlety of his writing, is that he was able to complete the project begun by Henry Fielding of providing a critical foundation for the novel. "Novel-criticism in English,” Watson tells us, "does not grow, as the art of analysing poetry grows, painfully over the three centuries that separate us from Dryden. It just happens.” And it happened because Henry James was asked by his New York publisher to add prefaces to a definitive collection of his novels.

Those who believe good criticism to take its rise most naturally from the failure of a creative life should be directed here, where the balance between criticism and creation seems almost designedly perfect. Certainly the dominant tone of James's criticism is not, like that of Dryden's apologetic. James's prefaces are in no sense works of self-justification. ${ }^{70}$ 
James came to write these prefaces late in life; he often felt that the writer of his early

novels was another person altogether, and could not always recall what had led him to

make such decisions as he made.

The professional critic has something to learn in humility from James's fastidious uncertainties: "The sunk surface has here and there, beyond doubt, refused to respond: the buried secrets, the intentions, are buried too deep to rise again..." the disclaimer reminds us of neo-critical theories that urge the critic not to waste time over the author's intention. The resemblance is only superficial. For James is perceptive enough to see that mere impossibility does not rule out an endeavour, and that no species of criticism is ever likely to enable us utterly "to take intellectual possession.” There are kinds of criticism that lead us to within shouting distance of the work, and kinds that lead us further and further away; and James is clear that 'the buried secrets, the intentions' of the novelist are what the imaginary novelist Vereker in "The Figure in the Carpet” (1896) called "the thing for the critic to find."

We are left to wonder here, and it is an important question we ask, can a pragmatic critic ever be free from asking and even attempting an answer to the question,- - what did the author mean by that? Authorial intention did not disappear when literary theorists came to the conclusion that it was essentially unknowable; it held on quite subversively; holds on yet today, waiting to be returned to just consideration.

But let us return to James; his accomplishment is too significant to end our discussion of him upon a controversy he could not have seen, nor imagined.

The extent of James's revolution in the criticism of the novel is difficult to overstate. Before he wrote, none of the ordinary assumptions of twentieth-century novel-criticism were current; and James not merely made them current but even added many of the delicate qualifications which we expect a pioneer to leave to his successors. It was James who, in the deceptively mandarin prose of his prefaces, made us look for a total, unifying meaning in novels by identifying the points of departure of his own; it was James who taught us to see such significance as being organized part by part, and to study the interrelations of such parts; it was James who defined for us the role of morality in the novel as having to so with "special precept," or the demands of social conformity, and James who 
pointed to the inevitable falsity of fiction as well as to its essential truth.... And all this is effected with no Arnoldian imperatives, no open injunction but that of "life" itself and no obtrusive aspiration to legislate for other novelists. ${ }^{71}$

One might argue that James achieved with the novel what his friend Arnold had hoped to achieve with poetry (James wrote his earliest criticism after reading and absorbing Arnold's criticism); but as Watson points out, Arnold had tried to do so by imperative and injunction. James, the truer pragmatist, was content to do that of which Arnold could only speak.

\section{T. S. Eliot (188 - 1965)}

As we come into the early twentieth century, we find criticism attaining to that maturity that tends to betray itself in divergence and controversy. Watson begins by looking at T. S. Eliot, whom he treats as largely an unconscious Arnoldian.

What does seem clear is that Eliot is Arnold's successor in terms of the audience he expects for criticism: a minority audience, aware of itself as a cultural leadership, and peculiarly vulnerable, like Arnoldians, to the seductions of intellectual snobbery. ${ }^{72}$

The Arnoldian influence probably should surprise us much less than the sudden shift that criticism takes from readers back to poets. Whatever his elitism or snobbery, Arnold honestly meant to do well by his fellow readers, be they Barbarian, Philistine or Populace. Despite what Menand and others may think, as we have seen, Arnold was not without his democratic sentiments, his desire, if not for greater liberty, at least for greater equality. Eliot's retrenchment, turning his back upon the common reader, is more than a small revolution. With Eliot literary criticism has entered the charmed circle and shut the door on all outsiders. 
Watson, a literary historian, is understandably conscious of the role of history and historical reasoning in criticism; he notes how Eliot follows Arnold's approach to historicism.

...it is a tribute to the fading power of historicism that Eliot, like Arnold, seeks to maintain a façade of historicism behind which to develop a doctrine of poetry very like Arnold's own - the poetry of the past existing as a 'simultaneous order' and inviting study not for what it is to the poet and his first reader, but for what it is to the practicing poet of our own day - 'the object as it really is,' in Arnold's words, where 'really' aptly suggests a certain contempt for previous judgments. ${ }^{73}$

But Eliot seems to go a step further than did Arnold in this respect. Arnold sought to discover the present in the past, to find that which was adequate to the moment and so to allow progress, to transform an unpoetic age into a poetic age. Even if "Eliot's real historical sense ... is far finer than Arnold's, who seems to live and think in a strait-jacket of mid-Victorian enlightenment,"74 Eliot's real interest is in what he can borrow for his own purposes: "Eliot behaves towards the dead poets of Europe with all the casual skill of a shoplifter in a department store.”75

Eliot was conscious of what must surely be the greatest distinction between his critical tenor and Arnold's: beyond the question of historicity lay the question of communication.

I enjoy Shakespeare's poetry to the full extent of my capacity for enjoying poetry; but I have not the slightest approach to certainty that I share Shakespeare's feelings; nor am I very much concerned to know whether I do or not. In short, Arnold's account seems to me to err in putting the emphasis upon the poet's feelings, instead of upon the poetry. We can say that in poetry there is communication from writer to reader, but should not proceed from this to think of the poetry as being primarily the vehicle of communication. Communication may take place, but will explain nothing. ${ }^{76}$ 
If Eliot could not see the "slightest approach to certainty" that he could share in Shakespeare's feelings, Arnold, as we have noted, set aside certainty and merely asked if he might be able to approach those feelings, to come "near"'m to them. Perhaps Eliot is more the modern,- - he seems to leap frog us into the late twentieth century in his assurance that "communication may take place, but will explain nothing.” He wards himself from confrontation with other poets and other minds, content that his own mind must be sufficient to make sense of the tatters of poetry he has purloined from the vaults of history, - his readers are on their own; his influences carelessly dismissed; his trust lies only in those two great divinities,_- God and himself.

For Eliot, ultimately, the utility goes out of criticism; Arnold held on to a sense of the utility of criticism to the very end, and passed that sensibility on to many an Arnoldian critic among whom we must, to some degree, count Dewey. Eliot preferred that poetry be poetry and religion be religion; he had no interest in the cross-talk between the two that Arnold found so fascinating, nor, for that matter, in light of his conversion to dogmatic Christian beliefs, could Eliot countenance Arnold's attacks upon religious dogma. "I do not mean that Arnold's conception of the use of poetry, an educator's view, vitiates his criticism. To ask of poetry that it give religious and philosophical satisfaction, while deprecating philosophy and dogmatic religion, is of course to embrace the shadow of a shade." ${ }^{77}$

Perhaps most interesting for us, Watson finds in Eliot an echo of Arnold's struggle with the tension between the individual and society. "Contempt for historical

\footnotetext{
${ }^{\mathrm{m}}$ Arnold, Culture and Anarchy, 1916, pg. CPW 5:182. See Chapter 5 of the present study for a more comprehensive discussion of Arnold's hermeneutics.
} 
criticism is confirmed in Eliot's argument as it develops: poets do not express themselves in poetry, but escape from themselves by 'a continual extinction of personality." "78 We have seen this sort of personal suicide already in Arnold, when he rather dramatically killed his poem Empedocles, because, containing as it did too much of himself, it had failed to capture the tenor not of the age as it was, but of the age as he, the poet, had the responsibility to make it. In February of 1848, Arnold, quoting from one of his own poems, wrote to Arthur Hugh Clough, “'Not deep the Poet sees but wide,'- think of this as you gaze from Cumner Hill toward Cirencester and Cheltenham..79 For Arnold, the poet must raise his eyes to the horizon, look wide and far, gaze from the heights across the broad plains of cities and towns, see all of humanity, and see humanity from all sides, a task that cannot be performed if one’s views are too personal,_- "where man his deepest personal feelings being in play, finds poetical expression as man only, not as artist.." ${ }^{80}$ He said of the civilization of the Greeks: "they regarded the whole; we regard the parts." ${ }^{81}$

Watson finds this concept, both in Arnold and Eliot, difficult to absorb. He treats Eliot's conception as a mere paradox; he is, nonetheless, aware that Eliot's desire to efface personality and individuality was an expression of his fundamental conservatism,- - his reaching back toward the authority of church and dogma. Watson sees a similar conservatism in Arnold, and we would be wrong, no doubt, to think that Arnold had not at least some wistful measure of hope that something, and a sentimental something at that, is retained from the past. But Arnold's real measure here is pragmatic and moralistic. Pragmatic: it seeks a middle ground between the extreme romance of 
individualism and the order and responsibility of classical stoicism. Moralistic: it is didactic,— desiring to say something,— to communicate. For Eliot, Arnold's thoughts are the mere "shadows of shades." Eliot was no pragmatist, and it is not surprising that “the despairingly high ideal of achieving a 'musical order' in language 'without losing the contact with the ordinary everyday world with which drama must come to terms, ... is,” as Watson points out, “on his own telling, unattainable.”82 With no faith in communication, with an approach to the dynamics between individual and society that reverts too easily to the deus ex machina of divine authority, how could Eliot hope to achieve in any full and satisfying way that pragmatic goal of making "contact with the ordinary everyday world.” Fragments in a discontinuous world were all he found,much to his dismay,- and fragments were all he could leave behind.

\section{A. Richards (1893 - 1979)}

As I said earlier, with I. A. Richards, Watson's critical faculty fails him and us. He tells us that Richards pioneered the "Anglo-American New Criticism of the thirties and forties” and undeniably his work had a rich impact on these later critics, but Richards himself does not fall comfortably into new criticism, nor does he quite belong to semioticians, although he pioneered the idea of a science of symbols. Dewey wrote of Richards’ now classic early work The Meaning of Meaning (written with C. K. Ogden), that it is "a significant book, and one which lacks little of being of first-class importance,” and he particularly called attention to the fifth chapter, “The Canons of Symbolism," "in which the authors most definitely present their constructive proposition as to the development of a science of symbolism.”83 
The peculiar position of language, as indicated by the authors, is that it refers to things - in the most general sense of all kinds of situations and objects - through the medium of ideas or thought, in which speaker and listener are implicated, the matter being still further complicated by the fact that the function of many words is emotive rather than symbolic: that is, words are used to arouse attitudes as well as to make statements. ${ }^{84}$

Watson compares Richards to Coleridge as a theoretician "who indulged in literary analysis only as illustration of method.” ${ }^{85}$ Both writers, he tells us, wrote as amateurs proud of their amateur status, “as if the run of a gentleman’s library and a few bright ideas were bound to be more fruitful than the soul-destroying concentration of the specialist."n With an interest in psychology, Watson expects that Richards would “insist upon poetry as a communication between poet and reader ... , since any attempt to harness psychology to the service of criticism is bound to insist upon poetry as a strictly analysable human activity, like Wordsworth's 'men speaking to men'.” He notes the following passage from Richards’ The Principles of Literary Criticism with incredulity

("at the very point in the book where the doctrine that 'communication is ... [the artist's] principle object' is proclaimed"). ${ }^{86}$

Whatever psycho-analysts may aver, the mental processes of the poet are not a very profitable field for investigation. They offer far too happy a hunting-ground for incontrollable conjecture ... Even if we knew far more than we do about how the mind works, the attempt to display the inner working of the artist's mind by the evidence of this work alone must be subject to the gravest dangers. And to

\footnotetext{
${ }^{\mathrm{n}}$ Watson: The Literary Critics, 1962, pg. 198; we must note how far Watson is from Johnson who could have expressed something of the same thought relative to specialists. Watson, as a literary historian, is a specialist and, perhaps, too much of the conservatism of a specialist informs his judgments. Nonetheless, it may be fair to say that practical criticism may have in it a certain conservatism (using the phrase in its very general sense of conserving some aspect of the past), because of its need to use traditions and conventions as a ground for its critical activity. Dewey's generally dismissive attitude toward tradition, to my mind, covers up his rather robust use of tradition and convention as a critical ground for his judgments.
} 
judge by the published work of Freud upon Leonardo da Vinci or of Jung upon Goethe, ... psycho-analysts tend to be peculiarly inept as critics. ${ }^{\circ}$

The tenor of this passage suggests that Richards, like the new critics, would scorn as intentional fallacy any attempt to understand the intentions of the writer. This is Watson's primary concern,- can we study the psychology of literature if we alienate the writer's intentions from our criticism? He goes on to state that, "the almost total absence of psychological criticism ... is the most astonishing negative fact of all English criticism.”87 But psychology has, as Michel Grimaud, writing in The New Princeton Encyclopedia of Poetry and Poetics tells us, always been a part of literary criticism.

All criticism is in a sense psychological criticism, since all criticism and theory proceed from assumptions about the psychology of humans who make or experience or are portrayed in literature. Literature both embodies the psychological assumptions of its makers and is realized through the psychological assumptions of its interpreters. Even critics who posit an "objective" text are making a psychological assumption, namely that the perception of that text can be independent of the activities of the perceiver's mind. ${ }^{88}$

My guess would be that Watson would not particularly balk at this,- - that is until we get to the final statement. The practical critic, I suspect he would say, would hold that determining the degree of independence of the perceiver's (or conceiver's) mind is a prerogative of the critical act itself; in even suggesting that a broadly applicable or universal aspect of criticism is the denial that such activities of the mind have relevance, the theorist has over-stepped the bounds. His animus here is primarily with the new critics, then, and not with Richards, per se.

\footnotetext{
${ }^{\circ}$ Watson: The Literary Critics, 1962, pg. 199-200. We ought to note the short passage which Watson has here elided, "Much that goes to produce a poem is, of course, unconscious. Very likely the unconscious processes are more important than the conscious, but even if we knew..." I. A. Richards, Principles of Literary Criticism, London: Routledge, 1924/1926/2001, pg. 24. Watson's disregard for the unconscious may well be that feature of practical criticism we have already noted in Lamb’s "waking judgement."
} 
Nonetheless, this issue of communication, as Watson had pointed out is of more than minor significance to Richards. Notice, nonetheless, in the following passage on the psychology of the writer, that a concern with the intention of the writer is not entirely alien to his approach.

...the reluctance of the artist to consider communication as one of his aims, and his denial that he is at all influenced in his work by a desire to affect other people, is no evidence that communication is not actually his principal object. On a simple view of psychology, which overlooked unconscious motives, it would be, but not on any view of human behavior which is in the least adequate. When we find the artist constantly struggling towards impersonality, towards a structure for his work which excludes his private, eccentric, momentary idiosyncrasies, and using always as its basis those elements which are most uniform in their effects upon impulses; when we find private works of art, works which satisfy the artist, but are incomprehensible to everybody else, so rare, and the publicity of the work so constantly and so intimately bound up with its appeal to the artist himself, it is difficult to believe that efficacy for communication is not a main part of the 'rightness' which the artist may suppose to be something quite different.

That the artist is not as a rule consciously concerned with communication, but with getting the work, the poem or play or statue or painting or whatever it is, 'right,' apparently regardless of its communicative efficacy, is easily explained. To make the work 'embody,' accord with, and represent the precise experience upon which its value depends is his major preoccupation...

This is not quite the same as Eliot's statement that we noted earlier,

We can say that in poetry there is communication from writer to reader, but should not proceed from this to think of the poetry as being primarily the vehicle of communication. Communication may take place, but will explain nothing. ${ }^{89}$

With Richards we have no open dismissal of the role of communication in art. Indeed, we are very close to Dewey’s statement (perhaps ultimately derived from Richards) in Art as Experience, "Since art is the most universal form of language, since it is

\footnotetext{
P I. A. Richards, Principles of Literary Criticism, London: Routledge, 1924/1926/2001, pg. 21-22. As we know from Dewey, a phrase like "easily explained" generally indicates that the ensuing explanation will be awkward and cumbrous.
} 
constituted, even apart from literature, by the common qualities of the public world, it is the most universal and freest form of communication." ${ }^{90}$ Even Richards' emphasis on the “experience” seems to suggest that we have strayed into Dewey territory. But Richards did not entirely satisfy Dewey. He erred, as Dewey thought, by failing to see that "meaning" in the work of art is intimate with both the self of the viewer and the object of art itself.

The misconception of what takes place in what is called projection is, in short, wholly dependent upon failure to see that self, organism, subject, mindwhatever term is used-denotes a factor which interacts causally with environing things to produce an experience. The same failure is found when the self is regarded as the bearer or carrier of an experience instead of a factor absorbed in what is produced ... But this emphasis upon the self is for a special purpose, and it disappears when the need for control in a specified predetermined direction no longer exists - as it assuredly does not exist in an esthetic experience, although in case of the new in art it may be a preliminary to having an esthetic experience.

As intelligent a critic as I. A. Richards falls into the fallacy. He writes: "We are accustomed to say that the picture is beautiful instead of saying that it causes an experience in us which is valuable in certain ways. . . . When what we ought to say is that they (certain objects) cause effects in us of one kind or another, the fallacy of projecting the effect and making it a part of the cause tends to recur." What is overlooked is that it is not the painting as a picture (that is, the object in esthetic experience) that causes certain effects "in us." The painting as a picture is itself a total effect brought about by the interaction of external and organic causes. The external causal factor is vibrations of light from pigments on canvas variously reflected and refracted. It is ultimately that which physical science discoversatoms, electrons, protons. The picture is the integral outcome of their interaction with what the mind through the organism contributes. Its "beauty," which, I agree with Mr. Richards, is simply a short term for certain valued qualities, in being an intrinsic part of the total effect, belongs to the picture just as much as do the rest of its properties. ${ }^{91}$

In other words, Richards was so far from a pure textual critic that he retains a concern for the nature of beauty and a willingness to remove from the text its role in producing the sense of beauty we feel when viewing the object. Dewey, on the other 
hand, sees the object as being an equal contributor to the sense of beauty we perceive. If for example, I were to hold up a rose and a daisy,- - and say that I find the rose more beautiful than the daisy,_- certain "valued qualities" of the one,_- its satiny texture, the close interleaving of its petals, the sensuous curve of its contours,- I have, by way of criticism, compared to the "valued qualities" of the other,_- its straight, thin petals, the simple button-shape of the yellow flower head at its center. Even were I to reverse my opinion and declare the daisy the more beautiful of the two, these valued qualities would not cease to belong to each,_- even if I had no words beyond the plaintive "beautiful" to express these qualities, they would still remain. Beauty may be in the eye of the beholder, but so too is the object that evokes the sentiment.

But we have bypassed Richards, and must hurry on to our conclusion of this summary history of literary criticism. We shall, however, return to Dewey shortly.

\section{Cleanth Brooks (1906 - 1994) and New Criticism ${ }^{\mathrm{q}}$}

Because it has already drawn so much of our attention, and so much of Watson's animadversion, we must spend a few minutes on the new criticism, but we will turn from Watson to another source. Encyclopedias with their short, condensed entries may be among the most essential of pragmatic writings. Dewey contributed significantly to encyclopedias; indeed, some of his best commentary on Arnold comes from his

\footnotetext{
${ }^{\mathrm{q}}$ I have set aside Watson's discussions of William Empson and F. R. Leavis. As with Richards, Watson is not sufficiently sympathetic with either of these critics for his assessment to do them justice. And I must admit that I am not sufficiently familiar with their work to provide an adequate clarification. Watson carries us up through the critical world that influenced Dewey. We have seen what use Dewey made of Richards, and how Dewey could find in Richards a pragmatic source that Watson missed. I have found no significant indications that Dewey responded to the new critics, although, Dewey is vast, and I know that I have, as yet, pierced but a fraction of his voluminous writings, - - all the same a sampling of obvious searches in the electronic database returned no responses.
} 
encyclopedic writing. So let us turn back to The New Princeton Encyclopedia of Poetry and Poetics for a short (less than two pages) article on "The New Criticism” signed by T. V. F. Brogan (one of the volume’s editors) and Cleanth Brooks (who was, himself, a significant practitioner of new criticism). ${ }^{r}$

When John Crowe Ransom published The New Criticism in 1941, he apparently meant no more by the title of his book than to designate the criticism then current. ... The critics with whom Ransom was primarily concerned were I. A. Richards, William Empson, T. S. Eliot, and Yvor Winters. But Ransom's book was a sustained, though respectful, attack upon these four figures; and the critic that he desired to see, an "ontological critic," was conspicuous by his absence from the modern scene. ${ }^{92}$

Nonetheless, the term stuck and reflected itself back upon Ransom and his followers. But just what is the new criticism? "One aspect," say Brooks and Brogan, "of the new criticism which is often seized upon as central is 'close reading' " which is "a concern for nuances of words and shades of meaning.” But, as our authors point out, this is a quality that "has characterized much modern criticism.” Rather more important is what one wishes "to do with a text." In this regard the semantic readings of Richards and Empson had a significant impact on the new criticism. "More crucial" than close reading, say Brooks and Brogan, is the premise "that literature contains a distinct kind of knowledge,"

${ }^{\mathrm{r}}$ Cleanth Brooks, with Robert Penn Warren, wrote Understanding Poetry (1938/1950) a college text book that had tremendous impact. My own copy shows all the signs of a long and varied classroom life: underlining sporadically throughout, marginal notes that seem to clearly have their source in the external validities of a classroom professor, poems with notes every few lines, - simile, metaphor, simile, metaphor (metaphor scratched out, above it, in a hasty hand, hyperbole),- - rhyme schemes noted at the beginnings of lines, A, B, B, A, C..., on the end pages a handful of mathematical calculations showing that my copy of the book seems to have made an appearance in a math class of some sort and, being present, was put to good use, and the greatest treasure of all, stuffed in between the pages, a mimeographed exam addressed rather formally "To the Student in English B, 2a, or 2b:" - "you are free," say the instructions on this sheet, "to do as much reading about these poems as you like, to discuss them with your fellow students, and to make notes on this sheet;" - a sterling invitation to enrich the page with ornately patterned with marginalia,- - my favorite being a note that two lines of Swift allude to Dickens, a fascinating display of Swift's prescience, and perhaps a gentle jibe at the new critic's lack of historicism. 
knowledge that is "not essentially a matter of 'statement'," but rather "the rendering of an experience" in which "the old dualism of form and content," for many of the new critics, was rejected. "Thus, such factors as metaphor, tone and even rhythm cannot be dismissed as mere incitements to emotion; they have a bearing on meaning itself.” This is reflected in “the New Critics' concern for unity of the literary work: many of them championed a strenuously achieved unity." However, this was not a unity founded upon homogeneity; "they argued that the most mature literary art was not content to associate like with like but sought to bring into meaningful relation materials that we commonly think of as quite unlike.”93 Brooks and Brogan, however, bring the discussion back to the issue of "close reading."

Yet, the hallmark of the New Critics themselves continues to be "close reading," a strategy very often taken to be their limitation: that is obsessed with the microscopic examination of the text in hand, they never looked beyond it. Thus they had no regard for the fact that literary works are written by human beings. Actually, there was little likelihood that the New Critics could forget that importance of the author, since most of them had undergone the literary training of the earlier day, which was chiefly a study of literary history and of the lives and times of the canonized authors, a study in which the standards of literary evaluation were by and large extrinsic to the text itself. ... If we are interested in literature, per se, we shall - in spite of all difficulties of definition - in the end have to appeal to the text.

This is the upshot of the much-maligned and ill-understood "intentional fallacy." Wimsatt and Beardsley did not dismiss as of no consequence the author's intention or - more captiously still - deny that the author had any intentions at all. Rather they insisted that what counted were achieved intentions - those that are manifest in the work itself.

There is no reason why a critic should not be involved in all three concerns: with the writer, with what the writer has written, and with its effect on the reader. In fact, most of the New Critics were so concerned. But it is very important that the critic remain aware of the distinctions. ${ }^{94}$ 
At the risk of succumbing to the worst excesses of intentional fallacy, I cannot forebear noting that in this passage one can quite nearly hear and feel the sullen anxiety with which Brooks has brooded over these thoughts for the better part of a lifetime (surely they are the thoughts of a man who has been at the heart of a movement, and if I err in assigning them to Brooks, I can only offer my most sincerest apologies to Brogan). Would it were true that intentional fallacy allotted the sort of broad, pluralistic concern for all three major portions of the hermeneutic model. The caveat, however, must give us pause,_- "what counted were achieved intentions." How then to account for the interest that literary critics have always shown in an artist's failures ("the poet, in this line, attempts to...”)? Either such statements of authorial intention are manifestly wrong, or the theory is too unaccountably rigid for the pragmatic critic.

The closing paragraphs of this article have a fascinating poignancy to them: a sense of loss and sufferance that echoes back through T. S. Eliot, Arnold, Coleridge, and Johnson to the early critical writings of Dryden.

[The New Critics] believed, for example, that Dante and Shakespeare still speak to our own century, and that their works have universal value, including literary value.

In our own age such a view is not easily maintained. Yet if all "literary" judgments are merely relative, literary criticism, both "New" and age-old, becomes radically changed. All literary criticism henceforth is reduced to "historical" studies indeed, and, as in current writing, to socio-psychological studies of popular taste. ${ }^{95}$

Echoes of Dewey's thought are quite noticeable in several aspects of the new criticism agenda, although we would not expect by the use of the language that we are 
witnessing anything of a direct influence. ${ }^{\mathrm{s}}$ The rendering of experience sounds like Dewey, but the experience falling into a peculiar kind of literary knowledge, separate and separable from gross experience, suggests that Dewey would not have been entirely comfortable with the new criticism. The duality of mind-experiencing and thingexperienced, which we have already seen Dewey complaining of in Richards' work, is very much present in the new criticism. Arnold, in his contrarian way would, no doubt, have found his disagreements, but he was probably not so far from the new criticism as one would suspect. He would agree upon the need for unity in a work of literature, but would hardly have been willing to subject it to the extreme rigor Brooks and Brogan suggest. He often found interesting and intricate ways to meld heterogeneous thoughts, but generally made much of pretending that they were really homogenous all along. He did think that there was a special language of literature and a special language of science (Richards developed this distinction following Arnold's cue). Arnold found the language of literature in the Bible; in Literature and Dogma, arguably his most sustained effort in practical criticism, he argued for reading the Bible as literary language, not as scientific language. His emphasis on the nature of the literary language of the bible concerns its appeal to experience,_- "that habitual dwelling on the rules thus reached, that constant turning them over in the mind, that near and lively experimental sense of their beneficence, which communicates emotion to our thought of them, and thus incalculably heightens their power." ${ }^{96}$ The words echo remarkably in the new criticism, the concerns are oddly continuous, but the approach, the "free play of mind," is so different.

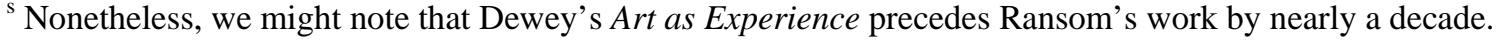




\section{Stanley Fish (b. 1938) and Reader Response Theory}

With Stanley Fish we break, rather rudely I suppose, into the present. Toward the end of the last century theoretical criticism came to dominate the literary landscape. Although, in the last few years, critics have begun to return to a focus on textual criticism, having tired of the progressive permutations of "theory." I have a suspicion we are on the verge of a renaissance in practical criticism, or at least a revaluation of what practical criticism has to offer with its tendencies toward the pragmatic, historic and unabashedly judgmental. I am afraid my survey approach forces me to reduce the rich and varied critical landscape of late twentieth-century theoretical criticism,- - losing much of great value in the process, - for, frankly, in these varied theoretical notions much may be mined of great relevance and utility to practical criticism. Nonetheless, I shall focus upon one specific theory, - that which is called reader response. In it I hope we will find an echo, decidedly awkward, of the pragmatism of practical criticism.

Stanley Fish is the "self-proclaimed inventor of reader-response theory." 97 In reader response theory we see a direct reaction against new criticism. Indeed, the way it is often put is that the new critics privileged the text, while older critics, such as Johnson and, most reprehensively, Arnold, had privileged the author. Surely, it was time now to privilege the reader. We have seen how much this frustrated Cleanth Brooks, who lived long enough to find himself and his theories pushed to the sidelines and dealt with in that rather heavy-handed way that a new generation tends to deal with its immediate predecessors. Nonetheless, we would be wrong to see reader response theory as entirely negative in its approach to literature,- - in many respects it is considerably more positive 
and perhaps even more optimistic than its most immediate predecessor of a purely theoretical mold,-_ deconstruction.

Fish, in particular, seems unafraid to give reader response theory a somewhat more positive spin,- - to allow that some movement of thought, of communication, can reside within the critical process. But he holds on to some rather unnecessary, to my mind, theoretical dogma,_- the emptiness of the text, the irrelevance of authorial intention,- - that prevent the necessary and important relevance of the value of the reader's response to literature from taking its deserved place in the critical process.

In his essay Interpreting the Varorium, Fish uses the 1970s publication of the Milton Varorium, ${ }^{98}$ to establish the general parameters of his reader response theory. He takes several of Milton's sonnets and shows that they can and have been interpreted quite differently,- in some cases the difference of interpretation creates something of an absolute polar opposition. For example, the final lines of one of Milton's sonnets read, He who of those delights can judge, and spare To interpose them oft, is not unwise.

The word "spare" can be read as "leave time for or refrain from.” As Fish points out discerning between the two readings "is crucial if one is to resolve the sense of the line.”99 He then goes on to point out how reasonable and persuasive each interpretation is. His own argument is not at all unsound, although it leaves the poem in a state of ambivalence,- - unresolved at least in terms of its didactic intentions. However, Fish points out that ultimately the reader will either resolve the problem or move forward in a conflicted state. 
Our first inclination would be ask, - what did the author intend? Fish answers this in much the same way that the new critics did. What the author actually intended is unknowable to the reader. However, before we so easily accept such an answer let us quickly return to our discussion of the relationship between rhetoric and hermeneutics. In hermeneutics we saw that the act of interpretation is always directed from the reader through the text to the author. The interpretation of the reader is, barring those elements of unconscious understanding, a known quantity. The author's intention is, however, a hypothetical, vaguely discernible through the text. With rhetoric, however, the opposite is true. The author views the unknown reader through the text; the intention is knowable; the reader's response is not,- - in rhetoric the interpretation is hypothetical. If we go back to the origins of criticism in English, we might quickly note that Dryden was actually looking at his prefaces from this rhetorical point of view. For him the intention was knowable, the interpretation hypothetical, and his desire, persuasive, not interpretive, was to influence the reader's interpretation. If we move from Dryden to Johnson and Arnold, we find the professional critic who saw himself as a kind of intermediary between the author and the reader for whom the conventions of both interpretation and persuasion, hermeneutics and rhetoric, were freely available. The critic had an insider's knowledge based on study and expertise,- — we have seen how George Saintsbury provided us with an unrepentant apologetic for such a role. With De Quincey, most particularly, although we see echoes in Arnold, Lamb, and frankly most of the others we have offered here, we find a refreshingly pure, if we may call it that, reader's response. His question was not what did Shakespeare mean by the knocking at the door? but why did I respond as I did 
to the effect of the knocking at the door? For De Quincey, however, Shakespeare does not disappear, the knocking is real knocking, not an empty nothing purely fabricated in his own mind, and the reader to whom he speaks was a genuinely anticipated reality.

Fish, however, seeks to reduce the three elements that have so concerned us, intention, text, and inference, into a singularity (if we will recall our discussion of Jamesian pluralism in an earlier chapter, we will note that the approach here is monadic, not pluralistic). “This, then, is my thesis: that the form of the reader's experience, formal units [text], and the structure of intention are one, that they come into view simultaneously, and that therefore the questions of priority and independence do not arise.”100 We should recall Dewey's response to Richards, that we have failed when "the self is regarded as the bearer or carrier of an experience instead of a factor absorbed in what is produced.” 101 If we go back to our conception of the tentacled mind, we realize that Fish has once again isolated himself as a reader; where Dewey would be inclined to press past the doubtful limits of the senses, Fish is too aware of the Humean mote and our subjective biases. Dewey as we have seen does not ignore these problems, but, unlike, Fish he sees them as problems worthy of inquiry and capable of being moved from a state of dubiety into a state of some conclusiveness, even if that conclusiveness must carry forward some marks of contingency. Most particularly, his pluralistic sensibility balks at the reduction of object and inference, even while he is well aware that the two must remain intimately connected.

I have said that Fish has isolated himself as a reader, but this seems to have troubled Fish. He sought to account for the ongoing and fruitful activity of criticism by 
suggesting the existence of what he calls interpretive communities. His account of these interpretive communities is fascinating. He has argued himself into a corner by holding on to Cartesian dubiety, even while recognizing his own turn toward a kind of Deweyan pragmatism, - the result is curiously, delightfully awkward in that very positive sense of awkwardness I have been trying to uncover throughout this dissertation. "Interpretive communities," he tells us, "are made up of those who share interpretive strategies not for reading (in the conventional sense) but for writing texts, for constituting their properties and assigning their intentions.”102 Now on one level, Fish has simply shifted from hermeneutics to rhetoric. He has recognized what is so often misconstrued in reader response and that is that a reader, if she wishes to share her interpretation, or even to speak it to herself, must turn from being a reader (in the conventional, hermeneutic sense) to being a writer (in the rhetorical sense). As we shall see in the next chapter this movement is of the utmost importance both from a critical point of view and from an educational point of view. However, we need not follow Fish in denying the existence of the text or its ability to carry meaning, nor in confusing the reading activity with the writing activity, nor need we imagine that the two are a duality existing wholly in opposition to each other. Like objectivity and subjectivity, mind and body,- - an individual's ability to read and write are contiguous, not continuous. They exist side-byside, inform each other, partake of similar objects, and produce common threads, but they are enough different in nature that we may speak of them distinctly.

Because these points will be relevant as we move forward, let me state clearly my critique of Fish's reader response theory. 
1) Coming from a pragmatic point of view, I follow Dewey in recognizing that the objects of art, be they text, painting, sculpture, dance, or what have you, participate in our interpretations and are not absorbed and dissolved in the interpretive act. The dismissal of the text is not only impractical, it is ultimately unnecessary and ill-suited to the act of practical criticism, no matter how much it may appeal to a certain theoretic ideology.

2) Our inability to, in a pure and unadulterated way, verify the content of authorial intention with anything quite approaching to empirical precision is by no means an argument that such intention does not exist. Only if we imagine the poem to be a unauthored object, like a rock or stone (and only if we have no notion of divine authority we wish to hold on to) can we come to such a conclusion. In other words, if we look at the world at all rhetorically, as Fish has found himself having to do, we must accept that intention exists. In the next chapter I will speak more on this head in reviewing Arnold's notion that while we may not be able to come to a perfect understanding of authorial intention, we may come "near" to it. Even if he will not admit it, this is precisely where Fish is headed with his "interpretive communities" which exist, as did the Johnsonian and Arnoldian critic, in a kind of intermediary space between author and reader,_- although, honestly, Fish’s attempt to include the reader in the interpretive community is refreshing and not at all unwelcome to my way of thinking. 
3) The apparent incoherence in reader interpretations is overstated by Fish as a kind of absolute. Even if the readings of the word "spare" in the case of Milton’s sonnet may create clearly oppositional interpretations, those interpretations must share a considerable commonality for the distinct opposition centered upon this one word to be apparent. Somehow the two readings seem to belong to a family of interpretations to which, for example, a reading of "spare" as the tire in the trunk would seem ludicrous and purely nonsensical. This understanding of interpretations as existing within familial relationships is a corollary to Arnold's conception of "nearness" and is necessary to make Fish's conceptions of “interpretive communities” relevant.

4) As I have already made clear, the critical act contains both the rhetorical and the hermeneutical, the persuasive and the interpretive. The movement from interpretation to intention is real and significant. Most importantly it makes clear that the act of reading, if it is not to be seen as wholly passive, leads us to understand interpretation and persuasion (reading and writing) in a dynamic sense. Fish begins with such a dynamic sensibility, but fails to follow it all the way through,_- fails to recognize the ping-pong effect that comes from moving back and froth between the two, and the importance that the relationship between the two has for an understanding of the critical process.

5) On a very different level, I am inclined to note what Watson pointed out so clearly to us in our discussion of the various practical critics through the centuries,— they did not take their theory too seriously. Theory was a means 
to an end, not an end in itself. Fish gets something of this, but tries to make of it a paradox, and ends up parodying Oliver Wendell Homes assertion that, "It is the merit of the common law that it decides the case first and determines the principle afterward." ${ }^{103}$ In truth Holmes is suggesting that the reader's role is a significant one, that attempts to fit itself to its context. Fish, alternatively, lets the larger contextual world create a pattern of reading that vitiates all possibility of a "pure" reading. The truth, I suspect lies between the two.

6) Finally, a certain odd neuroses continues to hang over Fish's reader response theory,- - a fear of the author and the author's authority. But if the reader is to take on the role of producing intentionality, as Fish has clearly suggested is necessary, then we must come to terms with authority, - we must recognize that authority is not some inherent evil. I shall say more of this, again, in the next chapter.

\section{A Criticism of Criticism}

Arnold's statement that "poetry is a criticism of life" 104 came under constant critique almost from the moment he uttered it. Dewey, on the other hand, was one of its proponents.

The saying of Matthew Arnold that poetry is a criticism of life sounds harsh to the ears of some persons of strong esthetic bent; it seems to give poetry a moral and instrumental function. But while poetry is not a criticism of life in intent, it is in effect, and so is all art. For art fixes those standards of enjoyment and appreciation with which other things are compared; it selects the objects of future desires; it stimulates effort. This is true of the objects in which a particular person finds his immediate or esthetic values, and it is true of collective man. The level and style of the arts of literature, poetry, ceremony, amusement, and recreation 
which obtain in a community, furnishing the staple objects of enjoyment in that community, do more than all else to determine the current direction of ideas and endeavors in the community. They supply the meanings in terms of which life is judged, esteemed, and criticized. For an outside spectator, they supply material for a critical evaluation of the life led by that community. ${ }^{105}$

Dewey invested criticism with even more fluency than had Arnold. He saw in this "criticism of life" the means by which philosophy, if not poetry, could fulfill "a moral and instrumental function.” Beside a philosophy that he felt had become too inwardly focused, too obsessed with metaphysical and epistemological questions, too much populated with philosopher-accountants numbering the angels that could dance on the head of a pin, too inclined to over-value an ideality purposely separate from the problematic world of experience, he viewed a philosophy animated by criticism,"philosophy," he tells us in that passage to which Eames has already sent us, "is inherently criticism, having its distinctive position among various modes of criticism in its generality; a criticism of criticisms, as it were."

Leaving behind criticism as "a matter of formal treatises, published articles," Dewey pressed criticism into daily, minute-to-minute, use. "It occurs whenever a moment is devoted to looking to see what sort of value is present; whenever instead of accepting a value-object wholeheartedly, being rapt by it, we raise even a shadow of a question about its worth, or modify our sense of it by even a passing estimate of its probable future." He found a "rhythmic alternation” among "slight agreeable acceptances, annoyed rejections and passing questionings and estimates," - a rhythmic alteration that made up "the entire course of our waking experience, whether in revery, in controlled inquiry or in deliberate management of affairs." ${ }^{\text {107 }}$ Criticism, then, is 
essentially a native function of the human mind,- essential to the instrumentality of experience. What Dewey gives us here is almost more a matter of vector than of method,- - a direction for thought, as opposed to an internalized mechanics of thought. Pragmatic, practical criticism pre-dates Dewey, as we have shown, and as he knew all too well.

What Dewey does is redirect the valence of criticism: his is not the passage from internal awareness toward external (via the errant senses); nor is it the rude external inhabiting a world of intractable objectness; nor, for that matter, is it the older world of authority coming down from on high. The vector has changed, or rather it has been all but exploded. The object and the thought poses a kind of simultaneity. The object does not father the thought, no more than the thought may induce the object. Object and thought each possess substantial reality. Thought does not move from internal to external, nor from external to internal, deductively and inductively,_- or, as Dewey noted of our waking experience ${ }^{t}$ of acceptance and rejection, it appears in a kind of rhythmic alternation or succession.

Dewey, we should note, is here trying to mend the gap between what C. P. Snow would later call the "two cultures,"108 science and literature. "Philosophic discourse," according to Dewey, "partakes both of scientific and literary discourse. Like literature, it is a comment on nature and life in the interest of a more intense and just appreciation of the meanings present in experience.” Its role, in this respect, is "reportorial and transcriptive," but only "in the sense in which the drama and poetry have that office.”109

${ }^{t}$ Cf. Lamb’s “judgment yet all the time awake.” Charles Lamb and Adam Phillips (editor), Selected Prose, 1985, pg. 202. 
An office, one must add, that not all drama and poetry share. As in Art as Experience, Dewey here (in Experience and Nature) allows himself to be strongly responsive to that naturalistic strain in art that was yet playing itself out in the art of his time. Nonetheless, he needs but a taste of what may lay within the compass of literature, that part of literature which Arnold had attempted to expand to the whole in his "poetry is a criticism of life.”

Dewey continued, “[philosophy’s] primary concern is to clarify, liberate and extend the goods which inhere in the naturally generated functions of experience." What it need not take from literature is its fictive nature,- - "it has no call to create a world of 'reality’ de novo, nor to delve into secrets of Being hidden from common sense and science." ${ }^{110}$ That philosophy is not a fictional genre should hardly surprise us, but Dewy uses this commonplace as platform to attack the conception of philosophy as having a “stock of information or body of knowledge peculiarly its own.",111

"Its business is to accept and to utilize for a purpose the best available knowledge of its own time and place.”112 This is no awkward echo; Arnold’s voice returns here with astonishing force and clarity. "I talk,” said Arnold, “of knowing the best which has been thought and uttered in the world.”113 Like literature, philosophy must make use of that great sphere of contextual knowledge that surrounds and inhabits our thoughts and of that knowledge it must make choice, it must discriminate. "To pass beyond direct occurrence, even though the passage be restricted to an attempt to define value, is to begin a process of discrimination which implies a reflective criterion.”114 
But who, we ask, is to say which is the best? Who is to perform this act of discrimination? I suspect, Arnold and Dewy would have answered these questions differently, but I am not so sure that they would have pointed us in radically different directions. Arnold maintained more than a little faith in the canonical, however not so much as his current followers and detractors would suggest. He knew all too well that the canon was malleable. He had not, as we saw above, completely thrown out historicity and its relativism. He knew the canon ${ }^{\mathrm{u}}$ changed, but did not expect that its changes were so gross as one expects Dewey would have found them. Dewey, I am quite sure, would have said that the existence of a canon, be it of literature, or science, or social reform, is a moot point. That such canons exist is irrelevant beside the more pressing question of how they come into being, and more importantly what role they play in human thought and philosophical criticism. I think he would have concurred with Fish that we form interpretive communities that formulate, in a very loose sense, the canons of thought which we use to enable our interpretations,_- although I am quite sure that Fish would be more than a little scandalized at my suggestion that he would in any way favor a canon of any sort, as the word canon has become today a distinctly political hot button. Canon is a hard term; it does possess an implication of solidity, of immutability, and for many today it has come to imply an oppressive tendency, a tendency to deny access to the marginalized of society. The danger, pointed out by many before me, is that, absent a

\footnotetext{
${ }^{\text {u }}$ Here we may treat canon as a broad category of those thoughts and utterances from which a group of thinkers, a culture, a society draw some portion of their conception of value; post-modernism possesses a canon, amorphous and dynamic, but we must suspect that all canons bear such qualities to some degree or another. When Dewey says, "the best available knowledge of its own time and place," he creates such an informal canon.
} 
conception of the canonical, the danger will be that new canons will be instituted and become dogmatically held before their canonical qualities are quite realized.

\section{Conclusion}

While it is not our purpose here to determine the nature of the canonical, reflecting upon its existence,_- its inevitable existence, I would suggest,_- leads us to the issues we shall have to deal with in the next chapter.

Certainly a capacity for discrimination exists at the level of the self; we all may decide what it best and what is worst for ourselves, we may make our lists and publish them to the world. But as Fish suggests something larger is going on,- - a kind of interpretive community exists in which we perform our critical activities. The voice of the other is present, and will be heard, no matter how we may wish to dismiss it, no matter to what degree we are certain that our own individuality immunizes us and grants us the special privilege of knowing our own mind and going our own way, of "doing as one likes"115 as Arnold so aptly put it.

What we take from this chapter is a sense of how practical criticism functions,its use of theory as a means, not an end,- - its waking judgment that insists upon a certain consciousness of experience and its constituent parts,- - its hermeneutic and rhetorical fluency, willing to move back and forth between reader and writer, interpreter and persuader,- its ability to unite a broad tolerance to a profound skepticism of authority. All of these we will attempt to bring together in the following chapters. 


\section{Notes}

${ }^{1}$ Arnold and Allott (editor), "Resignation: To Fausta,” pg. 89-90.

${ }^{2}$ S. Morris Eames, Introductory material, Dewey, pg. ew.3.xxxvii.

${ }^{3}$ S. Morris Eames, Introductory material, Dewey, pg. ew.3.xxxvii.

${ }^{4}$ George Watson, The Literary Critics, 1962, Baltimore: Penguin.

${ }^{5}$ Watson, The Literary Critics, 1962, pg. 12.

${ }^{6}$ Watson, The Literary Critics, 1962, pg. 13.

${ }^{7}$ Dewey, Experience and Nature, 1925, pg. lw.1.298.

${ }^{8}$ Watson, The Literary Critics, 1962, pg. 39.

${ }^{9}$ Watson, The Literary Critics, 1962, pg. 63.

${ }^{10}$ Alexander Pope, Essay on Criticism, 1711 (written 1705-9, Watson's note), 1l. 119-23, quoted in Watson, The Literary Critics, 1962, pg. 63.

${ }^{11}$ Watson, The Literary Critics, 1962, pg. 63.

${ }^{12}$ Watson, The Literary Critics, 1962, pg. 81.

${ }^{13}$ Watson, The Literary Critics, 1962, pg. 95.

${ }^{14}$ Watson, The Literary Critics, 1962, pg. 95.

${ }^{15}$ Watson, The Literary Critics, 1962, pg. 97.

${ }^{16}$ Watson, The Literary Critics, 1962, pg. 97.

${ }^{17}$ Watson, The Literary Critics, 1962, pg. 98.

${ }^{18}$ Watson, The Literary Critics, 1962, pg. 99.

${ }^{19}$ Watson, The Literary Critics, 1962, pg. 104.

${ }^{20}$ Watson, The Literary Critics, 1962, pg. 114.

${ }^{21}$ Watson, The Literary Critics, 1962, pg. 111-112.

${ }^{22}$ Watson, The Literary Critics, 1962, pg. 117.

${ }^{23}$ Watson, The Literary Critics, 1962, pg. 113.

${ }^{24}$ Watson, The Literary Critics, 1962, pg. 112.

${ }^{25}$ Dewey, Art as Experience, 1934, pg. lw.10.272.

${ }^{26}$ Dewey, Art as Experience, 1934, pg. lw.10.11.

${ }^{27}$ Watson, The Literary Critics, 1962, 131.

${ }^{28}$ Charles Lamb, Selected Prose, 1985, Adam Phillips (editor), pg. 202; from the essay "Sanity of True Genius,” first published New Monthly Magazine, May 1826.

${ }^{29}$ Charles Lamb, Selected Prose, 1985, Adam Phillips (editor), pg. 202.

${ }^{30}$ Dewey, Ethics, 1908, pg. mw.5.246.

${ }^{31}$ Dewey, Art as Experience, 1934, pg. lw.10.287-8.

${ }^{32}$ Dewey, Liberalism and Social Action, 1935, pg. lw.11.19.

${ }^{33}$ Dewey, Liberalism and Social Action, 1935, pg. lw.11.19.

${ }^{34}$ Watson, The Literary Critics, 1962, pg. 141.

${ }^{35}$ Quoted in Watson, The Literary Critics, 1962, pg. 141.

${ }^{36}$ Watson, The Literary Critics, 1962, pg. 141.

${ }^{37}$ Quoted in Watson, The Literary Critics, 1962, pg. 141.

${ }^{38}$ Watson, The Literary Critics, 1962, pg. 141; "tend to disappear" is footnoted to W. K. Wimsatt and Monroe C. Beardsley, “The Affective Fallacy,” Sewanee Review, lvii (1949), reprinted in Wimsatt, The Verbal Icon (Lexington, Kentucky, 1954).

${ }^{39}$ Watson, The Literary Critics, 1962, pg. 142.

${ }^{40}$ Watson, The Literary Critics, 1962, pg. 160.

${ }^{41}$ Watson, The Literary Critics, 1962, pg. 154.

${ }^{42}$ Collini, Arnold, 1988, pg. 1.

${ }^{43}$ Watson, The Literary Critics, 1962, pg. 144. 


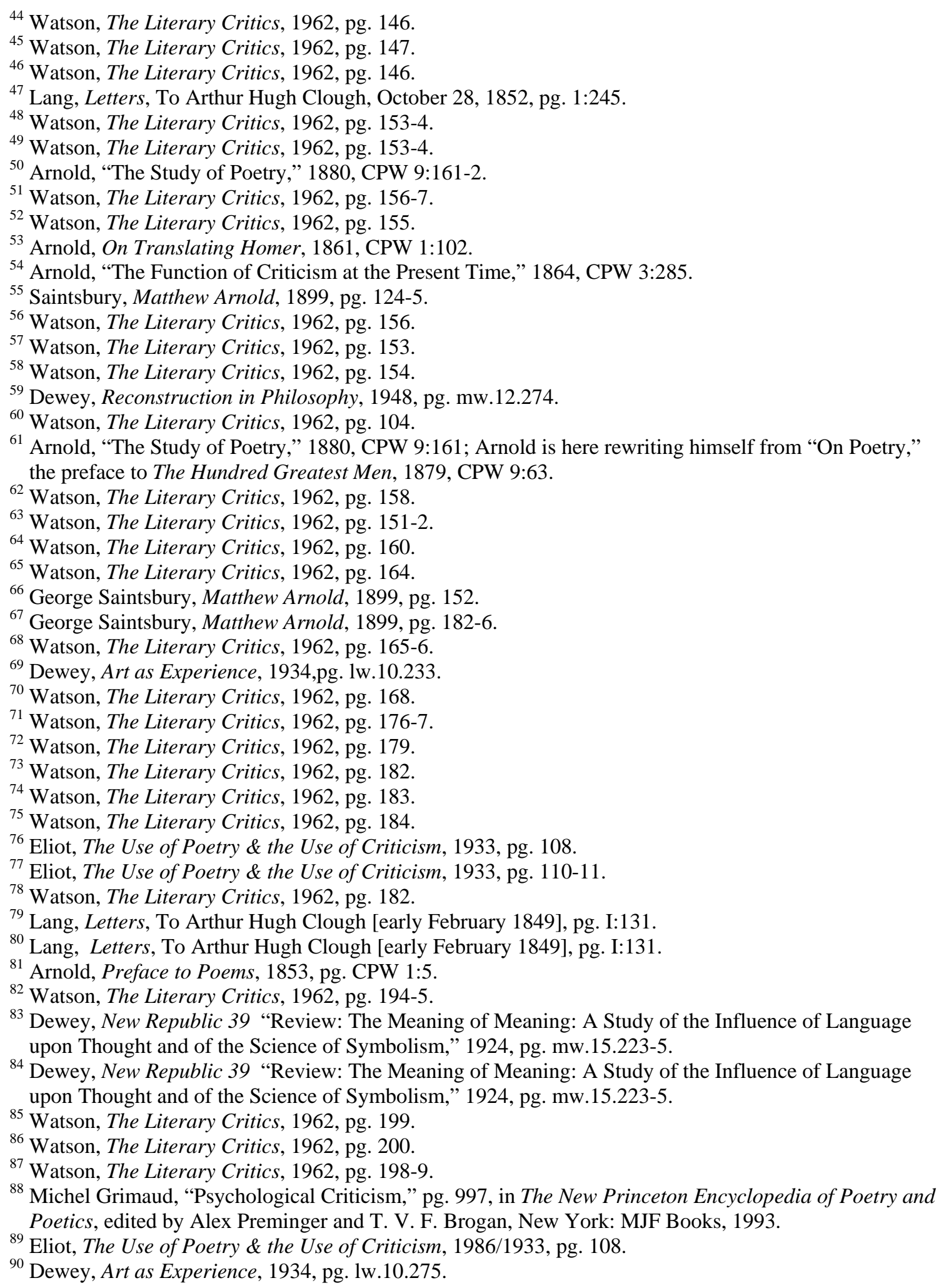


${ }^{91}$ Dewey, Experience and Nature, 1925, pg. lw.10.255.

${ }^{92}$ Cleanth Brooks and T. V. F. Brogan, “The New Criticism,” pg. 832, in The New Princeton Encyclopedia of Poetry and Poetics, edited by Alex Preminger and T. V. F. Brogan, New York: MJF Books, 1993.

${ }^{93}$ Cleanth Brooks and T. V. F. Brogan, "The New Criticism," pg. 833, in The New Princeton Encyclopedia of Poetry and Poetics, Alex Preminger and T. V. F. Brogan (editors), 1993.

${ }^{94}$ Cleanth Brooks and T. V. F. Brogan, "The New Criticism," pg. 834, in The New Princeton Encyclopedia of Poetry and Poetics, Alex Preminger and T. V. F. Brogan(editors), 1993.

${ }^{95}$ Cleanth Brooks and T. V. F. Brogan, "The New Criticism," pg. 834, in The New Princeton Encyclopedia of Poetry and Poetics, Alex Preminger and T. V. F. Brogan(editors), 1993.

${ }^{96}$ Arnold, Literature and Dogma, 1873, CPW 6:179.

${ }^{97}$ Leitch (general editor), The Norton Anthology of Theory and Criticism, 2001, pg. 2069.

${ }^{98}$ Note from Leitch (general editor), The Norton Anthology of Theory and Criticism: A Varorium Commentary on the Poems of John Milton, general ed. Merritt Y. Hughes, 4 vols. (New York: Columbia University Press, 1970-75).

${ }^{99}$ Fish, "Interpreting the Varorium," 1976, 1980, in Leitch (general editor), The Norton Anthology of Theory and Criticism, 2001, pg. 2073.

${ }^{100}$ Fish, "Interpreting the Varorium," 1976, 1980, in Leitch (general editor), The Norton Anthology of Theory and Criticism, 2001, pg. 2083.

${ }^{101}$ Dewey, Experience and Nature, 1925, pg. lw.10.255.

${ }^{102}$ Fish, “Interpreting the Varorium,” 1976, 1980, in Leitch (general editor), The Norton Anthology of Theory and Criticism, 2001, pg. 2087.

${ }^{103}$ In Menard, Pragmatism a Reader, 1997, pg. xx.

${ }^{104}$ Arnold, "Wordsworth," 1879, CPW 9:46.

${ }^{105}$ Dewey, Experience and Nature, 1925, pg. lw.1.159.

${ }^{106}$ Dewey, Experience and Nature, 1925, pg. lw.1.298.

${ }^{107}$ Dewey, Experience and Nature, 1925, pg. lw.1.299-300.

${ }^{108}$ C. P. Snow and Stefan Collini (editor), Two Cultures, 1959/1993.

${ }^{109}$ Dewey, Experience and Nature, 1925, pg. lw.1.304-5.

${ }^{110}$ Dewey, Experience and Nature, 1925, pg. lw.1.305. One cannot but smile at Dewey's linking of metaphysical concerns with fictional realities.

${ }^{111}$ Dewey, Experience and Nature, 1925, pg. lw.1.305.

${ }^{112}$ Dewey, Experience and Nature, 1925, pg. lw.1.305.

${ }_{113}$ Arnold, "Literature and Science", 1882, CPW 10:58.

${ }^{114}$ Dewey, Experience and Nature, 1925, pg. lw.1.297.

${ }^{115}$ Arnold, Culture and Anarchy, 1869, CPW 5:115. 
From Dover Beach

Ah, love, let us be true

To one another! for the world, which seems

To lie before us like a land of dreams,

So various, so beautiful, so new,

Hath really neither joy, nor love, nor light, Nor certitude, nor peace, nor help from pain;

And we are here as on a darkling plain Swept with confused alarms of struggle and flight, Where ignorant armies clash by night.

-Matthew Arnold ${ }^{1}$

\section{The Intentional Mind}

We have seen, so far, how the mind when reaching out into the world of objects can, using Dewey’s extraordinary image, take on the character of a tentacled mind apprehending its surroundings in a nearly physical way. Dewey pushed us to see the mind and body as inseparable, challenged us to move past the Cartesian dubiety in which the mind consists of abstracted thoughts walled off in a vacuum of intellect held at a distance from the world by our imperfect senses. However, as we began to explore this world of objects, we became aware that some objects bore the signs of other minds and bodies at work, - minds which had acted with apparent intentionality. This led us to explore the practical necessities of the critical mind,- - a mind that was wakeful and reasoning; a mind that sought to explain itself even as it explained the world its tentacles had apprehended; a mind that trusted its own emotive response, but not so far as to think that that emotive response did not require demonstration; a mind not entirely shaped by 
theoretical abstractions, but not entirely alien to theory either; a mind in which the particular had equal relevance with the general; a mind that appealed to some sense of commonality,— to a common reader, a general opinion, a trusted source, an interpretive community, perhaps even a universal truth,_- but a mind that could, as easily, set general opinion aside and declare its own rationale and meaning; a mind, finally, that must bear the burden of judgment,_- its own and that of others.

With these critical qualities in place, we now take the difficult but necessary step of traveling past the object and confronting the intentions that lie beyond it.

\section{The Fable of the Rock}

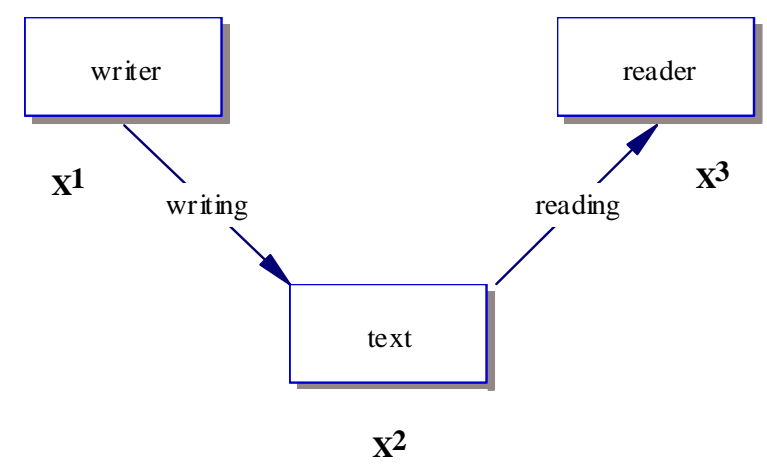

Illustration 2: A simple model for understanding the systemic relationships implicit in any hermeneutic analysis.

Returning to the hermeneutic model (Illustration 2) introduced several chapters ago, we can now map the leap that Dewey's tentacled mind makes with a little more precision. When he tells us that the mind reaches its tentacles out and encounters the world, he is referring to the relationship between $X^{2}$ and $X^{3}$. He grants to the text a meaning, $\mathrm{X}^{2}$, but not an author. To get to an author we must follow the diagram back and attempt to discern from the author an intention, $\mathrm{X}^{1}$. Now if the text we are looking at is, 
for example, a large rock,- let us make it a very large rock, a boulder, and it is sitting in the middle of a road down which we wish to travel,- - the meaning of that large rock, to the tentacled mind, might be, 'I must circumvent this rock to get to my destination which lies on the other side of the rock.' The author of the rock's meaning in this case is reflective back to the self,- - interpretation and meaning are one and the same (when we look at reader response theory, this is the condition we are dealing with). The reader observes the rock and assigns a meaning, $\mathrm{X}^{2}$, to the rock,- meaning in this case being, 'this rock is an obstacle to be circumvented.' Only in a fable would we ask of the rock, "Why have you blocked my way? What is it you intend by being an obstacle to my progress?”

The confusion here between author and reader has created quite a number of intractable philosophic problems to some of which we have already witnessed Dewey's response. He would tell us that to have authored the thought "this is an obstacle" is not the same as having conjured up the obstacle itself. Dewey's notion of the tentacle mind is helpful here in that it suggests how intimate the thought and object are and preserves us from more finicky notions of metaphysical relationships and diaphanous traces. The object need not disappear simply because a meaning had been "assigned" to it by the reader. And no matter to what extent the meaning is personal to the reader, the object must continue to participate in that meaning,- that is to say, were there no rock, then there would be no obstacle, and the statement "this rock is an obstacle" would be wholly meaningless. 
Now suppose we wanted to search for further meaning, for some measure of the existence of the rock, for its ontological "being," - this would involve moving past the immediate capacity of the tentacled mind. To seek such meaning is to seek an author for the rock and to ask that author, "What is your intention? When you made this rock, what did you mean by it? And why did you place it in my path?” Such questions lead to teleology, - and, often, to a conception of a god or god-like being, particularly when we are dealing with an object which has no other foreseeable author,_- what I will call an "unauthored object;" — for those comfortable with the idea of a divine creator, this would be a "divinely-authored object." The unauthored object is a unique quantity in hermeneutics; it defies our model and seems wholly without intention. Certain aspects of our conception of God seem to have come about in an effort to fill this gap; to provide for the authorship of the many apparently unauthored objects that exist in the world encountered by our tentacled minds. When we speak of God the creator we are in this mode of thought. Both Arnold and Dewey in their conceptions of God attempted to remove this supernatural aspect from the idea of God. We shall deal with that concern more fully in the final chapter. For now we need to recognize that the unauthored object causes some real problems for us. We have seen already how we are inclined to assign meaning to an object; and we have seen three possible ways of comprehending that meaning. In one case, the meaning resides entirely within the object, and we find ourselves seeking authorship and intentionality within the object,_- often finally resting that authorship in something supernatural or divine. In the second case, we place all of the meaning in the mind of the observer to the extent that the object becomes an 
irrelevancy. We can equate this to some degree with reader response theory,recognizing that writer's like Fish perceive a more complex and dynamic character to meaning, but nonetheless, are inclined to dismiss the object from any participation in that meaning. In the third case, we assign a portion of the meaning to the object and a portion to the observer's inference, while recognizing that in both cases the meaning is dependent upon both. This final version is harder for us to put our finger on, because it is not passive. The other two views are to some degree passive,- - but with Dewey meaning occurs within the interaction between mind and object, and so is present in both while at the same time being entirely dependent upon the active interaction between them.

Now, let us take the same rock and fashion a different fable out of it. A young woman in search of adventure is following a trail through a mysterious and unexplored country. She comes upon a large rock in the midst of the trail; mountains block her progress upon either side. A giant steps forward and looks menacingly at the young woman. "Why," asks the young woman, "have you placed this rock in the trail?" "Only I am large enough to move the rock," says the giant, “you must pay a toll, or I will not move the rock, and it is many days journey around these mountains.”

The tentacled mind can reach out, but only the mind in congress with another mind can fathom a solution to the problem. This rock does, indeed, have an author, and that author, in our fable, is a fabulous giant; more modestly he might be the toll-taker on a toll-road, the bureaucrat behind a desk, the clerk at the teller's window, the teacher in front of the class, the boss in his corner office. No supernatural imaginings need confound us here. Quite simply, to solve the problem we must reach out the tentacles of 
our mind to the object, recognize the nature of the object, $\mathrm{X}^{2}$, and then press beyond the object to its author, from whom we must seek an understanding of that author's intention, $\mathrm{X}^{1}$. From these we can form an inference, $\mathrm{X}^{3}$, which may lead to a solution to our problem. In other words we have to recognize that the rock is an obstacle, $\mathrm{X}^{2}$; understand that the obstacle has an author, and seek to understand the author's intention that we must pay a toll, $\mathrm{X}^{1}$; and formulate an inference, $\mathrm{X}^{3}$, to wit, pay the giant, travel round the mountain, trick the giant in good fable-like fashion, or slay the giant David and Goliath style, which is probably the least wise measure since it leaves our adventuress on the wrong side of an unmovable rock,- - but we shall leave all of that to the tellers of tales.

A sort of protracted movement occurs when we present the full intercourse between the giant and the young woman. The rock and the giant's speech are both part of the initial text the meaning of which is 'an obstacle here has an author in this giant who means by this obstacle that a toll must be paid for the obstacle to be removed.' As a conversation ensues between the young woman and the giant, they trade places as author and reader, - a sort of ping-pong effect from $\mathrm{X}^{1}$ to $\mathrm{X}^{2}$ to $\mathrm{X}^{3}$, after which $\mathrm{X}^{3}$ becomes an $\mathrm{X}^{1}$ and the process continues. We call this dialog. In the last chapter, we saw that in such a movement we find a ready mixture of hermeneutics, interpretation, and rhetoric, persuasion. Kathy Eden in an essay entitled "Hermeneutics and the ancient Rhetorical Tradition" begins by pointing out that "Schliermacher, often considered the father of modern hermeneutics, notes in his 'Outline for the 1819 Lectures' that 'The unity of hermeneutics and rhetoric results from the fact that every act of understanding is the obverse of an act of discourse.,"2 She concludes that "the division between legal and 
stylistic strategies of ancient rhetoric and hermeneutics will develop into an opposition; and this opposition will shape the history of interpretation theory through the Renaissance.”3 And we might comfortably add that that opposition remains in place today.

Now, we spoke earlier of something called the unauthored object. We note that when the mind reaches out toward such an object it seeks meaning in the nature of that object, and assigns that meaning to the object. That assignment of meaning, as we noted, exists both in the object and the mind, and most particularly in the activity of observation that uncovered the meaning. We might describe such a process scientific. I will also refer to this as the half journey, because if we look at our hermeneutic model we will see rather quickly that it consumes only half of the model. Now admittedly, with an unauthored object nothing exists on the other side of the model,- - we have no writer and no perceivable intentionality.

Now suppose we are dealing with a recognizably authored object, say a poem,-and not one of those poems written by that room full of monkeys who are studiously attempting Hamlet. Meaning now has three assignable nodes,_- the reader, the text and the writer. The new critics, with something of an eye toward science, I believe, opted for the half journey,- - they went out to the text and stopped. The author was out of bounds, because, as they had learned from science, to move past the object to the author was to move toward something unknowable, perhaps even supernatural. Thus, the intention of the author being unknowable need have no affect on the reading of the poem. Again following science, which insisted on the objectness of the object, the affect of the reader 
was also an irrelevancy. Reader response theory later came along and declared that the affect of the reader was alone relevant since the poem itself, with an equal appeal to the objectness of objects, could not contain any meaning, and, therefore, the new critic had been deluded in finding any meaning in the poem at all. Meaning, clearly had been created by the reader, the poem was incidental to the whole process, and, of course, by this time the author had been forgotten altogether. If the scientific approach was a necessary half journey, one cannot but wonder that the reader response is no journey at all.

The whole journey, from reader to author and back, is what will concern us here. We may as well let literary criticism go where it may, but for the human sciences our concern must always be with one singular concern, how does a thought move from one mind to another? And we must go the whole journey to discover the nature of that movement.

\section{Arnold's Hermeneutics}

In an easily overlooked passage of Culture and Anarchy, Arnold presents a crisp, hermeneutic argument,- - almost a hesitant appeal rather than a persuasive exclamation; in it he deploys a single word that draws him toward pragmatism in his own unique way and sets him beyond the pale of Humean skepticism. That single word is "near."

...perfectly to seize another man's meaning, as it stood in his own mind, is not easy; especially when the man is separated from us by such differences of race, training, time, and circumstances as St. Paul. But there are degrees of nearness in getting at a man's meaning; and though we cannot arrive quite at what St. Paul had in his mind, yet we may come near it. ${ }^{4}$ 
"Near.” Not exact, not perfect, merely “near.” The movement of a thought from one mind to another may never be perfect, but perhaps we may approach to "nearness." Metaphysics, ontology, teleology, classical logic and a great host of other scholarly studies each in its own way is a tribute to the subtlety and evasiveness of the human mind. Epistemology has, today, been reduced to a cartoon battle of positivistic absolutes and metaphysical traces. ${ }^{5}$ But the movement of thought from mind to mind remains a curious beast, untamed and unrepentantly present in those casual experiences that Dewey believed were the most important aspects of modern philosophy. We might join Samuel Johnson and kick a stone in attempt to relieve ourselves of Berkeley's and Hume’s dubiety, ${ }^{6}$ or we might join Dewey in overleaping the limits of our perceptions with our octopus-tentacle minds. But this movement of thought from mind to mind with its necessity of traveling through the hard, casual world, and its penchant for baffling even the most commonsensical and empirical amongst us remains at the core of philosophical enquiry, whether that enquirer wishes to be traditionally metaphysical, radically poststructural, or pragmatic and worldly.

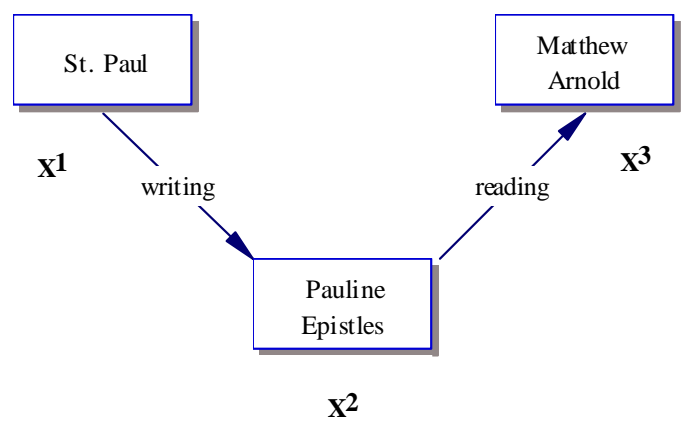

Illustration 3: Arnold and St. Paul. 
The problem that Arnold addresses here is, nonetheless, easily diagrammed (see Illustration 3). In this diagram, St. Paul appears in the left-hand box; his thoughts or intentions are represented by $\mathrm{X}^{1}$. Arnold's understanding of St. Paul is shown on the right-hand side and is labeled $\mathrm{X}^{3}$. Standing between the two are the texts of the Pauline epistles. The problem that Arnold raised is whether it is possible to "seize another man's meaning, as it stood in his own mind.”

Continuing in our systematic approach, let us rephrase this problem as something of an algorithm. Again, $\mathrm{X}^{1}$ represents St. Paul's intention, “as it stood in his own mind.” $\mathrm{X}^{2}$ represents the texts of the Pauline epistles. $\mathrm{X}^{3}$, then, represents Arnold's inferences from reading these texts.

What, asked Arnold, is the relationship between $\mathrm{X}^{1}$ and $\mathrm{X}^{3}$ ? Given the “differences of race, training, time, and circumstances," can the thoughts of Paul, $\mathrm{X}^{1}$, ever come to equal the thoughts of one of his readers, $\mathrm{X}^{3}$, so many years on? Our initial response must be, no. No, they cannot be equal.

Does it follow then that $\mathrm{X}^{1}$ and $\mathrm{X}^{3}$ are unequal? Is the distance from one man's mind to another's so great? Is the divide that Hume described between a man's mind and a billiard ball doubled when we move through that object (in this case the texts of the Pauline epistles) and try to discover the intention of its author?

Well, says Arnold, “...perfectly to seize another man's meaning, as it stood in his own mind, is not easy." However, "though we cannot arrive quite at what St. Paul had in his mind, yet we may come near it.” 
In other words, if we were to state our problem as an algorithm, we would reject $X^{1}=X^{2}=X^{3}$; but at the same time, we would think $X^{1} \neq X^{2} \neq X^{3}$ too emphatic and too suggestive that the divide is utterly impassable.

$\mathrm{X}^{1} \cong \mathrm{X}^{2} \cong \mathrm{X}^{3}$, then, must be our only choice (reading this as $\mathrm{X}^{1}$ is congruent to or near to $\mathrm{X}^{2} ; \mathrm{X}^{2}$ is congruent or near to $\mathrm{X}^{3}$ ); and, by the commutative law of the Deweyan leap, $\mathrm{X}^{1}$ is congruent or near to $\mathrm{X}^{3}$.

But congruence is not a given. It requires effort; as Arnold tells us, it "is not easy;" it requires a reader who is disinterested (desirous of knowing from multiple points of view, that is to say of knowing the minds of others whether or not doing so is in the reader's own interest, or more vulgarly, the reader is just downright curious) and who is willing to engage in a "free play of mind" (willing, that is to accept the uncertainty that the intentional fallacy rather categorically dismisses when it declares emphatically that the intention of the author is so unknowable as to make any discussion of authorial intention irrelevant and, in any event, utterly déclassé).

While today most of the efforts in hermeneutics tend to focus on the right-hand side of this equation, neither Arnold nor Dewey were comfortable with the subjectivism implicit in overstating the reader's role in the equation. In Dewey, the leap past the limitation of the senses to an essential intimacy with the object, the text, the thing, was necessary to human understanding. "Meaning," he constantly told us, was the result of that experience, of that intimacy with the object world that comes from trial (ex-peri-). Subjectivism he understood as the unrewarding product of our callous separation of mind 
and body. Moreover, Dewey insisted that our understanding is invariably social, not individual.

Equally, for Arnold, the author was not dead (one cannot even imagine him expressing such a thought); the author's intention was real and relevant, the text was a valued intermediary, and the reader’s imagination, “the free play of mind,” essential. Arnold's criticism depended upon a balancing of all three elements: writer, text and reader. Much as Dewey laments the dualism of mind and body, we can readily picture Arnold, were he alive today, wondering what misbegotten metaphysics had led us to sever writer from text, text from reader, and reader from reality.

Arnold's was not a simple, posited world in which, upon a whim, we may have “things as they really are,”- for Arnold, seizing another’s thoughts, understanding the intention of the writer, "is not easy ... yet we may come near it.” And Arnold insisted upon a critical role for the reader whose "free play of mind” enabled the process, allowed an approach to "nearness.” Arnold made his own rather triumphant leap, although admittedly he did so before our agnosticism had grown so round as to doubt the possibility of authorial meaning. He simply tells us "we may come near it" and in his simple conception of "nearness" we have all we need to overcome the waywardness of our dubiety, provided we are willing and capable of handling the uncertainty within which Arnoldian criticism inevitably deposits us. ${ }^{\text {a }}$

\footnotetext{
a Much has been made of Arnold's critical method and critical judgments as a continuation of a kind of criticism that is overly sure of itself, dogmatic, and parochial. I little doubt that Arnold can at times come across as much too cock-sure and prepossessing, but Arnold's irony and playful method cut against his own attempts at certainty. Moreover, as Dewey well understood, the Arnoldian critical method and critical judgment are necessary for any attempt to deal with a world of uncertainty.
} 
In other words, the movement of thought between two minds, which is the ultimate problem of all human science, requires that we address the following:

1) The capacity for the mind to overcome the limits of perception; neither hermeneutics nor rhetoric can make anything out of an isolated mind. The Deweyan leap, the tentacled mind, addresses this issue.

2) The existence of a text, an intermediary; no amount of dubiety can set aside the necessity of some conception of the real qua real,-_ of a mechanism for moving thought from one mind to another, no matter how imperfect such a mechanism must inevitably be.

3) Things (texts) have an intimate relationship to thought; the thing is the grit of sand (Arnold's salt), the thought the pearl that forms about it. That relationship is inherently active and not passive,- - its memorial movement into knowledge can be a bit confusing, but this intimate relationship between things and thought is fundamental to the movement of thoughts between minds, - we think back to the Gnostic God who needed something to think about in order to have a thought.

4) The meaning of a text is sufficient and needs no recourse to an author, but only if we do not ask of the text, 'why do you exist?' The half-journey $\left(\mathrm{X}^{3}\right.$ to $\mathrm{X}^{2}$ ) is a modest measure that has produced much that is good. Without recourse to Dewey, "science” has obstinately availed itself of the Deweyan leap, assuring itself that nothing relevant stands upon the other side of meaning. Human sciences cannot be so sanguine. 
5) When texts have human authors, the method and art of human science is to understand the path from $\mathrm{X}^{3}$ to $\mathrm{X}^{2}$ to $\mathrm{X}^{1}$ and back. In other words, the human sciences depend upon the full measure of the hermeneutic model. In all of the human sciences, we have a reader with an interpretation, a text with a meaning, and an author with an intention.

6) The hermeneutic model reveals the essential uncertainty of all human understanding. We cannot ever have the perfect equation $\mathrm{X}^{1}=\mathrm{X}^{2}=\mathrm{X}^{3}$; authorial intention cannot equal textual meaning cannot equal reader inference. But, as Arnold tells us, we can nonetheless, come "near". If human science is to be a science at all, then it is concerned with approaching

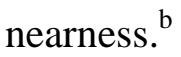

7) The hermeneutic model, in admitting the author, admits authority. No real understanding of hermeneutics can come from denying authority, nor from any romantic demonization of the author. Authority must find its just expression in the sciences, or they are doomed to be no science at all. Neither the zealot's recourse to dogma, nor the anarchist's desire for an absolute freedom of the self can function in any fluent way as a method or model for understanding authority.

8) Finally and perhaps most importantly, the method of hermeneutics is active and additive, which is tantamount to saying it is educative. The half-journey

\footnotetext{
b I am reminded of the old saw that 'close only counts in horseshoes and hand grenades.' Now as 'close' is 'perfection' in all things hermeneutic, and as the whole of the human sciences are hermeneutic in nature, then I wonder which of the two is our better metaphor: the backwoods sport of carousing philistines, or the disorienting missile of militant violence?
} 
from $\mathrm{X}^{3}$ to $\mathrm{X}^{2}$ depends, within the confines of its singular observation, upon no movement of thought from one mind to another. As Hume told us, "even after I have had experience of many repeated effects of this kind, there is no argument, which determines me to suppose, that the effect will be conformable to past experience.” ${ }^{\text {’c }}$ The experience he speaks of, the observation of the billiard ball striking its mate, is an experience of the $\mathrm{X}^{3}$ to $\mathrm{X}^{2}$ variety. An experience that follows from $\mathrm{X}^{3}$ to $\mathrm{X}^{2}$ to $\mathrm{X}^{1}$ and returns upon itself, $\mathrm{X}^{1}$ to $\mathrm{X}^{2}$ to $\mathrm{X}^{3}$, has a very different effect. The relationship between a human observer and an object is not on the same order as the relationship between a human observer and a human actor. If we deny intentionality to the actor, then the observer has his or her inference alone upon which to establish meaning. When we grant the actor (or author) intentionality, the observer must inevitably determine a relationship to the actor,-— superior, equal to, or inferior. If superior to the actor, then nothing about the actor really can be learned; the actor is no more than another billiard ball incongruously smacking its mate. If inferior, the neuroses of authority in the worst sense of

\footnotetext{
${ }^{\mathrm{c}}$ Although most of us do precisely what Hume suggests, we have no reasonable ground for doing so. We assume that when one billiard ball strikes another the second ball will move,-_ and generally speaking we are not at all wrong to imagine such a causative facility is present in the world. Thus the movement from $\mathrm{X}^{3}$ to $\mathrm{X}^{2}$ is, indeed, educative. As Dewey often pointed out (he showed an odd favor for this rather sadistic little example) a child reaches toward a flame, burns itself and learns that the flame burns. Had the child reached forward to touch the flame and been stopped by its mother who then directed the child not to touch, this experience, which requires the fuller hermeneutic cycle, might well have not produced the necessary effect. Some things, perhaps, require the individualized discovery in which the individual engages the brave surface of the world with his or her tentacled mind. But as we shall see, the half journey that Dewey perhaps overly insisted upon is insufficient. The child must make discoveries on the other side of the object, must move past the $\mathrm{X}^{2}$ to understand the in and outs, ups and downs of authorship, for the world we live in is made up of objects with living breathing authors with whom we must learn to communicate. The surface alone can tell us only so much.
} 
the word come into play. As the two, observer and actor, approach equality a movement between them becomes not only possible, but, perhaps, inevitable. Ultimately, even the half-journey stands within the context of the full hermeneutic model. The half-journey from $\mathrm{X}^{3}$ to $\mathrm{X}^{2}$ is impossible, as science, if we attempt to conduct it outside of the greater dialogue of language,_- Fish's interpretive communities; it depends for its leap across the perceptual void upon a constant intercourse with others. ${ }^{\mathrm{d}}$ Science all too often diminishes authorial intention out of a fear of the uncertainty and subjectivity that comes with any conjecture of what goes on behind another person's brow, or a fear that all such speculation can only lead to superstitious teleology. Human science, as we have learned through the limitations of behavioralism, cannot follow the same course. And education is nothing if it is not a human science.

$$
\text { Co3 } 80
$$

Let us return to the rock standing in the middle of the road. With Dewey's help we have stepped past the obstacle of the senses, but the problem still sits there before us, - a great rock in the middle of our path. No fairytale giant will step out to remove it for us. We have only our own resources, our own capacity to reason, to understand,- to act. Do we push upon the rock never heeding that it will not budge; do we alter our path; do we elicit the aid of others; do we forego our journey; do we wait for some divine agency to roll away the stone? Both Dewey and Arnold understood that the problems we

\footnotetext{
${ }^{\mathrm{d}}$ Louis Menand in The Metaphysical Club (2001) demonstrates how American pragmatism was founded upon the statistical necessities of taking multiple measurements in sciences (such as astronomy) in order to establish the reasonable, statistical center, and thus the most probably accurate answer. Science is full of such intriguingly collaborative methods of overcoming the limitations of the senses and, for that matter, of the hermeneutics of the movement of thought from one mind to another.
} 
confront in experience demand a critical ability. Dewey moves our minds out into the world, but he does not expect that, in doing so, we have magically solved all our problems. We have simply shifted the center of the problem. The limitations of our senses, our intellectual biases, our capacity to apprehend the world, even the arbitrariness of our language $\mathrm{e}^{\mathrm{e}}$ - - all of these limitations, which have made hermits of our modern thought, remain active, even if they no longer have quite the isolating effect they traditionally have had.

Arnold and Dewey both recognized that a process of criticism is necessary if the mind is to function effectively within these complex boundaries. As Dewey says, Immature and undisciplined mind believes in actions which have their seat and source in a particular and separate being, from which they issue. This is the very belief which the advance of intelligent criticism destroys. The latter transforms the notion of isolated one-sided acts into acknowledged interactions. The view which isolates knowledge, contemplation, liking, interest, value, or whatever from action is itself a survival of the notion that there are things which can exist and be known apart from active connection with other things. ${ }^{7}$

\footnotetext{
e The reference to arbitrariness in language is to Saussure. A central tenant of Saussure's theories was that the sound components of language,_- which Saussure called "phonemes",_ are "arbitrary;" they have no meaning beyond their sound and the meaning we associate with that sound has been assigned in a purely arbitrary fashion. To clarify this, the word "cat" contains three phonemes "c-a-t" which correspond not to the letters but to the sounds that the letters represent. Saussure confuses two things here, the initial act of associating a sound with a phoneme, and the recollection of that association,_- in other words the initial association may have been arbitrary, but as the meaning continues from one individual to another, it ceases to be arbitrary and becomes, to the contrary, conventional. While this arbitrary quality in language (and phonemes are not alone the only arbitrary elements of language) may affect the efficacy of language in carrying meaning, we cannot say (as though arbitrariness were a sort of magical quality that confers its inconsequence upon all it touches) that language may be wholly characterized as arbitrary. It must be to some great degree the very opposite of arbitrary; it must be intentional and communal, for these are the functions that make it a language,_- language we might say is Fish's interpretive community writ large. Our language may be a war zone between the arbitrary and the conventional, but this does not leave us without some hope that, despite what arbitrariness our language may bear, we may approach or come near to meaning. Language is to my mind the perfect example of pluralism; neither continuous nor anarchic, it depends upon what efficacy it has on the contiguous connections that hold it together. See Ferdinand de Saussure, Course in General Linguistics, 1983.
} 
When we turn to our discussion of the reflective mind we shall gain a greater insight into what Dewey means when he says that "knowledge, contemplation, liking, interest, value” have no separable existence. For now let us just say that by reflection neither he nor Arnold mean that traditional hermit-like creature we call "contemplation;" that "knowledge” is knowledge of things not of evanescent ideals; that "liking, interest, [and] value" derive their necessity from our immediate experience, and without that experience they have no real, tenable existence. We shall see that universals, far from disappearing in Dewey’s philosophy, take on a different character than we generally incline to give them:

Orders, relations, universals are significant and invaluable as objects of knowledge. They are so because they apply to intensive and extensive, individualized, existences; to things of spacious and temporal qualities. ${ }^{8}$

We shall explore these issues in later chapters; "the very belief which the advance of intelligent criticism destroys” is what concerns us now,- - the criticism that transforms the "immature and undisciplined mind.”

\section{The Accepted Authority and the Wikipedian Drudge}

I want to relate an experience I had just recently. Needing a bit of a break from my dissertation, and feeling myself in something of a careless mood I surfed out to Wikipedia and settled on the article there devoted to Matthew Arnold where I did some casual editing. Wikipedia is intriguing as a pragmatic experiment in reconstruction. Participants in the project are not called “writers;” they are instead called “editors.” One does not "write” an article, but rather "edits” it using available sources. Wikipedia asks 
its editors to write from a neutral point of view (called NPOV in the inevitable acronyms of modern speech). ${ }^{\mathrm{f}}$

This concept of neutrality is an interesting one, and, as we shall see, has some intriguing hermeneutic implications. Let me give an example of how it can affect the Wikipedia editor. If as a result of my current study of Matthew Arnold I would feel comfortable saying:

Arnold saw the ancient Greeks not as people living in a distant past, but rather as "moderns" who dealt (several thousand years ago) with all the problems we face in the modern world. When he speaks of distance in the following lines from "Dover Beach" the distance refers to the modern English, not to the Greeks; it is not the Greeks who are distant from the English; it is the English who have distanced themselves from the Greeks.

Sophocles long ago

Heard it on the Aegean, and it brought

Into his mind the turbid ebb and flow

Of human misery; we

Find also in the sound a thought, Hearing it by this distant northern sea. ${ }^{9}$

\footnotetext{
${ }^{\mathrm{f}}$ Wikipedia contributors, "Dover Beach," Wikipedia, The Free Encyclopedia, http://en.wikipedia.org/wiki/Wikipedia:Five_pillars (accessed August 13, 2007):

All of Wikipedia's official policies and guidelines can be summarised as five pillars that define Wikipedia's character:

- Wikipedia is an encyclopedia incorporating elements of general encyclopedias, specialized encyclopedias, and almanacs. All articles must follow our no original research policy and strive for accuracy; ...

- Wikipedia has a neutral point of view, which means we strive for articles that advocate no single point of view. Sometimes this requires representing multiple points of view; presenting each point of view accurately; providing context for any given point of view, so that readers understand whose view the point represents; and presenting no one point of view as "the truth" or "the best view". It means citing verifiable, authoritative sources whenever possible, especially on controversial topics. $\ldots$

- Wikipedia is free content that anyone may edit. ...

- Wikipedia has a code of conduct: Respect your fellow Wikipedians even when you may not agree with them. Be civil. ...

- Wikipedia does not have firm rules besides the five general principles elucidated here. Be bold in editing, moving, and modifying articles, because the joy of editing is that, although it should be aimed for, perfection is not required. ...
} 
By the explicit rules of Wikipedia, I should not enter this text directly into the article. Wikipedia invites me to edit not as an expert or accepted authority, but as a finder of expert testimony. If I were to publish the thought above separately from Wikipedia (which by virtue of this dissertation process I suppose I shall), and another individual should find it and think it was a reasonably valid comment and I a reasonable authority, he or she could then post it to the encyclopedia. My only option as an editor who happens to have coined such a thought about Arnold and this, his most famous poem, is to search for a reasonably similar comment in the work of an accepted commentator. Should I find such a comment (and at this point I have not ${ }^{\mathrm{g}}$ ), then I might be able to prepare an addition to the article referencing the accepted authority and worded in such a way that it reflects that commentator's thoughts, and attempting, as best I can, not to allow my own thoughts to interfere with how I present the idea.

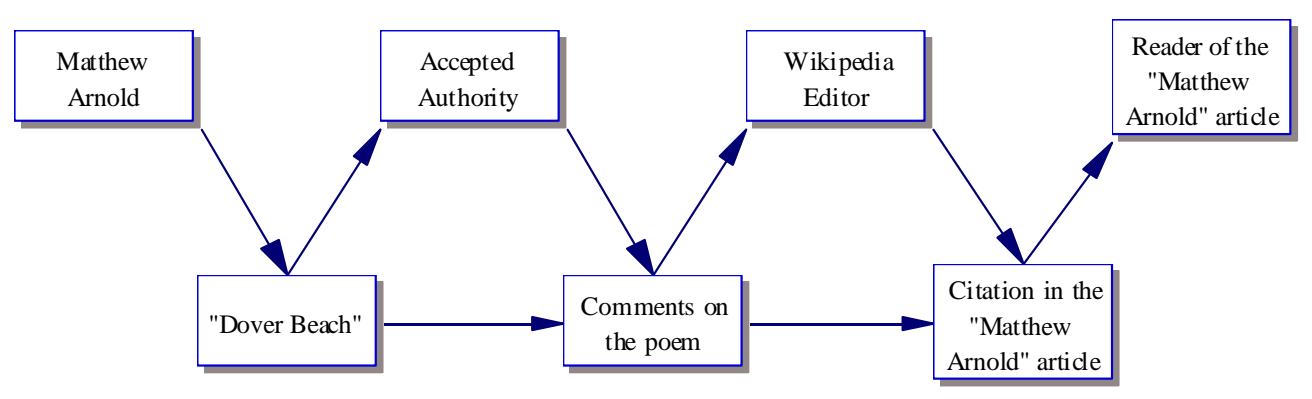

Illustration 4: Editing an article in Wikipedia.

This process, when fully mapped out using our hermeneutic model, suggests an interesting distancing from the original to the final Wikipedia article, the accepted authority sitting midway, intermediate between the article and the original research (see

\footnotetext{
${ }^{\mathrm{g}}$ Although in my reading of the commentators on Arnold I have the pressing feeling that I had read something of the sort somewhere, but, for the life of me, I cannot find my way back to it.
} 
Illustration 4). Wikipedia refers to itself as a tertiary source; not a primary source, as would be Arnold's texts; nor a secondary source as would be the comments of an accepted authority; but tertiary, the third in line, and one need only count the boxes in this illustration to see that tertiary is precisely the right term. ${ }^{\mathrm{h}}$

A few things to note in this mapping:

1) Matthew Arnold and the article reader have monotonic roles, at least as I have portrayed them in this mapping: Matthew Arnold is seen only as a writer; the reader of the article is seen only as a reader. Nonetheless, we may fairly assume that Arnold was himself a reader; to what degree his poetry has been influenced by that reading, that is to say, to what degree it has a secondary status, is an open, and highly important, question. A reader of the article who opts not to become an editor can fairly be portrayed as having a monotonic role, but the question always remains as to what degree any reader is ever fully passive, truly stabling his or her thoughts within the mind and allowing them no form of expression, no opportunity to inform any future actions. We must assume that to some degree the monotonic role, the pure writer, the pure reader, are specious anomalies (as

${ }^{\mathrm{h}}$ I offer no comment here on the quality of that massive encyclopedic enterprise that Wikipedia has become; such comments could only, at best, be anecdotal. And they are not needed for us to accept the process of editing in Wikipedia, as that process has been defined in a manner that is reasonably characteristic of a tradition that runs deep within western culture; while that tradition is subject to much reasonable, and even a little unreasonable criticism, nonetheless, it is a tradition that has held on quite tenaciously and shows no sign of deteriorating. I need only point to the many endnotes that clutter the back pages of each chapter of my dissertation, and ask why are they here? Tradition alone may be a sufficient answer to some, I think rather that we do feel a need for some parallel line of authority pulling the polemic out of its too grave intensity and dangerous inwardness. In the chapter on the reflective mind I hope to address this issue more closely. 
Fish we note had conjectured) of the modeling process; they quite simply do not exist in reality. What does exist, however, are the act of reading and the act of writing which, provided we allow for the uncertainties that attend any active, dynamic process, are reasonably distinguishable.

2) The corollary of what I have said above about the false monotonic value of the roles of the original author (Arnold) and the article reader, can be seen when we note that the accepted authority and the Wikipedia editor have obvious dual roles as both reader and writer. The two roles, however, should strike us as significantly different. In the first case, the full possibilities of inference, intentionality and textual analysis are available to the accepted authority; in other words, the accepted authority, usually, has the freedom to express something of these full possibilities in the accepted authority's comments on the primary text. I qualify this with the word “something," because I am not sure that any individual ever has available the full possibilities of inference, intent and textual analysis. Even with simple texts the three are significantly complex qualities with potentially infinite dimensions; pragmatically, however, no commentator ever has need to search out the infinite possibilities of any of these dimensions. The three elements take on a familial relationship, that is they approach each other, or attain to an Arnoldian "nearness.” The accepted authority is, as often as not, an accepted authority because she possesses an ability to recognize and bring about these familial relationships, avoiding those possibilities of the infinite dimensions which would lead too far away from "nearness." We may debate where her 
abilities come from,-_ I would agree with Fish that to some degree they come from her membership in an interpretive community, but because I have not wished away the actual poem, I am willing to allow that some of that authority comes from a familiarity with the poem as object.

3) The Wikipedia editor, as I have already noted, may share the duality of role (reader and writer) with the accepted authority, but the relationship to intention, inference, and textual analysis is surprisingly different. For the Wikipedia editor intention and inference are largely off limits. The editor is not to attempt to read too deeply into the intentions of either the accepted authority or Matthew Arnold, himself. The editor's own inferences about either are equally limited in their relevance particularly to the extent that they are associative or move to any great degree away from the fundamental familial relationship with the text. Textual analysis is likewise limited in that the editor is looking for those statements from the accepted authority that most clearly and directly suggest the nature of her understanding of Arnold's intention, the text's meaning, or the authority's inferences about either. The editor's work as a reader, thus, is largely circumscribed: the understanding of intention cannot go beyond the most immediate and visible sense available in the accepted authority’s written comments; textual analysis, thus, is almost blind to the metaphorical nature of language; and inference is limited to that which the editor needs to construct a reasonable statement (in performing the writer's role) that is tightly bound in familial relationship to the written comments of the accepted authority. Rigor and 
limitation defines the role, but we should not think that in this limitation we find something that is somehow incongruous with the nature of the hermeneutic process. As we have already noted, the accepted authority becomes an accepted authority because of an ability to recognize within the three elements (intention, inference and text) a familial relationship and express this familial relationship in her own comments. The editor is doing the same thing, but within much more constrained standards and with a focus almost solely upon the intervening text (denuded, as much as possible, of intention and inference). "Nearness" for the editor, if done well, approaches to a perfection of close reading.

4) Finally, let us look at the relationship amongst the texts themselves. As I have already noted three texts make up this sequence: the primary text, in this case the poem "Dover Beach," the secondary text in the form of a comment from the accepted authority, and the tertiary text, a statement that the Wikipedia editor places into the article on Matthew Arnold. As I have already suggested, the text of the poem itself must have some relationship to the two subsequent texts. Arnold described the critic's role as an effort "to see the thing as in itself it really is." The thing he speaks of, then, is, in this case, the text of the poem. While the commentaries of the accepted authority are nominally based upon the original text, "the thing as in itself it really is," they can often move rather far from the actual text. By way of example, let us look at a passage from "Dover Beach.”

But now I only hear Its melancholy, long, withdrawing roar, Retreating, to the breath Of the night wind, down the vast edges drear 


\section{And naked shingles of the world. ${ }^{10}$}

Now, let us see how Park Honan "reads" the text. He relates the phrase "vast edges drear" to a hypothetical memory of Wastwater, in the Lake District.

In the Lake District Arnold knew the severity of one fine, plunging line of mountainous grey 'scree' running into translucent depths of water, as though falling into the middle of earth. Wastwater on dark days is metaphorically severe. He had seen the line of scree in the rain lately, and it is possible, though not certain, that his memories of Wastwater and Dover's beach combine in an image of "vast edges drear."

Honan strays from the poem itself, although cautiously ("it is possible, though not certain”), and in doing so he attempts to enter the poet's mind. To move past the text in hope of finding clues to authorial intention, he imagines an Arnoldian memory lying hidden within the verses, which the archeologist critic must dig deep to find.

We may recall Cleanth Brooks words that "what counted were achieved intentions - those that are manifest in the work itself." ${ }^{12}$ Is that what we have here? Is this an intention that is manifest in the work itself? Has Honan imaginatively "seen the thing as it really is"? Such questions must always hang upon the edge of this reaching out toward the intentional; Honan admits this himself when he says, "it is possible, though not certain." "It is possible, though not certain," - these are the words within which the pragmatic judgment is inevitably formed. And it is the capacity the pragmatic critic has for ascertaining the reasonableness of the possibility, the depth of the uncertainty, and, quite as 
importantly, the relevance of the conjecture to the whole (multum in parvo) ${ }^{\mathrm{i}}$ that establish the virtue of the critic, — the likelihood that we shall care one way or another what the critic has to say.

The tertiary text, on the other hand, is answerable to rather different qualifications. Here our sense of "nearness" shifts from the intention to the text itself, and we are unsatisfied with the results if they do not meet the more rigorous, if more modest, standard of a reasonably direct equation, a near one for one equality. Thus as a Wikipedian editor my own comment needed to adhere closely to Honan's original, no matter how far his comment ranged from Arnold's original. And so I wrote: “[Honan] also connects the 'vast edges drear' to a possible memory of Wastwater in the Lake District, which Honan describes as 'mountainous grey 'scree' running into translucent depths of water.' ”, 13

$$
\cos 80
$$

Today the term "accepted authority" seems rather awkward. What does it mean to be “accepted,” let alone an “authority”? These questions bear no easy answers. Although, time and again, in our ordinary, daily lives, we revert to some sense of authority. When we bring our cars to a stop before a simple red stop sign, do we ask ourselves, - upon whose authority was that placed here? Why do I accept such an authority, anyway? And not all of us fully accept even this authority,- if no police are

\footnotetext{
${ }^{\mathrm{i}}$ I have chosen here a reading of the poem which is quite susceptible to the critique that it elaborates the particular without illuminating the whole. Honan does not push beyond what I have offered here upon this particular issue. But then, one might argue that he was writing a biography, not a poetic study, and that this poetic vision of Lake District 'scree,' whether tied to the poem or not, may, nonetheless, tell us something about Arnold, or rather that Arnold is the thing that Honan wishes to see "as in itself it is."
} 
around why should a stop sign be regarded as anything more than a suggestion?

Sometimes our egos will turn an external authority around, and we end up imagining that the thought is wholly our own, but the thought comes so easily to us that acceptance seems hardly an issue, and the authority of the thought feels no more tyrannous nor extravagant than is common sense,- - which is, of course, one of the names we give to such accepted authorities. Authority plays through our lives in such unusual and interesting ways; even when it appears to be an absolute it somehow bears the weight of some contingency or other;- - even when life seems most anarchic, some measure of order steps in to shape it toward a less fragmented middle-ground.

Fish gives us a possible clue to the nature of accepted authority in his conception of interpretive communities, - the word acceptance, at least, surely flows from this community,- an interpretive community will accept some authorities and not others. And yet, I suspect that Fish meant us to see the interpretive communities as themselves the authority, not the individual members. When an individual member becomes an authority our fear of authority tells us that we are seeing a return to the heroic, the idolized individual, with a resultant marginalization of all those who are not held up as heroes, and with this a failure to recognize the degree to which thoughts and ideas are socially constructed. On the other hand if the authority is seen as residing in the community, then our fear of authority quickly recognizes the equally dangerous hegemony with its tendency to exclude or marginalize all other communities. I, frankly, think that the accepted authority is simultaneously both a representative and completer of the communal thought, while representing something of a step forward that we may 
equate with something individual in nature. And I think we may come to such a conclusion without regressing into a Carlylean hero-worship, or a hegemonic demonization of communal authority.

A fear of authority has come to dominate to an extraordinary extent the ethos of our modern intellect: conspiratorial hegemonies are the inevitable trappings of power; if absolute authority corrupts absolutely, then authority in any form is absolutist and therefore absolutely corruptive; and rules are meant to be challenged; - the last of these is not in itself so frightening as is the implication that seems to linger about it, that somehow this act of challenging confers upon one the mantle of past martyrs whose challenges bore real dangers and required real courage: I wonder how much courage it takes today to declare oneself, for example, an atheist? I cannot help but feel that our too easy answers to the problems of authority have led us to a new kind of philistinism.

Arnold and Dewey both were aware of another sort of tyranny, the opposite of authority, — the tyranny of an uncritical individualism. Arnold called this "doing as one likes.”"14 Arnold saw “doing as one likes” as the undoing of liberty, and for Arnold liberty was but one third of the French revolutionary cry for democracy: "liberty, equality, and fraternity.” But, as Arnold noted, liberty and equality are often at odds,no sooner have we declared that we are intent upon doing as we like, than, if we are at all reflective, we feel the press upon someone else and the inevitable faltering of our democratic bent. Before we turn to questions of authority, then, let us take a brief look at Arnold's and Dewey’s approaches to democracy. 


\section{Democracy}

For Arnold and Dewey democracy, as both a description and a prescription, was inevitable,_- description because the world they were born into mandated democracy, made it a necessary functionary of modernity,- prescription because the path of progress, necessary in itself, lay in the direction of democracy. This is perhaps less obvious with Arnold than with Dewey. Louis Menand in his wonderful book, The Metaphysical Club: A Story of Ideas in America, which features Dewey so significantly, makes only three references to Arnold. In the first of these Arnold is the fanatic prophet of anarchy; in the second two references, he is part of that grand Victorian triumvirate, Arnold, Carlyle and Ruskin, that Menand describes as anti-industrial and anti-democratic.

${ }^{j}$ Given comments like that which follows, surely one cannot be surprised that Arnold might easily be taken as an enemy of democracy.

This movement of democracy, like other operations of nature, merits properly neither blame nor praise. Its partisans are apt to give it credit which it does not deserve, while its enemies are apt to upbraid it unjustly. Its friends celebrate it as the author of all freedom. But political freedom may very well be established by aristocratic founders; and, certainly, the political freedom of England owes more to the grasping English barons than to democracy. Social freedom,- equality,that is rather the field of the conquests of democracy. ${ }^{15}$

When we read that English barons were as capable of securing political freedom

as was English democracy, we are, no doubt, justified in wondering that Arnold is not too much of an apologist for the aristocracy,- - and something in Arnold always seems to

\footnotetext{
${ }^{\mathrm{j}}$ I mean no unfairness to Mr. Menand. Arnold, Carlyle and Ruskin are not central to his topic, and for nearly a century, and even more so in the past half century, they have become the easy factotums of Victorianism. Nonetheless, how odd it is that three such idiosyncratic thinkers should so casually be yoked together. The usage suggests more the gravity of the magnum nomen, the great name that conjures even when the particulars associated with it are long forgotten. Menand, The Metaphysical Club: A Story of Ideas in America, 2001, pg. 195, 307, and 312.
} 
temper his criticism of aristocrats. ${ }^{\mathrm{k}}$ Perhaps we too closely equate democracy with political freedom, or perhaps Arnold’s ready irony overly obscures his thought; nonetheless, the final sentence here ought to jar us out of our complacency. What apologist for the aristocracy ever declared so willing the virtues of equality as does Arnold? Would Johnson not have condemned him as a Leveler? But Arnold's passion for equality is real; it is how he expressed his own liberalism.

Now can it be denied, that a certain approach to equality, at any rate a certain reduction of signal inequalities, is a natural, instinctive demand of that impulse which drives society as a whole,- - no longer individuals and limited classes only, but the mass of a community,- - to develop itself with the utmost possible fullness and freedom? Can it be denied that to live in a society of equals tends in general to make a man's spirit expand, and his faculties work easily and actively; while to live in a society of superiors, although it may occasionally be a very good discipline, yet in general tends to tame the spirits and to make the play of the faculties less secure and active? ${ }^{16}$

The French Revolution, as we have already noted, was not so distant from Arnold that he could not look back upon it with a certain fear mixed with a liberal, even romantic zeal. For Arnold, the phrase-maker, that immortal motto of the revolution,- liberté, égalité, fraternité,- - was not to be taken lightly. He was very conscious that liberty and equality were often at odds; that “doing as one likes,” did not necessarily promote equality within society. In his essay "Equality” (according to Collini, “deliberately heterodox and remarkably radical"17) he declares that "inequality materialises our upper class, vulgarises our middle class, brutalises our lower."18 With this in mind, we can more readily understand how he came to associate freedom with the emptiness of middleclass philistinism.

\footnotetext{
k Surely calling the aristocrats "barbarians" was not meant to ingratiate him to the peerage,_- but the reality is that the term seems to have had little ill-effect.
} 
Having, I say, at the bottom of our English hearts a very strong belief in freedom, and a very weak belief in right reason, we are soon silenced when a man pleads the prime right to do as he likes, because this is the prime right for ourselves too....19

Dewey had his own misgivings about freedom, a sense that it could be overstated, that it was not, in itself, an inalienable right,_- although, indeed, he wondered if inalienable rights existed at all.

The view that love of freedom is so inherent in man that, if it only has a chance given it by abolition of oppressions exercised by church and state, it will produce and maintain free institutions is no longer adequate. The idea naturally arose when settlers in a new country felt that the distance they had put between themselves and the forces that oppressed them effectively symbolized everything that stood between them and permanent achievement of freedom. We are now forced to see that positive conditions, forming the prevailing state of culture, are required. Release from oppressions and repressions which previously existed marked a necessary transition, but transitions are but bridges to something different. $^{20}$

Like Arnold, Dewey doubted that rights were anything more than cultural and historical attributes of society,- they were no more aspects of individual men and women than was that individualism that today we prize so dearly,- - but it is the nature of individualism that we must learn it from our society, if we are to allow it any expression in our own lives.

The function of culture in determining what elements of human nature are dominant and their pattern or arrangement in connection with one another goes beyond any special point to which attention is called. It affects the very idea of individuality. The idea that human nature is inherently and exclusively individual is itself a product of a cultural individualistic movement. The idea that mind and consciousness are intrinsically individual did not even occur to any one for much the greater part of human history. It would have been rejected as the inevitable source of disorder and chaos if it had occurred to anyone to suggest it:- not that their ideas of human nature on that account were any better than later ones but that they also were functions of culture. ${ }^{21}$ 
With Dewey’s phrase “disorder and chaos” Arnold’s “anarchy,” his antithesis to culture, comes to mind. Dewey succeeds here, as we have seen him do any number of times, in both echoing and denying Arnold. Like Arnold he questions the efficacy of a democratic culture built entirely upon individual freedom, even while he links Arnold's fear of anarchy to that past culture that derided the liberating of liberalism. Arnold's fears were real and, perhaps, inevitable to his time. For Dewey, the Terror of the French Revolution and the Chartist revolts (which seemed ever to threaten to overturn nineteenth century England, at least in the imaginations of Arnold and his peers) were historically distant and irrelevant. One need merely look at Dewey’s response to the Pullman Strike when he arrived in Chicago the summer of 1894 to see the difference between Dewey and Arnold.

...the other night I met a young fellow about 28 or 30 who was out organizing railway unions. He was quite willing to talk, as quick as he had sent out his telegrams ordering the men out at midnight... I only talked with him 8 or10 or 15 minutes but when I got through my nerves were more thrilled than they had been for years; I felt as if I had better resign my job teaching \& follow him round till I got into life[.] One lost all sense of the right or wrong of things in admiration of his absolute almost fanatic sincerity \& earnestness, \& in admiration of the magnificent combination that was going on. Simply as an aesthetic matter, I don't believe the world has seen but few times such a spectacle of magnificent, widespread union of men about a common interest as this strike evinces. ${ }^{22}$

Arnold's response to the Hyde Park incident provides wonderful counterpoint. As Park Honan put it, Arnold “...was hardly detached and calm when London’s commissioner of police prohibited a large meeting in Hyde Park which the Reform League had set for July 23, 1866.” Despite the efforts of their leaders to move them past the park and on to Trafalgar Square, Honan continues, "the crowds became violent and 
smashed down a thousand yards of Hyde Park railings." Later, rioters "stoned the windows of Sir Richard Mayne, the police commissioner, as Matthew and Fanny Lucy [Arnold's wife] watched from their balcony.” Arnold was furious, but nonetheless, wrote his mother, "I do not think it a bad thing that the principle of authority should be so weak here.”23 Like his fellow philistines (and Arnold could, as the occasion demanded, laughingly admit himself to their company), he understood that placing too much power in the State was as great a cause for concern as was the violence which could so suddenly swell up from below. We must remind ourselves that Arnold's alternative to anarchy was culture. While he was inclined to recommend that his fellow English could tolerate placing a little more power in the state, he was no more prepared than they to grant it such authority that it should become a police state.

Ultimately, for both Arnold and Dewey, the outward expression of democracy is insufficient. Neither can bring himself to equate democracy so easily with freedom, nor is either of them entirely satisfied with the mere mechanics of the political realities of a democratic state. In the following excerpt from Freedom and Culture, Dewey puzzled over the progress of democracy.

I have referred with some particularity to Jefferson's ideas upon special points because of the proof they afford that the source of the American democratic tradition is moral—not technical, abstract, narrowly political nor materially utilitarian. It is moral because based on faith in the ability of human nature to achieve freedom for individuals accompanied with respect and regard for other persons and with social stability built on cohesion instead of coercion. Since the tradition is a moral one, attacks upon it, however they are made, wherever they come from, from within or from without, involve moral issues and can be settled only upon moral grounds. In as far as the democratic ideal has undergone eclipse among us, the obscuration is moral in source and effect. The dimming is both a product and a manifestation of the confusion that accompanies transition from an old order to a new one for the arrival of the latter was heralded only as conditions 
plunged it into an economic regime so novel that there was no adequate preparation for it and which dislocated the established relations of persons with one another. ${ }^{24}$

The contingent phrase Dewey uses here to describe democracy suggests Arnold's concern for the relationship between freedom and equality. He allows that Jeffersonian democracy permits “freedom for individuals,” but only provided that that freedom is “accompanied with respect and regard for other persons and with social stability built on cohesion instead of coercion.” So the balancing of these two elements, freedom and equality, was important to both Arnold and Dewey, but here Dewey introduces a new element, which was also important to Arnold: “The source of the American democratic tradition is moral.”

Dewey's morality is not so often noted today as perhaps it ought to be. Dewey rather nonchalantly drops the word morality into his discussion of education throughout much of Democracy and Education, as if to say, "but, of course, education has a moral role; why should I try to convince you of something we all know and understand, when other problems of education are more readily apparent and more necessary to our current discourse?” Nonetheless, he ends the book, - a book which he regarded as his most important philosophical treatise, — with a chapter entitled "Theories of Morals." 25 This was, I think, no accident.

The question that seems most interesting to me is: why do we take so little note of Dewey’s morality? I was recently at a conference where the question of Dewey's approach to morality was raised in a way that seemed to invite a raw kind of emotionally charged response from the audience,- - a question was fired back from an audience 
member which immediately linked the word "absolute” to "morality." I suspect that for many of us this linkage is rather strong; morality seems so dependent upon a kind of absolutism, upon “oughts” and "shoulds," that the word itself has come to fall into that class of ne'er-do-wells we call authoritarian,_- it is the final recourse for the overclass, the hegemony, a readymade tool for those who wish to dominate.

For Dewey this was not the case. Morality was, nonetheless, a thing to be reconstructed. In the next chapter we shall have more to say about morality; for now let us look at Dewey’s conception of reconstruction as a kind of authority.

\section{Reconstruction as Authority}

The concept of reconstruction is an essential aspect of Dewey’s philosophy. I have recently noted some attempts to link the term with deconstruction, but Dewey’s reconstruction behaves quite differently. ${ }^{l}$ He is amply aware of the historical realities that inform thought. "About what goes on today hangs a cloud of thoughts concerning similar things undergone in bygone days.”26 But he is more interested in clearing away those clouds, than he is in exploring them to find the traces of their inadequacies. They are inadequate, that is enough; only the reconstructed thought is adequate. The problem must be solved in the immediacy of the present, particular to the moment and to the

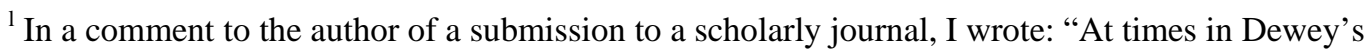
argument, he almost suggests a complete disregard for traditional thought; when he does turn to an analysis of the past, his approach is not really deconstructive; he operates almost as a sort of casual historicist (one who uses history rather loosely, even, at times, primitively); moreover, he holds too strongly to the notion that 'things' have meaning (telos) for him to fit comfortably among deconstructionists.”
} 
individual, and in which the individual has the satisfaction that the reconstruction is true to experience and thus gained through the ex-peri of personal trial.

Dewey’s reconstruction of morality is a case in point. We find his argument, as we have already noted, in the final chapter of Democracy and Education. The first thing we note is that Dewey has not isolated himself from current or common conceptions of morality. He says "it is a common place of educational theory that the establishing of character is a comprehensive aim of school instruction and discipline.” He is also concerned about concepts of "inner and outer, or the spiritual and the physical" that are "the currency of moral ideas." 27 The first of these, "the establishing of character," he is more willing to accept (suggesting that, to some degree, his thought is a continuation of aspects of Victorian morality ${ }^{28}$ ); the second, and we should hardly be surprised, he outand-out rejects. His rejection of the "inner and outer" conceptions of morality becomes the key to his reconstruction. Morality concerns conduct; conduct is action; morality must concern itself with both the thought that precedes (and follows) the act, and with the act itself. In typical Deweyan fashion the traditional bifurcation of act and actor is abruptly set aside.

He also assigns to moral actions some significant qualities: moral actions are purposeful; they express foreseen ends; they involve the mental trial of pros and cons; and they involve some longing or desire. These attributes taken together suggest the critical act we reviewed in the preceding chapter. Something of a waking judgment is clearly implicit here. As Dewey puts it, "all this means an accentuation of consciousness; it means a turning in upon the individual's own attitudes, powers, wishes, etc."29 This 
concept of "turning in" also appears in Arnold with a distinctly moral sense to it. This consciousness is extremely relevant to Dewey's reconstruction; within that consciousness Dewey allows the individual a certain capacity to "think" during the act, and not merely allowing thought a place that is a priori or a posteriori to action. Here again we see something of the difference between Dewey's reconstruction and today's deconstruction. A kind of fatalism adheres to deconstruction,- - a sense that the very nature of the words that perform such an inevitable role in our thought have a character in and of themselves that action cannot overcome. Dewey undercuts this fatalism when he allows the individual this more dynamic quality of thinking within the act, of overhearing and overseeing, as it were, both thoughts and actions. By moving into this pragmatic realm of experience, the obstructive capacity of language is diminished, although not removed entirely. Not that thought is always capable of successful overseeing and overhearing: "This role of mind in continuous activity is not always maintained, however.” Desires and aversions can form blocks to successful action. "Except where there is a disciplined disposition, the tendency is for the imagination to run loose. Instead of its objects being checked up by conditions with reference to their practicability in execution, they are allowed to develop because of the immediate emotional satisfaction which they yield.” The "disciplined disposition" becomes its own sort of authority; we recall here how adamant Dewey was in Experience and Education that discipline not be denied a role in education. In which respect, we have one of Dewey's most memorable statements on the role of authority in modern thought:

It may be a loss rather than a gain to escape from the control of another person only to find one's conduct dictated by immediate whim and caprice; that is, at the 
mercy of impulses into whose formation intelligent judgment has not entered. A person whose conduct is controlled in this way has at most only the illusion of freedom. Actually he is directed by forces over which he has no command. ${ }^{30}$

As we have already noted, the spirit of fatalism simply has no ground in Dewey’s reconstruction of morality. The active, changeable self, he points out, is often missing from moral arguments. In the absence of this active, changeable self only two systems of morality may derive: an older traditional morality which moves the agency for change outside of the individual and places it within an external authority, the church, the state, the community, which "in its collective and corporate character"m inhabits an obligation to direct individual behavior; alternatively, we may turn to the more recent, utilitarian philosophy (which Arnold, like Dewey, found uncomfortable) in which the individual acts according to self-interest. ${ }^{\text {n }}$

Even if we accept that morality is founded upon an active, changeable self, the question becomes, are moral judgments based upon intelligence or character?

A noteworthy paradox often accompanies discussions of morals. On the one hand, there is an identification of the moral with the rational. Reason is set up as a faculty from which proceed ultimate moral intuitions, and sometimes, as in the Kantian theory, it is said to supply the only proper moral motive. On the other hand, the value of concrete, everyday intelligence is constantly underestimated, and even deliberately depreciated. ${ }^{31}$

Meanwhile, "the value of everyday intelligence is constantly underestimated.” Dewey dismisses the teaching of character as "some kind of catechetical instruction," a reliance

${ }^{\mathrm{m}}$ The phrase is Arnold's. Arnold, “Ecce, Convertimur ad Gentes,” 1879, CPW 9:15. “Arnold frequently uses the definition of the State which he ascribes to Burke: 'the community [the people] in its [their] collective and corporate character.' The conception is Burkean, but the precise definition apparently is not." Super's note, CPW, 9:333.

${ }^{\mathrm{n}}$ Dewey felt that "both sides [i.e. the absolutists and the individualists] assume that the self is a fixed and hence isolated quantity.” Dewey: Democracy and Education, 1916, Page mw.9.361. 
upon "sentimental magic." ${ }^{32}$ The intellectual side of the debate Dewey presses back to Socrates and Plato,_- "no man does evil knowingly but only because of ignorance of the good.” “Aristotle," Dewey points out, "at once attacked the Platonic teaching on the ground that moral virtue is like an art, such as medicine; the experienced practitioner is better than a man who has theoretical knowledge but no practical experience of disease and remedies.”33 However, Aristotle, Dewey tells us, misread Plato and ignored the rather crucial role that Plato had given to "years of practical habituation and strenuous discipline. Knowledge of the good was not a thing to be got either from books or from others, but was achieved through a prolonged education. It was the final and culminating grace of a mature experience of life.” Whether this is Plato or Plato as a Dewey surrogate, we approach here Dewey's middle ground and an important part of Dewey's reconstruction of morality. Neither the doctrinal lessons of a moral catechism, nor a steeping in the knowledge of the intellect can take the place of the wisdom of the shaping years of experience. We should also note Dewey's emphasis upon the value of what he calls "everyday intelligence." This is not merely a simple call to populism; if morality is distanced from the everyday, becomes a knowledge attainable only by special study and intellectualization, then for the mass of human beings it can only be accessed as a received idea and so a Kantian intellectualization ends up having the same character as the authoritarian catechisms of morality.

Dewey completes his reconstruction by attempting to shift morality from the "sentimental" and the overemphasis of "convention and tradition," to a much broader interpretation: “As a matter of fact, morals are as broad as acts which concern our 
relationships with others. And potentially this includes all our acts, even though their social bearing may not be thought of at the time of performance."34 The emphasis here on the social character of morality is an important one, and adds a certain power to this particular reconstruction of morality (Dewey attempted the venture multiple times). Elsewhere Dewey seems to leave the individual engaged in moral reasoning in a rather strangely isolated state; in such cases his definition of morality differs little from the ethical reasoning of Derrida which so particularizes the individual case as to allow for no opportunity to generalize. Dewey was no enemy of generalizations; he saw generalizations as a necessary function in the thought process, even if they had the unfortunate habit of manifesting themselves as objectified ends that were all too easily idolized and removed from their necessarily contextual ground. Perhaps because here, in Democracy and Education, he is concerned with the place of morality in education, he ends his reconstruction upon two significant conditions:

(i) In the first place, the school must itself be a community life in all which that implies. Social perceptions and interests can be developed only in a genuinely social medium - one where there is give and take in the building up of a common experience.

(ii) The learning in school should be continuous with that out of school. There should be a free interplay between the two. ... The absence of a social environment in connection with which learning is a need and a reward is the chief reason for the isolation of the school; and this isolation renders school knowledge inapplicable to life and so infertile in character. ${ }^{35}$

Perhaps better than any other passage in Dewey’s writings this final chapter of Democracy and Education suggests the importance of social character to the true Deweyan experience. We have seen how in his discussions of problem solving and the 
fundamental nature of experience he seemed to stand upon the dissolution of the mind and body duality, but failed to reach past the object toward the intentionality of others, the wider social horizon of experience. But here the social nature of experience is drawn perhaps as clearly and directly as anywhere in Dewey’s writings.

The moral and the social quality of conduct are, in the last analysis, identical with each other. It is then but to restate explicitly the import of our earlier chapters regarding the social function of education to say that the measure of the worth of the administration, curriculum, and methods of instruction of the school is the extent to which they are animated by a social spirit. ${ }^{36}$

To not see in this argument the counterpoint to, or rather completion of, his conception that the aim of education is to meet the needs of the individual learner would be to do a gross injustice to Dewey's larger conceptions of morality and education. In other words, when we say that for Dewey the aim of education is to meet the needs of the individual learner, we must understand that education is social and therefore moral,_- thus the aim of education is to meet the individual's needs, and those needs are inherently social and moral.

We are left now with the question of how Dewey's reconstruction relates to intentionality and authority. Does reconstruction really turn its back entirely upon the past? Does it truly create of the individual a self-sufficient authority? Has it that integrative power that Dewey hoped for such that "science and emotion will interpenetrate, practice and imagination will embrace"? ${ }^{37}$ I think we have seen that the answer to the first two questions is an unhesitating no: it neither turns its back entirely upon the past, nor does it enable the individual anything like a libertarian's extreme desire for self-sufficiency, although, in Dewey's most hyperbolic moments, it may seem 
to do just that. The answer to the last question is more equivocal, not so much because experiential reconstruction itself has failed, as that the age in which we live seems so intent upon continuing the bifurcation of "science and emotion, practice and imagination" at so awkward and dizzying a pace. The extreme, hyperbolic Deweyan reconstruction in which we, each of us as an individual, must depend upon our own reconstruction of every thought and experience surely in no age could be adequate; in an age moving as fast as ours, such a method has its immediate and obvious limitations.

In the introduction to Reconstruction in Philosophy, Dewey, writing in an almost agitated tone, tells us that "to the vested interests, maintenance of belief in the transcendence of space and time, and hence the derogation of what is 'merely' human, is an indispensable prerequisite of their retention of an authority which in practice is translated into power to regulate human affairs throughout-from top to bottom.” In the absence of such authority, "there is, however, such a thing as relative-that is relational—universality.”

The universality that belongs to scientific theories is not that of inherent content fixed by God or Nature, but of range of applicability — of capacity to take events out of their apparent isolation so as to order them into systems which (as is the case with all living things) prove they are alive by the kind of change which is growth. ${ }^{38}$

In other words, the necessity for universals and their authority does not disappear in light of reconstruction. A sort of universal-light, or what Alain Locke called a "local universal,"39 becomes necessary, - functioning in much the same way that aesthetic theory does for the practical critic,- - something to be called upon as needed, but toward which the critic need feel no greater fealty than the measure of a sound judgment aided 
by such a universal may allow. The extreme of authority in "vested interests” is simply too unnuanced, but Dewey is at a loss as to how to make sense of such a new conception of universality; his "there is... such a thing as relative—that is relational—universality" seems unconvincing,- - Dewey shows us here one of those moments when, thinking aloud, he stumbles a bit too awkwardly. On the other hand, I have found, in one of Dewey's papers on logic (the sort of essay that exists now solely in the back pages of The Collected Works), an attempt to answer the question “What Are Universals?” Without digressing into a rather technical argument, Dewey concludes that universals have a "necessity ... in regulating inferences," that the universal has a logical function which it performs through symbols, but that a danger exists in "ignoring the operational basis and function" of these symbols, and, finally, that "implication and inference [must be brought] into relation with each other." ${ }^{\text {40 }}$ Setting aside the ontological character of much of what has come down to us in the form of the great, all-truthful, all-knowing universals, with their sense of having enshrined the color and character of the world in an altogether too neat and too presumptive world view, something of relevance still remains in the logical and pragmatic universal when, without overreaching, we balance its implications (that which we have been calling intentionality) against the homely, direct inferences of our experience, — that is to say, when we allow them their unpretentious and essential role in our critical reflections.

\footnotetext{
0 "Vested interests" is no longer the term of choice; it has been replaced by the term hegemony." I suppose that is because the older phrase has become so over-used that it seems inevitably to come dressed in a business suit and puffing on a large phallic cigar, looking like a grainy black-and-white film noir image, altogether too retro to invoke much fear and anxiety.
} 


\section{Culture as Authority}

Let us turn back now toward Arnold. We have seen already something of how Arnold treats issues of intentionality. We have relied to some extent upon his assurance that we may come near the thoughts of another, although we hardly needed such an assurance. Our pragmatic experience, that which Dewey has called "concrete, everyday intelligence, ${ }^{41}$ ratifies this. We have all of us found ourselves, now and then, coming winningly close to the thoughts of another,- - and while the skepticism of poststructuralism has readily assured us that we each have unique thoughts or our own,-— few of us in our "concrete, everyday intelligence" have assumed that this meant a complete inability to close upon the thought of another. We know that in our everyday conversations we have the varying experience of approaching and receding from a perfect understanding of those with whom we converse. Sometimes we are more in tune with others, sometimes less so; we never achieve a perfect understanding, but our understandings are often sufficiently adequate to allow us to move through the course of our day; while we might wish to achieve better understandings, we know that understanding cannot be made better, if it has not some positive value upon which to build in the first place.

Arnold, however, in his approach to criticism asks a question that will become increasingly important: need we understand the intentionality of another with absolute perfection? For those who see in Arnold only the prophet of culture, this question, no doubt, has gone unnoticed; as the prophet of culture he seems to be saying that if we read the ancient Greeks, and by so doing gain culture, we will have the capacity to think 
effectively. Jokingly, we might say that, if we have read our Homer and Sophocles, we may set our minds aside and let the Greeks do our thinking for us. Stated in that fashion we can see why Dewey set aside the most ridiculously reductive notions of high culture and great books,- - whether they come from Arnold's followers or his detractors.

When we look more closely at this question (need we understand the intentionality of another with absolute perfection?), we begin to see that Arnold's relationship to the ancient Greeks and high culture were far more equivocal than we may have originally imagined them to be. Here is one statement from Arnold in which this question is imbedded. It is the same statement we looked at when we were exploring Arnold's approach to criticism in the last chapter.

...the method of historical criticism, that great and famous power in the present day ... The advice to study the character of an author and the circumstances in which he has lived, in order to account to oneself for his work, is excellent. But it is a perilous doctrine that from such a study the right understanding of this work will "spontaneously issue."”

Historical criticism attempts to understand a text by looking at its author's biography and the historical context in which the text was produced. In doing so, historical criticism puts a premium on the intentions of the author and the context of the text. Rather significantly, historical criticism, as a result, began the process of diminishing the role of the reader's inference which, by the time of the New Critics, would be thoroughly pooh-

\footnotetext{
P Arnold: “A French Critic on Milton,” 1877, 8:175. Quoted in Watson: The Literary Critics, 1962, 144. The French Critic in question is Edmond Schérer. One might argue that in this statement Arnold is suggesting that even history must be viewed as a whole and not in its parts. Watson does not say this, but he does demonstrate how Arnold took what he wished from the historical view even as he openly dismissed it.
} 
poohed, only to rise phoenix-like from the unsentimental and unromantic ashes of modernism into its current guise as reader-response theory. ${ }^{\mathrm{q}}$

Let us follow Arnold as he continues the thought in the preceding quotation.

....it is a perilous doctrine that from such a study the right understanding of this work will "spontaneously issue." In a mind qualified in a certain manner it will not in all minds. And it will be that mind's "personal sensation." It cannot be said that Macaulay had not studied the character of Milton, and the history of the times in which he lived. But a right understanding of Milton did not "spontaneously issue" therefrom in the mind of Macaulay, because Macaulay's mind was that of a rhetorician, not of a disinterested critic. Let us not confound method with the result intended by the method - right judgments. The critic who rightly appreciates a great man or a great work, and who can tell us faithfully life being short, and art long, and false information very plentiful - what we may expect from their study and they can do for us; he is the critic we want, by whatever methods, intuitive or historical, he may have managed to get his knowledge. ${ }^{\mathrm{r}}$

The phrase "personal sensation," which Arnold sets off in quotation marks, suggests very much the value he wishes to place upon the reader’s inference, and intuitive readings may have the value of historical readings, but all depends upon the development of the critical mind that is making the judgment. Macaulay's rhetorical mind had not the power to grasp Milton. But a “disinterested critic” could. Now immediately we must ask ourselves, how is it possible to reconcile the word "disinterested" with the phrase "personal sensation”? Is the critic not most "disinterested" when she allows the history of the poet and the historical context of the poem to inform her study, leaving "personal sensation” out altogether? We might, at this point, simply dismiss Arnold's thoughts as

\footnotetext{
${ }^{\mathrm{q}}$ In saying this I am, indeed, suggesting that reader-response theory and post-modernism, in general, have something of a sentimental and romantic underpinning; Bloom picks up on this, but where he seems to be dismissive, I, to the contrary, find in this sentimentality and romanticism something of a saving grace,I only wish it were more consciously understood and had less the darker character of sentiment and romance, had something more of the wonderfully naïve sympathies of early romanticism.

r Arnold: “A French Critic on Milton,” 1877, 8:175. Quoted in Watson: The Literary Critics, 1962, 144.
} 
deliriously unsystematic, or we might follow Trilling in recognizing that Arnold was pointing toward a more pragmatic position in which the various elements of the critical process are held in balance by "disinterest," or "the free play of the mind.” Arnold's “disinterest” does not rule out personal inference, but serves to balance its input, to ensure that it does not dominate to the extent that "the thing as in itself it is" disappears beneath the weight of "personal sensation." At the same time, no simple formula, like that of historical criticism, can suffice if the experience of the critic has led him to "rhetoric" when "disinterest" is needed. We are here again at that point of balance between the rhetorical and the hermeneutic which qualified our discussion of reader response theory in the last chapter.

For Arnold the succession of experience was intimated in that word we most strongly associate with him, “culture.” Arnold's phrase "the best of what has been thought or said" comes uncomfortably close to presenting culture as little more than a great books list. As Dewey put it,

Matthew Arnold's definition of culture, the "best of what has been thought and said" ... regards education as essentially a process of instruction by which the mind is molded into conformity with the models presented in the subjects studied. $^{42}$

Trilling, however, insisted that,

Arnold's culture, as he was careful to point out, does not signify what the word commonly does, a vague belletristic gentility; it means many things but nothing less than reason experienced as a kind of grace by each citizen, the conscious effort of each man to come to the realization of his complete humanity. ${ }^{43}$

Three of Trilling’s phrases here jump out right away: “reason experienced,” "a kind of grace by each citizen," and "realization of ... complete humanity.” In the first phrase, 
"reason experienced," we can see an obvious echo in Dewey. The second phrase, "a kind of grace by each citizen," uses religious language to describe the sensibility that culture creates in the individual; in its traditional usage grace is conferred upon an individual by an external agent, an authority, often God. But grace is also a kind of beauty of form. For Trilling, something more is involved here than a mere dispensation; Arnoldian culture is at once both an external authority and a kind of freedom; it falls not upon the religious supplicant, but upon the democratic citizen, and because it is democratic it is born not out of a supernatural authority, but an authority of both the self and the community. The third phrase is even more mercurial and contains a rather intriguing tension. The sentence we just looked at in which Dewey dismisses Arnold's culture is followed by this sentence.

As opposed to naturalism, humanism insists that the truly educative factors are to be found in contact with the past history of mankind, especially as past humanity has left an expression of itself in literature and art. ${ }^{44}$

Humanism may imply, as Trilling suggests the "realization of ... complete humanity," but it has, since the renaissance, come dressed in the anachronistic cut of a Greek tunic. Arnold's Hellenic fervor is a matter of record, and he, no doubt, overstated the role of Greek literature in education, but Arnold's writings suggest that Dewey's word "conform" is an overstatement. Arnold's "free play of mind" hardly seems to suggest a desire for conformity; his attack upon the philistinism of his time was surely not the result of a desire to conform; his reticence to read the past from an entirely historicist point of view is not the normal pattern of one wholly enamored with the past as a pure dictate. Everything seems to point to a subtly different reading of "culture," somewhat 
more in the way of Trilling's, a reading of culture that moves closer to a convergence with Dewey's concept of experience as the operating motive in education, even if Arnold falls far short of Deweyan reconstruction.

In this passage, Arnold regards "seeing things as they are" as a "scientific passion.”

But there is of culture another view, in which not solely the scientific passion, the sheer desire to see things as they are, natural and proper in an intelligent being, appears as the ground of it. There is a view in which all the love of our neighbour, the impulses towards action, help, and beneficence, the desire for stopping human error, clearing human confusion, and diminishing the sum of human misery, the noble aspiration to leave the world better and happier than we found it,_- motives eminently such as are called social,_- come in as part of the grounds of culture, and the main and pre-eminent part. Culture is then properly described not as having its origin in curiosity, but as having its origin in the love of perfection; it is a study of perfection. ${ }^{45}$

We are probably safe to say that Arnold uses the word "scientific" in a somewhat different way than does Dewey. For Arnold, at least as he uses it here, scientific need not mean "that which is not art;" rather the phrase might best be glossed as "a passion for knowledge,” or “a passion to study a thing at a very deep level,” or as Arnold, himself, glosses it, "the sheer desire to see things as they are." Scientific then is pulled into the sphere of culture; but as a thing that is in itself insufficient. Dewey seldom says this, seldom quite lets on that science is insufficient, but he, nonetheless, regularly carries us past science as method toward that larger something, a purpose or aim, a fellow feeling, a utopic and optimistic sense of progress, or as Arnold puts it, "the love of our neighbour, the impulses towards action, help, and beneficence, the desire for stopping human error, 
clearing human confusion, and diminishing the sum of human misery, the noble aspiration to leave the world better and happier than we found it."

We might feel a little startled to find Arnold using the phrase "an impulse toward action” in such a positive sense considering Arnold's attack upon Philistinism in precisely such terms, bewailing the drive to action that fails to appreciate the virtues of reason and critical thought. But Arnold's culture is an active agency, and he invariably emphasized its active nature. As Collini puts it, Arnold

... treats culture not just as something we can acquire or possess, but as something that is an active force in its own right. One indication of this is the frequency with which he uses the word with an active verb: culture "endeavours to see and learn, and to make what it sees and learns prevail," culture "conceives of perfection ... as a harmonious expansion of all the powers which make the beauty and worth of human nature," "culture has a rough task to achieve in this country," and so on. ${ }^{46}$

This active quality is easily overlooked; it has something of the feeling, as Trilling recognized, of Deweyan pragmatism; it is the curiosity that pulls us out of ourselves and moves us toward, and around, and through the things which we encounter in our world. Inactive culture is the fetish world of great books that sit on shelves collecting dust.

However, the passage above ends with the sentence: "Culture is then properly described not as having its origin in curiosity, but as having its origin in the love of perfection; it is a study of perfection.” Arnold has systematically taken two of his most important ideas about culture and told us that each in itself is insufficient. The desire to know, the "scientific passion," is inadequate by itself; the active nature of culture is also inadequate on its own. Culture points toward perfection, it is "the love of perfection; it is 
a study of perfection.” Notice he does not say, culture is perfection. ${ }^{\mathrm{s}}$ He is not speaking of an end state, but of an animating force. For Dewey, this animating force was "progress;" for Arnold, the classical aesthete, it was "perfection.” Arnold tells us clearly, these things of perfection are "motives eminently such as are called social." He seeks a social as much as an aesthetic perfection.

We now have a portrait of culture that includes: 1) a passion for knowledge; 2) a desire to reach out of the self (curiosity) in order to see the thing as it really is; 3) a reaching toward perfection, a kind of progressiveness, that is both social and aesthetic. Which of these elements did Arnold wish us to see as authorities?

Now, if culture, which simply means trying to perfect oneself, and one's mind as part of oneself, brings us light, and if light shows us that there is nothing so very blessed in merely doing as one likes, that the worship of the mere freedom to do as one likes is worship of machinery, that the really blessed thing is to like what right reason ordains, and to follow her authority, then we have got a practical benefit out of culture. We have got a much wanted principle, a principle of authority, to counteract the tendency to anarchy which seems to be threatening us. $^{47}$

While Dewey's description of Arnold's culture as “a process of instruction by which the mind is molded into conformity with the models presented in the subjects studied" ${ }^{48}$ may not be quite an honest description, we cannot completely clear Arnold of a focused interest in authority, any more than we can clear Dewey of such a charge; Dewey's use of words like "control" and "order" do not seem so fully charged with negative, antiauthoritarian energy as they are in some of his followers. Arnold was quite aware that in authority, he was moving against the excesses of liberty, of those who thought that

\footnotetext{
${ }^{\mathrm{s}}$ At least not in this passage, although he does so elsewhere.
} 
liberty could be reduced to the simplistic “doing as one likes.” Moreover, in suggesting that the English ought to repose greater authority in the state than had previously been their wont, he was aware that to go too far in that direction would not be wise, but he trusted to the native English distrust of state authority to keep such a movement in check. In other words, he is neither an authoritarian, nor a thorough antiauthoritarian. Our age has little capacity for dealing with such intermediate positions in thought. Dewey himself occupied a similar position; he neither wished to see an all-powerful state, nor a completely emasculated state. Indeed, he provided the grounds for that path of American liberalism which seeks to use the state as a buffer between the extremes of libertarian individualism and the autocracy of wealth or industry. He spoke of "socially organized intelligence,” which could mean both the informal ways in which we act together in concerted collaboration, but could also mean the more formal ways we organize ourselves in states or institutions or other such associations,- - indeed, he does not even rule out corporations, even in virtue of his critique of corporate philistinism. He positioned this "socially organized intelligence" in opposition to a "continuation of drift with attendant improvisations to meet special emergencies” or “dependence upon violence." ${ }^{\text {49 }}$ One sees in these terms something of an echo of Arnold's fears of anarchy, and in "socially organized intelligence" an evolution of Arnold's concept of culture. One also sees in the comparison between an aimless "drift" and a "dependence upon violence" a concern for a position that falls between the laissez-faire of "doing as one likes" and the heavy hand of authoritarianism. 
Nonetheless, the positions that Arnold and Dewey occupy upon this issue are substantially different. Few would accuse Dewey of taking too strong an authoritarian position. On the other hand, Arnold's views on authority have recently been described as "repugnant.” Quite frankly I am not sure I can readily accept en totale Arnold's conceptions of authority, particularly where it is defined by that excessive elitism he gives it in the essay we discussed earlier entitled "Numbers; or the Majority and the Remnant" in which he describes the special responsibility of that remnant capable of most effectively understanding the world and its culture,_- a position that Dewey rightly and often criticizes. At the same time, Dewey often falls awkwardly into the platitudes and hyperbole of antiauthoritarianism. Indeed, neither seems able to reach a truly balanced middle ground, and we may attribute some of that to the need that both felt to produce an argument that was adequate and responsive to the time in which they lived.

Nonetheless, we come, at this point, to the awkwardness of that middle ground situated in the low valley between mountains of excess,- - the echoes of those excesses battle in violent and clumsy cacophony. However, I strongly believe that only by fashioning some reasonable middle ground in which authority participates in a reasoned and human way can we hope to found an education that is both experiential and natural. In the next section I will attempt to form such a ground within a hermeneutic system,-all too conscious I must admit that such a system would be alien to both Arnold and

\footnotetext{
t Lincoln Allison, "Matthew and his Imaginary Friend - Matthew Arnold's Culture and Anarchy," http://web.archive.org/web/20070516043743/http://www.socialaffairsunit.org.uk/blog/archives/000721.p hp, retrieved on 27 August, 2007. Although, frankly, this paper seems to me to be one of the most curious readings of Arnold I have yet seen. Allison reads Arnold as hating the aristocracy and trying to further the ends of the middle class. No other critic of Arnold has, to my knowledge, proposed such a turn about. But Allison's great concern is that Arnold has favored the state, and so he is, to Allison, repugnant.
} 
Dewey. But if I am to fashion an adequate response from my reading of these two authors, I ought to follow Arnold and Dewey and not tie myself too securely to the past. For both Arnold and Dewey such an appeal to the adequacy of the moment was a pragmatic necessity; I see no reason it should not be so for me as well.

\section{The Hermeneutical-Rhetorical Relationship}

Let us return then to our simple hermeneutic model. We have seen its relevance at the beginning of this chapter to issues of authority. In the hermeneutic model that demonstrates the tertiary relationship of the Wikipedia editor, we saw that each author (Arnold, the accepted authority, and the Wikipedia editor) bore a certain relationship to the original text,_- in this case the poem "Dover Beach.” This relationship is commonly described as one of "authority." Logically, we would assume that Arnold, himself, bears a significant and immediate authority with respect to the poem; indeed, we cannot help but be struck by the obvious, - the word "authority" derives ultimately from the word "author." Thus to author a text is to take upon oneself the manifest intention of authority. As I hope to show, this simple realization is quite relevant as we seek to pull authority out of that awkward valley into which it has fallen.

The authority of the secondary position, that which we have called "the accepted authority" is, as a result a little more ambiguous. That which the secondary commentator authors is a statement "about" the work produced by another author. The secondary commentator takes upon herself the task of "exegesis," or interpretation,- - we should remember that interpretation is the central issue of hermeneutics. The tertiary editor, as 
we saw, produces a very different type of interpretation, one more purely object-oriented and far less inferential.

Nonetheless, ultimately, the signal relevance of hermeneutics lies not in its ability to systematically map out these rather obvious relationships amongst author, text and reader, but in its attempts to explain the nature of these relationships and to account for the nature of the process whereby the reader attempts to make anew the meaning of the text. If that meaning has no relationship to the intention of the author, if the author bears no authority relative to the text, then we have good reason to ask whether or not interpretation has really occurred. We are stuck within that half-journey that the science of objects allows, and have failed in that most essential aspect of the hermeneutic, or more properly the hermeneutical-rhetorical relationship: the movement of thought from one mind to another.

As we have already noted, authority has come to mean something considerably greater than the mere crafting of a text. In the concept of authority we can see the essence of an ethical relationship between the writer and the reader. In the authority that is violent and intrusive, we see the desire of the writer to impress the text's intention upon the reader in that gross and barbaric way that we have come to fear, for we know it reveals a frightening shadow all too much a part of the darker edges of humanity. (I am inclined to suspect that something of this resides in Arnold's satiric conception of the aristocracy as Barbarians willing to impress their slow-witted intent with heavy hands and little recourse to right or reason.) 
Each of the elements of our model bear a distinct ethical character. Let us map these characteristics before proceeding further.

\section{Ethos of the object}

The ethos of the object is relatively simple (see Illustration 5). An object either has an author, or it does not. Additionally, we might add that it either has a reader or it has not. For example, let us take a mote of dust floating in space too distant from highpowered microscopes to be seen and too small in itself to be even substantially "read" in our fumbling attempts to map the distribution of black matter in the universe. We might comfortably say of it that it has no "reader." Has it an author? Well, yes and no. Much depends upon what we are willing to accept as authorship. Even were we to set aside the intelligent creation, we do have the reasonable question of whether or not those physical activities which deposited this particular mote of dust in this particular empty and unnoticed corner of space amounted, in their way, to a kind of authorship. For each object such questions are the relevant ethos of their hermeneutical-rhetorical relationship. We do not need to answer the question of whether God the creator set that mote of dust in that distant void, or whether the Big Bang is itself a mythopoeic author. Were we to do so we would only find ourselves devolving into the very metaphysical concerns Dewey disdained. 


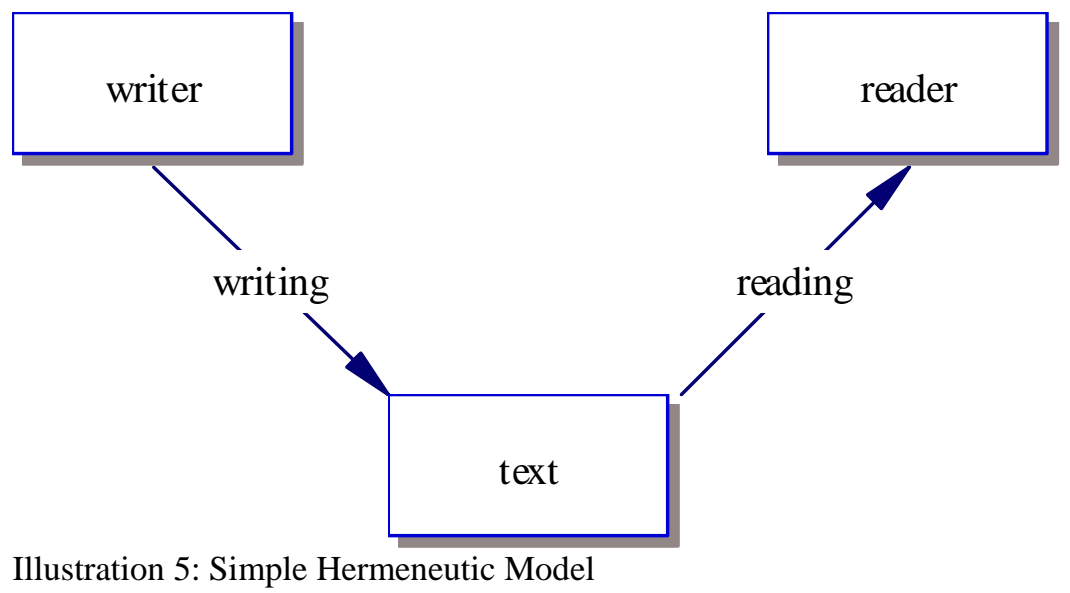

\section{Ethos of the writer}

We now must turn to the ethos of the writer and the reader. Let us begin with the writer. As we have already pointed out the writer is our traditional author-ity. Much of our antiauthoritarianism can be understood as our fear of the imposition of the author's intent upon the reader. When the author declares, “thou shalt behave as I would have you behave,” something in our modern, liberty-minded sensibility galls, and we vomit up our distaste and displeasure. "Who are you," we ask, "that you should think to author us?" This sensibility has become rather oddly wrapped around the concept of intention. The new critics, as we have seen, coined intentional fallacy as an extension of a reasonably scientific rationale, - we cannot read the intention of the author, because we cannot read minds; therefore, we have no alternative, but to read the text that lies before us as if it had no author, - if the intention truly lies within the text, then we will find it without attempting in anyway to read past the text. In today's disquisition of the same premise, the inability to know the author's true intention is repeated almost aphoristically, - a received idea, one we should all know and accept easily as a sort of common sense 
paradigm. But the underlying concern seems to be that intention itself is an invidious thing,- - if we accept the intention, we accept with it the deference and subservience we associate with our feudal past; science itself forced upon us a kind of new and awkward noblesse oblige,- - a deference and subservience to the object. The only way then to be rid of the impress of intentionality and with it the debilitating effects of subservience and marginalization was to isolate the critical act within the inferential range of the reader. Not merely the hermeneutical half journey of science, but a journey that goes no farther than the confining walls of the human skull. Dewey, no doubt, would say that dubiety had won out,_- shake his head and say that subjectivism was no reasonable response. When we use language to direct and order with the unmistakable impress of intention, we find ourselves in an inevitably ethical relationship between the author and the reader. We do not write laws expecting them to posses no intentional valence,-— to fail (even though they often may) to carry our desires and expectations with them. Now I make no moral judgment here as to whether it is right or wrong to make laws. Dewey made no such judgment and, indeed, fully respected the rule of law even as he disparaged the more intense violence of authoritarianism. However, the law, the order, the decree, the "thou shalts" of the Decalogue,— these are but a portion of author-ity. Arguably, all texts, - gestures, actions, that broad range of what we are calling texts, - - have, at their heart, this essential ethical relationship. So long as a text has an author and a reader, the two are connected ethically,- their relationship, one to another, is of the greatest relevance to the nature of meaning and understanding. Author-ity has to it a range of 
ethical relationships both to the object it authors and to the readers of that object. Let us rehearse but a few of the more obvious of these:

- To either the text or the reader, the writer may feel superior, or inferior, or equal to,_- if as a student I am writing a report for my professor, knowing that the professor is more knowledgeable than am I on the topic at hand, I may feel some sense of inferiority to my reader (the professor) and that, no doubt, will inform my writing. Frankly, in portions of this dissertation I have felt just such a disquietude; nothing can so remarkably humble one as the enormous quantities of scholarship that are the remarkable product of but a few passing decades.

- Toward the reader, the writer may feel a degree of either ill-will or, its opposite, sympathy; indeed, all manner of directed emotions may inform the authorial act: repugnance, disdain, love, loyalty, respect... In each we find a different character of ethical relationship; a different sensibility engrosses the text's author-ity and each carries the author's intentions more or less surely toward the reader.

- Patronage is a kind of sympathy, one which has come to feel uncomfortable to us today, - an awkwardness surrounds it, for its sympathy is charged with a sense of superiority; we have come to feel that the patronizing or paternalistic tone is not so very disinterested as it may claim to be,- we wonder if its appeal to sympathy is not really a mask for self-serving aims. While I have little doubt that the patronizing deserves 
our ethical concerns, as a part of the hermeneutic relationship it can be very complex, and deserves more consideration than we often today give it,- - I say this with no desire at all to recommend it, only to suggest that it deserves our critical response.

- Another essential characteristic of that type of authority we so disdain today is the desire to persuade or dissuade,- - that is to say the rhetorical character in which the point of view of the author is impressed upon the reader. Dewey and Arnold were both polemical writers; as a result neither is free of this characteristic of authority. Fish is also a polemical writers whose disingenuous pretense that "you will agree with me (that is, understand) only if you already agree with me" is one of the most extraordinary attempts to hide to the essentially rhetorical nature of writing that I have ever seen. ${ }^{50}$

- Arnold, as we have noted, used the word "disinterested," but he did not mean by this term a desire not to persuade,- - nor for that matter did he see in disinterestedness a need to subvert the natural inferences of the writer. Nonetheless, we may note a kind of "disinterestedness" that sits upon the opposite side of suasion. Some authorial voices take to such a disinterest reasonably well. Our Wikipedia editor, we might say, should have little truck with suasion and much with disinterestedness. But the writers of laws, voices of the state, perhaps have little option in such matters. Where 
laws do not persuade or dissuade, as the case may be, they have little efficacy.

- Another characteristic that has become quite overwhelmingly difficult for us is intentionality encompassing an absolute state, or universal; particularly when that sense of absolutism seems bent upon impressing itself, through authored acts or texts, upon the reader. Dewey, as we have seen, wrote a short autobiographical text entitled "From Absolutism to Experimentalism,” by which he (if I have read his intention correctly) meant (through the very title itself) to show that he had turned away from an absolutistic point of view. Now to what degree he fully achieved that, at least within the rhetorical bounds of his own writing, is an open question. His turn from absolutism, one might argue, was, itself, not an absolute turn. We have already seen how he found it necessary to attempt to bring about a return of something that met the needs (pragmatic and rhetorical) of the universal. This particular ethical relationship (absolutism, universalism), I suspect, shall remain a troubling one so long as we place the degree of importance upon it that it seems now to bear. When we allow the absolute or universal to be simply a position we approach not so much contingently, but pragmatically, as needed,-— when we remove from the concept of the universal that overwhelming demonization it is now subject to,- - when we realize that universals are often merely banal and at times even benign,- - then they will cease to 
have that marginalizing and malicious effect upon us that they seem now to so egregiously possess.

- Many other relationships, too many to fully rehearse here, are a part of the ethical nature of author-ity, of our common role as authors. To note but a few more in quick succession: dissimilitude and all the degrees of verisimilitude that lie between it and honesty; hubris as it shades off toward humility; certainty not as the opposite of uncertainty but of ignorance (uncertainty, here, is that state of partial knowing that lies between the certainty and ignorance) $)^{\mathrm{u}}$; the desire to offend; the desire to bear homage; the elitism and professionalism of our specialized languages; the metaphysics of our relationship to the object world; and many, many more.

I have used the phrase "our common role as authors," which may perhaps be the most important aspect of the ethos of authority. Quite simply, we are all authors,authority is not that thing that we demonize as the marginalizing hegemony, or the dictatorial state, or the oppressive oppressor. We have mistaken authority for authoritarian.

That we are all authors is fundamental, I think, to properly understanding the nature of author-ity. To know that we all will, in our lifetimes, follow the ethical mapping above and greet our readers with disdain, or absolutism, or sympathy, or

\footnotetext{
${ }^{u}$ Certainty may also be taken to mean a psychological state relatively synonymous with absolutism; these two qualities of certainty are often confused; nothing is quite so amusing as the philosophers who try to put certainty in opposition to uncertainty (with a clearly stated preference for uncertainty) not realizing that in the process they betray their own desire for a curiously awkward kind of certainty.
} 
fraternity; we will patronize some and worship others; we will exercise the range of degrees between superiority and inferiority; we will, in essence, be human. Nothing of value can come from demonizing one half of the ethical relationship, no matter which half it is. Those who are overtly evangelical (whether they be on the right or the left) are, to my mind, as human as are the most neutrally unprepossessing amongst us. No matter what the full range of our emotions, ideas, dispositions, beliefs, - these ethical relations will continue with us. Only if we turn to a fuller understanding of intentionality, to the full hermeneutical-rhetorical relationship, can we properly prepare ourselves to meet the richness of human interaction. If we deny that richness we are all, each of us, the poorer for it.

\section{Conclusion}

Authoritarianism may well be the single most significant philosophical issue of the twenty-first century. Surely we all know what a scourge it has been upon both our past and present; how it has shaped itself into an undeniable adversary of individuality; how it has subtly worked its way into our thoughts giving rise to prejudice and intolerance; how it has formed itself into self-serving hegemonies; how it has corrupted absolutely that alone which can be absolutely corrupted,_- the human soul; how it has bureaucratized the manner of business and driven the simple desire to make an honest dollar into the corruptions of profit and greed; how upon its verge stand the weak and improvident, the poor and infirm, the wretched, tired, humble masses, the social outcasts, 
the people of the margins, those for whom authoritarian zeal and its helpmate power have made this chance Eden of modern life a foul and woebegone wasteland.

Deweyan liberalism recognized the virtue of the state. Dewey saw in the state a capacity to offset the overreaching of industry and corporate interests. In this respect Dewey was very much in tune with Arnold who argued, perhaps overly so, the necessities of granting to the state such authority as the promulgation of mandatory primary education. Arnold's grumbling against liberalism was directed at that liberalism that sought liberty at the expense of equality, which allowed a liberalism of capital, but failed to address the educational needs of both the poor and the middle class. In gross (and certainly much too simplified terms), we might say that, today, the religious right sanctifies the authority of religion, while demonizing the authority of a state it sees as all too secular. The economic right sanctifies the authority of wealth, capital, and technology, while demonizing the authority of the state and tolerating the authority of religion only provided it remains aloof from the concerns of capital. The left forms a rather mixed group, but often finds itself comfortable with the authority of the state, but uncomfortable with the claims to authority in religion, corporations, or wealth. Libertarians, of course, demonize all authority save that of the self.

Now even given that these are broad and unnuanced portraits, what becomes apparent as we look across the spectrum of belief today is that for each position we may note an authority that is acceptable and an authority that is not. The questioning of authority is an inevitable part of every position, but so, too, even if not stated as such, is the acceptance of authority. Being myself a centrist, I find virtues in all authority 
(religious, capital, wealth, corporate, cultural, environmental, economic, global, and, of course, that most central to liberalism, the self). But I also recognize the limitations in each. I cannot see how denying to each its authority in any way is a sane response to the world we live in, nor can I see how an undue idolization can lead to any productive action. The latter Arnold called philistinism, the former, anarchy. If, indeed, authority is the most significant philosophical issue of the twenty-first century, then can we really grapple with it, if we have so utterly demonized or sanctified it that we may not look at it with fresh eyes?

The issue of divine authorship, so many years after Arnold and Dewey each believed himself, in his own way, to have satisfactorily reached some measured solution upon the matter, seems to me, today, to remain an awkward issue which cannot be easily set aside. For Arnold, the divine author was the fount of authority, to be accepted implicitly even as one turned aside the foolishness of superstition; for Dewey, the divine author was the source of an authority that no longer had root and purpose, even though meaning and value continue to reside within nature, which he refused to reduce to "an indifferent, dead mechanism.”v For myself, as it is my intention to rehabilitate our conception of authority, something of real and practical value yet resides there; something of an inevitability yet clings to our deepest, least guarded thoughts; authorship

\footnotetext{
v Dewey: Experience and Nature, 1925, Page lw.1.28: "The isolation of traits characteristic of objects known, and then defined as the sole ultimate realities, accounts for the denial to nature of the characters which make things lovable and contemptible, beautiful and ugly, adorable and awful. It accounts for the belief that nature is an indifferent, dead mechanism; it explains why characteristics that are the valuable and valued traits of objects in actual experience are thought to create a fundamentally troublesome philosophical problem.”
} 
is no mere fiction of language, nor a primitive anomaly of thought, but something with a kind of substance, beyond the tentacled-mind, but real in its own way, nonetheless.

If removing intentionality from the tools available to the literary critic serves as a contraceptive to the dominating effects of authority, it likewise proves to diminish the possibilities of an intimacy between reader and writer. Arnold's voice, his manner, his style, as Stefan Collini tells us "depends upon creating a sense of intimacy with the reader." The effects of that intimacy could be equivocal; "if we are prone to feel that our own views are implicitly being slighted..., then the tone merely arouses impatience and resentment. ${ }^{51}$ But is such an equivocation sufficient cause for rejecting the potential of an intimacy between author and reader? Such an intimacy has its dangers,- in an authority too neurotically, despotically expressed; or in a voice that subtly insinuates itself; in a mystification of the other, the imagined author, through an inference grown too bold; or in the self-defeating, self-effacing ideality of a morbid hero-worship. As well, it has its positives, - in the breaching of the text as object-barrier; and in the movement towards the other; in the tolerance it can enable for other-thought; and in its sole capacity to remedy that great blight of modernity, alone-ness. 


\section{Notes}

${ }^{1}$ Arnold and Allott (editor), "Dover Beach,” pg. 242-43.

2 Eden, "Hermeneutics and the ancient Rhetoric Tradition," in Brendan Dean Schildgen (editor), The Rhetoric Canon, 1997, pg. 127.

${ }^{3}$ Eden, "Hermeneutics and the ancient Rhetoric Tradition," in Brendan Dean Schildgen (editor), The Rhetoric Canon, 1997, pg. 144-5.

${ }^{4}$ Arnold, Culture and Anarchy, 1916, pg. CPW 5:182.

${ }^{5}$ Jacques Derrida, Spivak (translator), Of Grammatology, 1976.

${ }^{6}$ See Boswell, The Life of Samuel Johnson.

${ }^{7}$ Dewey, Experience and Nature, 1925, pg. lw.1.324.

${ }^{8}$ Dewey, Experience and Nature, 1925, pg. lw.1.325.

${ }^{9}$ Arnold, "Dover Beach” Allott: pg. 239-243.

${ }^{10}$ Arnold, "Dover Beach” Allott: pg. 239-243.

${ }^{11}$ Honan, Matthew Arnold: A Life, 1981, pg. 234.

${ }^{12}$ Cleanth Brooks and T. V. F. Brogan, "The New Criticism," 834, in The New Princeton Encyclopedia of Poetry and Poetics, 1993.

${ }^{13}$ Wikipedia contributors, "Dover Beach," Wikipedia, The Free Encyclopedia, http://en.wikipedia.org/w/index.php?title=Dover_Beach\&oldid=150660550 (accessed August 11, 2007).

${ }^{14}$ Arnold, Culture and Anarchy, 1869, CPW 5:115.

${ }^{15}$ Arnold, "Democracy," 1860, pg. CPW 1:7-8.

${ }^{16}$ Arnold, "Democracy," 1860, pg. CPW 1:8.

${ }^{17}$ Collini, Introduction to Matthew Arnold: Culture and Anarchy and other writings, 1993, pg. xxiii.

${ }^{18}$ Arnold, "Equality," 1878, CPW 8:302.

${ }^{19}$ Arnold, Culture and Anarchy, 1869, CPW 5:121.

${ }^{20}$ Dewey, Freedom and Culture, 1939, Page lw.13.68.

${ }^{21}$ Dewey, Freedom and Culture, 1939, Page lw.13.78.

${ }^{22}$ Letter, John Dewey to Alice Dewey, 2 July 1894, in Hickman and others, 2005, 1894.07.02 (00152); also, Martin, 2002, p 161.

${ }^{23}$ Honan, Matthew Arnold: A Life, 1981, pg. 340-41.

${ }^{24}$ Dewey, Freedom and Culture, 1939, Page lw.13.178.

${ }^{25}$ Dewey, Democracy and Education, 1916.

${ }^{26}$ Dewey, Reconstruction in Philosophy, 1920, Page mw.12.80.

${ }^{27}$ Dewey, Democracy and Education, 1916, Page mw.9.356.

${ }^{28}$ Cf. Collini, Public Moralists, 1991.

${ }^{29}$ Dewey, Democracy and Education, 1916, Page mw.9.357.

${ }^{30}$ Dewey, Experience and Education, 1938, Page lw.13.41.

${ }^{31}$ Dewey, Democracy and Education, 1916, Page mw.9.363-4.

${ }^{32}$ Dewey, Democracy and Education, 1916, Page mw.9.364.

${ }^{33}$ Dewey, Democracy and Education, 1916, Page mw.9.364-5.

${ }^{34}$ Dewey, Democracy and Education, 1916, Page mw.9.367.

${ }^{35}$ Dewey, Democracy and Education, 1916, Page mw.9.368-9.

${ }^{36}$ Dewey, Democracy and Education, 1916, Page mw.9.367-8.

${ }^{37}$ Dewey, Reconstruction in Philosophy, 1920, Page mw.12.201.

${ }^{38}$ Dewey, Reconstruction in Philosophy, 1920/1948, Page mw.12.262.

${ }^{39}$ Locke, Alain and Leonard Harris (ed.) The Philosophy of Alain Locke: Harlem Renaissance and Beyond (Philadelphia: Temple University Press).

${ }^{40}$ Dewey, “What Are Universals?” 1936, Page lw.11.113.

${ }^{41}$ Dewey, Democracy and Education, 1916, Page mw.9.363-4. 
${ }^{42}$ Dewey, "Contribution to Encyclopaedia and Dictionary of Education," from the article: "Aims and Ideals of Education," 1921, Page mw.13.400.

${ }^{43}$ Pg. 252, Matthew Arnold, Lionel Trilling, Harcourt Brace Jovanovich, New York, 1939.

${ }^{44}$ Dewey: "Contribution to Encyclopaedia and Dictionary of Education," from the article: "Aims and Ideals of Education," 1921, Page mw.13.400. Text has been adjusted to sentence case and internal references (q.v.) have been removed.

45 Arnold, Culture and Anarchy, 1869, CPW 5:91.

${ }^{46}$ Collini, Arnold, 1988, pg. 85.

${ }^{47}$ Arnold, Culture and Anarchy, 1869, CPW 5:123.

${ }^{48}$ Dewey, "Contribution to Encyclopaedia and Dictionary of Education," from the article: "Aims and Ideals of Education,” 1921, Page mw.13.400.

${ }^{49}$ Dewey: Liberalism and Social Action, 1935, pg. lw.11.61.

${ }^{50}$ Fish, "Interpreting the Varorium," 1976, 1980, in Leitch (general editor), The Norton Anthology of Theory and Criticism, 2001, pg. 2089.

${ }^{51}$ Collini: Arnold, 1988, pg. 12-13. 
"Below the surface stream..."

Below the surface stream, shallow and light, Of what we say we feel-below the stream, As light, of what we think we feel-there flows With noiseless current strong, obscure and deep, The central stream of what we feel indeed.

- Matthew Arnold ${ }^{1}$

\section{The Reflective-Response Mind}

Reflection, contemplation, meditation, the pensive life. The mind alone; the body a hollow, forgotten shell. When I think of the contemplative life I tend to think of the old Christian hermits like St. Anthony sitting in a cave in the desert, the devil spying upon him awaiting that moment when he may blast the poor saint's mind with the sore temptations of earthly pleasures, or St. Jerome as Dürer as drew him, in his cell huddled over a massive codex, translating the bible, line by line word by word, at his feet the lion from whose paw he pulled the evil thorn; or I think of the Buddha sitting under the Bodhi tree awaiting enlightenment; or Kant walking the gray streets of Konigsburg, a brown study by which his neighbors set their clocks.

One cannot imagine Arnold sitting still long enough, nor putting aside that sly irony and wit that he depended on, to ever be mistaken for a wizened old hermit. As for Dewey, one pictures him at his typewriter, a bit of a parody of St. Jerome, the children running about and playing loudly throughout the house, he unmindfully tapping out page upon page, pressing his thoughts forward with no backward glance. 
We may picture Arnold and Dewey as thoughtful, intelligent men, but neither recommends himself as an icon of contemplative thought. Nonetheless, for both men, the reflective mind was an essential part of the educational process. For Arnold, culture was a thing that revealed its virtues only to those who read critically and reflectively; for Dewey, reflection was the essence of educated thought; not passive, not reserved for seers and wise men, not a thing outside the common pattern of life, but a thing essential to life, an active part of life.

We have followed our hermeneutic model as it reached out toward the object with the tentacled mind, as it queried the object with the critical mind, as it reached past the object with the intentional mind, only to become aware that intentionality moves in two directions. The recognition of the latter, that the mind must deal with two intentionalities, that that flows from the object and that, which we have called inference which flows from the reader's own thoughts, leads us to the necessities of the final movement of mind,- - the reflective-response mind.

\section{Our Mental Furniture}

In How We Think, Dewey established his conception of reflection and moved it from a passive role in human thought, to a role of centrality. Thought for Dewey was the term for the stream of indiscriminate activity in the mind; reflection the term for thought that is actively ordered, consecutive, moving toward intention, pulling at and away from uncertainty or uneasiness.

In the first place thought is used broadly, not to say loosely. Everything that comes to mind, that "goes through our heads," is called a thought. To think of a 
thing is just to be conscious of it in any way whatsoever. Second, the term is restricted by excluding whatever is directly presented; we think (or think of) only such things as we do not directly see, hear, smell, or taste. Then, third, the meaning is further limited to beliefs that rest upon some kind of evidence or testimony. ${ }^{2}$

The third sort of thought (belief) has two aspects to it:

.... belief is accepted with slight or almost no attempt to state the grounds that support it. In other cases, the ground or basis for a belief is deliberately sought and its adequacy to support the belief examined. This process is called reflective thought; it alone is truly educative in value... ${ }^{3}$

Reflective thought, then, is the substance of education. It is not the indiscriminate stream of thought (this conception of a stream of thought Dewey took from William James), nor our ability to bring to mind those things out of our memory or imagination which are otherwise not physically present. The final distinction is that which underlies Dewey's conception of reconstruction. When we examine a thought (i.e. reflect upon it) we must ask ourselves how valid is this thought? The asking of this question and the feelings of perplexity and uncertainty that arise from it are the essence of reflective thought.

Reflection is a process in which our thought moves out of that haphazard, undifferentiated stream, "this random coursing of things through the mind," ${ }^{4}$ in which we spend so much of our lives, and becomes organized, consecutive, intentional.

Reflection involves not simply a sequence of ideas, but a consequence-a consecutive ordering in such a way that each determines the next as its proper outcome, while each in turn leans back on its predecessors. The successive portions of the reflective thought grow out of one another and support one another; they do not come and go in a medley. Each phase is a step from something to something... ${ }^{5}$

Reflective thought produces belief, but not all beliefs are the products of reflective thought. 
[Some] thoughts grow up unconsciously and without reference to the attainment of correct belief.... From obscure sources and by unnoticed channels they insinuate themselves into acceptance and become unconsciously a part of our mental furniture. Tradition, instruction, imitation —all of which depend upon authority in some form, or appeal to our own advantage, or fall in with a strong passion - are responsible for them. Such thoughts are prejudices, that is, prejudgments, not judgments proper that rest upon a survey of evidence. ${ }^{6}$

In the last chapter we suggested that Dewey provides us with some warrant for accepting that authority has a role in our educative processes. Here he is suggesting the very opposite; here authority is placed in clear opposition to reflective thought. Thought grounded upon someone else's word, upon authority, is not reflective thought,-— not "correct belief." In so many ways this is, perhaps, the most problematic of all of Dewey's concepts.

Imagine, if you would, for yourself, the effort needed to really clear your mind of all its mental furniture. We would need to begin by setting aside everything that Dewey has just told us,- - why? Because not having formulated the thought ourselves, we should need to come at again, without Dewey's aid, to construct this notion in our own terms, through our own experiences,- - which we might even be able to do for the conception of prejudice he gives us here, but could we do the same paragraph after paragraph, page after page,_- at some point we trust to some degree in Dewey's experience and reasoning, and let our critical judgment take the place of our reconstructive experience,-not entirely, but at least to some extent. ${ }^{a}$ Dewey's voice takes on something of the

\footnotetext{
${ }^{a}$ One might argue that the distinction Dewey is making concerns not what is phenomenally correct, but rather what makes for a "correct belief" (nominal belief), - we can assume, then, that another sort of belief, let us call it "received" rather than "incorrect," stands in opposition, and that such a belief is not a "correct" belief simply because it is not a belief that the individual has derived directly from experience. Nonetheless, the tone of the passage, and Dewey's tendency to be dismissive of the traditional, the ready-
} 
quality of an authority,- - but, of course, were we to overly idolize that authority, to say, "well Dewey is always right; he is so much smarter than I could ever be," - then we would be doing precisely the opposite of what Dewey asks us to do. Instead, we find ourselves, pragmatically somewhere in the middle, as always, and an awkward middle it is. Ultimately, we will probably come to the conclusion that Dewey is simply, here, in one of those hyperbolic modes that his polemical spirit often drives him toward.

Now, if indeed this passage, is hyperbolic, then Dewey has moved to such a hyperbolic state in order to make a particular point. I think that point is quite simply that reflection is a difficult, "troublesome" as he says here, activity.

Reflective thinking is always more or less troublesome because it involves overcoming the inertia that inclines one to accept suggestions at their face value; it involves willingness to endure a condition of mental unrest and disturbance. Reflective thinking, in short, means judgment suspended during further inquiry; and suspense is likely to be somewhat painful. ${ }^{7}$

I cannot believe that Dewey meant to hang us out in a perpetual state of mental anguish, but I do think he was keenly aware that the reflective state was one that often required some sort of goad or prod to get us to jump into it. Surely he knew that some people would do so without much prodding, but hyperbole here trumped hesitancy since his intention was to goad those who needed goading into this painful state which they naturally tended to avoid.

Assuming, then, that we are able to move past the lethargy of inertia, what is this reflective thought? Is it the whole complex of reconstruction? Is it practical criticism? Is it the movement from inference to intention that characterizes our role as reader-

made, the received, clearly suggests that this other type of belief is, indeed, decidedly negative and "incorrect." 
writer? Or is it simply, as Dewey says here "judgment suspended during further inquiry”? I suspect that ultimately it is all of these things. Again, if we go back to our hermeneutic model, what we see in reflective-response is a kind of recursion, our tentacled mind has moved out beyond itself, $\mathrm{X}^{3}$ to $\mathrm{X}^{2}$ to $\mathrm{X}^{1}$, and now it returns, $\mathrm{X}^{1}$ to $\mathrm{X}^{2}$ to $\mathrm{X}^{3}$, and we must make something out of the journey,- - we must draw our inference, but we do so under certain specific conditions. Rather astonishingly, the dubiety we had thrown out with Hume in leaping past the limitations of our senses returns now in a most uncomfortable way.

To maintain the state of doubt and to carry on systematic and protracted inquirythese are the essentials of thinking. ${ }^{8}$

Dubiety,— doubt,_- uncertainty, — suspension of judgment,— our greatest danger in approaching these states is to think that they are absolute states. That Dewey asks us to move into a state of dubiety and remain there. We are rather in the midst of a quest for certainty,_- "The quest for certainty is a quest for a peace which is assured, an object which is unqualified by risk and the shadow of fear which action casts."” However, the quest for certainty is inherently active,_- it seeks a change in states of knowing, and thus it is, forever, inside "the shadow of fear which action casts." For Dewey reflective thought is active thought, judgment may be held in suspension, but thought continues to move, and that movement, because of the suspension of judgment, is a fearful one. Perhaps, a shade overly dramatic, but without these elements of fear, doubt, and uncertainty we might easily allow reflection to devolve into a mind in stasis. Fear, doubt, and uncertainty provide the motive force that moves the mind forward, that 
prevents its falling into stasis. But fear, doubt and uncertainty have, as well, pressed the mind to seek that which lies outside of the reflective mind, as Dewey defined it.

The ulterior issue is the possibility that actual experience in its concrete content and movement may furnish those ideals, meanings and values whose lack and uncertainty in experience as actually lived by most persons has supplied the motive force for recourse to some reality beyond experience: a lack and uncertainty that account for the continued hold of traditional philosophical and religious notions which are not consonant with the main tenor of modern life. ${ }^{10}$

Reflective thought, then, with Dewey, begins to move away from our traditional notions of the contemplative. It is the mind in a state of unrest, querulous, uncertain, seeking,- - psychologists call this mental state cognitive dissonance. Neither Dewey nor Arnold are quite so clinical. Dewey characterizes reflective thought as tenacious, with a “willingness to endure,” to follow this mental disturbance to its ends, - - to discover its own intentionality. An echo of Arnold comes through here.

It is true that the critic has many temptations to go with the stream, to make one of the party movement, one of these terrce filii; it seems ungracious to refuse to be a terrce filius, when so many excellent people are; but the critic's duty is to refuse, or, if resistance is vain, at least to cry with Obermann: Périssons en résistant. ${ }^{11}$

Reflective thought, then, is driven by uncertainty and dubiety, by “mental uneasiness,”12 but does not rest in this state. "The problem fixes the end of thought and the end controls the process of thinking."13

\section{Dipsychus}

Dewey defines and rather fully describes reflective thought in the first chapter of How We Think. The concept of reflective thought, however, comes at the end of my argument; in so many ways it is not the starting point of thought, nor did Dewey think it 
was. In Experience and Nature he somewhat carelessly equates the testing and substantiating of his conception of reflective thought with the phrase "the final act of knowing.”

Starting from one good, treated as apparent and questionable, and ending in another which is tested and substantiated, the final act of knowing is acceptance and intellectual appreciation of what is significantly conclusive. ${ }^{14}$

But if this is, indeed, the final act of knowing, how are we not locked back within the internal mind and once more isolated from the larger object-laden world? Dewey had with his metaphor of the tentacled mind forced us outside of ourselves, out into the world of objects. He had directed us toward a critical encounter with the objects of the world. As we noted in the first chapter such an encounter can be only a half-journey, if we do not attempt to understand the authorship and intentionality of the object. Arnold with his hermeneutic concerns for getting "near" to the thoughts of another carried us further upon our journey, but Dewey, as we have seen, in his unsystematic way was not unconcerned with issues of intentionality. As we return upon our journey, having traveled through the object to the object's author, we come to the "turning in" that concerned both Arnold and Dewey. This "turning in" has an inherent danger to it,_- something must keep us from locking our thoughts back within the reflective mind. What is it that keeps us from ever thinking that we have found the "final act of knowing" even if what we have found is "significantly conclusive"? Somehow our mind must return to the world of objects and not fall into that passive state of acceptance that ultimately was anathema to both Arnold and Dewey. 
A hermeneutic view, or rhetorical view, for that matter, would suggest that "the final act of knowing" occurs when knowledge moves from the mind in which it had started into another mind. Now we might argue that the mind of the individual, through experience, is no longer the mind in which the experi- (from trial) thought had begun, but Dewey does not satisfy us upon that head. His reflective thought is active, dynamic, a process that occurs over time, so that the final act of knowing may occur in a mind that has changed in the course of its reflection, but its movement toward acceptance and appreciation is the product of that reflective thinking, and thus the product of $a$ mind, not of two minds. Dewey does not push us toward any sense of two-mindedness in reflective thinking, and would, no doubt, have thought that the worst excesses of two-mindedness already existed in our dualism of mind and body.

However, something of significance does happen when we realize that the object we have encountered in the world is an object we have authored ourselves and thus bears our own intentionality. We might call such an act "overhearing ourselves.” A poem by Arnold's good friend and fellow poet, Arthur Hugh Clough, entitled Dipsychus makes this point rather poignantly.

Arthur Hugh Clough was for many years Arnold's closest friend. They had both been at Rugby together under Arnold's father, Dr. Thomas Arnold. Clough was a few years older and went up to Oxford four years before Matthew. In 1841, Clough received a "second" in the examinations for degree. When he received the news, he hiked to Rugby to see his surrogate father, Dr. Arnold. The younger Tom Arnold saw his friend “with face partly flushed and partly pale, 'I have failed,’ he said."15 
Clough appears to have begun work on Dipsychus in 1850 during a vacation trip to Venice, but worked on it up to his death. It was left unpublished when Clough died in 1861, at age 43. Clough's widow published a version of it in 1865 . But the poem has troubled every editor since; Clough himself did not prepare a final draft, but left the poem in multiple states over several manuscript volumes. In what appears to be the earliest version, the poem is a dialog between Faustulus and Mephisto. At some point, Clough seems to have changed the dramatis personae to Dipsychus, literally two-mindedness, and the Spirit, who may or may not be Mephistopheles. The poem is divided into one or two parts and as many as fourteen scenes, a prologue and an epilogue,-— all depending upon which edition one consults. Clough's little drama is set in Venice, where Dipsychus begins with a reflection upon a poem he (reflecting biographical details of Clough himself) had written earlier in Naples. The poem is "Easter Day, 1849," and includes the following lines.

Christ is not risen!

Christ is not risen, no, He lies and moulders low;

Christ is not risen. ${ }^{16}$

The words of "Easter Day, 1849” express Clough’s denial, not of Christianity, which is how we may read the words today, but that aspect of Christianity which his mentor, Dr. Arnold, had described as superstition. Dr. Arnold did not go so far as to see in the resurrection a superstitious belief, but both Matthew and Clough certainly did. Ultimately, the Arnolds and Clough are part of that peculiar nineteenth century agnosticism which was often more actively religious in belief and act than anything we 
might think of as agnosticism today. In Matthew Arnold's case, he tried to hold onto the essential ethical character of Christianity and the poetry of the language of the bible, while rejecting any traces of superstition. In Clough's case, the concern was more personal, more a question of his own choices in life and how they were to affect him, as we shall see.

However, what most interests us here is how these opening words to Dipsychus demonstrate the very sort of overhearing oneself we have been looking for. From its first publication, indeed, even before it was published and had circulated only in manuscript, Clough was seen in the character of Dipsychus. In a passage Clough cancelled, he wrote:

What we have written like a brother sticks, And we like parents hug it. Is it vanity That makes it such a solace? is it self love In watches of the night and when the soul Is sick and begs for medicine, to recur To what had been its medicine in old days, And repeat-over poems of one's own? Why should not other people's do as well? ${ }^{17}$

Here we have the problem of overhearing drawn out for us in fairly clear terms. The poet wonders, am I overhearing myself simply because my own words are a kind of medicine for my soul, - they remind of the feeling they infused into me at the time I uttered them? Thus overhearing may be merely a sort of self-nostalgia, a return to the home which the self had once inhabited. But Clough’s queries here sound much more like Dewey’s reflective thinking than a mere nostalgic memory floating to the surface to provide medicine for a sad and lonely moment. Clough queries these memories and in doing so he places himself into what Dewey described as “a condition of mental unrest and disturbance.”18 He adds a query that, with our interest in hermeneutics, gives an 
intriguing turn to the thought: why, he asks, is this affect true of his own poems, "Why should not other people’s do as well?”

Something very non-Deweyan results from this reflective thinking: inaction. Somehow, this overhearing of oneself has resulted not in the active, dynamic problemsolving that Dewey proposed and which made reflective thinking for Dewey such an essential part of the educative process. In the first part of the poem, Dipsychus is led through a series of Faustian temptations. The spirit, trying to pull him out of his theological musings suggests a dalliance with a passing prostitute. But Dipsychus’ idealism reacts in disgust. As he faces other temptations, he struggles with his response to the active world around him; he wonders just what the Spirit is:

What is this persecuting voice that haunts me?

What? whence? of whom? How am I to detect?

Myself or not myself? My own bad thoughts, Or some external agency at work, To lead me who knows whither? ${ }^{19}$

Here the hermeneutic concerns again are fleshed out for us. "Myself or not myself?” Even if it his own conscience, he might well ask the same. If I overhear myself, is that self of old, yet myself now? Do I own "My own bad thoughts”? And in owning them, am I completely undone? Can I yet act? And if this is "some external agency at work," where is it leading me? The external agency, the voice of the other, the intentionality that I can no longer distinguish from my own inference,- will it con me? Will it lead me astray, take advantage of me, repress me, oppress me, have its way with me? This fear of being taken advantage of, being made a fool, being deceived, runs through much modern aesthetics and beyond that into much of our modern zeitgeist. 
Matthew Arnold [says Dewey] somewhere quotes with approval the saying of a French writer that the chief advantage of education is the assurance it gives of not being duped. A more positive statement is that the profit of education is the ability it gives to discriminate, to make distinctions that penetrate below the surface. One may not be able to lay hold of the realities beneath the froth and foam, but at least one who is educated does not take the latter to be the realities; one knows that there is a difference between sound and sense, between what is emphatic and what is distinctive, between what is conspicuous and what is important. ${ }^{20}$

Somehow education had not the same robust effect upon Clough that it appears to have had on Arnold and Dewey. Not that either was any less likely to be conned (certainly not Dewey who has a few somewhat embarrassing moments in his life history when he seems to have fallen into a scheme which if not intentional conning, was, nonetheless, not particularly wise). But their reactions seem not to have been the sort we see here, where Clough seems to be upon the verge, not of being conned, but of actually conning himself. Clough's great struggle is not only with himself, but with that leap into the world that Dewey wished us to make when he placed experience at the center of his educational theory.

Anthony Kenny, who accepts the two-part division of the poem, describes the second part of the poem thus:

The second part of the drama differs from the first in several ways. Whereas the temptations of part one are such as beset all human beings, the problems of the second part concern the specific choice of a career for an individual with the gifts, ideals and history of Clough himself. Is there any career which can be chosen without a betrayal of ideals? Can an idealist frame a life for himself without fitting into any of the slots provided by the world? ${ }^{21}$

In the next chapter we will explore this problem a little further. For now let us say that Clough's profession of his ideals and abilities just did not match the realities the world called him to. Struggling to find a way to act in the world, he lets the Spirit take over and 
make his decisions for him,- - what career path he should follow and, even, whom he should marry.

Action is what we must get, it is clear, And one could dream it better than one finds, In its kind personal, in its motive not; Not selfish as it now is, nor as now Maiming the individual. If we had that, It would cure all indeed. Oh, how would then These pitiful rebellions of the flesh, These caterwaulings of the effeminate heart, These hurts of self-imagined dignity, Pass like the seaweed from the bows Of a great vessel speeding straight to sea!

Yes, if I could have that; but I suppose We shall not have it, and therefore I submit. ${ }^{22}$

In an awkward echo of the poem, Clough sent a letter to his future father-in-law who had demanded that Clough have a living of $£ 500$ before marrying his daughter. Clough, in America at the time unsuccessfully seeking work, with an opportunity for a position back in England that would allow him to rise to the necessary $£ 500$ after an intolerably long eight years, placed the decision in the older man's hands. Clough's abandoning of his responsibility to make a decision for himself, his cry of "I submit," annoyed his family and friends. The "self-imagined dignity" did not fall from the bows "Of a great vessel speeding straight to sea," but of a much smaller vessel about to flounder upon the rocks.

"Dipsychus" ends with a prose epilogue in which Clough addresses an unnamed uncle who admits he dropped "into a doze while the young man was driveling through his later soliloquies" and declares that the poem's protagonist is much too conscientious and pious. "It's all [Dr.] Arnold's doing; he spoilt the public schools.” To which Clough replies- 
"You see, my dear sir, you must not refer it to Arnold, at all at all. Anything that Arnold did in this direction-_"

"Why, my dear boy, how often have I not heard from you, how he used to attack offences, not as offences - the right view-against discipline, but as sin, heinous guilt, I don't know what beside! Why didn't he flog them and hold his tongue? Flog them he did, but why preach?”23

Matthew Arnold and Arthur Hugh Clough were both products of Dr. Arnold’s Rugby. Nonetheless, they seemed to have turned out quite different. Clough has clearly learned that critical skill that Arnold called culture and Dewey called reflective thinking. But Clough continued to flog and preach to himself in the way the great man had done, contemplating, reflecting, meditating forever upon the heinous sin of which he believed himself guilty. He knew its source; he knew that the voice of conscience was both his own voice and a voice he had absorbed from Dr. Arnold. Now we should not carry the equation between Dipsychus and Clough too far. Clearly they are different; Clough demonstrates that he is, to some degree, more self-aware than is Dipsychus even if he fails in some of the same ways. Nor is failure total; Kenny suggests that his marriage was a happy one, and if he was not as successful in career matters as was Matthew (who, in any event, was no particularly great success), after a good deal of struggle he did seem to find a place for himself; ultimately, he responded to the call of reality as eventually we all must. $^{\mathrm{b}}$

\footnotetext{
${ }^{\mathrm{b}}$ I have so used Clough as a mannequin for ideals of irresolution and inaction that I feel compelled here to quote from Anthony Kenny's biography to suggest that no simple reading can really suffice for any man's lived life, particularly not one so complex as Clough's. "Undoubtedly, Clough suffered from an incapacity to take decisions promptly, and an inability to perform well on demand, whether it was a matter of passing examinations or of surmounting professional hurdles. These defects were the downside of his ability to see both sides of a question, and his reluctance to compromise his integrity on serious issues. ... In fact, in poetry and life, Clough was his own man. Having experimented in the style of many
} 
Arnold (Matthew that is, for we turn away now from the good doctor) certainly had a robust inclination to overhear himself. His repeated catchphrases and constant working and reworking of his social and educational ideas (which were often much the same thing) suggest a mind that is more than a little self-aware.

Dewey, on the other hand, almost never quotes himself. Every text seems like something taken up anew; even those words we have come most to associate with Dewey, such as the omnipresent experience, seem to be less catchphrases and more a kind of unstudied mental furniture. Perhaps this is not surprising given Dewey's conception of reconstruction and reflective thinking which, as Dewey describes them to us, must have an extemporaneous quality that overhearing oneself too liberally would clearly curtail. Nonetheless, overhearing oneself is not entirely absent from Dewey. His short autobiographical sketch "From Absolutism to Experimentalism" suggests that he could overhear and overlook his own words and actions,- - that he could be retrospective, if not particularly introspective.

Nonetheless, our comparison of the three men suggests that some sort of balance in overhearing oneself is essential if the activity of reflective thought is not to become the passivity of contemplative thought. Or put another way, the question may be how to allow for contemplative thought in all its passivity without disabling the active nature of Deweyan reflective thought, or for that matter Arnoldian culture. Of the three, Arnold seems to suggest something of a middle ground. Arnold is not without his vanity, nor his polemical certainty, but while a number of his readers may wish to define him by these uniquely his own.” Kenny, Arthur Hugh Clough, 2005, pg. 288. 
characteristics, a “disinterested” critical reading of Arnold (such as that Collini provides in his elegant and balanced essay in the Past Masters Series) is likely to weigh these negative qualities alongside his more positive qualities. What Arnold does suggest most strongly is how to hear both the internal voice and the external voice and combine them in a way that does not blunt either, while at the same time it presses ever toward action (or conduct in Arnold's vocabulary). I believe this is best described in that kind of hermeneutical-rhetorical process we have been concerned with, and in what follows I will do my best to evolve just such a model.

\section{Hermeneutics, Rhetioric and the Reflective-Response Mind}

The attentive reader will, no doubt, have noticed that the title of this chapter is not the reflective mind, but the reflective-response mind. However, I have focused so far upon reflective thought in Dewey, Arnold and the life manqué of poor Arthur Hugh Clough. So strongly does the word reflective suggest contemplation, and to such a degree must some element of contemplation be present for reflective thought to do its necessary task, that the term may well lead us too far astray. And so I would suggest a change in terms.

Dewey, as I have pointed out, needed his reflective thought to behave in an active and not a passive manner. It needed to respond to the world and to be responsive to the world; it needed to continue to reach out of itself and not become, once again, hopelessly enclosed in the walled off skull of internality. It needed, as we have already pointed out,

a hermeneutic and a rhetorical character. Arnold recopgnized much the same: he saw 
how easily satisfying one's own limited aims and desires could limit the mind and create a kind of philistinism, an obtuse parochialism of narrow-mindedness. His urge that the learner ought to turn outward to the writings of another age or another culture (in Arnold's case, this latter was French and continental) he saw as a way of combating a stasis of mind; his free play of mind had, as we have seen, both an element of experience in it, and a seeking of other cultural stimuli,-— other intentionalities.

At the risk of creating a horrible, unwieldy jargon term, I can find no better expression of this need to continue the outward movement that Dewey has bequeathed us in his conception of the tentacled mind than to call this aspect of mind "reflectiveresponse.” Neither term by itself seems wholly adequate. We have seen the two-minded effect of a mind mired in contemplation, and both Arnold and Dewey were intent upon setting aside the opposite condition,- - a philistinism of a mind that merely responded without due reflection. Reflective-response is meant to stand between the inaction of a mind unstrung and lost within contemplation, and a mind so active that action itself becomes its only purpose and end.

Such a mind, then, is necessarily relational. It is the mind as it reaches out to another intentionality, even while it finds the expression of its own intentionality. This relational aspect of the mind, as such, is of a strikingly ethical nature. We can best understand it, I believe, by continuing our mapping of the ethics of the mind which we began in the last part of the preceding chapter. We now turn to the role of the reader. We will find that our emphasis on response, however, changes the role of the reader substantially,- for now we see that only in the hermitage of contemplation may we have, 
what Fish thought an impossibility, the reader in purity. In reflective-response we now have the true reader-writer, - the importance of this dual role in learning and life cannot be overestimated.

\section{Ethos of the reader}

In the last chapter we looked at the ethos of the text and the ethos of the writer. We now come to the ethos of the reader, and in it we will find the turning in which we have found central to the nature of reflective-response thought.

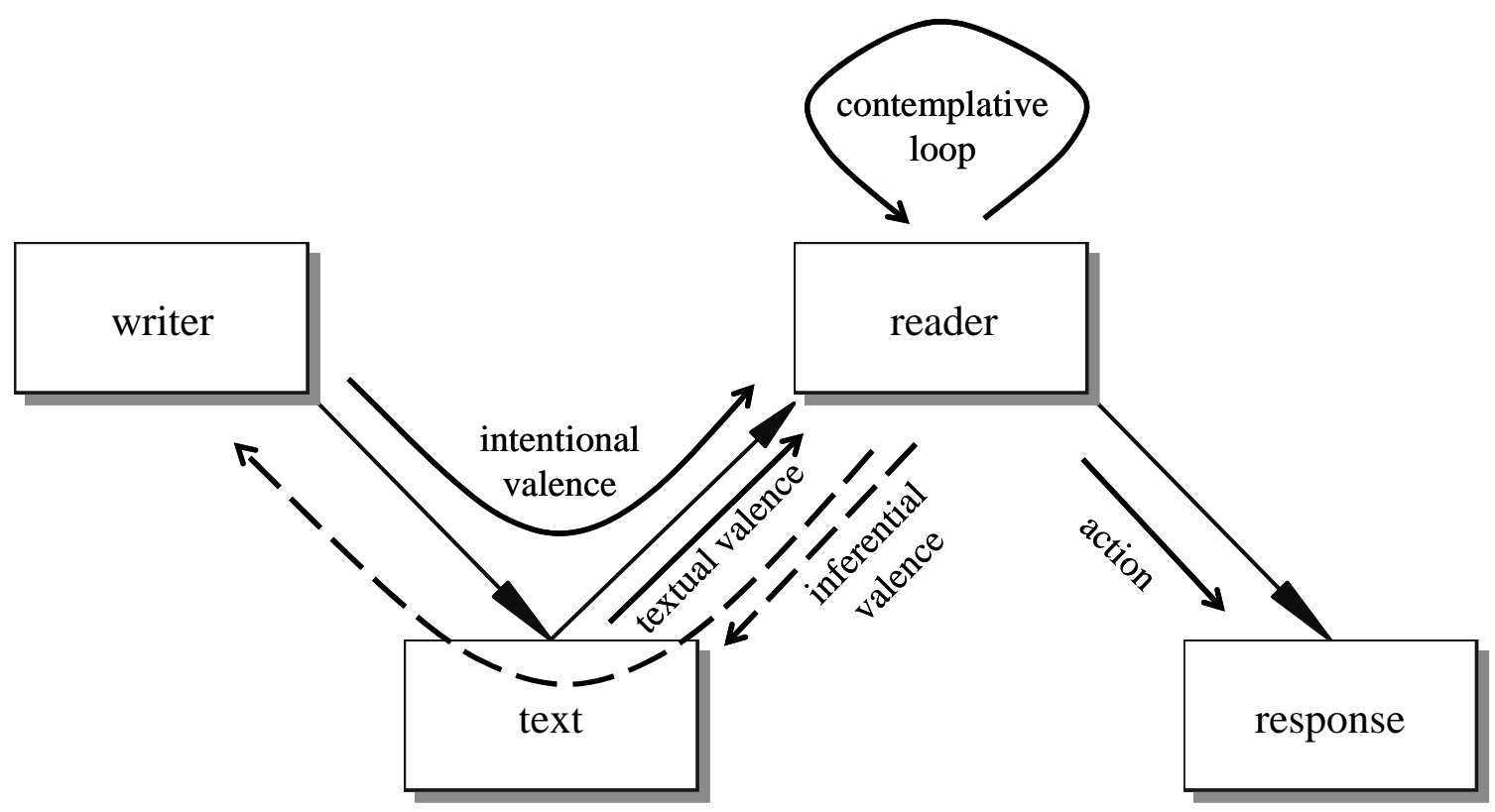

Illustration 6: Hermeneutics of reflective-repsone thought

In some ways the ethos of the reading process may be more difficult than that of the writing process. This is not because the writer need be less ethical. Indeed, our sense that authority has its dangers is not unfounded. Authority may become burdensome, oppressive, and repressive when the author (writer) makes no accommodation for the 
reader, allows the reader little or no freedom of response. Undeniably the ethical challenge to the writer is real and significant.

The complexity of the reader's position comes from the difficulty of determining the moment when the reader ceases to be passive and becomes in turn an active writer. In other words, how long are we to allow for Dewey’s suspension of judgment to stand us in place? Even the passivity of what appears to be no response can become, as we have seen in Clough's "I submit," a kind of response. Thus the reader must manage the twin ethos of the reader and the writer. The reader-writer possesses both the ethical relationship to the initial writer (superior, inferior, equal to; submissive, rebellious, collaborative, etc.) and the weight of a desired ethical relationship with a new reader, that reader to whom the reader-writer's response is addressed. Even if that reader is the writer of the earlier text, the relationship is a new one because the response is a new text.

Let us look first at the reader side of this reader-writer. In all cases, the reader has a greater difficulty than does the writer in determining the difference between the text and the writer's intention. I have shown, in Illustration 6, two separate valences of thought which arise in the reader's interaction with the text. These are the intentional valence and the textual valence.

On the surface, these two valences are less difficult for the writer. She can write her text, reread it, and ask the question, “Is this what I meant to say?” Now no answer perfectly resolves that question; always she will have the curious uncertainty that the word she has chosen may strike the appropriate chords in her own mind, but may not do so in the mind of any reader. We can each of us tell our own tales of inadequacies in this 
activity, and show how a perspicacious reader has helped a writer qualify these very issues. But the perspicacious reader we speak of here is one who has learned how to distinguish the text from the intention behind the text and with skilled dialog has discovered the means of aiding the writer in "finding her voice" and refining her text to a greater "nearness" to that intentionality which lay behind the initial urge to write. This perspicacious reader, then, is our reader-writer par excellence.

This reader-writer, then, must ask the critical question: "Is this text true to the writer's intentions?” Any answer must be, by definition, hypothetical. Moreover, the problem is further confused when the textual valence and intentional valences become confused with the reader's inferential valences (again, see Illustration 6). One of the inferential valences is directed at the text and asks the question, "What do I understand by this text?" The second, longer valence, is directed toward the writer and asks, "What do I understand of the writer's intentions?” These valences differ from the original valences in that they reflect (respond to the text) in terms that are more broadly associative, containing the context that the reader has absorbed and created through experience. Needless to say, these valences bear the greater possibility of bias, — not that the intentional or textual valences contain no bias, but that the biases they contain are those of writer and text.

Now none of these valences appears in our tentacled minds as entirely separable; they are hopelessly confounded with each other, and much has been made in recent years of the impossibility of ever teasing them apart. Arnold's challenge that we attempt, at least, to come to a "nearness" in dealing with the thoughts of those others with whom we 
have shared the world, either in the present or in the distant past, suggests, quite simply, that we can, at least, try to create such a separation, and through our response, test them, give them trial, expand them in the experi- of our experience.

This is why the reader-writer is so important. Were we but a reader, no such experiment, is tenable. Our thoughts would sit isolated in our own minds, and we would become the parochial residents of a fantastic planet of our own creation, - such that we should not be at all surprised when our friends ask us whimsically, "So what planet do you come from?”

Only a careful application of those aspects of the critical mind we have already discussed can allow us to begin to fully distinguish one valence from another. As Dewey puts in How We Think:

What is important, is that every inference shall be a tested inference; or (since often this is not possible) that we shall discriminate between beliefs that rest upon tested evidence and those that do not, and shall be accordingly on our guard as to the kind and degree of assent yielded. ${ }^{24}$

Reflective-response thought includes a constant sampling of all four valences, but it samples, as well, from a kind of internal loop: the contemplative loop shown above the reader in the illustration. This contemplative loop draws upon past experience, knowledge, authorities that we have absorbed and accepted, and our own fancies and imaginings. The contemplative loop can draw us far from the initial intentional and textual valences, so broad is the associative power of the mind. Dewey rather strictly admonishes against the building of castles in the air, but nonetheless notes that "even when a person builds a castle in the air [the individual] is interacting with the objects which he constructs in fancy." ${ }^{25}$ Truly reflective thoughts have a continuity with the 
objects with which the thinker is interacting. But only by pushing those thoughts back out into the world, by responding and continuing the process of interacting, can the reflective individual hope to comprehend their veracity. Moreover, as Dewey points out, in the truly reflective mind, our experiences and authorities may find themselves tested in each new application of reflection. Do they stand up to the current reading? How do they play out as we try to balance the four valences of reading?

Our response, in this mode is not, as we noted above, a final act. It is, rather, a part of the reflective process. It becomes part of the experi-, the "from trial," of experience. Reflective thought does not end with active response, but rather is enabled through this response. Were we in dialog with the writer of the text, rather than reading a book, we might ask, “What do you mean by that?” In a written text, we can still ask such questions. I find myself writing in the margins of books. The margins of my Dewey and Arnold books often run over with comments and questions stretching from the top, down the sides and around the bottom of the pages. Dewey was adamant that the reflective thought process was not a thing to be locked inside the head and left to the passivity of contemplative thought. In doing so, he causes us to reconsider our entire conception of human thought. The critical mind truly engaged with the objects of reflection is a mind that is neither passive nor retiring.

\section{Conclusion}

Arnold had popularized his own conception and example of the critical mind stretching itself across the world of human concerns; not content to just look at literature, he moved into social, educational, and religious issues; he applied the critical thought he 
had learned in literature, through and with the ancient Greek and Roman classics, but not entirely limited by them, to the many issues that a lived-life raises to consciousness. Dewey took this active, dynamic, fully-engaged critic and built his pragmatic philosophy around such a mind.

This active notion of mind, if we accept it, militates against any idea we may ever have had of a pure writer or pure reader. What we really have, in the hermeneuticrhetorical model, is a reader-writer, engaged with the objects of the world, listening or reading critically, conscious of the intentionalities that have authored the world of objects, balancing the valences of thought and response reflectively, and, consciously, moving in and out of the authority of writing.

In educational terms this means that we can never be happy with any educational process that centers itself upon only one of the four aspects of mind we have been exploring. A discovery learning that excludes the give and take voices of learner and teacher is just as insufficient as the oracle learning of the lecture delivered in mumbling voice from the podium.

The reader-writer is, in hermeneutic terms, the very model of the ArnoldianDeweyan learner. 


\section{Notes}

${ }^{1}$ Arnold, "Below the surface stream...," Allott, pg. 543.

${ }^{2}$ Dewey, How We Think, 1910, pg. mw.6.182.

${ }^{3}$ Dewey, How We Think, 1910, pg. mw.6.182.

${ }^{4}$ Dewey, How We Think, 1910, pg. mw.6.183.

${ }^{5}$ Dewey, How We Think, 1910, pg. mw.6.183.

${ }^{6}$ Dewey, How We Think, 1910, pg. mw.6.184.

${ }^{7}$ Dewey, How We Think, 1910, pg. mw.6.191.

${ }^{8}$ Dewey, How We Think, 1910, pg. mw.6.191.

${ }^{9}$ Dewey, The Quest for Certainty: A Study of the Relation of Knowledge and Action, 1929, pg. lw.4.7.

${ }^{10}$ Dewey, The Quest for Certainty: A Study of the Relation of Knowledge and Action, 1929, pg. lw.4.86.

${ }^{11}$ Arnold, The Function of Criticism at the Present Time, 1864, pg. CPW 3:276.

${ }^{12}$ Dewey, How We Think, 1910, pg. mw.6.191.

${ }^{13}$ Dewey, How We Think, 1910, pg. mw.6.190.

${ }^{14}$ Dewey, Experience and Nature, 1925, pg. lw.1.320.

${ }^{15}$ Kenny, Arthur Hugh Clough, 2005, pg. 60.

${ }^{16}$ F. L. Mulhauser (editor), The Poems of Arthur Hugh Clough, 1974, pg. 199.

${ }^{17}$ F. L. Mulhauser (editor), The Poems of Arthur Hugh Clough, 1974, pg. 684.

${ }^{18}$ Dewey, How We Think, 1910, pg. mw.6.191.

${ }^{19}$ F. L. Mulhauser (editor), The Poems of Arthur Hugh Clough, 1974, pg. 222.

${ }^{20}$ Dewey, "Education as Politics," 1922, pg. mw.13.329.

${ }^{21}$ Anthony Kenny, Arthur Hugh Clough: A Poet’s Life, 2005, London: Continuum, pg. 224.

${ }^{22}$ F. L. Mulhauser (editor), The Poems of Arthur Hugh Clough, 1974, pg. 272.

${ }^{23}$ F. L. Mulhauser (editor), The Poems of Arthur Hugh Clough, 1974, pg. 294.

${ }^{24}$ Dewey, How We Think, 1910, pg. mw.6.202, emphasis Dewey's.

${ }^{25}$ Dewey, Experience and Education, 1938, pg. lw.13.25. 


\section{From The Scholar-Gipsy}

Still nursing the unconquerable hope, Still clutching the inviolable shade, With a free, onward impulse brushing through, By night, the silver'd branches of the gladeFar on the forest-skirts, where none pursue,

On some mild pastoral slope

Emerge, and resting on the moonlit pales

Freshen thy flowers as in former years With dew, or listen with enchanted ears, From the dark dingles, to the nightingales!

- Matthew Arnold ${ }^{1}$

\section{An Adequate Echo}

Before I move on to a discussion of my findings, I would like to present an example of the sort of issue in which the four minds (tentacled, critical, intentional and reflective-response) play so singular a role. Each of us at some point, or, in the plural, at multiple points, in our lives must decide upon a future path, a career, a profession, a vocation, a means of sustaining ourselves and those nearest and dearest to us. A large debate exists upon this very head,- - should indeed education be a means to a vocational end, or is the choice of a vocation rather incidental to education which serves a different purpose. Dewey confounded things mightily by introducing vocational education early into the curriculum, not so much as a means to achieve vocational training, as that the direct problem solving of vocational activity better suited itself to the growth of the tentacled mind,- - it presented situations with clear problems and allowed for experience 
as experimentation, in ways that "book learning" could not. Nonetheless, he clearly saw vocation as an outcome of education, or more properly as that inevitable means by which an individual expressed the sum of his active life.

An occupation is the only thing which balances the distinctive capacity of an individual with his social service. To find out what one is fitted to do and to secure an opportunity to do it is the key to happiness. Nothing is more tragic than failure to discover one's true business in life, or to find that one has drifted or been forced by circumstance into an uncongenial calling. A right occupation means simply that the aptitudes of a person are in adequate play, working with the minimum of friction and the maximum of satisfaction. With reference to other members of a community, this adequacy of action signifies, of course, that they are getting the best service the person can render. ${ }^{2}$

One might expect that Arnold, with his emphasis on the cultural learning that comes from books would have taken an entirely opposite stand, but anyone who has read even a few of the reports he wrote as a school inspector knows that he was keenly aware of the vocational needs that school children had. ${ }^{3}$

Dewey viewed vocational training as something that came after,-— after childhood that is,- - and here we see Dewey in that tendency he always had, and never seemed quite conscious of, to view education as a childhood activity, even while he was making statements that clearly extended education past the early years.

The only adequate training for occupations is training through occupations. The principle stated early in this book ... that the educative process is its own end, and that the only sufficient preparation for later responsibilities comes by making the most of immediately present life, applies in full force to the vocational phases of education. The dominant vocation of all human beings at all times is livingintellectual and moral growth. ${ }^{4}$

Whether or not an occupation can fully be learned in situ, on the job, is the real question here,- - few would deny the need to continue the learning process within the occupation itself. But how much of a vocational education belongs in our schools, and to which 
schools, and which ages of youth, it belongs, is and always will be contentious, - - and I am certain of only one thing, that I cannot solve it in the small space I have afforded it here.

But another question of equal value and perhaps even equal importance comes with the question of vocation. Who decides the individual's choice of career? Now democratic as we are, the answer that jumps quickly out, is that this must be a decision that the individual makes, - it cannot properly be decided by anyone else. If the individual wishes to be a lawyer, then every opportunity should be afforded the individual to meet that desire. If the individual wishes to be an artist, then likewise, all opportunity should come her way. And so on. Now we have no sooner said all that than something itches in the back of our skull, and we say, well, we understand that some ability is needed for each of these careers, and we are not all equally possessed of these skills, and absent the skill, or the available training, or the leisure of a long education that father’s money makes possible,_- well, all these other external factors just bully their way in,- - we wish they would not, but they do. Dewey, we might note, in the passage above, hedges his bets to some degree,_- "that the aptitudes of a person are in adequate play, working with the minimum of friction and the maximum of satisfaction.” He does not indicate that such a condition need be the product of voluntary choice.

The truth is that the choice of a career, for any individual, no matter how well off, is never entirely in the hands of that individual. In some cases this is due to an unfairness inherent in the system, - in particular, the poorer one is, the less likely one will be to have options available. Certain ethnic groups and women in general have suffered great unfairness in the way of freedom of choice in employment,- - and I would never argue 
against the need to remedy these unnecessary prejudices. But a simple thing like supply

and demand can upset the plans of even the well-heeled, while certain innate inabilities

cannot be wholly overcome even by vast wealth and personal connections.

\section{Vocations and Professions}

A passage from Matthew Arnold's younger brother, Tom Arnold, in his autobiographical book, Passages in a Wandering Life, seems so apposite I cannot forebear citing it at some length.

An old controversy, and one that, I suppose, will never be decided, relates to the comparative wisdom or unwisdom of a father's determining the future career of his son, and bringing him up under the persuasion that he must reconcile himself to that and think of no other; or, on the contrary, leaving him free to make his own choice, down to the very close of the years of education and preparation. My father, Dr. Arnold of Rugby, so far as his judgment may be inferred from his conduct in the case of his two elder sons,- - his other sons were too young at the time of his death for the question to have arisen as to them,- - was of the latter opinion. He must have seen how strong was the bent of my eldest brother's mind towards poetry, and literary composition in general; and to the best of my belief he never thought of prescribing to him in any way either the field within which, or the aims towards which, he should set his genius to work. Both my brother and I looked forward to a residence at Oxford as the natural close of life at public school, and my father regarded the matter in much the same light, trusting that, after Oxford, each would find the groove suited to him. For us, and for all his children, the precept flowed steadily from his life, still more than from his lips, "Work." Not, work at this or that—but, Work.

In my case, it must be confessed, his confidence was somewhat rash; and there is no telling whether difficulties which I escaped, or was helped through, simply because I bore an honoured name, might not have overwhelmed me under other circumstances. ${ }^{5}$

Among the various needs of life: food, shelter, clothing, transportation, family, social position, and so on, we may argue which are needs, which are wants, which have the command of necessity and which the selfish acquisitiveness of desire, but that such needs find expression and seek relief in some form of compensated employment is a truth 
of our age, as of any other,- a small truth, no doubt, if one expects the rise of a classless society and the fall of vulgar capitalism,_- but, I must admit, I am not so sanguine as to place much expectation upon these eventualities within my own lifetime. Thus, for today at least, these are the obstacles that our outstretched tentacles encounter and must somehow surmount.

In today's increasingly secular world, we still have an astonishing recourse to religious terminology. When we speak of "the work we do," our means of earning a living, we use two terms out of religion: vocation and profession. Most of us no longer recognize these as religious terms. They are merely the upper end of a list of synonyms at the bottom of which we find job, which, of uncertain Middle English origin, does not have the social cachet of the Latinate terms vocation and profession. Vocation derives from the Latin vocatio, a call or summons; profession from Latin professus, to declare publicly. ${ }^{6}$

Putting the two terms side-by-side, we are immediately struck by a significant difference between them: a vocation is that activity toward which, in its original religious sense, we are called by God; a profession is that which we declare publicly, but which reflects our internal beliefs. In other words the two terms outline a sense of both externality and internality,- the vocation involves a call that is external to the individual; the profession involves the public declaration of a revelation that has occurred within the internal self.

The words vocation and profession are freighted with a number of additional meanings that we must take note of. Vocation today has come to have a strong association with craftwork or hand labor. Our vocational schools are schools that teach 
us how to do things, and we think of them as relatively free of theory and the liberality of a liberal education,- - in them the Dewey-Newman notion "that the educative process is its own end" " seems at odds with the notion that the eventuality of a well-paying job is the real end that most students have in mind.

Profession, on the other hand, we use to refer to those roles which are of the highest order, well-paid, and requiring significant mental dexterity. Traditionally these were the clergy, the lawyer, and the doctor, but in recent years the idea of a profession has reached throughout society. This sense of a hierarchical relationship between professions and vocations is deeply rooted in our society,- - as deeply rooted as the separation of mind and body that Dewey sought to undo; indeed, we can little doubt that the distinction between mind and body has had its influence upon the hierarchy between the two terms: the hand labor of vocation sits at the bottom of the wrung, the mental labor of profession at the top. Certainly, Dewey thought so,_- indeed, he said as much.

The basis of the conflict is itself imbedded in a social dualism: the distinction between the working class and the leisure class. The social concept must therefore propose a twofold goal: on the one hand, action, work, must no longer be considered servile and mechanical, but must become liberal and enlightened through their contact with science and history; on the other hand, education must no longer constitute the distinctive mark of a class. It must no longer be seen as a leisure pursuit, an intellectual stimulant, but rather as a necessity for all free and progressive social action. ${ }^{7}$

\footnotetext{
${ }^{a}$ Dewey, Democracy and Education, 1916, pg. mw.9.320. See also, John Henry Newman, The Idea of a University, 1852. A phrase like "its own end" seems odd coming from Dewey. Nothing else does he allow as an end in itself, indeed, much of his writing seems to be directed toward shifting away from ends that have become reified and held separate from life and experience. Only if we see education as synonymous with life and experience can we make sense of this notion. In which case, his use of that notion out of a liberal education that education "is its own end" moves past Newman's without quite being totally inconsistent with it. Once again we may point out how his thought follows from Arnold whose notions of a liberal education are more dependent upon experience. See Alan Ryan, 1998, Liberal Anxieties and Liberal Education.
} 
As a faculty member of a university, he was aware of that strange bias which somehow places the university professor above or in some ways outside of both vocations and professions. The university professor deals only in matters of the mind and has not even that subtle whiff of practicality and labor that adheres to the professions of preaching, lawyering and doctoring. As Dewey put it, "it is enough to say that the connection between ordinary graduate work and preparation for teaching confers upon graduate work a perceptible professional flavor.” ${ }^{8}$ This was Dewey’s way of smugly ${ }^{\mathrm{b}}$ noting that his fellow professors were already tainted with professionalism, even if they had, for whatever reason, not allowed themselves to realize this.

This distinction between vocation and profession has become increasingly ambiguous as more and more job holders seek to position themselves amongst the professionals. If a distinction does still exist between the two words, it would appear to be largely dependent upon how the individual practitioner perceives his or her role in society. We have come to speak more and more of professionalism in ways we do not speak of vocationalism. Professionalism suggests an adherence and loyalty to a collective we call "the profession," or the class of all others who formally do the same type of work that we do. The profession, in its corporate character, ${ }^{\mathrm{c}}$ will often issue a code of ethics, regulate admittance and membership, and provide the character of an ideal or perfect practitioner. Now, frankly, the same often occurs with those whom we regard as possessing vocational jobs, but our bias toward the intellectuality of the professions

\footnotetext{
${ }^{\mathrm{b}}$ Whether Dewey can ever be truly smug or ironic is debatable. For my part, I think, at times, he could be, but his writing is so dry and awkward that whatever irony it may have often goes unnoticed.

c "Its corporate character" is part of the phrase that Arnold loved to quote from Edmund Burke, the State is "the nation in its collective and corporate character." Arnold, "Democracy,"1860/1861, CPW, 2:26.
} 
leads us to consider professionalism a more appropriate characterization than vocationalism.

Given the difficulties that the words vocation and profession present, I would like to substitute "calling” for vocation, and “declaration” for profession. By "calling” I mean something external to oneself acts upon one to either suggest or dictate a role in life,we may also see in this something of the intentionality of the world we live in. By “declaration” I mean that one has, usually through some process of trial and error, come to a conclusion about one's role in life and made a public declaration of that role; we may see in this the critical mind at work, analyzing and sorting amongst various experiences,- - but we also cannot help but note that often such declaration among the young and those of limited experience is rather absent in critical, or reflective-response thought.

In pre-modern times, one's position in society invariably had the qualities of a calling with little of the self-determination of a declaration. Now, certainly, for the great mass of men and women, the high drama of a formal call to duty, a shout from up on high, an angelic annunciation, was notably absent. With little ceremony, the peasant had her work or duty set out for her. She knew what she was to do, how she was to behave, with whom she was to consort, how she was to raise her children, where she was to live, even where she was to be buried when she died. Much the same was true in the classes above her. We might call this less dramatic calling to one's life duties the silent vocatio. It needed none of the drama of a call from heaven, even if heaven might be invoked as witness to its inevitable rightness. 
For a few members of society, some measure of choice was available. The drama of our two terms outline the nature of this choice; one might receive a call by way of a bright light from heaven knocking one off one's horse and into the dusty road to Damascus, or a figure of the crucified lord might appear charging one's body with the bloody stigmata of duty,- - alternatively, one might come to profess, after years of profligacy and worldly experience, one’s personal belief, hard won, marked by all the variety of personal experience,_- only after much time, much tribulation, much deep thought and reflection, can one come to one's true profession. ${ }^{\mathrm{d}}$

In a more worldly sense, the sons (if not always the daughters) of the upper classes often faced the struggle of choice. The choice could be made for one if the call came from the literal (not figurative) father, and, of course, society had its dictates as well, even for the upper classes. Nonetheless, some at least of the members of the upper class possessed the possibility of a declaration that would arise usually from a series of trials, an attempt at the church, at law, or at court;- - from these experiences might arise an inner realization of one's profession, one's declaration. To have the option of a declaration over a calling was not a particular favorable condition. Far better to be the elder son and be "called" to one's rank and position, than to be the younger sons making odd trials at the variety of professions in which talent and ability had more relevance than it ever would in matters of mere inheritance.

Arnold's school inspectorship strikes me as something of a calling; he chose what was available, the job that his mother's connections were able to secure for him. He had no great desire to become a school inspector, found the work arduous and dull, felt (no

\footnotetext{
d These are, of course, the respective callings of Saints Paul and Francis and the confessional profession of Saint Augustine.
} 
doubt quite correctly) that he was not adequately prepared for it, but continued on, nonetheless, achieving some tolerable competence, and some notable achievements. His declaration, that inward sense of needing to do something, to declare something, became the work of evenings and weekends in his study. His declaration moved him toward the professions of poet and essayist, but even in this, particularly in his prose work, we find a sense of calling, of the real tug of externalities. Dewey on the other hand came to his choice through a series of experiences (worldly only in the most banal sense); his declaration was philosopher, and his life was spent in a near flood of declarative writings. But Dewey was, himself, not without some sense of a vocatio. For Dewey, that calling comes from life itself; his turn away from books and older philosophies is an attempt to remove the possibilities of a false calling, so that he might hear more clearly what he believed to be his true calling,_- "the concrete diversity of experienced things."9

A far larger portion of the work population today finds itself faced with the twin sirens of calling and declaration. The silent vocatio, still present, makes itself felt both more subtly and often more egregiously, while the vicissitudes of the declaration are felt by all. I wonder that a major part of that which we call the modern sensibility or the modern problem does not come from the struggle we all surrender to so early in our lives as we try to discover how the twin impact of calling and declaration will affect us. And I, frankly, read the major writings of both Arnold and Dewey as eternally caught up in the struggle to avoid this Charybdis and Scylla.

My niece, who is sixteen and readying herself for college, ${ }^{\mathrm{e}}$ has recently been badgered by well-meaning adults (myself included) wanting to know what she plans to

\footnotetext{
${ }^{\mathrm{e}}$ Or rather was at the time I wrote this; she is now eighteen and enrolled in the business school at UT.
} 
study when she goes off to college. "I keep asking," she usually replies, "for someone to give me a list of salaries, so I can pick the job that makes the most money." Upon hearing this, her mother will screw up her nose and tell her how she will never be happy just working for money. And one of her uncles (not myself) will say that college is a process of self-discovery; that she must be willing to live with the uncertainty of trial and error as she finds the major that is right for her. I will admit my first reaction was not far from these. But I have a feeling that, in her own way, my niece was trying to tell us something about the process she was going through that we were unwilling to hear. How many of my own peers have gone through the same process without really discovering for themselves what that inner siren was trying to say? How many, myself included, thought they could simply ignore the calls of an external reality, only to find that external realities would ultimately have a greater impact upon our choices than we had expected them to?

Let us look at how these callings and declarations affect us today.

1) The declaration, which forces one to have to choose a job for oneself, is not historically a preferential state; the freedom it provides is significantly offset by the difficulty and weight of the decision, such that over the years more than a few individuals have fallen victim to it. ${ }^{\mathrm{f}}$

\footnotetext{
${ }^{\mathrm{f}}$ I think here of William Cowper, an eighteenth century English poet, and from whom I had earlier quoted some lines on Alexander Selkirk,- - Cowper suffered a nervous breakdown at the prospect of a job interview for a position in a law firm; he lived out his life in the country under the patronage of friends. But that is distant history; surely all of us know of someone, family or friend, who has not fared well in navigating the modern career world. This is a part of our modern age; we cannot, ought not, hide from it, but equally I wonder if we are not doing a disservice by suggesting that the answer lies solely within oneself.
} 
2) The root of the declaration, the need to determine one's own internal needs, invokes the Deweyan trial and error of self-discovery; it also demands a high degree of tolerance for uncertainty. The more one is inclined to want to meet internal needs, the greater is the demand upon one for a significant process of self-searching, self-discovery, and self-trial, - this is, of course, the liberalism of a liberal education. From this point of view, the liberal education is liberal because it liberates or individualizes, thus enabling a declaration,- - through it, supposedly, a profession is possible, and action, not inaction, follows in the train of a liberal education. (This was, as we have seen, more or less, Arnold and Dewey’s argument).

3) The calling has many implications today. Remember we have defined calling as the externalities that impact our career decisions. What are those externalities? For my niece they included a list of the salaries of the various professions (and vocations). However, are not the accepted disciplines in our universities somehow a type of calling? To what extent, then, do the how and what of what we teach within these disciplines act as their own siren calls? In other words, are not the very disciplines we admit into the university in their own way a kind of vocatio informing the individual's otherwise internal act of declaration? Surely, what we have left out, either by way of not allowing it a place as a discipline or by excluding it from our hows and whats, forms a separate type of calling,- - a negative calling, at least to those who wish to move toward the accepted professions. 
4) Society calls to us in so many ways; a panoply of advertising, entertainment, social prestige, utility and pleasure, custom and new,- - this is the calling of our modern world, and if it contains elements we would wish to undo and make better, the need, even in a bettered society, will inevitably arise for a means of navigating these various callings.

5) The silent vocatio has not disappeared. Many members of our society, particularly those at the lower levels, may feel (often quite rightly so) that they have little or no option available to them, no real choice in the pursuit of a profession. Their vocation is chosen for them, dictated by the class and position of their parents.

The problem of authority and intentionality is here made quite apparent. The social world, which manifests itself within external realities, gives us the inevitability of a "call," — reaching out, the invisible hand, if you would, grasping the individual, pulling each of us, no matter our class, no matter our personal disposition, toward that which society desires, and for which our individual desires may or may not be called upon to bless with a preferential declaration. If vocation is an external calling and profession an internal declaration, we have the very real conflict of our life's work: is it determined by our external circumstances or our internal preferences; is it that which Plato assumed,the one thing we are best suited for (which presumably we would prefer)? Or that which is alone available to us because of our external circumstances? We might hope, as Plato so logically, so rationally commends, that this invisible hand will distribute its largess by merit and talent, but talents are not evenly distributed, nor evenly desired, and the silent vocatio still has its say, particularly amongst the poor and marginalized. 
Surely most of us would have thought that the issue of the selection of a profession or vocation would prove a simple matter of the individual's need to grasp the world around and about, give it a thorough chew, and digest that bit that most appeals to individual taste. When social concerns appear, our immediate thought is to discharge our spleen upon the offending hand of society that so callously disrupts the individual urge.

Here we can see how necessary the four minds are to our education. If we have not reached out and discovered the world with our tentacled mind, the problem, such as it is, will take us by surprise if we ever become conscious of it at all. If we have not the critical faculty we will not uncover the intentionality inherent in those objects that obstruct our path. We shall have no recourse but to rail at them in ignorance, the eternal victims of an unwelcoming and unresponsive world. If we cannot understand the intentionality of those with whom we share this world, we will forever be responding only to the fantastical, unverified intentions (our demonization) of the ever-repressive other. Only by means of our reflective-response mind,- - testing, trying, communicating, engaging the world,- - can we hope to realize a reasoned and reasonable response to the pull and tug of calling and declaration.

\section{The Liberality of a Liberal Education}

Is an interest in the vocational needs of students tantamount to forsaking the liberality of a liberal education? Dewey did not think so. Rather he suggested that we should recognize "that men are consumers as well as producers, that leisure is as normal a part of life as labor, and that one of the most crying needs of our American society today is education to pave the way for a more aesthetic consumption of the products of work 
and a more rational and ordered leisure." ${ }^{10}$ An education that ignores the forces that are at work in contemporary life will neither achieve the needs of the present, nor those of the past.

The attempt to live in the past by way of inviting the soul of our youth to a leisurely and liberal culture merely throws the mass of them upon athletics and extra-curricular activities for their daily sustentation and thereby leaves them a ready prey to the hurried excitements, the Philistinish zeal for activity without knowledge, the love of mammon-like display, which are the serious evils of our American life. Less fear, less jealousy and envy, a freer imagination on the part of the professed upholders of liberal education, would result in a franker recognition of the directions in which genuinely intellectual responses can be awakened in the bulk of your youth today. The emancipation of intellectual power which would result from an open and aboveboard identification of motives for study with the main social interests of the day would secure an infinitely better preparation for a later unhurried enjoyment of leisure than results from an attempt to cultivate secluded plots which few care to enter. ${ }^{11}$

We need hardly point out here that Dewey’s subtext is Arnold; “the Philistinish zeal for activity without knowledge” surely makes that apparent. However, Dewey used Arnold's motifs to give Arnold a gentle nudge toward something a little more practical. Whether Arnold needed that nudge or was already headed there himself is matter for debate. The notion of humanizing one's profession through a liberal education was surely implicit in Arnold's writings. Frankly, however, I am inclined to think that the nudge was not uncalled for. While Arnold saw the need to humanize both our professional and private lives, to bring to them the critical perspective of culture, he did not seem, in the long run, to have recognized that this meant broader changes in the educational curriculum than were present in the existing practices of his dear, old Oxford.

Dewey is willing to condemn the notion of a vocational education when it is identified "with an immediate pecuniary aim," but not when it amounts to "a conception of the calling of man in fulfilling his moral and intellectual destiny."12 More than a little 
ambivalence seems to attend his discussions of the role of vocation in higher education.

The professional school was, to his mind, a separate species from the university with its general education. However, "to scold one's educational generation wholesale is a confession of practical impotency which I suppose even the most ardent classicist and culturist would be loath to utter." On the other hand, "to praise wholesale is to drift not merely with a tide but with every chance eddy and to forego the opportunity for intelligent direction and selection." ${ }^{\text {13 }}$ Dewey ended up taking a middle ground (as was his and Arnold's most common practice).

I often wonder whether in considerations similar to these we do not find a clue to the only meaning which can be intelligently assigned to the adjective liberal in the phrase "liberal education." Is it possible that training in law, medicine, or engineering when informed by an adequate recognition of its human bearing and public purpose should not be genuinely liberal? Is it anything inherent in these careers that confers upon preparation for them that sense of narrowness and selfishness carried by the ordinary use of the words "professional" and "technical"? Or is this signification due to the frequent limitation imposed upon them because of exclusion or neglect of the public interest they contain? Assuredly there is lack of imagination implied in the current identification of the humanities with literary masterpieces; for the humanism of today can be adequately expressed only in a vision of the social possibilities of the intelligence and learning embodied in the great modern enterprises of business, law, medicine, education, farming, engineering, etc. ${ }^{14}$

Setting aside concerns of convergences and divergences between Dewey and

Arnold, the sentiment here is surely at the heart of our attempt to trace a pluralistic path for education. In essence, Dewey is telling us that liberal education is no longer just a leisure-time, aristocratic pursuit. The liberality of a liberal education is that which "humanizes." Whether we come to our profession or vocation by way of a calling from without or a declaration from within, that which our society and we as members of that 
society most need is a way to remove the blinders ${ }^{\mathrm{g}}$ so that we might see the rich pastures of life, so that we may raise our eyes to the social horizon and see the whole of the world which animates and is animated by our vocation.

Dewey is, no doubt, right that each individual must reconstruct by trial and error the world of work until such time as it evolves into an internal revelation which one may publicly profess. But if one does not listen to that external call, then one is in danger of reconstructing the world in mis-measure with those realities which, whether one likes it or not, will inevitably force themselves upon one.

\section{Awkward, But Adequate}

Dewey, as we have seen, echoed Matthew Arnold who himself echoed so many of the voices that preceded and were contemporary with his own. Theirs were awkward echoes, as all such echoes invariably are. They caught at the intentionality of those voices they echoed, trying for a nearness, but more intent upon what Arnold called adequacy. Neither was an historicist in the accepted sense, but neither was ahistorical. They took what was adequate to their needs, to the times in which they lived.

That these echoes were awkward we might credit to the weight of modernity which challenged the response of both men. But such echoes are almost always in any age a somewhat awkward thing. Times change, needs change, but history bequeaths us the intentions of the past. No amount of reconstructing ever fully clears the deck. For all his fascination with the classical past Arnold was as bold in his reconstructions as was

\footnotetext{
$\mathrm{g}$ “One cannot gaze upon a body of graduate students animated exclusively by a desire to prepare themselves for future teaching without being reminded of horses which not only follow a beaten track but which wear blinders to make them unaware of fertile fields and flowery landscapes all about." Dewey: “The Modern Trend Toward Vocational Education...” 1917, pg. mw.10.153.
} 
Dewey. Their echoes are all the more awkward for their having attempted the thought that such rethinking and reworking entails.

I cannot but admit how awkward my own echoes feel to me and my necessary anxiety that my own reconstruction may not possess the admirable, if limited, adequacy of theirs. I have attempted to pull together a more pluralistic philosophy of education, more adequate, I hope, to today's needs than I find entirely apparent in that of either man. Although, as I have been at pains to make clear, all of the basic elements that I have been most concerned with were aspects to one degree or another of the thought they have bequeathed us. Their intentionalities, however imperfectly, echo here,— of that I am sure.

Like Dewey in How We Think, I have attempted to form my sense of this plurality by exploring the native functionality of the human mind. Like Dewey I have focused most of my attention upon the interpretive act. Unlike Dewey I have given greater emphasis to what I call the full journey from inference to the intentionality of the world in which we live, perhaps because, unlike Dewey, I feel that the age in which we live today has greater need for a rehabilitation of our conceptions of authority and intentionality than for a continued demonization of the manic character of the excessively authoritarian. We know well the dangers that extremes of authoritarian excess can produce; our fear and denial have not made them go away,_- arguably they have, perhaps, worsened their terrifying effects. Like both Dewey and Arnold, I search for the reasoned and reasonable middle ground,- - to my mind, that can only come with a renewed appreciation for and understanding of the intentional not only as it imposes upon us, but as we, often unwittingly, impose it upon others. The awkwardness of that 
conclusion is, in some ways, its saving grace. It lives in true uncertainty, not that false uncertainty that tries adventitiously to declare itself the opposing and opposite pole of positivist certainty.

\section{An Adequate, if Awkward Mind}

The four types of mind that I have discussed here, each in its own way, inform the purpose and conduct of education, and to my mind have done so for the length of historical human existence in all cultures and across all lands. I say that not out of desire for a universalism, but simply because each of the four minds seems to me to be an aspect of the hermeneutic and rhetorical models and thus a function of all social intercourse. Moreover, none of the four is an absolute declaration of a how or a what of education,each is contingent in its effect and expression,_- if what I have presented seems something of a structuralist argument, well, perhaps it is, but the structure itself is never, to my mind, so important as the nature of that described within it.

If the structure directs thought, acts as a kind of authority, I can only say that I must trust to my critical faculties in the hope that the very structure I have created will not in turn con me into false beliefs. I am quite sure that always some structure will present itself, some system of thought, some means of finding and ordering, of generalizing and drawing conclusions. I truly hope that in trusting to a simple structure such as this I am not being regressive. I have a pragmatic, perhaps even sentimental and romantic, faith that the structures of the world and of our languages are not so evil that they will forever repress and deny, and that if they do, at least may they do so in a way that is less repressive than that anti- or post-structural condition in which I repress and 
deny for myself what riches and virtues they may also possess. But I can only hope that my tentacled, critical, intentional, reflective-response mind can hold at bay the conning con, or at least allow me to learn from the experience and fashion an ever better and more responsive life.

I am sure of this much, were I Empedocles, I could only look into the volcano and wonder at its possibilities; then I would pick up the lumber that Dewey had brought to throw in, and take it home, and have a good read. 


\section{Notes}

${ }^{1}$ Arnold and Allott (editor), “The Scholar Gipsy,” pg. 342-343.

${ }^{2}$ Dewey, Democracy and Education, 1916, pg. mw.9.318.

${ }^{3}$ Arnold, Matthew and Francis Sanford (editor) (1889), Reports on Elementary Schools.

${ }^{4}$ Dewey, Democracy and Education, 1916, pg. mw.9.320.

${ }^{5}$ Tom Arnold, Passages in a Wandering Life, 1900, London: Edward Arnold, pg. v-vi.

${ }^{6}$ From Dictionary.com Unabridged (v 1.1); based on the Random House Unabridged Dictionary, (C) Random House, Inc. 2006. Accessed December 26, 2006. Note also the presence in any list of synonyms for "job" of the word "calling," clearly a derivative of vocation.

${ }^{7}$ Dewey, Education from a Social Perspective, 1913, pg. mw.7.120.

${ }^{8}$ Dewey, "The Modern Trend Toward Vocational Education in Its Effect Upon the Professional and NonProfessional Studies of the University,” 1917, pg. mw.10.152.

${ }^{9}$ Dewey, “From Absolutism to Experimentalism,”1930, pg. lw.5.150.

${ }^{10}$ Dewey, "The Modern Trend Toward Vocational Education...," 1917, mw.10.156.

${ }^{11}$ Dewey, "The Modern Trend Toward Vocational Education...," 1917, pg. mw.10.156-7.

${ }^{12}$ Dewey: "The Modern Trend Toward Vocational Education..." 1917, pg. mw.10.151.

${ }^{13}$ Dewey, "The Modern Trend Toward Vocational Education...” 1917, pg. mw.10.153.

${ }^{14}$ Dewey, “The Modern Trend Toward Vocational Education...” 1917, pg. mw.10.156. 


\section{Bibliography}

\section{Primary Sources}

\section{Matthew Arnold}

Francis Sanford (editor) (1889), Reports on Elementary Schools, (London: Macmillan and Co.).

Fraser Neiman (editor) (1960), Essays, Letters, and Reviews by Matthew Arnold, (Cambridge, Massachusetts: Harvard University Press).

R. H. Super (editor) (1960-1977), The Complete Prose Works of Matthew Arnold (Ann Arbor: The University of Michigan Press).

Kenneth Allott (editor) (1965), The Poetry of Matthew Arnold (London and New York: Longman Norton).

Miriam Allott (editor) and Robert H. Super (editor) (1986), The Oxford Authors: Matthew Arnold (Oxford: Oxford University Press).

Stefan Collini (editor) (1993), Culture and Anarchy and other writings (Cambridge: Cambridge University Press).

Lang, Cecil Y. (editor) (1996-2001), The Letters of Matthew Arnold in six volumes (Charlottesville and London: The University Press of Virginia).

\section{John Dewey}

Boydston, Jo Ann (editor) (1977), The Poems of John Dewey (Chicago: Southern Illinois University).

Boydston (editor) (1991, 2005), The Collected Works of John Dewey, 1882-1953, electronic edition (Chicago: Southern Illinois University Press).

Hickman, Larry A., Barbara Levine, Anne Sharpe, and Harriet Furst Simon (editors) (2005), The Correspondence of John Dewey, Volumes 1-3: 1871-1952 (Center for Dewey Studies and Southern Illinois University Carbondale).

All references to Dewey's prose writing use the page numbering conventions of the Collected Works, electronic edition (Boydston, 1991, 2005).

\section{Secondary Sources}

Arnold, Thomas (1900), Passages in a Wandering Life (London: Edward Arnold). Bédarida, Francois (1990), A Social History of England: 1851-1990 (London: Routledge).

Bergonzi, Bernard (2003), A Victorian Writer: The Life of Thomas Arnold the Younger (Oxford: Oxford University Press).

Bloom, Harold (1997), The Anxiety of Influence (New York: Oxford University Press).

Brooks, Cleanth and Robert Penn Warren (1938/1950), Understanding Poetry (New York: Henry Holt and Company). 
Carlyle, Thomas, Kerry McSweeney (editor), and Peter Sabor (editor) (2000), Sartor Resartus (Oxford: Oxford University Press).

Clough, Arthur Hugh, F. L. Mulhauser (editor) (1974), The Poems of Arthur Hugh Clough (Oxford: Oxford University Press).

Collini, Stefan (1988), Arnold (Oxford: Oxford University Press).

Collini, Stefan (1991), Public Moralists (Oxford: Oxford University Press).

Connell, W. F. and Fred Clarke (introduction) (1950), The Educational Thought and Influence of Matthew Arnold (London: Routledge and Kegan Paul Limited).

Cowper, William and Robert Willmott (editor) (18??), The Poetical Works of William Cowper, (London: Charles Routledge and Sons) ${ }^{\mathrm{a}}$

Derrida, Jacques and Spivak (translator) (1976), Of Grammatology, (Baltimore: John Hopkins University Press).

de Saussure, Ferdinand (1983), Course in General Linguistics (Chicago: Open Court).

Eliot, T. S. (1986/1933), The Use of Poetry \& the Use of Criticism, (Cambridge: Harvard University Press).

Ferguson, Margaret (editor), Mary Jo Salter (editor) and Jon Stallworthy (editor) (1996),The Norton Anthology of Poetry ( $4^{\text {th }}$ edition) (New York: W. W. Norton \& Company).

Feuer, Lewis S. (1958), “John Dewey's Reading at College,” in Journal of the History of Ideas, $19,415-21$.

Gross, John (editor) (1998), The New Oxford Book of English Prose, (Oxford: Oxford University Press).

Honan, Park (1981), Matthew Arnold: A Life (New York: McGraw Hill).

James, William and Kuklick (editor) (1987), William James: Writings 1902-1910 (New York: The Library of America).

Kant, Immanuel and Norman Kemp Smith (translator) (1965), Critique of Pure Reason (New York: St. Martin's Press).

Kenny, Anthony (2005), Arthur Hugh Clough: A Poet's Life (New York: Continuum)

Lamb, Charles and Adam Phillips (editor) (1985), Selected Prose (Harmondsworth, England: Penguin Books).

Leitch, Vincent B. (general editor) (2001), The Norton Anthology of Theory and Criticism, (New York: W. W. Norton \& Company).

Locke, Alain, and Leonard Harris (editor) (1989), The Philosophy of Alain Locke

(Philadelphia: Temple University Press).

Martin, Jay (2002), The Education of John Dewey (New York: Columbia University

Press).

Mazzeno, Laurence W. (1999), Matthew Arnold: The Critical Legacy ( Rochester, NY:

Camden House).

Meiklejohn, Alexander (1942), Education Between Two Worlds (New York and London: Harper \& Brothers).

${ }^{a}$ The late nineteenth century edition I used as reference is undated,- - the text appears to have been printed from old, worn plates, - an owner's signature on the title page is dated March 20, 1880,- - I suspect this is an 1860 or later printing of a collection that first appeared in 1855. 
Menand, Louis (1997), Pragmatism: A Reader (New York: Vintage Books).

Menand, Louis (2001), The Metaphysical Club: A Story of Ideas in America (New York: Farrar, Strauss and Giroux).

Mulhauser, F. L. (editor) (1974), The Poems of Arthur Hugh Clough (Oxford: Clarendon Press).

Stone, Donald (1997), Communications with the Future: Matthew Arnold in Dialogue (Ann Arbor: University of Michigan).

Preminger, Alex and T. V. F. Brogan (editors) (1993), The New Princeton Encyclopedia of Poetry and Poetics (New York: MJF Books).

Rockefeller, Steven C. (1991), John Dewey: Religious Faith and Democratic Humanism, (New York: Columbia University Press).

Roper, Alan (1969), Arnold's Poetic Landscapes (Baltimore: The Johns Hopkins Press).

Ryan, Alan (1995), John Dewey and the High Tide of American Liberalism (New York:

W. W. Norton).

Ryan, Alan (1998), Liberal Anxieties and Liberal Education (New York: Hill and Wang).

Santayana, George (1939), "Dewey’s Naturalistic Metaphysics” in The Philosophy of John Dewey, Paul Arthur Schilpp (editor) (Evanston, Ill.: Northwestern University).

Saintsbury, George (1899), Matthew Arnold (New York: Dodd, Mead and Company).

Schildgen, Brendan Dean (editor) (1997), The Rhetoric Canon (Detroit: Wayne State University Press).

Schilpp, Paul Arthur (editor) (1939) The Philosophy of John Dewey, ed. (Evanston, Ill.: Northwestern University).

Snow, C. P. and Stefan Collini (editor) (1959/1993), Two Cultures, (Cambridge: Cambridge University Press).

Super, R. H. (1970) The Time-Spirit of Matthew Arnold (Ann Arbor: The University of Michigan Press).

Totten, Samuel (editor) and Jon Pederson (editor) (2007), Addressing Social Issues in the Classroom and beyond: The Pedagogical Efforts of Pioneers in the Field (Charlotte: Information age Publishing).

Trilling, Lionel (1939, 1977), Matthew Arnold (New York and London: Harcourt Brace Jovanovich).

Watson, George (1962), The Literary Critics (Baltimore: Penguin Books).

Ward, Mrs. Humphrey (1918), A Writer's Recollections (New York: Harper \& Brothers). 


\section{VITA}

Mark David Dietz was born in Fairbanks, Alaska. He is the son of Edna May Dietz and Albert Emil Dietz. He attended Palmetto High School. He worked on his baccalaureate degree at Trinity University and Vanderbilt University where he graduated in 1980 with a B.A. in History. In 1993, he received a Master of Science in Business Administration with a focus on Organizational Behavior from the University of Texas at Dallas. Mark spent six years, from 1980 to 1986, in the United States Army ending his term of service as a company commander in the $101^{\text {st }}$ Airborne (Air Assault) Division. For thirteen years, 1986 to 1999, he worked for Texas Instruments in various positions beginning as a manufacturing supervisor and ending as a training manager and organizational development consultant. He has since worked as an independent consultant and full time employee for such organizations as Samsung Semiconductor, Hewlett Packard and Texas State University. He currently is Associate Director of Research for the National Alliance for Insurance Education and Research. Mark has (with O.L. Davis) co-written a chapter, "John Dewey and Social Action,” which appeared in early 2007 in Addressing Social Issues in the Classroom and Beyond: The Pedagogical Efforts of Pioneers in the Field (Charlotte: Information Age Publishing).

Permanent address: 3607 Greystone Drive, \#1913, Austin, TX. 78731

This dissertation was typed by the author. 